\title{
APHASIC COMPREHENSION OF FRENCH CAUSATIVE CONSTRUCTIONS
}

by

Jo-Ann Gendron

A Thesis Submitted to the Faculty of Graduate Studies and Research in Partial Fulfillment of the Requirements for the Degree of Doctor of Philosophy

Department of Linguistics

McGill University

(- Jo-Ann Gendron

Montreal, Quebec

April, 1992 
Independently proposed linguistic analyses permit us to characterize function words and inflectional morphology as one class. These elements are hypothesized to constitute heads or functional projections. In this thesis, the Head Accessibility Hypothesis is proposed to account for the representations aphasics have of lexical and functional projections. It maintains that, as a consequence of the interactional nature of the modular grammar embodied in the principles and parameters version of Government-Binding theory (Chomsky 1982,1986), syntactic deficıts may be due to problems at the level of access to the Mental Lexicon. The implications of this hypothesis for syntacic comprehension in general and for the compiehension of causatives by aphasıc patıents are tested in a serıes of batterıes admınistered to nine French aphasics and ten controls. The results support the proposal that the Head Accessibility Hypothesis correctly accounts for the patterns of present and absent linguistic elements in the representations computed by all types of aphasics. 


\section{RÉSUME}

Les analyses linguistiques nous permettent de caractériser les mots fonctionnels et la morphologie flexionnelle comme faisant partie d'une seule classe. Ces éléments constituent les têtes de projectıons fonctionnelles. Dans cette thèse, nous proposons I' Hypothèse d' Accessıbılité des Tètes pour explıquer les représentations de projections lexicales et fonctionnelles qu'ont les aphasiques. Cette hypothèse soutient que la nature interactionnelle de la grammaıre modularre que constitue la version paramétrique de la théorie du gouvernement et du lıage de Chomsky $(1982,1986)$ falt que les troubles syntaxiques pourraient être dûs à des problèmes au niveau du Lexique. Les implicatıons de cette hypothèse pour la compréhensıon syntaxıque des aphasıques en général et plus spécıfıquement pour leur compréhension des causatives sont vérifiées dans une série de tests de compréhensıon de phrases admınıstrés à neuf aphasıques et à dıx sujets normaux francophones. Les résultats confırment I' Hypothèse d'Accessıbilité des Têtes et supportent les prédıctıons quı en découlent quant à la disponıbilité des items lexıcaux et fonctionnels. 


\section{ACKNOWLEDGEMENTS}

After the funous pace that the completion of a thesis entails, one gladly takes a moment to publicly acknowledge one's indebtedness to those whose help has been Instrumental in bringing it about. Such a project could never have been executed without the cooperation of a great many people

First, I would like to thank my thesis supervisor, Dr. David Caplan for setting the highest stanaards of scholarship in his own work, ones which I have sought to emulate to the best of my abilities.

I would also like to thank Nancy Hildebrandt for this latter reason but most especially for writing two adaptaticns of her sentence comprehension database program which permitted me to co-ordinate the presentation of my results with those from the original test devised by Caplan and colleagues as well as the tests she devised for her own thesis. By totailing the responses and printing the summary score sheets, this program proved to be invaluable.

Without the narticipation of my test subjects, however there would be no thesis. I am especially grateful to the members and theır spouses of the Association des cérébrolésés du Québec, a self-help group for those who have suffered brain damage, for generously giving of their time and for their patience in permittıng me to conduct these tests. A special thanks goes to C. M. , the Laval chapter co-ordinator for helping me to reach additional subjects. In addition, I would like to acknowledge the late $M$. Clément Gélınas the founder of the organization who contributed to the group's openness and their willingness to not only help each other but also researchers in brain and language related 
disciplines.

I am also grateful for the participation of my normal controls. Thaiks for helping in their recruitment go to Mirelle Trembld;', LM, and Professor Nicole Domingue. Additional controls were suggested to me by Mme Arlette Po.ssant of the Centre de Recherche du Centre Hosprtalıer Côte-des-Neıges. Her generous offer came at a critıcal time. I would also like to thank Dr. A. R. Lecours, the director of this research facility, for creating an atmosphere where such a sharing of resources is commonplace.

I have also benefitted from participating in discussions with fellow students in the following study groups: the Neurolinguistic Study group, the ABD seminar and the Reflexive Clitic Workshop, the latter organized by Professor Mark Baker. Thanks to all the participants though for longevity the following should be mentioned : Jose Bonneau, Marc Campana and Alan R. Libert.

Special thanks also go to the many francophone students who allowed me to badger them for grammaticality judgments--Jean-Charles Beaumont, José Bonneau, Domınıque Rodier, Reıne PInsonneault and Mirelle Tremblay to name a few.

I am also grateful to Anne Rochette, Professor Edwin Williams and Professor Mark Baker for comments on previous versions of material dealing with the issues brought un in the thesis. Special thanks, however, to Professor Lisa Travis for invaluable guidance and for countless helpful and critical suggestions in the early stages of the thesis.

Sara T. Rosen generously discussed her own analysis of Romance causatives with me and Lisa Reed kindly sent me some of her work. This greatly clarified some of the issues for me.

Some help in the early stages of the statistical analyses was provided by Theodore Maniakas and Professor Lydia White who both supplied help at critical moments.

For their friendship, encouragement and moral support, I must single out Eithne Guilfoyle and Evanthıa Kehayı. Many thanks for stımulatıng discussıons and the sharıng of references; I would also like to thank them for help with programs that an old 
computerphobe such as myself found initially daunting. Without them, the thesis would no doubt have been much poorer.

I would like as well tis acknowlege Zofia Laubitz for a metıculous editing jok, accompli- hed under severe tıme constraints.

For kındness above and beyond the call of duty, I would like to sincerely thank both Professor Nicole Domingue and Professor Lydia White without whom this project could not have been finished 1 am especially grateful to Professor White for a critical review of the entire thesis as well as for many pertinent suggestions, which have allowed me to improve the final version.l would also thank the members of my thesis committee for helpful remarks.

Additional thanks go to both Professor Domingue and Professor G. L. Piggott for moral support and encouragement over the years.

Financial support for this research was provided by a McConnell Fellowship from MCGill University and a Quebec FCAC grant. In addition, some assistance was provided in the early stages of my graduate studies by grant FCAC EQ1660 to Professor Michel Paradis. Further financial support was obtained from Dr. David Caplan through MRC grant PG28 to Dr. A. R. Lecours. I am most grateful for this help as well as for the assistance provided by the McGill Linguistics Department in defraying some of the costs of thesis preparation.

Last though not least I would like to thank the members of my famly, Patricia, Louise, Terry, Dani and Mary, for putting up with me for all these years. I have also received their aid in preparing this thesis. Thanks to Loulse for material aid as well as for the use of her printer, to Terry for executing some of the tables in the Appendix and to Mary for countless hours of photocopying and for help with the typing. Special thanks to my mother who sustains all of us and who has helped me in ways too numerous to mention throughout all my studies. 


\section{TABLE of CONTENTS}

Abstract II

Résumé

Acknowledgements iv

List of Tables xII

List of Figures $\quad$ XV

Preface $\quad x v 1$

Chapter 1- The Explanatory Function of Functional Categories in Aphasia 1

1.1. Morphosyntactic Deficits 1

1.2. Comprehension Deficits 3

1.3. The Relation of Comprehension and Production and the Issue of Competence vs. Performance 6

1.4. Lexical and Functional Categories in Government-Bınding Theory 8

$\begin{array}{ll}\text { 1.5. Linguistic Analyses of Agrammatısm } & 13\end{array}$

Chapter 2- The Head Accessibility Hypothesis and the Testing of French Causatives $\quad 22$

2.0. Introduction 22

2.1. Section $1 \quad 22$

2.1.1. A New Account - The head Accessibility Hypothesis 22

2.3.2. Predictions of the HAH for production as a consequence of structural complexity 24

A. Lexical Categories $\quad 24$

B. Functional Categories 28

B.1.1. Determiners (DPs) 30 
B.1.2. Evidence of DPs in Aphasıc Data 32

$\begin{array}{ll}\text { B.2. Kase Phrases } & 35\end{array}$

B.3.1. Inflectional Phrases (IPs) 36

B.3.2 Evidence of IPs in Aphasic Data 39

8.4. Complement Phrases (CPs) 41

2.1.3. How does the Head Accessiblity Hypothesis compare with other linguistic characterizations of syntactic deficits? 42

2.1.4. Predictions of the HAH for comprehension as a consequence of structural complexity

2.1.5. Testing the Head Accessibility Hypothesis 47

2.2. Section 2- Linguistic Analyses of French Causatives 50

2.2.1. Some Properties of Causatives Cross-Linguistically 50

2.2.2. Analysis of the French Causative $\quad 54$

$\begin{array}{lll}\text { 2.2.2.1.1. Farre-lnf } & 54\end{array}$

2.2.2.1.2. Biclausal Account 61

$\begin{array}{lll}\text { 2.2.2.2. Faıre-Par } & 65\end{array}$

2.2.2.3. Behaviour of Clitics in Causative Constructions $\quad 67$

$\begin{array}{ll}\text { 2.2.3. Concluding Remarks } & 69\end{array}$

Chapter 3- Experımental Design $\quad 72$

3.1.1. Materials in the Object Manipulation Batteries 72

3.1.1. Description of the Object Manipulation Batteries (OMBs) 72

3.1.1.1. Original OMB $\quad 74$

3.1.1.2. Justification for Testing the OMB 75

3.1.2.1. Description of the Causative OMB (COMB) 77

3.1.2.2. Justification for Testıng the COMB 79

3.1.3.1. Description of the Pronoun OMB (POMB) 87 
3.1.3.2. Justification for Testing the POMB

(Clitıc Pronoun Battery) 88

$\begin{array}{ll}\text { 3.2. Subjects } & 91\end{array}$

$\begin{array}{ll}\text { 3.3. Procedural Methods } & 95\end{array}$

$\begin{array}{ll}\text { 3.4. Scoring } & 97\end{array}$

3.5. Data Analysis 99

$\begin{array}{ll}\text { Chapter 4- Group Studies } & 102\end{array}$

4.1. Test Results 102

4.1.1. 'Sentence Contrasts 1' 103

4.1.1.1. Total Aphasic Sample 103

$\begin{array}{ll}4.1 .12 \text { Normal Controls } & 107\end{array}$

$\begin{array}{ll}\text { 4.1.2. 'Sentence Contrasts 2' } & 111\end{array}$

4.1 2.1. Subset Aphasic Sample 111

4.1.2.2. Normal Controls $\quad 113$

$\begin{array}{ll}\text { 4.1.3. 'Sentence Contrasts 3' } & 116\end{array}$

$\begin{array}{ll}\text { 4.1.3.1. Subset Aphasic Sample } & 116\end{array}$

4.1.3.2. Normal Controls $\quad 117$

$\begin{array}{ll}\text { 4.1.4. 'Sentence Contrasts 4' } & 120\end{array}$

4.1.4.0. Obligatory vs. Optıonal Stiuctural Elements $\quad 120$

4.1.4.1. Total Aphasic Sample 121

4.1.4.2. Normal Controls 124

4.1.5. 'Senteiler Contrasts 5' 128

$\begin{array}{ll}\text { 4.1.5.1. Subset Sample } & 128\end{array}$

4.1.5.2. Normal Controls $\quad 130$

4.2. The Effects of Structural Complexity and

Educational Level on Syntactic Comprehension $\quad 133$ 
$\begin{array}{lr}\text { Chapter 5-Individual Case Studies } & 136\end{array}$

5.1. Aphasics without Major Comprehension Deficits 136

5.1.1. AG. 136

5.1.2. C.M. 140

5.1.3. J.T. 144

5.2. Aphasics with Some Comprehension Deficits 148

$\begin{array}{ll}\text { 5.2.1. D.C. } & 148\end{array}$

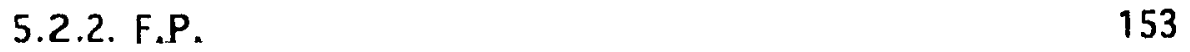

$\begin{array}{ll}\text { 5.2.3. J.R. } & 157\end{array}$

5.3. Aphasics with Major Comprehension Deficits 162

5.3 1. C.D. 162

$\begin{array}{ll}\text { 5.3.2. J.D. } & 167\end{array}$

5.3.3. P.R. 172

$\begin{array}{ll}\text { 5.4. Normal Controls } & 177\end{array}$

$\begin{array}{lr}\text { Chapter 6- General Discussion } & 179\end{array}$

6.1. Comprehension of Causatives and its Implication for the Understanding of Aphasıc Comprehension 179

6.1.1. The Processing of VP Complements vs. IP Complements 179

6.1.2. The Intactness of the Lexical Representation of Fatre 181

6.1.3. Interpretation of the Reflexive Pronoun Se 185

6.2. Interpretation of the Semi-Grammatical Causative (Faire-à) and Causative-Reflexive Causee 186

6.3. Structures with Stylistic Inversion 190

6.4. The Significance of the Four DP Sentences. 190

6.5. Extensions of the Head Accessibility Hypothesis 193 
$\begin{array}{ll}\text { 6.6. Conclusion } & 197\end{array}$

References

200

Apperıdices

210

Appendix A Summary of Group Results

211

Appendix B Summary Score Sheets for French Patients and

Subset of Controls For Each Battery and Each Paradigm 
Table 3.1.1. Sentence Types in the OMBs

Table 3.1.2. Sentence Types in the COMB 78

Table 3.1.3 Sentential Variables in the OMBs 86

$\begin{array}{lll}\text { Table 3.1.4. Sentence Types in the POMB } & 87\end{array}$

Table 3.2. Patient Data-Total Aphasic Sample 92

$\begin{array}{lll}\text { Table 3.3. Patient Data-Subset Sample } & 93\end{array}$

$\begin{array}{lll}\text { Table 3.4. Control Data } & 94\end{array}$

Table 4.1.1. Group Results- All 9 Aphasics 'Sentence Contrasts 1' 105

Table 4.1.2. Group Results- 10 Controls 'Sentence Contrasts 1' 108

Table 4.1.3. Significantly Different Sentence Types-

$$
\text { Patients } \times \text { Controls-'Sentence Contrasts } 1^{\prime} \quad 109
$$

Table 4.2.1. Group Results- 5 Aphasics 'Sentence Contrasts 2' 111

Table 4..2.2. Group Results-10 Controls 'Sentence Contrasts 2' 114

Table 4.2.3. Significantly Different Sentence Types-

Patıents $\times$ Controls -'Sentence Contrasts 2' 115

Table 4.3.1. Group Results- 5 Aphasics-'Sentence Contrasts 3' 116

Table 4.3.2. Group Results- 10 Controls-'Sentence Contrasts 3' 118

Table 4.3.3. Significantly Different Sentence Types-

Patients x Controls-"Sentence Contrasts $3^{\prime} \quad 119$

Table 4.4.1. Groun Results- All 9 Aphasics-'Sentence Contrasts 4' 122

Table 4.4.2. Group Results- 10 Controls-'Sentence Contrasts 4' 125

Table 4.4.3 a Significantly Ditferent Sentence Types- 
Table 4.4.3 b Signıficantly Different Sentence Types-

Patients $\times$ Controls-"Sentence Contrasts $4^{\prime}$

Table 4.5.1. Group Results- 5 Aphasıcs-'Sentence Contrasts 5'

Table 4.5.2. Group Results- 10 Controls-'Sentence Contrasts 5'

Table 4.5.3. Significantly Different Sentence Types-

Patients $x$ Controls-'Sentence Contrasts $7^{\prime}$

Table 5.1. Summary Results of Patient AG

Table 5.2. Summary Results of Patient CM

Table 5.3. Summary Results of Patient JT

Table 5.4. Summary Results of Patıent DC

Table 5.5. Summary Results of Patient FP

Table 5.6. Summary Results of Patient JR

Table 5.7. Sumrnary Results of Patient CD

Table 5.8. Summary Results of Patient JD

Table 5.9. Summary Results of Patient PR

Table A.A.1.1. Raw Scores, Means, and Percent CorrectTotal Aphasıc Sample-OMBs

Table A.A.1.2. Group Results- All 9 Aphasics (OMBs)

Table A.A.1.3. Significantly Different Sentence Types-

Total Aphasic Sample-OMBs

Table A.A.2.1. Raw Scores, Means, and Percent Correct-

Subset Aphasic Sample-OMBs

Table A.A.2.2. Group Results- 5 Aphasics (OMBs)

Table A.A.2.3. Significantly Different Sentence Types-

Subset Aphasic Sample-OMBs

Table A.A.3.1. Raw Scores, Means, and Percent Correct- 
xiv.

Table A.A.3.2. Group Results-10 Controls (OMBs) 219

Table A.A.3.3. Significantly Different Sentence Types-

Normal Controls-OMBs 220

Table A.A.4. Error Patterns for Object Manıpulation Batteries 223

Table A.A.5. Generalizability of the Present Sample to a Larger Population 233

Table A.B.1. Summary Results of Control OF 310

$\begin{array}{lll}\text { Table A.B.2. Summary Results of Control RL } & 321\end{array}$

Table A.B.3. Summary Results of Control LN 332 


\section{LIST of FIGURES}

Figure 4.1. Accuracy Rates Patients vs Controls-'Sentence Contrasts 1' 110

Figure 4.2. Accuracy Rates Patients vs Controls-'Sentence Contrasts 2' 115

Figure 4.3. Accuracy Rates Patients vs Controls-'Sentence Contrasts 3' 119

$\begin{array}{lll}\text { Figure 4.4. Effect of Linear Order on Subjects' Accuracy Rates } & 121\end{array}$

Figure 4.5a. Accuracy Rates Patients vs Controls-'Sentence Contrasts 4' 126

Figure 4.5b. Accuracy Rates Patients vs Controls-'Sentence Contrasts 4' 127

Figure 4.6. Accuracy Rates Patients vs Controls-'Sentence Contrasts 5' 132

Figure 5.1. Accuracy Rate of Patient AG - 'Sentence Contrasts 1' 138

Figure 5.2. Accuracy Rate of Patient CM - 'Sentence Contrasts 1' 143

Figure 5.3. Accuracy Rate of Patient JT - 'Sentence Contrasts 1' 146

Figure 5.4. Accuracy Rate of Patient DC - 'Sentence Contrasts 1' 151

Figure 5.5. Accuracy Rate of Patient FP - 'Sentence Contrasts 1' 156

Figure 5.6. Accuracy Rate of Patient JR- 'Sentence Contrasts 1' 160

Figure 5.7. Accuracy Rate of Patient CD - 'Sentence Contrasts 1' 166

Figure 5.8. Accuracy Rate of Patıent JD - 'Sentence Contrasts 1' 171

Figure 5.9. Accuracy Rate of Patıent PR - 'Sentence Contrasts 1' 175

Figure A.A.1. Effect of Number of NPs on Subjects' Accuracy Rates 221

Figure A.A.2. Effect of Number of Action Verbs on Subjects' Accuracy Rates 221

Figure A.A.3. Effect of Number of Inflected Verbs on Subjects' Accuracy Rates 222

Figure A.A.4. Effect of Maximum Number of Words on Subjects' Accuracy Rates 222

Figure A.B.1. Accuracy Rate of Control OF - 'Sentence Contrasts 1' 311

Figure A.B.2. Accuracy Rate of Control RL - 'Sentence Contrasts 1' 322

Figure A.B.3. Accuracy Rate of Control LN- 'Sentence Contrasts 1' 333 


\section{Preface}

This thesis examines aphasic comprehension and the nature of the sentential vartables that can facilitate or hinder this process. It is divided into the following sections:

Chapter 1 provides an overview of syntactic deficits in aphasia (both productive and receptive). We postulate that previous linguistic accounts, which capture some insights, should in some sense be combined wrth psycholinguistic approaches that have reached the consensus that some version of a closed-class hypothesis, in which function words and inflectional morphology are considered the loci of processing difficulty, is to be adopted.

Chapter 2 provides the theoretical justıfication for this approach. Working within a principles and parameters approach, we show that the functional categories, because they entall the creation of additional hierarchical structure, are indeed more at risk in the aphasic condition. We propose a new account of morphosyntactic deficits--the Head Accessibility Hypothesis--whici allows us to account for the deficits of both anterior and posterior aphasics. This hypothe sis is tested by examining French causatives. In the second section of Chapter 2, we present Rosen's (1989) theoretical analysis of these constructions. Both the farre-inf and the faire-par constructions are described, as is the behaviour of clitıcs, which exhibit the phenomenon of clitic climbing in these structures.

Chapter 3 is a detalled presentation of the experimental design we adopted to test the Head Accessibility Hypothesis. We discuss the materials we used in an object manipulation paradigm and we describe the subjects tested. In addition, the scoring and statistical procedures we utilized to analyze our data are fully reported.

In Chapter 4, sentence types are divided into relevant sets in order to highlight important contrasts and make the presentation of the large number of results clearer. 'Sentence Contrasts 1' examines various causative constructions which are contrasted with similar structures that contan either the same number of clauses or more; the latter 
group would be predicted to be more difficult to understand. 'Sen:ence Contrasts 2 ' tests the comprehension of pronominal clitics in dative and causative constructions, comparing these results with those obtained with full NP (DP) versions of the same structures. The 'Sentence Contrasts 3' test was undertaken to examıne the comprehension of reflexive clitics in causatives, contrasting them with passive full NP sentences, thus testing the theory of Grimshaw (1990) and Rosen (1989) that reflexive cliticization in Romance resembles passivization in its effects on phrasal structure. 'Sentence Contrasts 4 ' tests possible differences between structures in which hierarchical complexity is a consequence of the argument structure of the phrasal heads (complementation) and structures in which adjunction or coordination is responsıble for the additional branching. 'Sentence Contrasts $5^{\prime}$ examines only constructions that contain a wh-trace--relatives and cleft objects. These minumally contaın two CPS. Some unexpected information was also provided by the control data, in that we found a significant effect for level of education, permitting us to state with some confidence which sentence types are difficult to process and to explain the reasons for this difficulty on theoretical grounds.

Chapter 5 examines each aphasic tested on a case by case basis in order to confirm that the statistically significant results obtained in the group studies did not obscure individual performance.

Finally, Chapter 6 further extends the analyses of the results presented in the two previous chapters, showing that our initial hypothesis was confirmed. In addition, we were able to extend Rcisen's analysis of the faire -à construction. We discuss the processing of French causatives in relation to the Head Accessiblity Hypothesis. We also make some suggestions as to the generalizability of the Head Accessibility Hypothesis to both the morphological and to the phonological domains. Thus, it is to be preferred to other proposed hypotheses because it cuts across linguistic levels in a principled way, can account for a larger body of data, and is not modality-specific. 


\section{Chapter 1- The Explanatory Function of Functional Categories in Aphasia}

\subsection{Morphosyntactıc Deficits}

Linguistic aphasıology is an interdisciplinary approach to the language deficits experienced as sequelae to brain damage. From the linguistic point of view, aphasic data as external evidence offers a testıng ground for varıous theoretical analyses. From the point of view of aphasıology, linguistic analyses inform the aphasıc condition. There is an increase in explanatory adequacy and theories with real predictive power can be formulated.

Both in aphasiology and in theoretical linguistics, research has too often been anglocentric; however, major new insights have been attained as superficially very different languages have been studied. Analyses of English and English aphasic data have also been vastly enriched as a result. We propose a rigorous study of causative constructions in French, and we will show how aphasic comprehension of these structures allows us to characterize morphosyntactic deficits in a maxımally general way.

The two principal syntactıc deficits in aphasıa are agrammatism and paragrammatism. Agrammatism is a complex language deficit generally found In Broca's aphasics, i.e. patients who have suffered a cerebral accident in the anterior portion of the left, language dominant, hemısphere. A general clinıcal description of the syndrome is that the patients are non-fluent and tend to produce only major lexical category items--nouns, adjectives and verbs--while omitting function words and inflectional morphology. The syndrome was classically held to be an output disturbance, a deficit in language production only.

Paragrammatism, on the other hand, is generally found in the posterior aphasias-e.g. Wernicke's. The patients tend to be fluent but their speech may lack semantic content due to their production of neologisms and phrasal constructions which do not fit into the overall sentence structure, ı.e. selectional and subcategorization requirements are not 
respected. They are seen as having problems with the major lexical categories. Functional categories do seem to be avallable to them since they will of ten correctly inflect their neologistic productions. Posterior aphasics generally have comprehension deficits as well; in some cases these are so severe that they cannot understand single words or participate in the testing of sentence comprehension.

The patterns of retention/loss (misselection) exhibited by aphasics, both agrammatics and paragrammatics (to the extent that there are principled differences between them), will be examınzd using Government-Bindıng theory (Chomsky $1982,1986,1989)$ and attributed to lexical access probleins. Psycholinguists Bates and Wulfeck (1989), workıng from an entırely different perspective, have in fact proposed a version of the 'closed class hypothesis' which attributes morphosyntactic deficits to differential access to open and closed class items in the Lexicon. We feel that this parsımoniously explaıns the observed phenomena in a wide range of languages.

Due to the importance expressive deficits in aphasia have played in theory formulation and in the generation of linguistic analyses accounting for the patterns of retention/loss (misselection) exhibited by aphasics, we will, in addition to discussing receptive deficits (In the next section), briefly present some of these linguistically based hypotheses. These linguistic hypotheses, at first formulated to account for the production data, were extended to account for (asyntactic) comprehension. In Chapter 2, we will show how the existing theories are inadequate to account for the cross-linguistic data which are now available (Menn and Obler 1990) and we will propose a new hypothesis, the Head Accessibility Hypothesis, which accounts for both production and comprehension in a rather economical fashion. We propose to test this hypothesis by examınıng French causative constructions. The experimental results will also contribute to linguistic theory by supplying some external evidence confırmıng Rosen's (1989) analysis of these structures. 


\subsection{Comprehension Deficits}

Bradley, Garrett and Zurif (1980) proposed the functor theory (a version of the closed class theory) to explain agrammatic processing. They posited that the closed class elements normally have a special access route; the loss of this route in agrammatics prevents these aphasics from building syntactic representations. Their work provided a psycholinguistic explanation for locating the deficit in the structure building operations of the syntactic level.

When the syndrome first began attracting the attention of researchers, an untested assumption was that Broca's aphasics were agrammatic in production only. Their ability to arrive at seemingly acceptable interpretations of contextualized verbal material did not challenge the widely held assumption that they have normal comprehension. Berndt and Caramazza (1981), in a review of the syndrome, chronicle the work of Zurif, Caramazza and others in establishing that agrammatics' (and conduction aphasics') abılity to correctly interpret center embedded semantically reversible relative clauses of the type:

(1) The girl that the boy is hitting is tall. was impaired, and that improbable sentences like:

(2) The bird that the worm is eating is tlue. were systematically misinterpreted. The authors postulated that the algorithmic processes of sentence comprehension had been disrupted in these patients and that they relied overly on heuristic strategies to process incoming messages. When semantic constraints and pragmatic real world expectations could not be used to disambiguate utterances, Broca's and conduction aphasics responded randomly.

Heilman and Scholes (1976) also showed that both agrammatics and conduction aphasics could not reliabiy interpret the following sentences, where word order and grammatical morphemes must be properly decoded for correct interpretation: 
(3) I He showed her baby the pictures.

ii He showed her the baby pictures.

vs. ii He showed her baby pictures.

Only (3 iii) is truly ambiguous. The insertion of the in (3 I) and (j ii) disambiguates the sentences and should provide a structure to which only one interpretation can apply. Berndt and Caramazza (1981) posited on such evidence that the language processing parsing system is at fault, preventing agrammatics from bullıng a normal syntactic representation of the verbal input they receive.

Schwartz, Saffran and Marin (1980) had noted that the syntactic structures with which, for example, Caramazza and Zurif (1976) had chosen to test comprehension were particularly difficult ones. Therefore, in order to establish a lower bound on which syntactic structures cculd be understood by agrammatics, they chose to test sımple transıtive reversıble sentences such as:

(4) The clown applauds the dancer.

These were contrasted with passives:

(5) The dancer is applauded by the clown.

Their hypothesis was that in English, sınce gramınatical relations are determined in large part by word order, sentences of both types (4) and (5) would be interpreted as having subject-verb-object order (Bever1970), as neither the passive morphology nor the preposition by in (5) would be attended to by the agrammatic.

The authors concluded from their findings that their patients were no longer able to understand semantic notions nor could they map these relations (e.g. Agent, Theme, Goal, etc.) onto constituent structure. Caplan (1983a) rightly pointed out that anımacy had confounded their results. Other authors who tested with this paradigm in other languages such as Dutch (Kolk and van Grunsven 1985) showed the same pattarn of results, though to 
a much milder degree ${ }^{1}$. All these results led to agrammatism being considered as a central deficit in which all modalities were seemingly affected by the inability of the syntactic processor to deal with functional elements.

This central deficit analysis was compromised by the fact that case reports surfaced in the literature to the effect that expressive agrammatism could occur without asyntactic comprehensıon (Miceli, Mazzuchı, Menn and Goodglass 1983). In additıon, these kınds of comprehension patterns could be seen in other patient populations without the corresponding expressive deficits (Goodglass and Menn 1985). In a large survey of unselected English and French aphasics, Caplan, Baker and Dehaut (1985) also found that different patterns of comprehensıon deficits did not correlate with etıology or clinical type (see also Butler, Caplan and Waters 1988). Rather, certain variables related to the sentence types tested did have a determining effect on comprehension, e.g. number of NPs, number of verbs, argument structure of the verb, number of clauses and whether or not a linear order strategy could be successfully employed to obtain a correct response.

Investigations of aphasia in languages with richer inflectional systems demonstrate 1) that aphasics try to compute a VP (see Gendron's (1983) re-examination of Smith and Mimica (1984) on Serbo-Croatian and Hagiwara and Caplan (1990) on Japanese), and 2) that language-specific thematic role orders are preferentially processed. Bates and her colleagues have also found, despite the occasional use of semi-grammatical sentences, that there are no syndrome-specific comprehension patterns. Rather, it is syintactic complexity which best predicts error rates, even in non-brain damaged hospitalized subjects. The main difference is that Broca's aphasics tend to use all available cues to boost their performance while Wernicke's do not seem able to use redundant cues. Grammatical morphemes seem less robust than word order but they are understood significantly better than would be predicted if aphasics had no access to them at all. In fact, their

1 Whether this effect was due to differences between the subject groups or differences between the languages cannot be fully determined. 
comprehension is more problematic than their production; this is no doubt due to perceptual salience.

1.3. The Relation of Comprehension and Production and the Issue of Competence vs. Performance

We will deal with both the above-mentioned issuss in the present section because both involve the Mental Lexicon, how it is organized and how information is retrieved from It. In the absence of any evidence to the contrary, it is generally accepted that both comprehension and production make use of the same knowledge base (see Garnham 1985; Frazier 1988; Garrett 1990) Both comprehension and production involve lexical access and the construction of phrase structure The way the Lexicon is organized may be more efficient for one modality than the other, but the same organizational principles nevertheless apply for both. For example, it would aid access during comprehension if words with the same first segments were closely associated in the Lexicon This permits us to process words very quickly, when going from sound to meaning For production purposes, it is not necessary for them to be stored in close proximity, since in production we must go from meaning to sound. However, two phenomena lead us to believe that retrieval is similar for production 1) Fay and Cutler (1977) have discussed malapropisms, words that share phonological characteristics with intended targets (similar length, sound and stress patterns), and 2) the tip-of-the-tongue phenomenon, 1.e. we can describe many formal properties of a word we were not able to retrieve. Garrett (1990) describes the the two modalities as foliows:

In the relations thus suggested between comprehension and production, each system provides an error-checking mechanism for the other. Viewed in this way, the two are closely linked in their functions, and the fact of their similar design seems more inevitable than surprising. (p.166)

This is the case for the normal system. For this reason, we will occasionally discuss 
aphasic production data where relevant, especially since all the linguistic analyses which have been proposed to account for agrammatism were first formulated to account for production. In addition, what principally concerns us is the structure of the linguistic representations that may increase the pro:sessing load.

As long as the central deficit theory of agrammatism could be maintained, one could speak of a loss of the knowledge base or competence. However, not only were aphasiologists confronted by the modality-specific manifestations of syntactic deficits described above but, in tasks of grammaticality judgment, agrammatıc patıents were found to be sensitıve to the closed class vocabulary (Linebarger, Schwartz and Saffran 1983 ). Zurif (1996) cites work by Rosenberg et al. (1985), who utilized a dual task paradigm to examine the phenomenon known as the 'invisibility' effect. In a text of connected prose, normals were asked to cross out certain letters. They tended to do so correctly for open class items only. The letters in closed class items were not attended to, that is, they did not intrude on conscious awareness. In scrambled texts, the experimental subjects would notice the letters regardless of vocabulary type. Broca's aphasics, on the other hand, always attended to the letters regardless of vocabulary and textual type--normal vs. scrambled.

Wernicke's always disregarded the letters in function words regardless of the type of text. Broca's are able to deal with closed class items but we can see that they are not performing as normals do. Obviously, they are accessing these items differently, i.e. less automatically, than they would have done pre-morbidly, but they have not suffered a loss of competence; it is just that their performance has been altered. It is now the general consensus of psycholinguists that we are dealing not with loss but with problems of access. In section 1.5. below, we will see that the linguistic analyses of the syndrome talk of loss of competence--the proposal that we shall develop in Chapter 2 does not--it is a claim about performance. In order to understand the linguistic analyses of agrammatism reviewed in section 15 ., we will first present a brief introduction to some notions assumed within the theoretical framework adopted in this thesis. 


\subsection{Lexical and Functional Categories in Government-Bınding Theory}

Recent extensions of $X^{\prime}$-theory permit us to incorporate functional categories into the rule schemata first proposed to account for the phrasal structure of the major lexical categories, 2
l.e. $\quad N:[+N,-V]$
$A:[+N,+V]$
$V:[-N,+V]$
$P:[-N,-V]$

(6)

$$
\begin{aligned}
& X^{\prime} \cdots>\ldots X \ldots \\
& X^{\prime \prime} \cdots . . . X^{\prime} \ldots
\end{aligned}
$$

(6) maximally generalizes across categories; it captures the fact that the "lexıcal" category or $X^{0}$ projects to the $X^{\prime}$ or $X^{n+1}$ category which contans the head and the complements of the head. This intermediate level category then in combination with the appropriate Specifier, projects to the X" or maximal projection level (XP). Ordering information need not be encoded in the rule schemata themselves since the head parameter associated with a particular language, e.g. head-ınitial for Englısh, head-final for Japanese, will account for the ordering of all complements in relation to each head crosscategorially. Specifiers, however, often seem to be generated in the opposite direction to the complements. The direction in which the complements are attached in the tree is the unmarked theta-role assignment order for a language.

$X^{\prime}$-theory and $\theta$-theory are two interactive modules of the principles and parameters version of Government-Binding theory (Chomsky 1982, 1986). The theory has dispensed with the less explanatory and often redundant phrase structure rules of earlier formulations. ${ }^{3}$ The interaction of $X^{\prime}$-theory and $\theta$-theory (which is coricerned with the semantic ioles that a lexical item has to assign to its complements) generates a D-

2 Further discussion of these categories will be reserved for the first section of Chapter 2.

3 For those unfamiliar with this framework, we would recommend that they consult an introduction to the theory such as Cook (1988). 
Structure representation of a syntactic string. The old Transformational component has been reduced to one rule, Move $a$ which allows constituents to be moved, subject to certain generalized constraints. For instance, if a NP is moved it must be moved to an empty position which has not independently been assigned another $\theta$-role (this would result in a violation of the $\theta$-Criterion which stipulates that 'each argument bears one and only one $\theta$ role, and each $\theta$-role is assigned to one and only one argument' (Chomsky, 1982: 36)). In addition, other elements which can move must be constrained from moving too far; this is handled by Bounding Theory. The need for all overt NPs to be assigned (abstract) Case will often force movement to an empty argument position, since if a base-generated NP is not in a position to receive Case the structure will be ruled out by the Case Filter, which states that structures containing lexical NPs that do not have Case are Il-formed. The fact that empty positions are generated follows from the Projection Principle, which states that:

(7) Representations at each syntactic level (i.e. LF and D-Structure and Sstructure) are projected from the lexicon, in that they observe the subcategorization properties of lexical items.

(Chomsky, $1982: 29)$

The model of the syntactic component can be seen as:

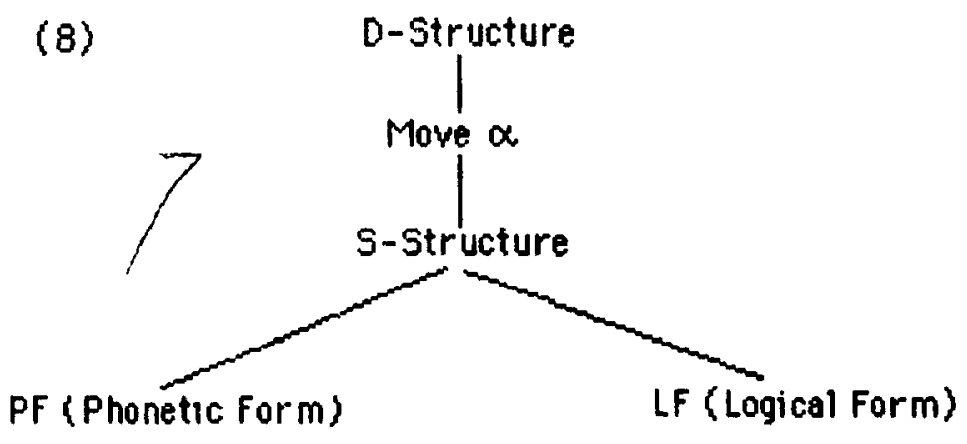

(Chomsky and Lasmik 1977)

Traces of movement remain and may be read off the S-structure representation because 
they are bound to or form a chain with the moved element. This binding falls within the scope of Binding Theory which deals with the referential relationships between elements and stipulates which combinations of elements, overt and empty, can constitute proper chains; whether through some intrinsıc property of their own (e.g. the contrast between anaphoric and pronominal elements) or because of the interaction of this sub-theory with e-theory or Case Theory (only one $\theta$-role and Case per chain). Finally, another subtheory of the grammar deals with the subject of infinitivals, which is an empty category called PRO; the postulation of such an element follows directly from the extended Projection Principle, which states that all sentences must have a subject. (In ruot sentences this may also be accomplished by the insertion of an expletive item such as it or there in sentences like: It rained last night, where it clearly cannot be referential.

Now that we have briefly discussed the relevance of $X^{\prime}$ theory to iexical categories, we shall present the extensions of the theory to the non-lexical or functional categories (for discussion see Abney 1986, Chomsky 1986, Fukul and Speas 1986, Gulfoylt' 1990). 4 In order to capture the parallelisms between the structure of noun phrase: and sentences, it has been proposed that these categories should be headed by the functicnal elements $D$ (etermıner) and INFL(ection) respectively. These 'heads' would then $c$ (onstituent)-select their unique complements NP and VP respectively. In addition, their intermediate bar level may licence a Specifier positıon. In the case of the Determiner Phrase, this will be necessary to provide an empty position to act as a landing site for the possessor in John's hat, for example. The genitive 's is the head of the DP; John is generated in the NP complement and has to move to get Case. This will account for the word order facts, as in (9).

4 There are some differences among these proposals. However, for the purposes of the present study a compromise position is taken since these differences do not affect the analysis of the aphasic phenomena in this first formulation. Further experimentation will no doubt require taking these differences into account in order to predict specific, and perhaps more subtle, deficits. 
(9)

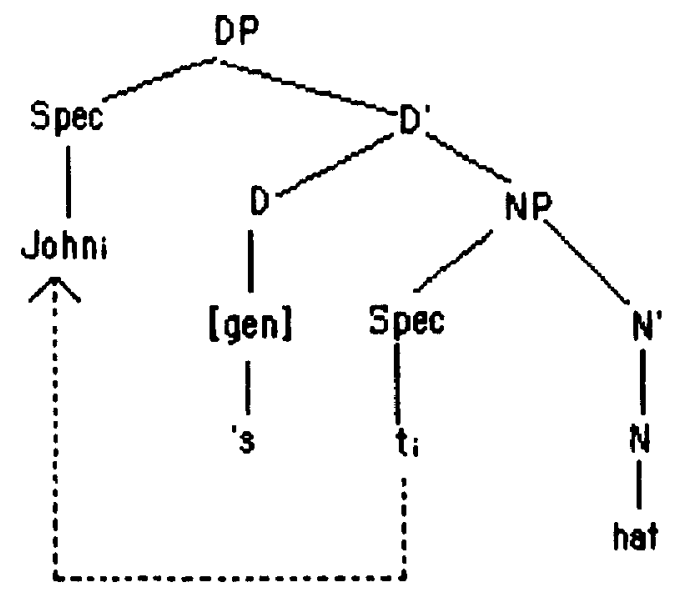

For the same reason, the IP (Inflection Phrasie) must also have a Spec(ifier) position so that the NP subject can move to this position from its base-generated position in the VP (assuming the subject-in-VP analysis proposed recently by Koopman and Sportıche (1988)) in order to get nominative Case from INFL through the mechanism of Spec-head agreement (see (10)):

(10)

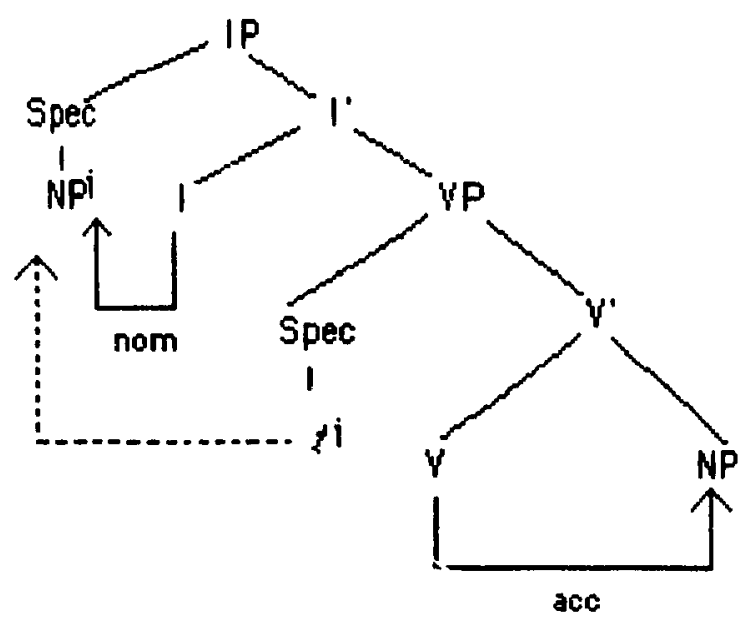

Note the resemblance betwet:n the mechanism for assigning nominative Case in the above tree and that for assigning genitive Case in (9). 
The functional category which selects for IP (the old S) is COMP and the projection of COMP (the old S') will form a CP (Complement Phrase) which is present in all root and most embedded sentences. The Spec of CP furnishes the landing site for wh-words in questions and relatives.

The last category we will discuss is called KP or Kase phrase; this was first proposed by Hale (class lectures) and later discussed by Lamontagne and Travis (1986). It attempts to reduce the Case Filter to an instance of the Empty Category Principle, which states that all empty categories must be properly governed (this is to constrain the proliferation of indiscrımınately generated empty elements). $\mathrm{K}$ is an empty category and will take a DP complement (which itself takes a NP complement). Being governed by a Case assıgner, $K$ will be properly governed and Case features will be transferred to the NP which needs Case.

Note the parallels between CP and KP and also betwcen IP and DP; both of the former take another functional category as complement, whereas the latter both take a phrasal complement that is the projection of a lexical category--VP and NP respectively. (In fact, a transitive VP will also take a functional category as its complement--DP; only NP having an inherently intransitive nature which need not take a complement of any kınd (cf. Grimshaw 1990).)

The functional and lexical categories are further distinguished by the lack of semantic content of functional categories; this is captured by the proposal that, although the functional head is the syntactic head of its category, it cannot be the semantic head, which in fact must be the head of its lexical complement. Lexical items are both the syntactic and semantic heads of their maximal projections (cf. Abney 1986). It follows that the generation of a functional head entals the generation of its complement in order to generate its semantic head; this is not the case with lexical categories, where the head is redundantly identified by syntactic and semantic criteria. 


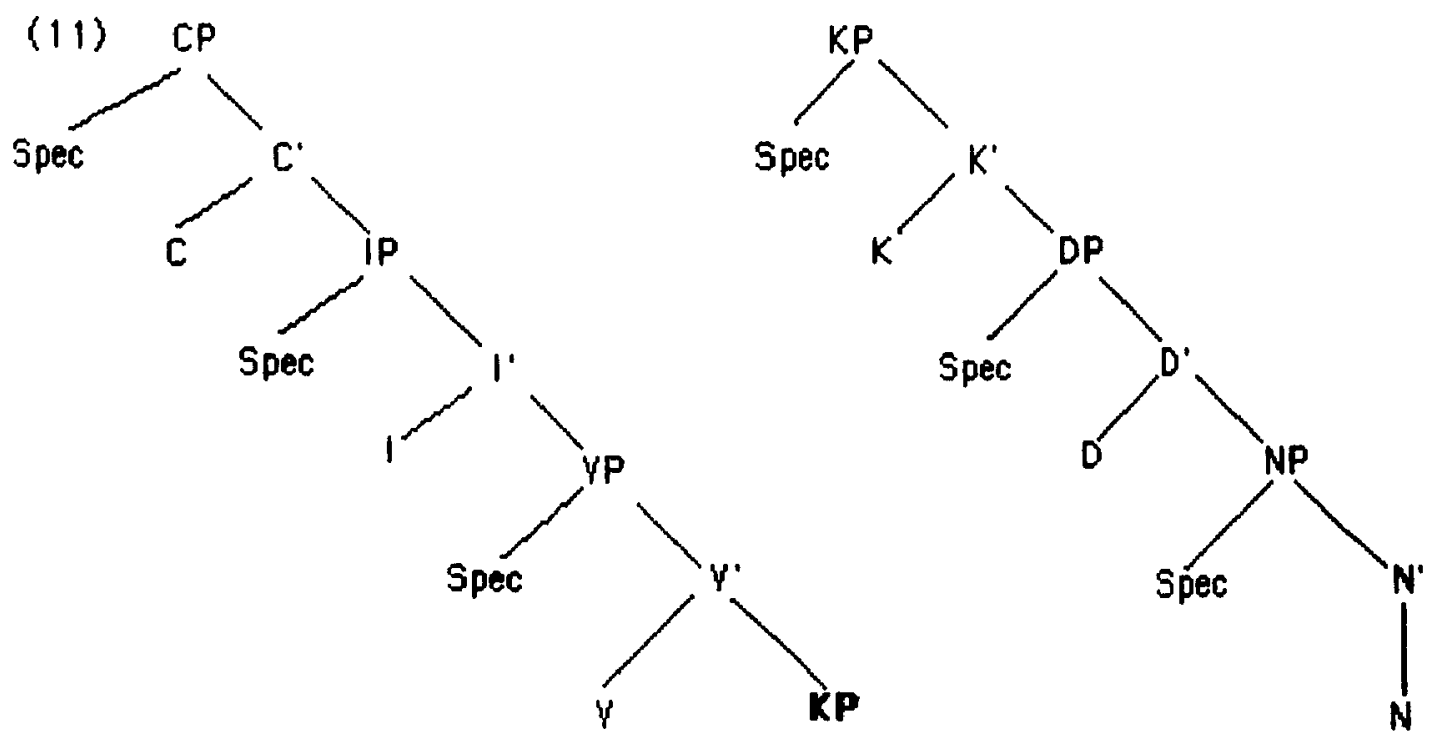

After this brief overview of the model of grammar, we will present the principal theoretical analyses of agrammatism.

\subsection{Linguistic Analyses of Agrammatism}

As agrammatism has seemed more amenable to linguistic analysis than paragrammatism, attempts have been made to characterize in linguistic terms the pattern of omitted versus retained elements. The reader should keep in mind the anglocentric bias of some of the earlier analyses. Kean $(1977,1978,1980)$ was the first to propose a principled linguistic account--the Phonological Hypothesis. She attempted to show that the pattern of agrammatic retention could only be characterized at the phonological level. She claımed:

( 12 ) A Broca's aphasic tends to reduce the structure to the minimal string of elements which can be lexically construed as phonological words in his language.

(Kean 1978: ex. (19)) 
The relatively 5 retained linguistic elements would thus consist of phonological words (hereafter P-words), i.e. Ns, As, polysyllabic Preps, and complex words containıng just +boundaries. The relatively omitted elements would be the phonological clitics (hereafter Pclitics), i.e. determiners, auxiliarıes, monosyllabic prepositıons, and inflectional and derivational affixes, the latter even including the + -boundary ones attached to word-level stems, e.g. the -ive in definitive. Compound words would be considered to contain two phonological words since they coritain \#-boundaries. Lapointe (1983) took issue with Kean's characterization, arguing that new developments in linguistic theory, especially the Increasing importance of the morphological sub-component in generative grammars, no longer supported Kean's analysis. Lapointe hypothesized that the deficit was at the morphosyntactic level:

( 13 ) A morphosyntactic description of agrammatısm

The relatively retained elements in agrammatısm are those stem-level items (of major categories) that are inserted into morphosyntactic structures during lexical insertion.

(Lapointe $1983: 24)$

This concentrated attention on the loss of the inflectional elements. Recall that these hypotheses are neutral between production and comprehension since Kean and Lapointe subscribe to the central deficit theory. Those elements relatively omitted in production would not be available in the input string of a comprehension task; therefore deficits would be due to their being uninterpreted.

Various other hypotheses were advanced to account for why the syntactic level is the approprate one at which to characterize the deficit. Caplan (1983b) puts forward the

5 This use of the imprecise term 'relatively' is characteristic of the field and is intended to account for the variability seen in aphasic performance. In some ways, we can see that, though these analyses are presented as theories of agrammatic competence, this 'variabilty' means that they are really theories about performance. 
Lexical Node Hypothesis, which states that only linear sequences of major lexical category nodes are created and interpreted with respect to thematic roles. The Lexical Node Hypothesis states that:

a. The syntactic representation avallable to agrammatics is the lexical category information of open-class items, i.e. the syntactic labels $N, V, A$ are retrieved during the process of lexical identification when these words are accessed from the Mental Lexicon.

b. The only supralexical category information avalable is retrieved at the same time and is constituted of the subcategorization frames which form part of the lexical entries.

c. These supralexical nodes may be more or less avallable according to a "depth" analysis by which the first nonlexical nodes to be recovered are those immediately dominating lexical category nodes; more deeply embedded structures would only reemerge or be reacquired later, in proportion to their nodal distances from lexical category nodes.

(Caplan 1983b: 186)

This is clearly a bottom-up approach. Grodzinsky $(1984,1990)$ offers a different structural account, positing that non-lexical nodes are in fact created but that their phonological content is misselected from a list of category-appropriate items. He proposed this hypothesis for Hebrew data which could not be accounted for by Kean's analysis. Hebrew patients do not omit elements rather, they misselect the vowel tier which comprises the Inflectional infixes to the consonantal root. Though the Hebrew data do not constitute counterexamples to Kean's hypothesis, since without the inflectional head there would be no 'phonological word', Kean cannot explain the misselection of elements, as in (14): 
( 14 ) salos milım... lo...slosa milim ve-'erba 'a ne'elam

(Three(F) words...no...three(M)(sıc) words(F)(sıc) and four(M) disappears(Msing.))

(Grodzınsky $1984: 104)$

Grodzınsky hypothesized that, in languages where lexical items depend both morphologically and phonologically on the inflection, a non-word or illegal phonological string can never be produced, so misselection often occurs (which is also typical of paragrammatism). He claimed that in Russian and Italıan, where major lexical category items are morphologically but not phonologically dependent on inflection, i.e. an uninflected stem is often a non-word but is pronounceable, misselection rather than omission by agrammatics is also predicted:

\section{(15) Russian:}

Osjen pered zimji

(Fall before winter (wrong case))

(Tsvjetkova and Glosman (1978) as quoted by Grodzinsky 1984: 105) In Grodzinsky (1990), the agrammatic is predicted to produce a string which is underlyıngly a complete articulated tree, with all lexical and non-lexical nodes. Then a pruning operation occurs which will delete all non-lexical termınals and all governed prepositions (p.106). This seems extremely counterıntuitive and he must arbitrarily stipulate the behaviour of specific prepositions. (We shall propose a principled account for this pattern of retention in Chapter 2.) Grodzinsky cannot account for the main verb omissions reported in the literature. Micelı, Silverı, Villa and Caramazza (1984) have hypothesized that the production of a verb entails the production of its arguments and necessitates a mapping of these elements onto syntactic structure, especially in configurational languages. Goodglass (1976), reporting on the result; of testing eight agrammatic patients with a Story Completion paradigm, stated that the combination verb+object was much more stable than subject + verb, i.e. subjects were omitted more often 
than objects. He contended that patients had difficulty crossing the constituent boundary between the verb phrase and the subject noun phrase.

In dealıng with the comprehension data, Grodzinsky has proposed the following:

\section{(16) The Trace-Deletion Hypothesis:}

The S-structure representation underlying agrammatic comprehension lacks traces. In interpretation, a Default principle is invoked that is defined as follows: If a lexical NP has no theta-role (that is, it is in a non-thematic position), assign it the theta-role that is canonically associated with the position it occupies, unless this assignment is blocked. In this case assign it a role from the next lower level in the Thematic Hierarchy.

Crucially, a fully elaborated tree is constructed and interpretive problems arise from difficulties in chain formations since the end or tall of the chain has been deleted. In a passive, for example, the Default Principle assigns the displaced Theme the Agent theta-role and Grodzinsky assumes that Agent is structurally assigned to the object of the preposition. He predicts that all sentences containıng two Agent theta-roles will be responded to at chance levels. In a reply to Grodzınsky. Travis (1983) advances a more parsımonious account of aphasıc disruptions in geneial, locatıng the impairment in the Lexicon. Her proposal differs from Lapointe's in that Lapointe allows stems to be stored in the Lexicon, retrieved and Inserted into syntactic structures, while Travis claıms that whole words are stored in the Lexicon, with misselection accounting for incorrect insertions into syntactic structures. 6

6 Both Grodzinsky and Travis are in agreement that only morphologically legal words of a language will be produced. However, the case of the Ndebele agrammatic (Trall 1970) may be sald to provide counter-evidence to this claim. Ndebele is a Bantu language which has an elaborate system of prefixation. The patient produced both forms with incorrect prefixes affixed to stems to which they are never attached in normal language and also zero-morph prefixes which left a bare uninflected stem. All these forms are non-words in the language. For example, for the correct form u+nogwatsha 
The postulated non-lexical nodes hypothesized by Grodzınsky are retained although they are left unspecified and lexically unrealized. In addition, Travis incorporates Rizzi's (1985, orıginally proposed in 1980) suggestions to incorporate $\theta$-theory into Kean's analysis.

Agrammatics have treen considered to have intact semantıc capacitıes. Rizzi discussed a tripartite division of $\theta$-assigners, $\theta$-assignees and elements not within the scope of the module. His claim is that $\theta$-assigners (heads of phrases, etc.) and $\theta$-assignees will be retained in agrammatism. Most $\theta$-assignees are NPs and as such are not distinct from Kean's P-words. It is in her P-clitics that a different subdivision of the data will be found. For example, to in I gave the book to Mary assıgns ur partıcipates in assıgning the Goal theta-role to Mary but to the infinitive marker is not a $\theta$-role assigner; according to Rizzı, the former is expected to be retained while the latter would not. (in fact, neither is retained, which is what Travis correctly predicted). In the light of this criterion, predicates, ı.e. predicate nominals, adjectives and verb phrases, would also be expected to be retained as iney assign a theta-role through predication. Modification relationships such as are entered into by attributive adjectives would not be expected to be avallable to agrammatics (this has indeed been demonstrated in Kolk (1978)).7

This analysis (which was extended to include bound P-clitics in Gendron (1986)) cannot explain the phenomenon of verb omission. Travis convincingly showed that the Lexical Node Hypothesis was too strong, as the subject could not receive a theta-role 8 since thetaroles are assigned under government, not by linear precedence relations. Some phrasal nodes

(rabbit), he produced such forms as I+gwatsha, um+gwatsha (both it and um+ are different class prefixes from the correct $u_{+}$) and o-gwatsha.

7 If we accept Grimshaw's (1990) and Higginbotham's (1985) analysis of modification, i.e. that the external arguments of both the modifier and the noun are identified and jointly satisfied, this mutual operation may be twice as costly. In addition, the structure of the phrase would be more complex.

8 This has been somewhat weakened by the subject-within-VP hypothesis, which does not require that that 0-role be assigned compositionally. However, the Agent i)-role still cannot be assigned within the first projection of the verb. 
must be available (e.g. an intermediate projection). There is a convergence of opinion that the grammatical description at the sentential level is crucial in characterizing the syndrome from a linguistic point of view.

One last proposal we will discuss is that of Ouhalla (1990) who makes the clam in (17):

(17) In agrammatic speech functional categories fail to project in terms of X-bar structures.

Their occasional presence would be due to their being adjoined to the unordered projections of lexical categories. This characterization is not supported by the data. It is not descriptively adequate, and it does not take into account main verb deletions since it assumes that all structures are projections of the predicate. In addition, it cannot speak to the differential presence of inflectional morphology in non-English and English speakıng aphasics since it predicts that ariy inflectional morphology that is present is aberrantly basegenerated in the lexicon. Thus, the fact that English agrammatics appear more impaired cannot be accounted for. He would therefore be predicting that the more 'normal' an utterance appears, the more aberrant is its representation. (This is not seen in the production data of non-English aphasıcs; see Menn and Obler 1990.) He also claıms that agrammatics exhibit word order problems, citıng studies of languages which show V2 effects, i.e. languages in which the verb moves to INFL and COMP--both functional heads (e.g. German and Icelandic). However, he is misrepresentıng these studies. Stark and Dressler (1990) explicitly maintain that there are very few word order problems in German agrammatics. The verbs in the aphasic data do not occur in second position because they are not tensed; they are either infinitives or participles and thus are correctly ordered sentence-finally. The authors presuppose that there may be missing auxiliaries, which, in the case of the sentences containing participles, would be the tensed elements in second position. In Icelandic, the data Is much the same and the authors cited by Ouhalla, Magnúsdóttir and Thráinsson (1990) never even discuss word order. This hypothesis may appear to be a mirror image of Caplan's, 
but Caplan's Lexical Node Hypothesis can at least correctly account for the word order facts while Ouhalla's cannot. Since he assumes that all parametric variation is accounted for by languages' functional categones and that the VP encodes dominance but not precedence relations, he cannot explain the following data. in Serbo-Croatıan (Gendron's (1983) reinterpretation of Smith and Mimica (1984) and in Japanese (Hagiwara 1988), it has been demonstrated that aphasics try to create a VP, I. e. the initial projection of the verb and its argument. A language's direction of A-role assignment appears to be resistant to brain damage and seems to be encoded with the lexical categories. However, the interaction of the extended Xbar theory with $\theta$-theory requires that some hierarchical structure be assigned since $\theta$-roles are assigned under government, which is a structural relation which holds between a head and its complement. The evidence cited above also demonstrates that Caplan's hypothesis must be revised, since some phrasal categories must be avallable.

Cross-linguistic work by Bates and her colleagues $(1987 \mathrm{a}, 1987 \mathrm{~b}, 1988,1989)$ in English, German and Italian has convincingly shown that aphasics (both anterior and posterior) can construct well-formed sentences in canonical word order (we might say, in thematic role order). Both German and Italian have considerably more closed class items to contend with, i.e. Inflectional morphology, yet these are produced with greater frequency than we would expect on the basis of the English literature. Hypotheses such as the Lexical Node Hypothesıs or Grodzınsky's hypothesis cannot account for the better retention of inflectional morphology by speakers of languages other than English. We will claim that these elements are produced not only to maintain morphological well-formedness but also because they redundantly encode information; they involve the interaction of several modules of the grammar, which may give the aphasıc a better chance of reachıng his target. In additıon, Bates et al. found that misselection rather than omission was characteristic of both agrammatics and paragrammatics. It seems that the theoretical distinction between these two classes of aphasics is becoming blurred.

In the next chapter, we will present a hypothesis which we feel correctly predicts the 
21.

retained versus missing linguistic elements. It accounts for both production and comprehension data and generalizes to all classes of aphasics. We will also discuss a particular syntactic construction, the French causative, which allows us to test our hypothesis. 


\section{Chapter 2- The Head Accessibility Hypothesis and the Testıng of French Causatives}

\subsection{Introduction}

Having described aphasics' syntactic deficits as well as some of the linguistic analyses which have been proposed to account for their observed behavior in the previous chapter, we will now propose an alternate hypothesis which we believe demonstrates both descriptive and explanatory adequacy. One of our main criticisms of other hypotheses was quite simply that they falled to account for the data and made wrong predictions. The first section of the present chapter will be devoted to a detalled elaboration of our account. We will discuss implications for aphasiological production and, more importantly for our present purposes, comprehension. Further, we will discuss a particular structure in French, the causative, which will permit us to test our claims. In Section 2, the linguistic analysis of French causatives which we will be assuming in this thesis is presented in some detall.

\subsection{Section 1.}

\subsubsection{A New Account-The Head Accessiblity Hypothesıs.}

The notion or construct head plays an important role at all levels of the grammar. As the head of a structure, an item acquires structural prominence and is consequently more likely to be considered salient. In order to account for the (relatively) retained and omitted items in data from aphasics, the following hypothesis is proposed:

(1) The Head Accessibility Hypothesıs (HAH) :

The categorial properties of a head and its subcategorization requirements will determine whether or not the head (and its projections) is accessible to the aphasic.

Saliency is an ill-defined concept. The semantıc saliency of the imageability of 
Items from the lexical categories affects the ease with which we can access lexical items from the Mental Lexicon. Inevitably, the more features that an item possesses - and these may be grammatical features in the case of a functional item - the more salient it will become. This additional "meaningfulness" will render it more salient; if this is coupled with structurally defined saliency - i. e. being a head of a phrasal category--the HAH will predict an increased success rate for accessing the functional item. The hypothesis in (1) is a claim about processing, 1. e. lexical access and phrase bulding, or performance, and not a clam about loss of lexical knowledge, or competence. This must be so to account for the attested varability both between patients (severity level within a clinical type) and within a single patient across tasks--production, comprehensıon, and grammaticality judgements - or even within the same task across testing sessions (see the work by Bates and colleagues which also advocates this view). In other words, we are assuming relatively Intact coinpetence but impaired access to that competence. The $\mathrm{HAH}$ attempts to characterize those aspects of linguistic representations which are associated with impaired access procedures.

Since what the HAH claims is that access is a function of the categorial properties of items which may act as heads, and the complementation these heads require, we can see that this will help us to define what constitutes structural complexity. This issue will be discussed at length in Section 2.1.2. We will see that anterior aphasics are particularly sensitive to structural complexity at all levels. Therefore, the less structure accessing an item requires the better. Anterior aphasıcs also greatly benefit from items which are more salient; therefore, the more features an item has the better. The HAH does not, however, rule out the possibility that certain deficits may affect a particular category (regardless of complexity). We speak in particular of posterior aphasics. It is well known that some cases of anomia are restricted to access problems with nouns, and Wernicke's aphasics too are known to have difficulties with the referential uses of words, particularly 
nouns (see also Linebarger (1989: 203) for a similar argument). Thus, posterior aphasics have a double problem in that, as more structure needs to be built up for a representation, their problems with semantics and reference interact with structural complexity. (In a case study, Caramazza \& Miceli (1991) demonstrate that, though a fluent patient could access nouns and verbs with the appropriate inflectional morphology when processing single words, in sentential stiuctures he could not properly assign thematic roles in morphologically ambıguous, semantically reversible sentences.)1

\subsubsection{Predictions of the HAH for production as a consequence of structural complexity} Structural complexity will be defined rather simply as the creation of additional hierarchical structure. This hierarchical structure is a direct consequence of particular categories' requirements for integration into a well-formed string. We will examine the categories in turn, beginning with the lexical categories and then discussing the functional ones.

\section{A Lexical Categories:}

Nouns, which you will recall from Chapter 1 are $[+N,-V]$, are more accessible than all other categories because only Ns need not take a complement but may have the structure in (2):

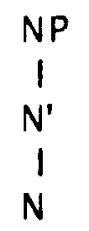

The external argument of the N ( R ) is satısfied by reference. However, if a NP does take a

1 Category-specific types of impairments are not unusual in aphasiology. There are, for example, category-specific semantic imparments within a circumsribed semantic field. The population mostly affected by these is again made up of posterior aphasics. 
complement, it has a thematic role tc be discharged and its structure will be more complex and more difficult to build than that in (2) above, witness (3):

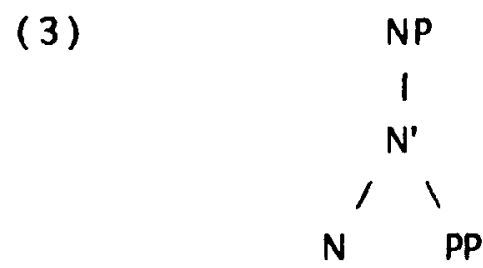

According to Higginbotham and Speas (Speas 1990), only nouns do not norrnally have event positıons in their theta-grids. This may make them conceptually simpler. Presumably, certain derived nouns would have an event position and these Ns may be more difficult to process for this reason (though it should not be forgotten that the item would also be morphologically more complex).

The fact that retrieval of nouns is easier than retrieval of all other categories is attested copiously in the aphasiological literature. (See Zıngeser and Berndt (1990), for Instance, for English data and Tzeng, Chen and Hung (1991) and Bates, Chen, Tzeng, Li and Opıe (1991) for Chinese.)

Adjectives, as $[+N+V]$, are the only other $[+N]$ categories. In English. Both adjectives and nouns take PP complements rather than the complements headed by functional categories that verbs must take (this will be discussed below). As was discussed In Chapter 1, adjectives are more accessible than verbs. However, Rizzi (1985) predicted and it has been shown empirically that predicate adjectives are preferentially produced while modifiers are less so (for some empirical confirmation, see Myerson \& Goodglass (1972) and Kolk (1978)). The HAH predicts this because the adjective is the head of the 
structure when used predicatively but not when used attributively:

Predicative Use of Adjective (the copula is not produced):

Small clause AP:

(4)

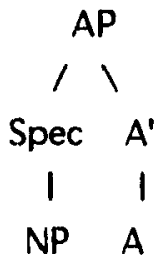

Modification Use of Adjective:

\begin{tabular}{cc}
\multicolumn{3}{c}{ NP } \\
\multicolumn{3}{c}{$/$} \\
Spec & $N^{\prime}$ \\
I & I \\
AP & N
\end{tabular}

The $A$, as the head of the structure in (4), is readily avallable. The noun is accessible as well because of its referential properties, 2 even though it makes the structure of the AP more complex. In the structure in (5), the $N$ is the head and the A is only the head of the AP in Spec position. Thus, the Adjective is structurally more prominent when it is used predicatively.

Of the three major lexical categories, the verb $[-N,+V]$ creates the most structurally complex phrases. Verbs have at least one argument. We adopt the subjectwithın-VP hypothesıs

2 This is true for all but paragrammatics, as discussed above. They may not retrieve particular nouns though structurally they are capable of neologistic creations that act as NP placeholders. 
(first proposed by Koopman and Sportiche (1988)). This is now generally accepted

(Chomsky 1992). Prior to this analysis, the NP subject was considered to be base-

generated in Spec of IP (more about IP below); now it must sımply move to this position in order to be assigned nominative Case. Examples of the structures of the two different kinds of intransitive VPs (1.e. unergatives and unaccusatives) are provided in (6) and (7) :

Intransitives:

Unergatives:

(6)

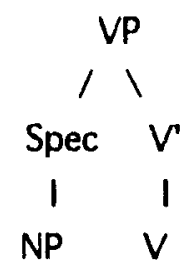

Unaccusatives:

(7)

$V P$
1
$V$
1
$V \quad N P$

Only one projection of the $V$ branches, either VP or $V^{\prime \prime}$ in (6) or $V^{\prime}$ in (7). ${ }^{3}$

A more complex structure is required for transitives since both the VP and the $V^{\prime}$ must branch to accommodate the verb's two arguments, as in (8):

Transitives:

2-place arguments

( 8 )

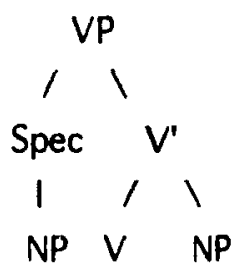

3 It may be the case that some aphasic utterances which seem to exhibit word order errors are in fact base-generated unaccusatives. This possibility will be explored in future work Involving production tasks. 
Note that for both intransitives and 2-place-argument transitives the structures are interpretable as VP small clauses. Aphasıcs may be said to be producing lexical small clauses when they are unable to produce fully elaborated sentential structure. (A similar analysis for children's utterances has been proposed by Radford (1990).)

A verb taking an additional Goal argument will involve more hierarchical structure than the simple transitive of (8), witness the structure in (9):

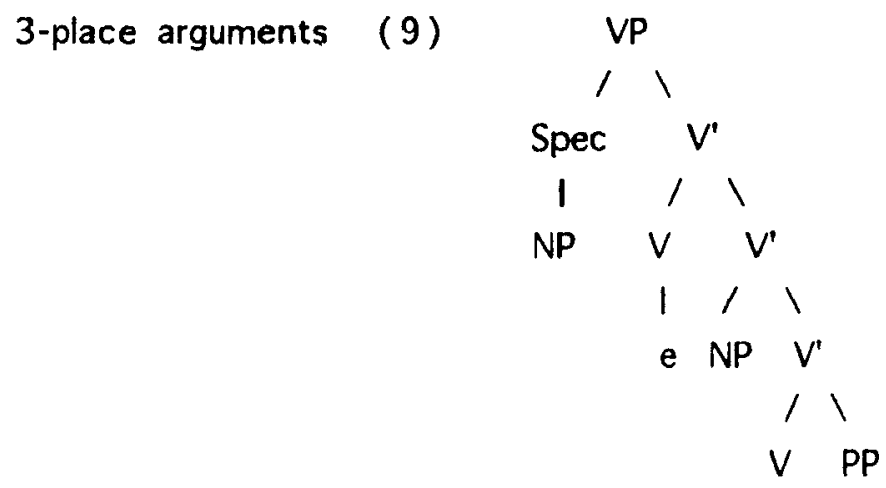

This structure (adapted from Larson (1988) by Speas (1990)) requires the $V$ to move to the empty verbal head in order to assign accusative Case to the Theme. This verb displacement is assumed to increase processing cost.

That these types are in fact more difficult to process has been reported in the literature. For exarnpie, in Hungarıan (MacWhinney and Osmán-Ságı 1991), Broca's aphasics have a tendency to omit the Goal argument and Wernicke's the Theme. Presumably, the aphasics can only generate one verbal head and one of the two arguments. They may be unable to generate the empty verbal head and the other argument. Micelı and Mazzuchı (1990) also discuss the tendency of their Italian Broca's patients to generate structures 
with missing Goal arguments. These results suggest that the two aphasic groups differ systematicaily in one respect, i.e. in the nature of the avallable argument; Wernicke's always have a tendency to produce more oblique forms.

Verbs taking infinitival complements are more complex than the forms discussed above but less complex than those takıng tensed clauses, for reasons which will be made clearer below. Infinitival complements are produced more often by aphasics than tensed clauses (Menn and Obler 1990).

Prepositions, like verbs, are $[-N]$; unlike verbs, they are also $[-V]$. This lack of $a+$ feature seems to capture the fact that, although a $P$ is a lexical category, it is consıdered a minor one. In additıon, although the $P$ takes a NP argument, the PP itself can be either the complement or the argument of another lexical category, e.g. of N, A or V, or it may be an adjunct phrase. It is predicted that, as true adjuncts may not be present at Dstructure (for a given sententral structure) (Lebeaux 1988; Speas 1990 ), adjunct PPs are more likely to be retaıned because individually they are not overly complex see (10). Argument PPs, because they are governed by a lexical category and withın its projection, are likely to be omitted. (See Grodzinsky (1990) and Canzanella (1990) for confirming evidence.)

PP
$/ \quad 1$
$P \quad N P$




\section{B. Functional Categories:}

In general, functional categories will be less accessible because of the extra structure they require. They have low semantic content; this is reflected in the fact that, although they head their own projections, they require the accessing of their semantic heads as well. Their semantic heads are those of the lexical categories which are their complements.

\section{B.1.1. Determiners (DPs)}

As Radford (1990) mentions, evidence for a D-system is found with the presence of the referential/quantificational determiners such as a, the , this, that, some, all, etc. As well, there are the possessive determiners 's, my, etc., as well as pronominals 1 , they etc. Unlike the lexical categories, functional categories are not theta-assigners; rather, they are theta-bınders. For example the, in combıning with a common noun, will merge or theta-identify its restricted property position with the referential argument position of the noun; these positions will thus be jointly discharged. This operation is a combination of merger and discharge and is therefore more complex than either of the simplex ones alone. (See Speas (1990) for further discussion.)

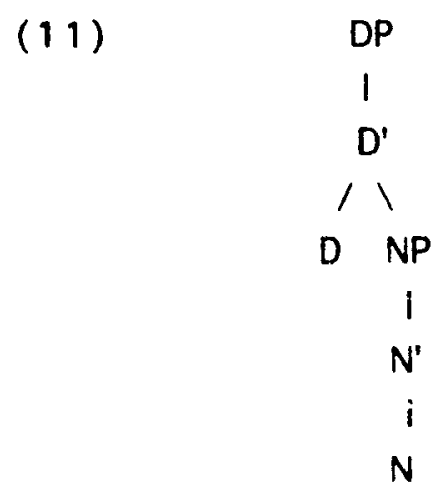


Note that the DP takes the preferentially processed NP as its complement.

Recall that the HAH claims that a head's features can aid retrieval. This is somewhat sımilar to the notion proposed by Bates and her colleagues of cue validity --1.e. the information load of a given item-- which they use to predict successful retrieval. Within a given language, the number of features included in the determıners will increase their chances of retrieval.

Determiners in languages such as German, where they contain information about gender, number and case, are produced more relıably than determiners in Italian, which lack case, though the latter are produced more often than the corresponding forms in English, which also lack gender and number features. The definite article the may thus only have a [+def] feature. In addition to rewriting as an article, the D node in English may alternatively rewrite as the possessive 's, i.e. as [+gen]; in this case, the structure would be as 11 (12) and the word order facts would be explained by a movement operation.

Genitıves:

(English)

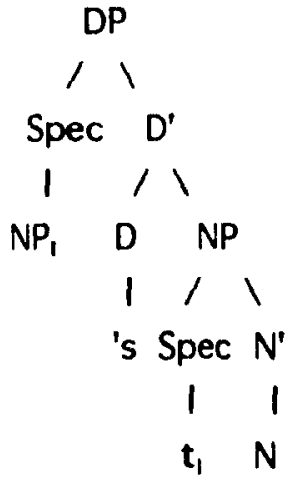

The additional structure needed to create a landing site for the movement of the possessive phrase from Spec of NP to Spec of DP may not be available due to the increased processing 
cost such additional branching structure entails at both NP and DP levels. Alternatively, we could see the difficulty as arising because of the creation of a chain. It is assumed that any chain with two (or more) members, l.e. a head and a tail, is structurally more complex than a one-member chain. Since, by definition, a chain consists of one $\theta$-role and one Case, then a lexical category which is base-generated and receives a thematic role and Case constitutes a chain.

\section{B.1.2. Evidence of DPs in Aphasic Data}

Articles are generally omitted by English agrammatics (Marshall1977) However, work by Bates, Hamby and Zurif (1983) shows that they can still lexicalize, in pragmatically appropriate ways, given or new information contained in three-picture scenarios in which one subject (or action) remains constant and one object (or action) is variable. Broca's aphasics performed appropriately by producing the definite article when referring to the given information but not when referring to the new. They enumerated the new information and only mentioned the given information once. (The Wernicke's, on the other hand, were not as sensitive to the given-new distinction.) The $D$ node in these cases would be marked [+ def ] and it would be expected to increase its "semantic" content (as opposed to a, which is [- def ]). There is mu:h evidence from other languages that if a morph is not a vable default choice, then the determiners are more likely to be produced if they encode additional grammatical features. In French, where the category encodes definiteness, gender and number, the definite article is very often produced (e.g. Tissot, 
Mounın and Lhermitte's (1973) syntactıc agrammatism, see also Feyereisen 1985,

Farrell 1985, and Jarema and Kehayı 1990). In Italıan, Bates et al. (1987a) found the same easier access to the category of determiners even though their presence is more redundant than in French since, in Italian, Ns are overtly marked for number and gender. In German and Greek, where it also encodes case information, Bates et al. (1987a) and Kehayı (1990), respectively also found that the article was produced more frequently than it is in English. 4

The structure described in (12) (and ex. (9) in Chapter 1) helps us to explain the omission or presence of this case. In English, the genitive marker is found under the [+gen] D node; for a noun like John in 'John's hat' to get Case, it must move from NPinternal position into the Spec of DP. This movement creates potential problems, e.g. Is the landing site avallable? This is the reason for the differential rate of production of the plural and the genitive, with the plural being more reliably produced than the genitive; regardless of whether we assume that the plural marker is attached in the Lexicon or within the NP itself, it is clear that the genitive involves a movement operation in English. 5 Contrast this with the consistent production of this form by German agrammatics reported by De Bleser and Beyer (1988), as well as the production of this form by a German transcortical motor aphasic who produced no other evidence of hierarchical

4 Though the incorrect article was sometimes produced, agrammatics in both these studies generally erred in the value for only one feature, 1.e. case or gender or number.

5 Still, the genitive is produced more consistently than the homophonic third person singular present tense marker. 
structure than well- constructed DPs (De Bleser et al. 1990). According to Giorgi and Longobardı (1991), the comparable German prenomınal genitive is lexically restricted and the form is attached in the Lexicon; thus there is no movement operation. For severely afflicted agrammatics, the noun phrase (NP/DP) may be the most complex structure possible. Agrammatics might be considered to exploit the referential uses of nouns.

On the other hand, paragrammatics with their word finding difficulties seem particularly impaired with nominal forms. This follows from the HAH because it is precisely the categorial status of $[+N]$ or the nominal head that makes it difficult to access. In a longıtudinal study of production data, Butterworth, Panzerı, Semenza and Ferrerı (1990) showed that a patient's recovery was only demonstrated by a reduction in errors in article use, which also corresponded to a decrease in the production of neologisms. 6 Thus, as the functional category which may inherit the feature $[+N]$ from the noun (see discussion of Abney's (1987) Inheritance Principle cited in Radford (1990-269)), the Det and DP are also at risk in paragrammatics. They have specific problems with reference. For additional evidence that they have problems with DPs, we note that, in comprehension, Lurıa's (1975) famius test of logıco-grammatical relations which necessitated understanding the difference between brother's father and father's brother was only successful with the anterior aphasics, the posterior or 'semantic' ones being unable to comprehend the construction.

6 That neologisms are predominantly caused by attempts at noun production can also be seen in an English patient, Mr. V., studied by Edwards and Garman (1988), as reported in Garman (1990). 


\section{B.2. Kase Phrases (KPs):}

As we saw in Chapter 1, KP or Kase-Phrase was first proposed by Hale and later discussed by Lamontagne and Travis (1986). As was shown earlier, it attempts to reduce the Case Filter to an instance of the Empty Category Principle. $K$ takes a DP complement, which itself takes a NP complement. Being governed by a case assigner, $K$ will be properly governed and Case features will be transferred to the NP, which needs Case, as all NPs do.

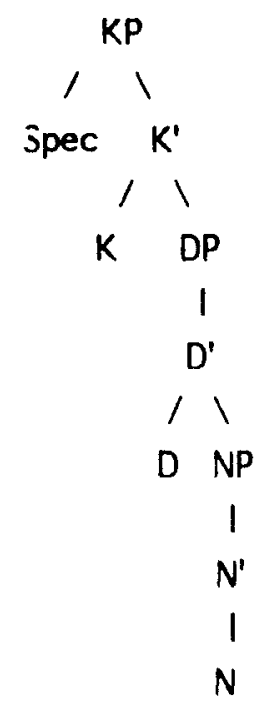

Note that the production of a KP, a functional category, requires that of another functional category, i.e. DP. This leads one to predict that KPs are more vulnerable than DPs. However, we would also predict that if a language realizes (overt) case, rather than Just assigning abstract Case as in English, this would lessen the processing cost; in comprehension, for example, the overt markıng would act as a local cue to grammatical functions, thereby putting less demand on short-term memory capacities. If in addition, Case is realized as a suffix, affixal requirements will lead to inproved retrieval. in fact, in languages like Hungarian (MacWhınney, Osmán-Ságı 1991) and Turkish (Slobin 1991), 
case endings are more often either produced correctly or substituted than umitted. (Broca's

aphasics substitute citation forms and Wernicke's more oblique forms). Further intrinsic properties of these heads account for differences in avallability in Turkish and Hungarian; in Turkish, case endings are both syllabic and stressed and are more often produced than the equivalent forms in Hungarian, which do not share these properties.?

\section{B.3.1. Inflectional Phrases (IPs)}

Evidence cited to show the presence of an l-system in English, for example,

Includes the following: infinitival to, modal, aspectual, copula, and dummy auxiliaries

(Radford 1990: 276). IPs take VPs as their complements. They also have a Kase feature-nominative-- to assign to the sentential subject. Whether the NP (DP) is in Spec of VP or in the complement position of unaccusatives and passives, it must move to Spec of IP to get case. Can the structure with its empty l-position be computed to act as a landing site? Presumably, if the limited resources of the aphasics have not been depleted by an overly complex structure elsewhere, such a position may be available. In terms of production, the approach taken here is strictly bottom-up, 8 i.e. we assume that the predicate is lexically accessed and that a small clause VP may be formed. Then, if inflectional elements can be accessed, this supra-structure can be constructed. For an example of the structure of a

7 In order to simplify the presentation of the lexical categories, we abstracted away from Kase phrases, etc., but it should be noted that, for the Theme of the 2- and 3-place transitives, as well as for the complement of the preposition, the structure should be a KP and not simply a NP. The other NPs must be assigned case by inflection.

8 A similar structure building approach is taken in Gulfoyle and Noonan (1988). 
sımple sentence containing a transitive verb, i.e. where the I has selected a 2-place VP complement, see (14):

2-place VP complement:

(14) IP

Spec I'

11

1 VP

11

Spec V'

$1 / 1$

DP $\quad \mathrm{K} \quad \mathrm{KP}$

I / I

D' Spec K'

I I I

D $\quad$ NP $\quad K \quad$ DP

I I

$\mathrm{N}^{\prime} \quad \mathrm{D}^{\prime}$

I I

N D NP

I

$\mathrm{N}^{\prime}$

I

N

There are additional assumptions regarding phrase structure which involve INFL.

This element is characterized by a feature complex which includes Tns (Tense) and Agr

(Agreement). If we take the concept of binary branching seriously (i.e. a node $\mathrm{Xn}$

Immediately dominates only two nodes, usually an $X^{n-1}$ and Spec or YP, depending on the

value of $n$ ), it was inevitable that a proposal such as Pollock s (1989) would be made.

Pollock claimed that, to account for the word order facts of French, INFL instead of being treated as an amalgam, should be elaborated into at least two maximal projections --a TP 
(Tense Phrase) and an AgrP (Agreement Phrase), 9 with AgrP being the complement of TP.

In addition, to account for what in older versions of the theory was called Affix Hopping,

auxiliary and main verbs in French (as well as in many other languages with a strong Agr)

are claimed to move to [+finite] I (or T) to pick up inflection. This would be an instance of

Head movement $(X 0)$ (head to head movement). French infinitives and past participles

would move to Agr or remain in their base-generated VP positions. In English, only

auxiliary have and be would move to $\mathrm{I}$, whereas main verbs could only receive Tns by

having I lower onto the verb; this kind of movement is considered more marked.

Infinitives and the present progressive may not move in English. The reason that main

verbs cannot raise in English reduces to theta-theory in that, if the verb is a theta-

marker, it must be able to transmit this ability va the trace. If Agr is strong, it will be

transparent and allow the transmission, if it is weak, as in English, it will be opaque and

prevent the transmission of the theta-role, resulting in a Theta-Criterion violation

Finally, modals are generated in INFL in English (cf Chomsky 1989) but not in French,

where movement of $V$ to $I$ is necessary.

For those languages in which verb movement is possible, the structure of the verb will be:

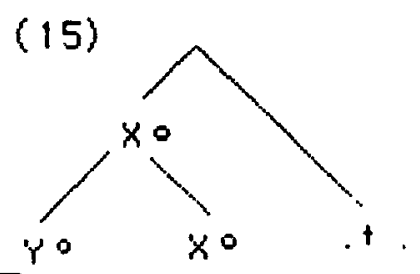

9 We are abstracting away from further articulation of the INFL node. Whether there is both an AgrS and an AgrO (subject and object agreement respectively) (Chomsky 1992) need not concern us at this time. 
In the case of affix lowering to the verb, as in English, the structure will be:

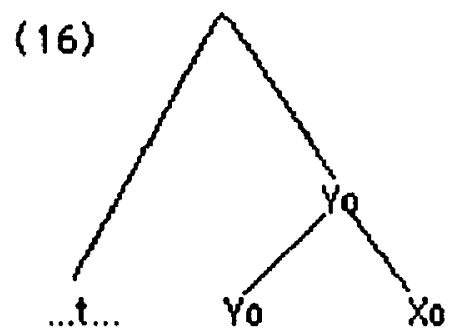

A complex element is created $\left[Y^{O}-X^{O}\right]$ in both cases. The head is $X^{0}$ in (15), i.e. the inflectional affix but Yo or the verb in (16), the English case (Chomsky 1989). Languages which have veib rassing will have verbs surfacing with an inflectional head since they are adjoined to INFL. In English, the inflection can never be the head, which we feel accounts for the greater proportional loss of inflection in the English agrammatism literature. Being a head makes an item structurally more prominent. The additional requirement that an affix cannot be left stranded in a representation increases its chances of being processed. This is supported by the aphasiological data from various richly inflected languages.

\section{B.3.2. Evidence of IPs in Aphasic Data}

The need for the verb in most languages to rase to INFL (head movement of an $X^{0}$ ) to get Tns explaıns why infinitıves, which need not do so, are preferentially produced by aphasıcs. This need for the verb to move permits us to see a certain parallelism with other structures which have displaced elements, i.e. a verbal trace must he in a properly formed 
40 .

chain with the head of the chain, the moved verb. In languages which have verbal forms that need an inflectional affix to project to the word level (no o-form being avallable), either inflected forms will be produced even though an erroneous choice may be made (see Kehayia (1990) for just such cases in Greek) 10 or these forms will simply be omitted. That is, despite the additional structure that the generation of IP entals, there are strong constraints that will allow neither the stem to surface nor the affix to remain stranded.

Therefore, we see that if, at a given moment, the aphasic can access the verb and its functional projection, he will produce an inflected form. If he cannot, he will omit the verb entirely. Thus, we can account for main verb deletion as a result of either fallure to access the verb or fallure to access the functional head--the inflection.

Fukul (1986) has claimed that Japanese lacks functional categories, though this may be too strong a claim since case particles do exist. However, Japanese does appear to have a defective INFL (no Agr). The verbal element must have a tense-like particle attached to it, in order to surface as a word. Agrammatics always produce these particles (Kamı 1984,1985). Case particles, on the other hand, which are often optional in certain contexts, are dropped. The fact that the verb and INFL are adjacent in the string due to the head-final parameter of Japanese may also help the agrammatic. Hindı has a rich agreement system and it is noteworthy that, as Bhatnagar and Whitaker (1984) have demonstrated, verbs are often omitted in agrammatism, presumably the articulated nature

10 It is also important to note that languages which permit null subjects have rich INFLs which allow the subject to be dentified. These additional person and number features increase the semantic weight or meaningfuiness of the affix. As we saw with determiners, the more features a functional category contains the better. 
of the IP would necessitate two movement operations to be properly inflected.

\section{B.4. Complement Phrases (CPs)}

All "normal" root sentences contain one CP (the old S'). Evidence for the presence

of this category includes overt complementizers, preposed auxiliaries and wh-phrases. The category $\mathrm{CP}$ is predicted to be the most difficult structure to process since its creation implies that of all the other categories, as it takes an IP as its complement; see (17):

(17)

The structure above represents a simple sentence contaınıng a transitive predicate with a 
NP complement. At this point, we can return to the issue of which VPs would be the most

difficult to construct, which could only partly be described earlier. It now becomes evident why inínitival complements are easier to process than tensed embedded clausal complements. An Event argument is realized canonically as an IP. A propositional argument will be realized as a tensed clause--a CP. A sentence containıng such a structure would consequently contain two CPs which themselves contain two IPs, two VPs, etc. In addition, two tensed verbs withın a structure would imply that two verbal movement operations are necessary. By contrast, an infinitive may remain within the VP This may account for the preferential use of the infinitive in all varieties of simplified registers since what is produced is a verbal Small Clause.

Both agrammatics and paragrammatics are known to avord complex sentences (see the work of Bates and her colleagues) Although parayrammatics do produce some subordinate clauses, these were found to be semantically unrelated to the matrix clause (Cooper and Zurif 1983 citıng Delıs et al.1979).

2.1.3. How does the Head Accessibility Hypothesis compare with the other linguistic characterizations of syntactic deficits?

The Lexical Node Hypothesis proposes that only the $x^{\circ}$ level of major lexical items ( i.e. lexical heads) is avallable to the agrammatic. However, it does not predict the differential hierarchy' exhibited within these classes: Noun > Adjective > Verb, with $[+N]$ being the feature shared by the first two. We would contend that the ability to project the 
phrasal category XP is not impaired per se. Rather, it is the interaction of other modules of the grammar with $X^{\prime}$ theory that leads to difficulties in production or comprehension. 11

Kean's Phonological Hypothesis falls to account for the phenomena of nominalization of verbs and verb omission. The better retention rates of inflectional morphology and free function words by speakers of languages other than English cannot be explained either. Lapointe hypothesized that only unınflected stems of major lexical categories tended to be retaıned; agaın, fallure to produce main verbs is not predicted.

Rizzi's incorporation of $\theta$-theory into Kean's account also privileges the lexical categories as they are the iterns involved within the scope of the module. $\theta$-marking is accomplished by heads of phrases which assign thematic roles under government to XP complements, the projections of some lexical head. Verb omissions are not predicted by Rizzi's formulation nor can he account for inflectional morphology when it is present. Grodzınsky's structural account cannot handle verb omission errors either nor can it predict the non-arbitrary choice of erroneous inflected items--agrammatics tend to produce citation forms, nominative case for nouns and infinitival forms for verbal targets. Even paragrammatics' propensity to misselect among oblique cases is not predicted.

Travis's account does share some features with the HAH by attributing syntactic deficits to problems of lexical access. We differ in not postulating the automatic creation of non-lexical nodes which are left lexically unrealized. If problems of access to lexical

11 Lapointe (1985) has extended Garrett's sentence processing model to suggest that phrasal fragments are independently stored in the Lexicon and have to be accessed along with lexical items. We will simply state that the maximally general rule schemata of example ( 6 ) in Chapter 1 remain resistant to brain damage. 
categories can be correctly predicted, similar access problems are predicted to occur for

functional categories, with the added stipulation that, since the latter must also involve the creation of their lexical complements, they are more difficult to process.

Ouhalla's $(1990,1991)$ account cannot handle differential processing within the major lexical categories. His account is very radical because he states that functional categories, when present, may only be adjoined to the rest of the structure. The more normal a patient's utterances may appear, the less his language would conform to principles of UG. Ouhalla cannot explain the word order facts either, since he does not assume that theta-role assignment is directional. Overwhelmingly, the evidence from various languages demonstrates that aphasics retain sensitivity to a language's particular direction for theta-role assignment.

We feel that our prososal correctly characterizes the relatively present or absent items in aphasic speech. We account for verb nominalizations by noting that the $[+N]$ feature of the head of the derived word --the derivational affix-- will account for the presence of the affix and that the aphasic need no longer produce a VP Small Clause. Main verb deletion is predicted to occur for two possible reasons: 1) the verb's (1-grid would require the creation of more complex phrasal reflexes, 12 and /or 2) the production of a tensed verb may require a verb movement operation, again, more higher-level syntactic structure is necessary to provide the landing site for movement (in this case, the INFL

12 They may in fact omit the whole of the predicate as well On other occasions, they may produce one argument of the verb in isolation. This would be like topicalizing this NP. They rely very much on the inferential capacities of their interlocutors to, in effect, buld structure around their reduced utterances. 
node, the head of which governs the head of the VP). We also account for the differential

production of inflectional morphology in languages other than English by showing that, in these languages, the inflection acts as the head of the combined form, whe! eas the stem is the head in English. A requirement for an affix may thus mitigate the difficulty in creating additional structure. 13

2.1.4. Predictions of the HAH for comprehensıon as a consequence of structural complexity In comprehension, the input string, which must be parsed, contains the correct combinations of lexical and functional categories. The structural complexity issues are similar to those affecting production but the task of the experimental subject becomes one of applying both top-down and bottom-up interpretive strategies. These may also be affected by the accessibility of the heads of phrasal categories. The predictions with regard to comprehension will be essentially the same as those for production, with the proviso that perceptual issues can interact to complicate the picture.

For example, grammatıcal morphology seems partıcularly vulnerable in this modality. This is due to the fact that normally it is not very salient perceptually. Both Turkısh and Hungarıan aphasics, as well as hospitalized orthopedic controls performed less well in a comprehension task (Bates et al.1991). Any type of global stress will reduce comprehension accuracy if it is dependent in large part on grammatical morphology for the

13 In fact, many of these languages permit null subjects because the subject can be identified by the inflectional morphology of the verb. The Spec of IP may not have to be constructed in these cases. 
disambiguation of semantic roles. In a recent experıment, Kilborn (1991) demonstrated that the use of a low-level noise mask in conjunction with stimulus sentences decreased the accuracy of German normals though it had little effect on the English normals, who continued to rely on word order strategies.

Investıgations of aphasia in languages with richer inflectional systems demonstrate 1) that aphasics try to compute a VP (see Gendron's (1983)re-examınation of Smith and Mimica (1984) for Serbo-Croatıan and Hagiwara and Caplan (1990), for Japanese), and 2) that language-specific thematic role orders are preferentially processed Bates and her colleagues have also found, despite the occasional use of semi-grammatical sentences, that there are no syndrome-specific comprehension patterns Rather, it is syntactic complexity which best predicts error rates. The main difference is that Broca's aphasics tend to use all available cues to boost their performance while Wernicke's do not seem sensitive to convergent cues. Grammatical morphemes seem less robust than word order but they are understood significantly better than would be predicted if aphasics had no access to them at all.

Work by Caplan and Hildebrandt (1988) also characterized processing complexity as the building of hierarchical stiucture (i.e. complex NPs). In addition, they showed that holding a NP without a thematic role in the syntactic structure increases processing load This directly affects the interpretation of passives, where the Theme role cannot be assigned to the subject NP before the processing of the verb down-line. This will aiso affect object relatives and clefts for similar reasons. There is little or no direct marking of non- 
canonical assignment of thematic roles in English and French. This is always more of a problem in non-case-marked languages since, in languages that encode grammatical functions morphologically, the functions are locally signalled The overt presence of grammatical morphemes in KPs, for example, will reduce the memory load of an aphası when sentences contain non-canonical word orders. The head of a chain will be more easily identified and the tail will therefore be expected. In English and French, the identification of chains is not as easy as in some other languages, for Case is not overt but abstract.

Hypotheses such as the Lexical Node Hypothesis or Grodzinsky's Trace Deletion Hypothesis (which claims that traces of movement are deleted, leading to chance performances on such structures as passives) cannot account for the better performances by speakers of languages other than English. The Head Accessibility Hypothesıs, on the other hand, would predict that the richer the morphological system of a language, the more likely it is that aphasics can access the "features" it contains to help build a representation of the sentence. Complex structures containing additional functional categories continue to prove problematic. Movement entails more hierarchical structure. Therefore, we expect imparments in performance due to the patients' attempt to build the head of the chain and all necessary links until the trace or empty category can be located at the tail (see Caplan and Hildebrandt (1988) for confırmation ).

\subsubsection{Testıng the Head Accessibility Hypothesıs}

In order to test the Head Accessibility Hypothesis in comprehension, we must use a 
structure with the following characteristics

1- the head of the construction must seem to have idiosyncratic properties This follows from the fact (stated in (1) that the subcategorization properties of a head will determine whether the complement will be lexically accessible to the aphasic.

2- the construction must not allow a linear order strategy to be applied, since this obscures the structural differences between sentence types for which such a strategy yields the correct response (this stipulation constrains the choice of structure very much) This holds for comprehension tasks only

3- the structure must contain only one tensed verb, i e it must have only one instance of $X^{O}$-movement This characteristic of the structure will control the number of verbal chains. In addition. this restriction is imposed to control the number of CPs, IPS and VPs, 1 e. If the structure has two tensed verbs it will most likely also have two CPs (with the possible exception of conjoned IPs) Thus, a monoclausal structure may be compared to a biclausal one containıng two IPS 4- the structure must contain an infinitival complement This is in part a consequence of 3 above. If we want to compare the structure with a biclausal one which contains an object control verb, the embedded verb cannot be tensed. 5-the structure must be base generated as transparently close to its surface form as possible. The reason for this is that movement of DPs must always be to the Spec position of a functional XP. Again, to compare the chosen structure with monoclausal ones, we want only one DP movement, to Spec of IP. Biclausal 
structures chosen will either involve a PRO as the infinitival subject of the

embedded verbal complement or an operator-variable binding relation arising from the predication of the relative clause to its head noun, where the head noun itself continues to occupy its proper position in the matrix clause.

We therefore chose to test the Causative contructions in French because:

1- the causative verb faire has the property of takıng a VP rather than an IP complement. ${ }^{14}$ (As we will see in the next section, it undergoes a process of partial argument structure merger which accounts for this property.) In addition, this construction shows the phenomenon of clitic climbing. Clitics, which are heads (Kayne 1989) moved to a functional category, can be tested. All other analyses would predict that they would not be attended to; however, the $\mathrm{HAH}$ predicts that they can be successfully processed, first of all because of their structurally salient status as heads and, more importantly, because their clitıcization to INFL, a functional head, will add to this category's semantic weight since clitics form a Case and $\theta$-chain.

2-the causative does not permit a linear order strategy to be applied since the two verbs are normally adjacent. The causee or agent of the embedded verb follows the verb.

3- only the causative verb is tensed in this construction, making comparisons with

14 This is a very unusual property as verbs normally take an IP or CP complement. This therefore makes the causative more complex than a dative, which takes an additional NP argument, and less complex than control verbs or perception verbs, which take infinitival complements which are IPs. 
monoclausal structures more direct.

4- the embedded verb is in the infinitive.

5- there is no NP- or wh-movement of elements in the embedded complement.

We predict that the lexical entry of farre will signal a non-canonical semantic role assignment and that the number of IP nodes contained in the sentence (I.e. one) will have a facilitatıng effect on aphasıcs' response patterns. The reason for testıng the aphasics with a comprehension task is to control the number of lexical and functional categories that they must process. As well, it would be very difficult to elicit causatives in a production task due to the possibility that the subjects might produce paraphrases, especially if they were using strategies to avoid structurally complex constructions. Other matters concern the difficulty of visually representing sentences contaıning two propositions, as well as the particular difficulty of picturing the rather abstract notion of CAUSATION. In the next section, we provide a detailed characterization of the structural properties of the French causative.

\subsection{Section 2.-- Linguistic Analyses of French Causatives}

\subsubsection{Some Properties of Causatives Cross-Linguistically}

Causative constructions encode two propositions, one expressing the notion of causation and the other, which is conceptually dependent on the first, the notion of the 
causative types across languages-- from analytic causatives, in which the causative verb

Is separate from the verb describing the effect of the causation, through morphological

causatives, in which the causative morpheme and the event predicate are related by a

productive morpl.ological process such as affixation, and to lexical causatives, in which the relation between the causative verbal form and the non-causative one is unsystematic and is best represented by suppletion ( e.g. kill/die). (Lexical causatives will not be discussed further in this thesis)

An example of a morphological causative can be found in Japanese, 15

\author{
(18) a. Taroo ga natarak-u \\ Taroo nom work-pres \\ 'Taroo works.' \\ b. Hanako ga Taroo o hatarak-ase-ru. \\ Hanako nom Taroo acc work-cause-pres \\ 'Hanako makes Taroo work.'
}

(Shibatanı, 1976: 241 as quoted in Rosen,1989:242)

The Causee Taroo in (18b) is in the accusative case but may also take a dative case particle

-ni since the verbal root is intransitive. Were the root transitive, then the causee could

only be marked dative because the direct object of the root would be case-marked

15 As some evidence that Japanese agrammatics can at least comprehend causative morphology, Hayata, Nojıma \& Fujıta (1985) (as reported in Hagiwara 1985) discovered that two Broca's aphasics who had a memory span of only two items could properly assign the thematic roles to the NP arguments in causative sentences in non-canonical word order, the most difficult sentence stimuli tested in their comprehension task. In a grammaticality judgment task, Hagiwara (1987) also found that aphasıcs were not impaired in judging sentences containing causatives. 
accusative. This phenomenon is attested cross-linguistically

There are two ways to analyze this structure In one, the affixation of the causative morpheme occurs in the lexicon. Thus, an $X^{n}$-place predicate becomes a $X^{n+1}$-place predicate and morphological principles, ı.e percolation of features and argument structure through the head of the word, dictate the derived argument structure of the causative verb form as a consequence of the affixation process (see Willams 1981a, 1981b) Such derived verbs are then predicted to act like underived verbs when they are inserted into the terminal nodes of syntactic structures This type of analysis preserves the cleal separation of derivational morphology and syntax proposed in the Lexicalist Hypothesis (Chomsky 1970).

The other type of analysis allows the causative morpheme to be inserted into a terminal node in D-structure and then permits the root verb to incorporate with it in the matrix sentence. This does not preserve the distinction between morphological and syntactic processes. Baker $(1985,1988)$ and Rosen (1989) use this approach. 16 In fact, Rosen's analysis of this type of Japanese causative closely parallels her analysis of Romance causatives, which we will discuss below.

English, on the other hand, exemplifies the analytic or periphrastic causative: (19) John made Bill sing.

Notice that there is no auxiliary element to before sing. To is the infinitival marker and

16 Which approach is to be preferred on theoretical grounds cannot be fully explored within the scope of this thesis. The reader is therefore referred to the works cited in the text as well as DI Sciullo and Williams (1987). 
norrnally it is generated in a [-finite] INFL, which would then be able to project to IP.

Since the inflectional head to is not present in (19), we might legitımately presume that the category IP is not present However, to does surface in the passive, as in (20):

(20) John was made to sing.

Since the inflectional head is present, it will project to the IP level. It is not a property of passivization to add clausal structure, in this case IP. Therefore, we will take the more coriservative approach and assume that IP is also present in the active sentence. Therefore, make must mınımally take an IP complement Make is an Exceptional Case Marking verb (ECM); it can assign accusative Case into the embedded clause to the subject of the infinitive In English, strict adjacency is required for Case assignment. In a structure with a transitive verb in the embedded VP, the lower verb will assign case to its NP complement. English causative verbs such as make and perception verbs such as see are considered not to subcategorize for full clausal complements (In the sense of CP) but rather for what have been termed Naked Infinitives (NI). Zubızarreta (1982: 231-232) quoting Gee (1976. 477) explains:

"Semantically, I believe Nl-constructions have a particularly close relationship between the VP in the complement and the higher perception verb (an almost "direct object"-like relationshıp)... If [this construction] has complementizerless or bare Ss [IPs], then there may be something of a lack of correspondence between syntax and semantics here...."

This may appear somewhat vague but it does capture the intuition of native speakers 
that the $\mathrm{NI}$ constructions are somewhat idiosyncratic Additional properties of Nls, according to Williams (1983: 302) are that they do not seem to take subjects with eithet narrow scope or arbitrary reference. nor do they evel show thematic independence in argument positions, I.e. have PRO as subjects.

English causative constructions conform to the Projection Principle, ie the subcategorization frame of the lower verb is maintained at all syntactic levels Thus, any Idiosyncracy of the $\mathrm{NI}$ construction is attributable to the lexical entiy of the causative verb) make.

\subsubsection{Analysis of the French Causative}

\subsection{Faire-Inf}

The facts are clearly more complex in the French causative than in the English.

Witness the following.

$$
\begin{aligned}
& \text { (21) I. Jean a fait manger Pierre. } \\
& \text { 'John made eat Peter' } \\
& \text { 'John made Peter eat.' } \\
& \text { ii. Jean a falt manger une pomme à Pierre. } \\
& \text { 'John made eat an apple to Peter.' } \\
& \text { 'John made Peter eat an apple.' }
\end{aligned}
$$

We see that the verb manger and its logical subject Plerre are inverted, the logical subject appearıng to be realized as a direct object in (211) and as an indirect object in (2111). 
The Theme argument of manger is pomme and it is in its usual position of direct object in (21ii) 17 The surface order of the embedded clause is VOS which is non-canonical for French. 18 However, according to various authors (e g. Rouveret and Vergnaud (1980)), the two verbs a falt and manger being adjacent, can be viewed as a verbal complex. The two individual verbs are cosuperscripted, indicatıng tiat they are "thematically indexed" and act as one verb; the canonical SVC pattern is thus reestablished for the sentence as a whole.

Varıous proposals have been put forward claiming that the Falre-Inf construction is best analyzed by parallel structures or by co-analysis. (See Williams (1980), Zubizarreta (1982,1985), Goodall (1987), and Di Sciullo and Williams (1987) for different approaches to parallel structures.) These co-analyses permit one structure to have two representations throughout the derivation, one that does not violate the Lexicalist Hypothesis and one which does, in which the causative verb and the adjacent "root" verb form a verbal unit, allowing the argument structure to be changed in the syntax, as is shown in (22).

(22) Jean a fait rire Pierre.

'John made !augh Peter.'

'John made Peter laugh.'

17 This is reminiscent of the Japanese case discussed above.

18 Although there have been recent proposals that the Subject is base-generated to the right of the verb in Romance languages, see e.g. Pierce (1989). 


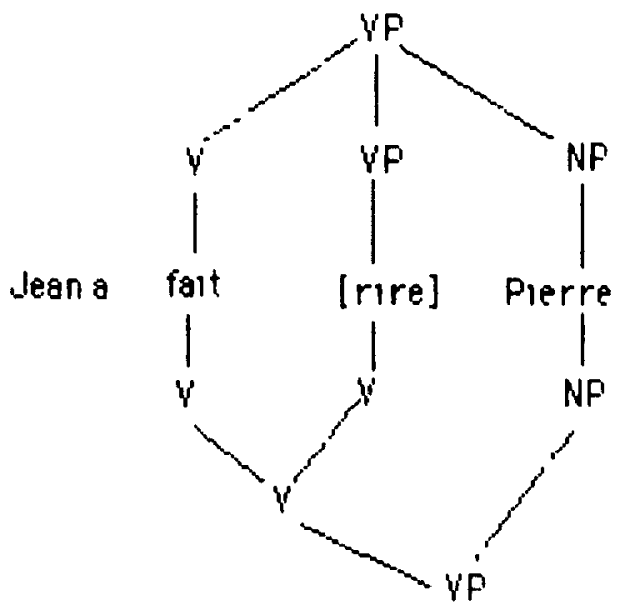

Earlier analyses also maintained that there were two structures in this

construction. Alssen $(1974,1979)$, for example (see also Kayne 1975), postulated a

biclausal deep structure and a monoclausal surface structure derived by à Verb Raısıng

transformation (i.e. movement of $V^{\prime}$, which is disallowed within the current framework)

for French and Turkish causatives. This option is no longer viable within the current GB

framework as it violates the Projection Principle since the verb's subcategorization

properties have not remained constant throughout the derivation. To avert such a violation,

parallel structures were proposed for Romance causatives.

Recently, there has been a move in the literature to analyze this structure as being

monoclausal, 1.e. with no additional IP node. 19 The analysis adopted in this thesis is of this

type, as is that of Rosen (1989).

Our analysıs falls within the Government-Binding framework of Chomsky (1982,

19 In the Relational Grammar framework, Davies and Rosen (1988) as reported by Blake (1990), have proposed a monoclausal analysis which posits that the whole inner predicate is forced into "chômage". Within Government-Binding theory, other analyses also claim that faire takes a VP complement, e.g. Rochette (1988). Rochette claims that the semantics of the causative determines the fact that it takes a VP complement Her analysis parallels that of Larson (1988) for double-object constructions, i.e. the embedded verb moves to an empty verbal head within the embedded VP to permit adjacency with farre. 
1986) In addition, the proposal that subjects are base-generated within the Spec of VP

and move to the Spec of IP position to get case (e g. Koopman and Sportiche 1988 ) is

assumed An example of this can be seen in (23) (repeated from (9), Chapter 1)

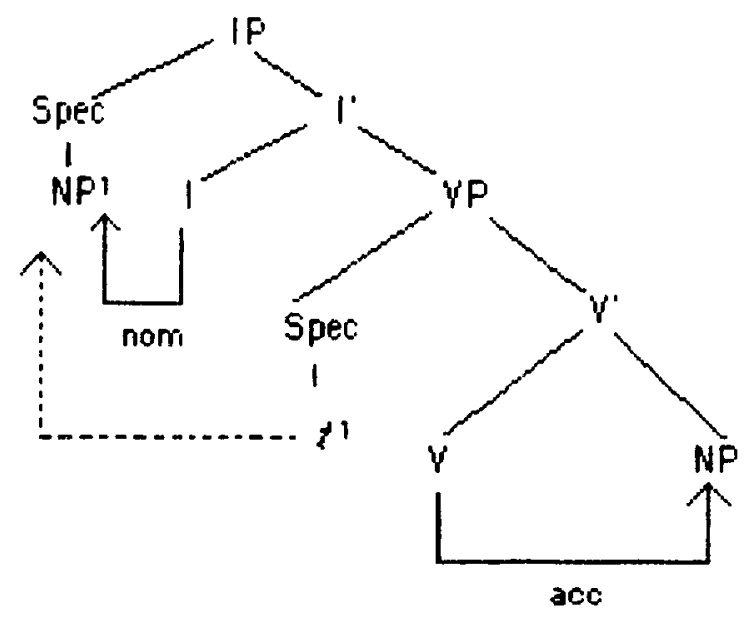

Finally, the more elaborated structure of IP proposed by Pollock (1989), 1.e. with a

$T(n s) P$ c-selecting a N(eg)P and the latter c-selecting AgrP is also assumed, as is shown In (24). 20

20 In order to simplify the exposition in the experimental sections of the thesis, in most cases AgrP and TnsP will continue to be discussed jointly as IP. The tree in (24) assumes the subject NP movernent of (23). 


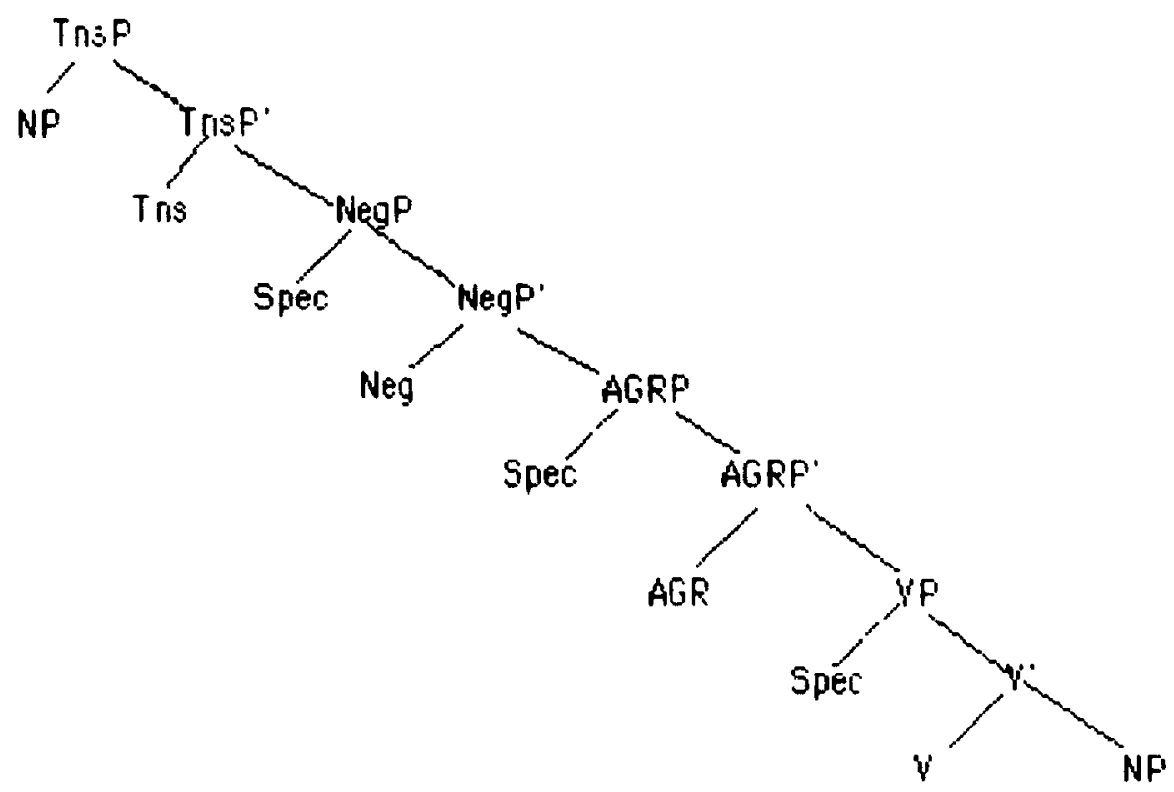

Rosen proposes an argument structure merger account for Romance causatives.

Like Grimshaw (1990), she accepts the need for an additional level of representation-the argument structure level--which mediates between a verb's Lexical Conceptual Structure (LCS) and its realization in phrasal syntax Separate operations can and do operate at this level with consequent reflexes in the phrase structure. Rosen proposes a mechanism to permit the partial merger of faire and the verb in its complement

$$
\begin{aligned}
& \text { (25) faire }[w(x)]<e> \\
& \text { 'make' } \mathrm{Ag} \mathrm{Ev} \quad \text { faire manger }[w[y(z)]]<e><e> \\
& \text { manger }[y(z)]<e> \\
& \text { 'eat' } \mathrm{AgTh}
\end{aligned}
$$

The semantic type of the complement of faure is an Event argument which, according to

21 Unlike Italıan, the merger in French and Spanısh is only partial. 
Giımshaw's (1981) Canonical Structural Realızatıon (CSR) princıple, is canonically

realized as an IP or a VP. The event structure of verbs < e > licences Inflection; the

mechanısm of binding the $<\mathrm{e}>\mathrm{s}$ of the two verbs has as a consequence that only one IP will be licensed, which forces the embedded verb to map into a VP complement rather than an IP 22 e.g.:

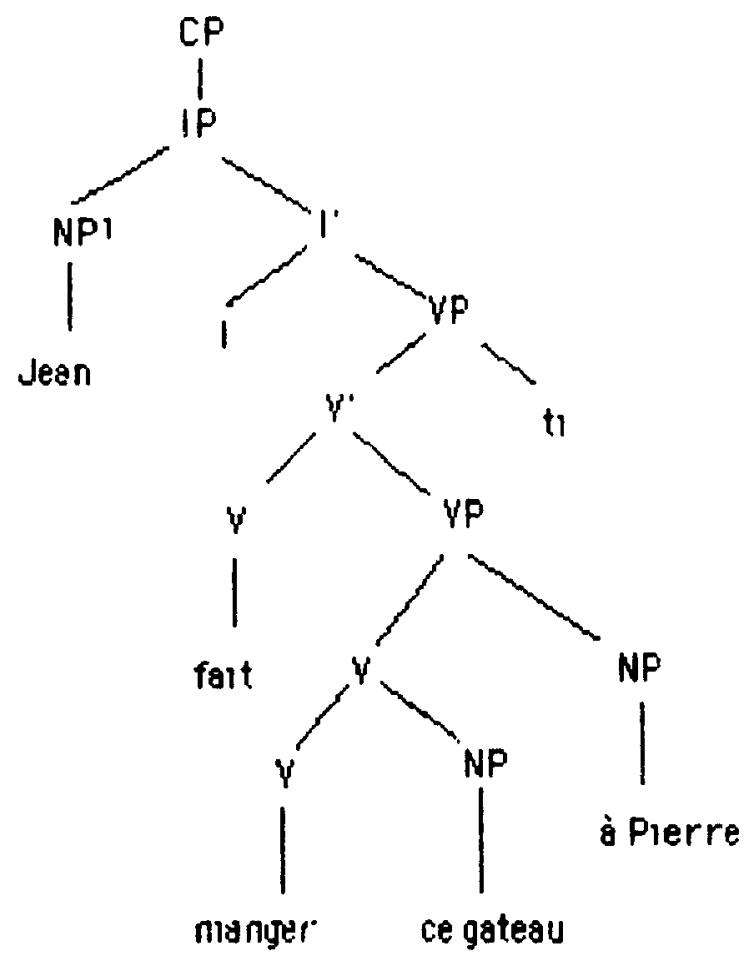

As Sportiche (1988) has argued to explain the behavior of quantifiers, the subject may be generated in Spec of VP and that Spec of VP may appear either to the right or to the left of $\checkmark$. Therefore the base generation of the embedded subject in that position in the causative construction need not be independently accounted for. The merger of the two verbs will simply combine their case arrays and the complex predicate will assıgn the number of cases available according to the Romance Case-assigning template, I.e. accusative and then 22 This structure abstracts away from the movement of faire itself. 
dative. When the embedded verb is intransitive, it will assign accusative Case to the embedded subject; when it is transitive, the causee will receive dative Case since the accusative will already have been assigned to the Theme of the embedded verb

In the case of intransitive compleme, its, both unergatives and unaccusatives can be straightforwardly accounted for by postulating that the unergatives will have a nonbranching $V^{\prime}$ and the subject will be generated in Spec of VP as a sister to the intermediate piojection; unaccusatives, on the other hand, will have a branchıng $V^{\prime}$ but a non-branchıng VP since these verbs have no external (or most prominent) argument The Theme of the unaccusative need not move to get Case as it normally would have to, because the accusative Case of faire will Case-mark the single argument of either type of verb regardless of the difference between the two positions, 23 for an unergative example see (27) and for an unaccusative see $(28): 24$

a. faire $[w(x)]<e>$

'make' AgEv faire dormir $[w[y]]<e><e>$
dormir $[y]<e>$
'sleep' $\mathrm{Ag}$

23 For those who advocate the subject-within-VP analysis, the Agent, which normally must move from the Spec of VP position to Spec of IP in o der to get nominative case, need not do so in this instance and will receive accusative case. It is for this reason that it looks like a direct object.

24 In keeping with Burzio (1986), we are assuming that Italian and French have the same class of ergative verbs and that one diagnostic for inclusion in this class is auxiliary selection, I.e. ergatives select essere / ètre, unergatives select avere / avorr. However, we are aware that this diagnostic is more reliable for Italian. 
b.

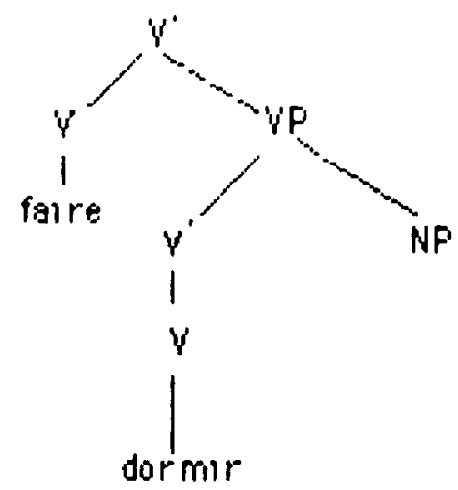

(28) a. faire $[w(x)]\langle e\rangle$

'make' Ag Ev

partı $[(y)]<$ e>

'leave'

Th

b.

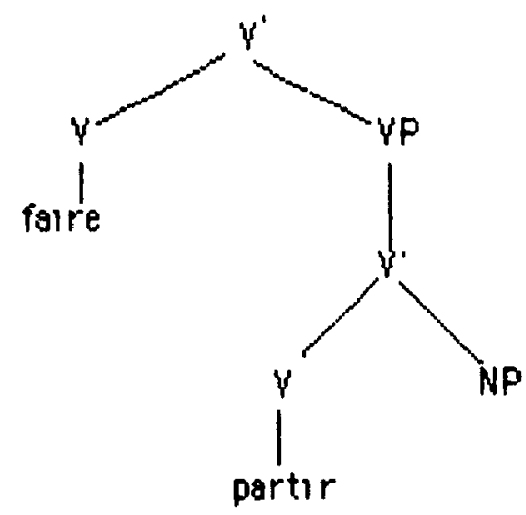

Before proceeding to the Causative (Farre-par) construction in section 2.2.2.2, we will present an alternative account of the Faire-Inf construction which helps to further highlight the features of Rosen's analysis which will prove crucial to the issues raised in this thesis.

\subsection{Biclausal Account}

fieed (1990a, 1990b, 1990c, 1991) presents a straightforwardly biclausal 
analysis of causative structures. All the background theoretical assumptions found in

Rosen's account are assumed here also. Because of the existence of tensed complements as

In:

(29) Mon Dieu, faites que mes parents reviennent vitel

'My God, make that my parents come back quickly!'

Reed argues that faire always subcategorizes for a CP complement This would appeai to obey Baker's (1988) UTAH (The Uniformity of Theta Assıgnment Hypothesıs).

(30) Identical thematic relationships between items are represenied by identical structural relationships between those items at the level of D-structure ( $p 46)^{2}$, Furthermore, unlike Rosen, Reed does not allow for the optional generation of the Spec of VP on either side of V'; therefore, there is no way to get the word order facts without a movement analysis, so it is the requirements of Case ineo $y$ that motivate the movement.

The mechanisms for the movement are VP adjunction, as permitted by Chomsky (1986), and/or short verb movement to Agr as in Pollock (1989) and movement of AgrP to Spec of $\mathrm{CP}$. Reed further assumes that farre, lassser and the perception verbs are marked for government chain formation, i.e. faire will govern the raised verb. In addition, if faire and the embedded verb share compatible case arrays, i.e. If they both can assign accusative case, the complex verb formation takes place. However, Reed claims that this "complexity " does not extend to $\theta$-markıng. An example to the comparable structure in (26) would be

25 However, a possible caveat to this is that, as noted by Jackendoff (1985), tensed and infinitival complements do not tend to mean exactly the same thing. This is certainly the intuition of any French speaker with regard to these tensed versions and the Causative (Faire-à ). 
63.

the following .

(31) D-structure' Simple Transitive verb

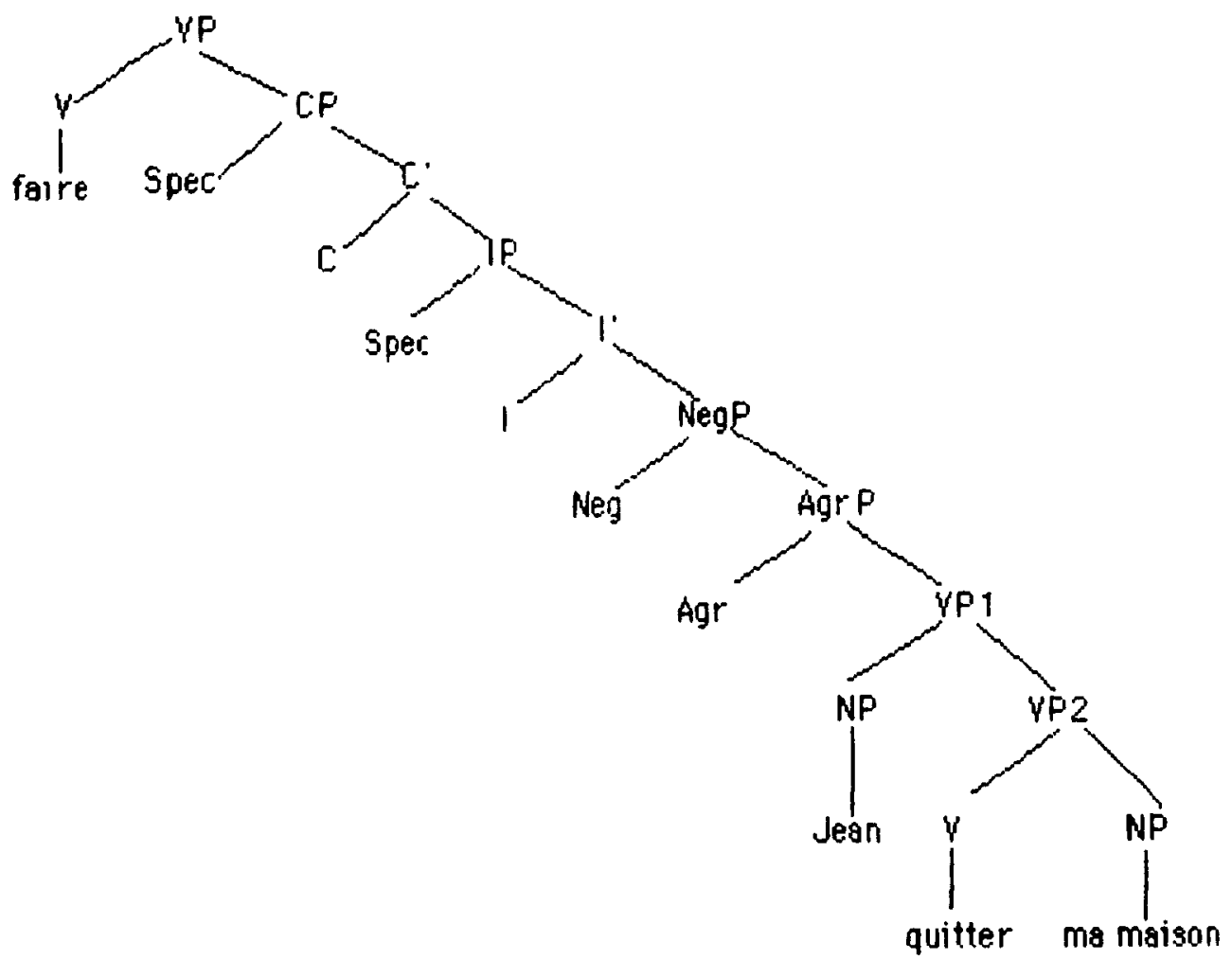

The S-structure after VP adjunction, movement of AgrP to Spec of CP and subsequent short verb movement to Agr would be as in (32): 


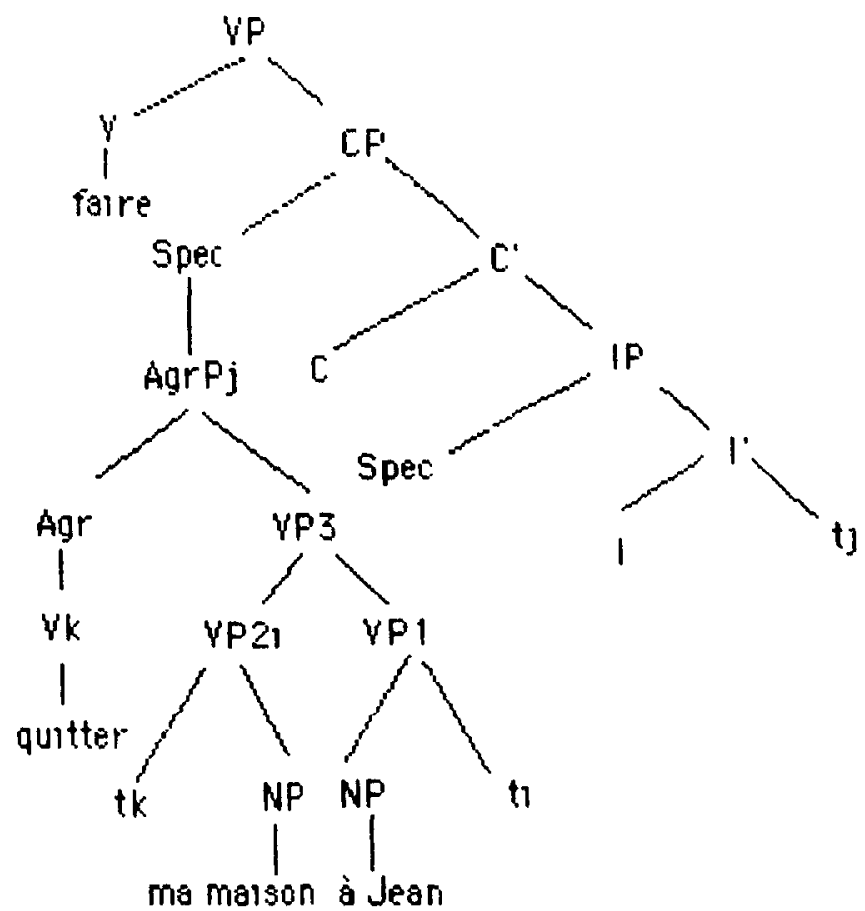

In this account, an intransitive embedded verb would also have to move so that it would be "close enough" to enter into government chain formation with the matrix verb in order to case-mark the NP argument of the displaced predicate. 26 In fact, Reed states that intransitives optionally allow elther direct Vo movement or VP-adjunction followed by Vo movement. This would lead sentences containing certain verbs to have slightly different Sstructure representations with regard to traces (and their indices). Indirect transitives such as téléphoner à which take a PP complement would only allow VO movement; VPadjunction would yield an ilicit S-structure. Simple transitives as in (32) must have VP. adjunction before Vo movement to account for the Case-marking facts; only this ordering yields a licit structure. This account would thus predict different S-structure

26 Note that intransitives of all types and indirect transitives do not form a complex predicate with the causative though they do enter into government chain formations. 
representations for faire-inf depending on the valency of the embedded verb selected. In and of itself, this should not lead us to reject this analysis and accept Rosen's. However, it can be argued that it lacks the simplicity of Rosen's, which posits a maximally general mechanısm, allowing the generation of more uniform (and more intuitively plausible) phrasal reflexes of argument structure representations. In terms of processing, Reed's account would predict that all Faire-Inf causatives would be very difficult to process due to the need to form multiple chains, any one of which could fall to be properly established. 27

\subsubsection{Faire-Par}

Faire-par constructions are uncontroversially held to take a base-generated VP complement. Burzıo (1986: 248 and 251) discusses the equivalent Italian construction.

27 Were we not testing the HAH itself by the use of French causatives, the HAH might allow us to choose between the two analyses. Results discussed in Chapter 4 will, in fact, appear to support Rosen's analysis over Reed's. In the above discussion, we wish to show that there are independent reasons to prefer Rosen's. However, since the bulk of the experimental contrasts involve faire-par and Reed's analysis Joes not deal with this construction, we will not pursue this issue further. 
(33) Marı fa [(e riparare la macchına (da Gıovannı)]

'Marla has the car repaired (by Glovannı).'

1. A subject of a appears impossible to characterize as an ec, since Its properties would not correspond to those of any of the established types of ec's.

11. Phrases anaphoric to the subject are impossible

III There are neither S-structure, nor D-Structure SSC effects.

[SSC=Specified Subject Condition]

He gives the structure of (33) as.

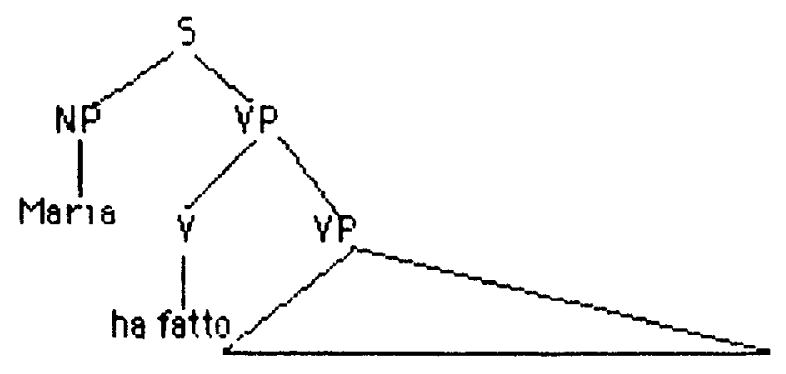

riparare la macchina da Giovann

Burzıo (1986 228)

Rosen uses the mechanism of argument structure merger previously described to account for this construction. The relation of faire-par (FP) to faire-Inf $(F \mid)$ can be seen by comparing the following representation with that given in (25). 
faire $[w(x)]<e>$

'make' Ag Ev

manger $[y-\emptyset(z)]<e>$

'to eat'

Th farre manger $[w[y-ø(z)]]<e>\langle e>$

Ag Th

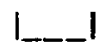

(passive)

It is assumed that the embedded verb in these cases acts like a passive. The external

argument of the verb is suppressed and the accusative case of the embedded verb gets

absorbed; the structure is still salvaged since faire has a case to assign to the $z$ argument.

An a(rgument)-adjunct par-phrase is added and the preposition will assign the Causee NP

a Case As an adjunct expression, the Causee becomes optıonal. However, there will be no

additional functional categories in the structure and no Spec of the embedded VP since the

subject position is suppressed 28 This structure is less complex than Fl because of the non-

branching nature of the embedded VP, it is the $V^{\prime}$ that branches The adjoined agentive

phrase does not add to sentential complexity because adjoined structures are not governed

by the lexical head (Chomsky 1986).

\subsubsection{Behaviour of Clitics in Causative Constructions}

Rosen also discusses the behaviour of clitics in these constructions. As opposed to

28 Guasti (1990) presents a different analysis of the FP causative. She assumes that there is a functional category INFP which takes an infinitival verb as its complement. The verb will move from the VP to the functional head to pick up the infinitival ending. The causative verb will select nominal features for the functional head and the embedded verb will also receive these by adjoinıng to INF. Crucially, there is neither an AgrP nor a TnsP in the embedded structure. 
68.

their behaviour in other structures, in which they are normally attached to the verb of which they are the complement, in causatives they clitic climb and attach themselves to faire, or rather to the INFL that takes the VP which faire heads as its complement, as in (36):

(36) $\left[\right.$ IP $[1]\left[\right.$ Agrp $\left.\left.\left[v p\left[v^{\prime} \vee \mathrm{cl}\right][\operatorname{spec} N P]\right]\right]\right]$

The clitıc must move to INFL; the only INFL avaılable is the one in the matrix clause and therefore it adjoins to that INFL

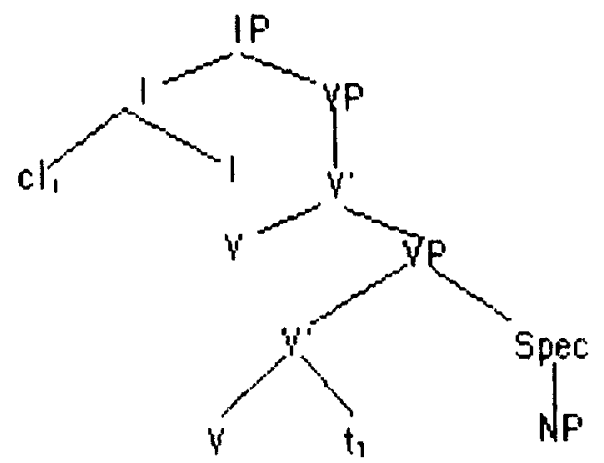

Rosen invokes Rizzi's (1990) Relativized Minımality Condition to show that there is no barrier to chain formation since only a closer governor of the same type can block antecedent government of a trace; since the clitic moves to an $A^{\prime}$ position and there is no intervening potential $A^{\prime}$ governor (since there is no intervening $I P$ ), the clitic will be able to be form a proper chain with its trace. 29

The attachment of reflexive clitics is performed as an operation on argument structures. As Grimishaw (1990) suggests, the se performs a similar function to

29 We will also assume Kayne's (1989) analysıs of pronominal clitics as heads and not phrases. In this same paper, Kayne also analyzes faire as taking a VP complement in FI constructions and accepts as uncontroversial the notion of FP as monoclausal. 
passivization, ie. the external argument of the verb it attaches to is satisfied and,

additionally, it lexically binds the internal argument:

$$
\text { farre raser }[x[y(z)]] \quad-\cdots>\text { fare se raser }\left[x\left[y_{1}-\infty\left(z_{1}\right)\right]\right]
$$

$$
\text { Ag AgTh } \quad \text { Ag Ag Th }
$$

(39) farre raser $[x[y(z)]] \quad-\ldots$ se faire raser $\left[x_{1}-\infty\left[y-\infty\left(z_{1}\right)\right]\right]$

$$
\text { Ag AgTh } \quad \mathrm{Ag} \mathrm{Ag} \text { Th }
$$

In (39), se can only be attached to the causative farre-par, otherwise the external y argument of the embedded verb will block the binding between the satisfied matrix external and embedded object arguments in the embedded VP of Fl, which is a Complete Functional Complex (CFC).

\subsubsection{Concluding Remarks}

In conclusion, we have adopted Rosen's analysis which postulates that both types of French causatives have a VP complement. Her analysis is accepted for the following reasons:

1. Recall that the nature of the argument that a verb subcategorizes for--Event vs. Proposition--determines the categorial status of the syntactic realization of the argument. Event arguments are realized as etther VP or IP, and Propositional arguments are realized as $\mathrm{CP}$. The English causative verb make takes an IP complement; there is no argument structure merger process operating on this structure in English. Rosen's account predicts 
that make takes an IP complement, Reed's stıpulates it. ${ }^{30}$ Reed's account proposes that there is more hierarchical structure in Romance causatives than in English ones This seems very counterintultive since Romance causatives are often perceived as closely resembling compound verb's

2. Rosen uses the (partial) argument structure merger process to accourit for both faire-à and faire-par causatives in a uniform way This process also permits us to see the interaction of reflexivization and causativization Reed proposes very different analyses of faire-à and faıre-par Faır ६-à involves several possıble movement operatıons--short verb movement to Agr, VP-adjunction and movement of AgrP to Spec of CP The choice of which movement is appropriate in a given structure is dependent on the argument structure of the embedded verb. Although she does not deal directly with farre-par, she alludes to Burzıo's analysis Thus the categorial status of the embedded complement of farrepar is uncontroversially VP There is no IP (or CP) between it and faire

3. In terms of processing, since Rosen's account claıms that the embedded complement of the verb faire will be a base-generated structure regardless of its transitive or passive nature, these causative structures are predicted to show similar accuracy rates to other structures of comparable complexity. On the other hand, Reed's account predicts that farre-inf constructions would be as difficult or more difficult to 
process than other biclausal structures 31 Causatives thus allow us to test our hypothesis that the properties of phrasal heads, of both the matrix and the embedded verb. will predict aphasics' ability to correctly interpret sentences which contain them. We will then contrast them with structures that take complements that entall the creation of either more or less complex hierarchical structures The $\mathrm{HAH}$ predicts that, as causatives select a VP complement rather than an IP or CP complement, aphasics will respond to intransitive versions of the faire-inf construction much as they would to a simple active it is also predicted that faire-par versions of the structure will be responded to more accurately than faire-inf transitive versions (recall that we are speaking of the valency of the embedded predicate) This is because the embedded VP does not contain a Spec position since the passivization of the VP has led to the suppression of this position Despite the different results that we are predicting for the two causative types, we still expect faire-à structures to cause fewer errors in interpretation than equivalent structures containıng IPs and CPs In Chapter 3, we will present in some detal the various sentence types which were designed to fully test these predictions.

31 Evidence will be presented in Chapter 6 which further indicates that Rosen's analysis is the correct one. 


\section{Chapter 3- Experimental Design}

3.1. Materials in the Object Manıpulation Batteries

\subsubsection{Description of the Object Manipulation Batteries (OMBs)}

All OMBs consist of 168 sentences, 12 tokens each of 14 types In order for the sentences to be completely reversible, all NPs designate anımate beings. I e anımals, since anımacy can bias subjects' interpretation of sentences In any sentence containing a contrast in the anımacy of the NPs, the anımate NP tends to be assigned the function of the Doe: of the action encoded by the verb

- The following description is true of all the OMBs Six anımal names are used, three are masculine nouns, three are feminine for one, la vache, the natural and the grammatical gender are the same
MASCULINE
FEMININE
l'eléphant 'the elephant'
la vache 'the cow'
le lapin 'the rabbit'
la grenoulle 'the frog'
le singe 'the monkey'
la chèvre 'the goat'

Each name is balanced across positions in the sentence (i.e they are assigned an equal number of times to the first, second, third (and fourth where applicable) NP slot in the linear string).

The verbs were all tested in the passé compose in French as this sounded most natural in this type of test situation. This is especially true in sentences containing two verbs (excluding the copula and auxiliaries), where the use of the present tense would indicate that the actions were occurring simultaneously. The verbs were carefully chosen to meet certaın criteria. Six verbs which were unambiguously intransitive were chosen 


$\begin{array}{lr}\text { bondir } & \text { 'to jump' } \\ \text { danser } & \text { 'to dance' } \\ \text { marcher } & \text { 'to walk' } \\ \text { sauter } & \text { 'to hop' } \\ \text { courır } & \text { 'to run' }\end{array}$

Twelve transitive verbs were used (the two verb sentences required that a greater number of these be avallable); a necessary criterion was that no gender cues be present in the past participle (most of the verbs chosen are of the regular -er type, the past participles of which are the homophonous é (masc) and ée (fem). The only three verbs not of this conjugation were tenir, sassir, and mordre, the past participles of which are tenu(e), saisı(e), and mordu(e)

$\begin{array}{ll}\text { frapper } & \text { 'to hit' } \\ \text { chatouller } & \text { 'to tickle' } \\ \text { embrasser } & \text { 'to kıss' } \\ \text { gratter } & \text { 'to scratch' } \\ \text { bousculer } & \text { 'to shake' } \\ \text { flatter } & \text { 'to stroke' } \\ \text { caresser } & \text { 'to pat' } \\ \text { tenir } & \text { 'to hold' } \\ \text { attraper } & \text { 'to catch' } \\ \text { saisır } & \text { 'to grab' } \\ \text { mordre } & \text { 'to bite' } \\ \text { serrer } & \text { 'to squeeze' }\end{array}$

In additıon, six dative verbs were chosen: 


$\begin{array}{ll}\text { offrir } & \text { 'to deliver' } \\ \text { amener } & \text { 'to take' } \\ \text { donner } & \text { 'to give' } \\ \text { apporter } & \text { 'to bring' } \\ \text { remettre } & \text { 'to return' }\end{array}$

To control for the gender cue in the feminine offerte and remise, these verbs were always tested with the three femınıne nouns while the masculine versıons of the past participles offert and remis were tested with the three male anımais In this way, no additional gender cue was present in the stımuli?

\subsubsection{Original OMB}

A. list of the sentence types used in this battery, which was not designed to test causatives, can be found in the following table

\section{Table 3.1.1. Sentence Types in the OMBs}

[01] [OMB1] Active (A2)

La grenoulle a frappé le singe.

The frog hit the monkey.

[02] [OMB2] Passive (P2)

Le singe a été frappé par la grenoulle

The monkey was hit by the frog

[03] [OMB3] Truncated Passive ( $\operatorname{Tr} P$ )

Le singe a été frappé

The monkey was hit.

[04] [OMB4] Cleft Object (CO2)

C'est la vache que le lapin a embrassé.

It was the cow that the rabbit kissed.

1 Exact translational equivalents were not always the most appropriate verbs to use in this context. For helpful discussions of datives which helped me revise the original OMB, carrying over the revisions into the two batteries which I devised specifically for the present research, I would like to thank Jody Davis.

2 This is not a problem for the causative verb since fait is invariant. 
[05] [OMBS] Dative (A3)

Le lapin a confie la vache a la chevie

The rabbit passed the cow to the goat

106] [OMB6] Dative Passive (P3)

L'éléphant a éte donné au sınge par la grenoulle.

The elephant was given to the monkey by the frog

[07] [OMB7] Cleft-Object Dative ( $\mathrm{CO} 3$ )

C'est la chevre que le lapin a donné à la vache.

It was the goat that the rabbit gave to the cow.

[08] [OMB8] Conjoined (C)

Le singe a gratté le lapin et a caresse l'éléphant.

The monkey scratched the rabbit and patted the elephant.

[09] [OMB9] Subject-Object Relative (SO)

Le singe que le lapin a saisl a bousculé la chèvre

The monkey that the rabbit grabbed shook the goat

[10] [OMB 10] Object-Subject Relative (OS)

La chèvre a frappé le lapın qui a sassı la vache.

The goat hit the rabbit that grabbed the cow

[11] [OMB11] Object-Object Relative (00)

Le singe a chatoullé la grenoulle que la chevre a bousculée

The monkey tickled the frog that the goat shook

[12] [OMB 12] Subject-Subject Relative (SS)

La grenoulle qui a tenu la vache a at trapé l'éléphant.

The frog that held the cow caught the elephant

[13] [OMB 13] Active Conjoined Theme (ACt) Le lapın a frappé la vache et la chèvre

The rabbit hit the cow and the goat.

[14] [OMB 14] Passive Conjoined Agent (PCa) La grenoulle a été caressée par la chèvre et la vache.

The frog was patted by the goat and the cow.

\subsubsection{Justification for Testing the OMB}

Although not originally conceived specifically to test the $\mathrm{HAH}$, this battery rather economically permits us to verify certain of the predictions which were discussed in the previous chapter. ${ }^{3}, 4$ [01 Actıve], [02 Passive] and [04 Cleft Object] are examples of

3 Given the large number of sentence types which need to be tested, it is fortultous that we can dispense with sentences containing only intransitive (unergative) verbs. Since they do not permit an incorrect response in comprehension tasks, the prediction of the HAH that such verbs are easier to process may in future be tested with a production task. However, it was possible to 
2-NP (actually 2-DP) sentences, they contrast in that the active sentence is clearly predicted to be easier to understand because it involves less structure The passive version of the sentence involves the construction of the Specifiel position of the functional categoly IP to allow a landing site for the Theme of the verb This is expected to lead to more incorrect responses than we would see for the active Despite this increased processing difficulty, we would still predict that passives contained within a single IP will be easier to process than the clefted structures because of the two CPs (and consequently two IPs) contained in the latter sentence type We chose to include [03 Truncated Passive] in order to verify the precise contribution of the explicit by-phrase in [02], i e whether it leads to greater or lesser accuracy

In order to test whether dative verbs are more difficult to process than simple transitives, the equivalent structures to [01], [02], and [04] were included, ie 105 Dative], [06 Dative Passive] and [07 Cleft-Object Dative] In each case it was assumed that the 3- NP versions would be more difficult because of the greater number of arguments and that, within the group of 3-NP versions, the same discrepancies in performance between passives, relatives and clefts would obtain, for the reasons given above.

In order to verify that it was indeed the argument structure of the verb which leads to processing difficulty and not merely the presence of an additional NP (or DP), sentence types [13 Active Conjoined Theme] and [14 Passive Conjoined Agent] were included. It is predicted that, because the verbs are active or passive versions of

use intransitives in sentences where the intransitive is an embedded verb; see sentence types [15], [16], [18] in the Causative OMB as well as sentence type [39] in the Pronoun OMB. Additional testing in a different paradigm which I adapted from Caplan \& Hildebrandt (1988)-- the Anaphora and Control Batteries-- also demonstrated that embedded intransitives are easier to process than the equivalent transitive versions for my French subjects Caplan (personal communication) has confirmed this to be a robust finding with his English subjects as well

4 Some additional justification for the use of some of the OMB sentence types will be reserved for more direct comparisons with the causatives. 
ditransitives, subjects would treat them more like [01] and [02] than like [05] and [06].

It was also necessary to include various structures containing two clauses These sentence types are often tested in psycholinguistic experiments. They acted as baselines for the structures tested in the Causative OMB (or COMB). [08 Conjoined] involves of the conjunction of two IPs. It permits a Parallel Function strategy to be utilised, 5 i.e. attributing the function of subject to the same NP for both actions described in the sentence. 6 It is predicted that this sentence type will be more difficult to process than [05 Dative] due to the increase in hierarchical structure The conjoined structure is, however, predicted to be easier than [12 Subject-Subject Relative], for which the Parallel Function strategy will also facilitate response, because the latter type involves two CPS [10 0bject-Subject Relative] should be more difficult than [05 Dative] for the same reason The two object relatives are expected to be more difficult because the whtraces are in object position. Interpretation of the embedded clauses requires the subject to fully parse the structures to arrive at the correct responses. A slight advantage stemming from the recency effect,, e. the last thing heard may be more salient, and the Parallel Function strategy, would lead to better performances on [ 11 Object-Object Relative] than on [09 Subject-Object Relative]. We also expect that both [02 Passive] and [06 Dative Passive] will prove less difficult to process than the two former structures.

\subsubsection{Description of the Causative OMB (COMB)}

Turning to the test specifically involving the causative, a list of the 14 sentence types can be found in the Table 3.1.2.:

5 Caplan, however, also counts this as evidence of the linear order strategy. We believe it is necessary to preserve the distinction.

6 Attributing the function of object of both verbs to the same NP is also an instance of this strategy. 
[15] [COMB1] Direct Object Control, Intransitive Verb (DOC + IV) Lá grenoulle a forcé le singe à bondir.

The frog forced the monkey to jump.

[16] [COMB2] Passivized Direct Object Control, Intransitive Verb (Pass DOC + La vache a été forcée par le singe à danser Iv)

The cow was forced by the rabbit to dance.

[17] [COMB3] Truncated Causative ( $\mathrm{Tr}$ Caus)

Le lapin a fait frapper la vache

The rabbit had the cow hit

[18] [COMB4] Causative + Intransitive Verb (Caus + IV)

La vache a falt danser le lapin

The cow made the rabbit dance.

[19] [COMB5] Direct Object Control + Transitive Verb (DOC + TV) Le lapin a forcé la chevre à frapper la vache

The rabbit forced the goat to hit the cow.

[20] [COMB6] Passivized Direct Object Control + Transitive Verb (Pass DOC + La grenoulle a été forcée par l'éléphant à caresser le singe.

The frog was forced by the elephant to pat the monkey

[21] [COMB7] Causative (Faire-à) (Caus F-à)

La grenoulle a fart caresser le singe à l'éléphant

The frog made the elephant pat the monkey

[22] [COMB8] Causative (Faire-par) (Caus F-par)

Le lapin a fait frapper la vache par la chèvre

The rabbit had the goat hit the cow

[23] [COMB9] Cleft-Object Causative (Faire-par) (CO Caus)

C'est l'éléphant que le singe a fart saisir par la grenouille.

It was the elephant that the monkey made the frog grab.

[24] [COMB10] Conjoined Causative (Conj Caus)

La grenoulle a fait frapper la vache et chatouiller l'éléphant par le singe.

The frog made the monkey hit the cow and tickle the elephant.

[25] [COMB11] Causative + Dative (Caus + Dat)

L'éléphant a falt apporter le singe à la grenoulle par la vache.

The elephant made the cow bring the monkey to the frog

[26] [COMB12] Causative + SS Relative (Caus + SS)

La grenoulle a falt chatouller l'éléphant par le singe qui a frappé la vache.

The frog made the monkey that hit the cow tickle the elephant.

[27] [COMB13] SS Relative + Conjoined Theme (SS + Conj T)

L'éléphant qui a chatouillè la vache et le singe a frappé la grenoulle

The elephant that tickled the cow and the monkey hit the frog. 
[28] [COMB14] Conjoined Clauses 4 NPs (No Deletıon) (Baselıne) (Conj Cls) La grenoulle a frappé le singe et la vache a chatoullé l'éléphant.

The frog hit the monkey and the cow tickled the elephant

\subsubsection{Justification for Testing the COMB}

Causatives allow us to examıne sentences which are monoclausal (i.e. containing only one IP (and CP). ${ }^{7}$ In order to test the hypothesis that sucil structures will be ea'sier to process than biclausal ones, other structures analyzed as being monoclausal or biclausal must be used as bases for comparison. If causatives, barring other interacting sentence variables, pattern with other monoclausal structures (as measured by number of correct responses) and differ from accuracy rates for biclausal structures, it will be considered support for the hypothesis that the computation of additional functiorial categories, specifically IP and CP, leads to a degradation of performance.

French canonical word order for sentences containing full NPs is NVN (SVO). We tested the following:

(1) i. Le singe a fait courir le lapın.

'The monkey made run the rabbit.'

'The monkey made the rabbit run.'

ii. Le singe a fait frapper la grenouille au /par le lapin

'The monkey miade hit the frog to/by the rabbit.'

'The monkey made /had the rabbit hit the frog.'

In (1i) we have $N_{1} V_{1} V_{2} N_{2}$ order. If the two verbs are viewed as a verbal unit, the sentence

will be interpreted as SVO (though both the $S$ and the 0 are agents). In order to mitigate the

7 However, Rosen does not call the structure monoclausal because, since the embedded VP complement to the causative verb functions as a CFC (Complete Functional Complex), it can be consıdered a Small Clause. We will contınue to refer to the structure as monoclausal though the reader should keep in mind our stipulation that the presence of IP is necessary for "clausehood". 
possiblity that such a causative + intransitıve verb might be perceived as some kind of compound verb and only allow the correct interpretation, another contrasting type is included -- the [17 Truncated Causative], which must involve an actor not mentioned In the sentence in order to be interpreted correctly:

(2) Le singe a fait frapper la grenouille.

'The monkey made hit the frog.'

'The monkey had the frog hit.'

Some third anımal must hit the frog. Should the agent of faire be chosen, we would have to assume that the patient is using a linear order strategy or the kınd of parallel function hypothesis sometimes seen in the responses children make to relative clauses.

Example (111) does not mimic canonical word order, here $\mathrm{N}_{1} V_{1} \mathrm{~V}_{2} \mathrm{~N}_{2} \mathrm{~N}_{3}$ must be interpreted as $\mathrm{S}-\mathrm{V}-\mathrm{V}-0-10$, where the $\mathrm{NP}$ in the $\mathrm{PP}$ is the agent of the second verb. However, within the lexical entry for the causative verb is information that presumably distinguishes it from others which do not exhibit noncanonical order. (Rosen (1989) would say that it is because it subcategorizes for a VP cornplement.)

The core of the Causative test is made up of sentences with three NPs. Given the following in French:

(3) Le lapin a fait frapper la vache par la chèvre.

'The rabbrt made hit the cow by the goat.'

'The rabbit had the goat hit the cow.'

we must compare it with other structures with par-phrases such as [ 06 Dative Passive](a monoclausal structure) and [20 Passivized Direct Object Control + Transitive Verb] (a biclausal stucture). Additional biclausal contrasts also include the 
relative clause types discussed previously and especially [09 Subject-Object

Relative] and [ 11 Object-Object Relative].

We find the following justifications for testing these structures.

1. The linear order of the lexical categories of the causative is $N_{1} V_{1} V_{2} N_{2}[$ par $] N_{3}$ which could be interpreted as $N_{1} V_{1} N_{2}[$ par $] N_{3}$ where $V$ stands for a complex $V$. We therefore contrast this with the Dative Passive which has a very similar linear order, $N_{1} V_{\text {aux }} V_{7} N_{2}[$ par $] N_{3}$. Neither structure allows for a linear order strategy.

In addition, an examination of simple Datives in the same patient allows us to obtain a baseline for the ability to interpret three place argument verbs. Does the complex predicate in the faire-à construction act like a simple three place verb? Such a contrast is not as direct in the faire-par construction as, according to the theory, the NP in the byphrase is considered an adjunct and not an argument of the complex predicate (see Grimshaw (1990) for a discussion of the different status of a-adjuncts and arguments). However, it must be identified as coreferential with the implicit (suppressed) agent, and whether the $\theta$-role can be assigned directly is open to debate. Only the very simplest type of faire-à constructions will be used because of its relative unacceptability and because of the ambiguity of à as a cue.

The Dative Passive also contains a nominal trace and is a sentence type in which movement has occurred, as opposed to the causative which, under one type of analysis, is base-generated as is (Manzıni 1983, Rosen 1989) and contains no trace; according to other analyses (e.g. Baker 1988, Reed 1990a, 1990b, 1990c and 1991) it does contain a verbal trace left by VP-to-COMP movement. For this reason, therefore, we want to contrast the Causative (Faire-par) and Dative Passive with a Cleft-Object Causative (Faire-par) structure $N_{1} N_{2} V_{1} V_{2}$ [par] $N_{3}$ or $N_{1} N_{2} V\left[\right.$ par] $N_{3}$, which contains a wh-trace like the relatives clauses discussed above. Cleft constructions are structures which indisputably have a mismatch between number of propositions and number of 
clauses, though there is considerably more structure in both 'clauses' of the causative construction.) We must then also examıne the Cleft-Object Dative $\left(\mathrm{N}_{1} \mathrm{~N}_{2} \mathrm{VN}_{3}\right)$ to examine the effects of having two preverbal NPs as opposed to two postverbal ones.

2. The Passivized Direct Object Control + Transitive Verb presents the patient with a string of the type $N_{1} V a u x V_{1}[$ par $] N_{2} V_{2} N_{3}$. Although the par-phrase is preverbal with respect to $V_{2}$ rather than postverbal, 8 it permits us to examine a case which does not permit a linear interpretive strategy. As a structure containıng a trace where one of the Agents is signalled by a par-phrase, it can also be contrasted with Dative Passive. A biclausal structure in French which permits a linear order strategy and which does not contain a trace (though it does contain the empty category PRO) is also Incuded - Direct Object Control + Transitive Verb. As in the causative, the same lexical items (1.e. the NPs) can hold the same thematic roles with respect to each other despite their not being in the same grammatical positions in the sentence or in the same slots in the linear string. The verbs used to test the control structures --forcer and inciter were chosen because they, like faire, are members of what Karttunen (1970, as cited in Rosen1989, pp. 32-33) has called 'positive implicatives', i.e. we know that the action in the complement 'clause' has been performed. In addition, both control verbs subcategorize for à rather than de as their complementizer; this in turn led to better contrasts with both the Causative (Faire-à) and the datives that were used.

3. Subject-Object Relative $\left[N_{1} N_{2} V_{1} V_{2} N_{3}\right]$ permits us to examine other

8 A sentence of the type Le singe a été forcé à frapper le lapin par la grenoulle may for experimental reasons seem a better contrast. However, the structure is ungrammatica! according to native speakers. Sentences of the type Le singe a forcé la grenoulle à être frapper par le lapin are considerably worse. The semantics of the verb forcer (and other verbs that could be used here) require a (positive) action verb in the embedded clause. You cannot get a stative reading of the passivized verb (Rochette, p.c.). To encode a sentence with an equivalent meaning, one would use Le singe a forcé la grenouille à se faire frapper par le läpin, which is still somewhat odd but acceptable. However, note that there is the confounding effect not only of the causative but also of the reflexive clitic. Testing of such a structure must await our having examined the structures in isolation. 
structures with two verbal categories adjacent to each other in the linear string, as in the French causative. In both Subject-Object Relative and causatives, part of the response pattern is alike -- the animal referred to by the first NP acts on the one designated by the third and final NP.

4. Object-Object Relative $\left[N_{1} V_{1} N_{2} N_{3} V_{2}\right]$ (recall the discussion of the possibility that the causative is perceived as $\left[\mathrm{N}_{1} \mathrm{VN}_{2} \mathrm{~N}_{3}\right]$ ). We thus have another category with two postverbal NPs; in addition, part of the pattern of response must be similar to the causative, i.e. the subject must have $\mathrm{N}_{3}$ act on $\mathrm{N}_{2}$.

5. Subject-Subject Relative $\left[N_{1} V_{1} N_{2} V_{2} N_{3}\right]$ does not permit a lineas order strategy; it shares part of its response pattern with Passivized Direct Object Control + Transitive Verb $-N_{1}$ acts on $N_{3}$.

6. Object-Subject Relative $\left[N_{1} V_{1} N_{2} V_{2} N_{3}\right]$ can also be compared with the biclausal structure, the 119 Direct Object Control + Transitive Verbl, which has the same linear string and the same response pattern, I e. $N_{1}$ acts on $N_{2}$ and $N_{2}$ arts on $N_{3}$. It is predicted that, in the absence of any confounding effect of the linear order strategy, the relativized structure containing two CPs should be more difficult to process than the control structures which have only one since the complement is an IP (if we remain consistent and consider the canonical realization of event arguments to be IP).

Patients are extremely sensitive to certain sentential variables; for some it is the number of NPs in the sentence, for others it can be the number of verbs. For this reason, sentences with only two NPs were included, e.g. [15 Direct Object Control, Intransitive Verb], [16 Passivized Direct Object Control, Intransitive Verb], [17 Truncated Causative] and [17 Causative + Intransitive Verb]. These were predicted to be easier to process because of the argument structure of the verbs involved. In addition, for those patients who have little difficulty with three NPs, four- NP 
sentences were included in order to test their maximum capacity. ${ }^{9}$ It was also hoped that patients who had some difficulty with three- NP sentences would still be able to understand a sufficient number of four- NP sentences because of the information contaned in the lexical entry of the causative verb (which is in some sense the head of the complex predicate). As a baseline, two simple sentences are conjoined (2Vs, 2NPs, 2CPs). To this we contrast [24 Conjoıned Causative], 225 Causative + Dative], [26 Causative + SS Relative] and [27 SS Relative + Conjoined Theme] in the embedded clause. Thus, an upper limit of interpretable NPs can be set. We predict that [25] should be easier than [24] since [25] has an embedded dative verb and [24] has conjoined VPs. [26] should be more difficult than both [24] and [25] since it contains an additional CP. [27] should be more difficult than [28] because of the embedding of the second clause and because a linear order strategy cannot be applied.

Some of the universal and language-specific features which help/hinder the assignment and interpretation of syntactic structure still have to be specified. As discussed in Chapter 1, the work of Caplan, Baker and Dehaut (1985) began to show that aphasic comprehension is a function of various sentential variables: number of NPs, number of verbs, number of propositions, number of words, i.e. sentence length, and use/non-use of a language's canonical word order, which may interact with the possibility of a patient using a linear interpretive strategy. Holding some of these variables constant makes it possible to examine in isolation the one that two given structures do not share, thus increasing our awareness of the precise contribution that that variable makes to sentence comprehension.

In order to conduct some of the analyses which we will report on in Chapter 4, we coded all such variables for the first 28 OMB sentence types. The reader is referred to

9 These decisions were made while testing the original group of five patients, three of whum (A.G., C.M. and J.T.) often performed flawlessly; the other two (C.D. and J.D.) were very impared on many simple structures. 
Table 3.1.3.10, 11

10 The caregory "number of Action Verbs" includes all non-copular verbs. "Maximum number of words" utilizes the count obtaned with sentences of each type that contain the noncontracted forms of the preposition à. The reason we have not coded the Pronoun OMB (see Section 3.1.3.1) is that it is controversial whether or not the clitics are NPs.

11 Certan of the variables are not completely independent of each other. For example, sentence length and the number of NPs in a sentence are positively correlated, for as the number of NPs increases so does sentence lensth. In addition, the number of action verbs establishes the number of propositions a sentence wil. contain. Ultimately, since most of the NPs in these sentences are arguments or adjuncts of suppressed arguments of some predicate, the algument structure of the verb can be seen to be interlinked with the other variables and really crucial in many instances for processing ease or difficulty. We expect that, as the value of each variable increases, this will be refiected in a decrease in the number of correct responses for certain patients. 
Table 3.1.3. Sentential Variables of the OMEs

\begin{tabular}{|c|c|c|c|c|c|c|}
\hline & SENTENCE TYPE & - MPS & - Action Vs & - Infl Vs & Mox $*$ WdS & Linear onder \\
\hline 1 & ondi & THO & One & One & $S|x|$ & 10 \\
\hline 2 & OMB2 & THO & One & One & Elgnt & ROO \\
\hline 31 & 0 MMB & One & One & One & Five & MO \\
\hline 4 & amBA & Twn & One & One & Mine & Mo \\
\hline 5 & OMB5 & Thros & one & $\mathrm{One}$ & Nine & 10 \\
\hline 6 & OMBG & Three & One & One & Eleven & MLO \\
\hline 7 & $\longdiv { 0 4 8 7 }$ & Three & one & One & Twelye & MLO \\
\hline ㅇ) & aribe & Three & Two & Two & Eleven & MO \\
\hline 9) & OMBS & Three & Two & Two & Eleyen & MO \\
\hline 10 & $0 \times 1810$ & Three & Two & TYo & Eleyen & LO \\
\hline 111 & AMBII & Three & Two & Two & Eleven & MLO \\
\hline 12 & anB 12 & Throe & Two & Two & Eloven & $M O$ \\
\hline 13 & atBi3 & Throe & One & One & Nine & 10 \\
\hline 14 & $\longdiv { \text { OMBIA } }$ & Three & One & ine & Eleven & HLO \\
\hline 15 & COMBI & Two & Tro & One & Eight & 10 \\
\hline 16 & Cotter & Tro & Tro & One & Ten & MLO \\
\hline 17 & COMB3 & Tro & TwO & One & Seven & $\mathrm{MO}$ \\
\hline 16 & $\longdiv { \operatorname { c o m } B 4 }$ & $T w 0$ & TwO & One & Seven & 10 \\
\hline 19 & Contes & Three & Two & ane & Ten & 10 \\
\hline 20 & CONB6 & Throe & Two & $a_{n}$ & Twolve & NO \\
\hline 21 & COMB7 & Throe & Two & One & Ten & MOO \\
\hline 22 & COMBo & Three & Two & One & $T \in \mathbb{R}$ & $\mathrm{MO}$ \\
\hline 23 & cortiog & Three & Tro & Two & Thirteen & $\mathrm{NHO}$ \\
\hline 24 & combio & for & Three & One & Forrteen & $1 \mathrm{MO}$ \\
\hline 25 & {$[\sqrt{2} \times 181]$} & Four & Tro & One & Thirteen & 120 \\
\hline 26 & LOTO12 & Four & Threes: & Two & Fiftoen & 110 \\
\hline 27) & Comb 13 & Four & Two & Two & Fourteen & MLO \\
\hline 28 & $\cot B 14$ & Four & Two & Two & Thirteen & LO \\
\hline
\end{tabular}


3.1.3.1. Description of the Pronoun OMB (POMB)

A third battery looks at sentences containing clitic pronouns Table 314 . contains

the sentence types in this battery

Table 314 Sentence Types in the POMB

[29] [POMBI] Dative-Theme chitıcized (Dat-th cl)

La chèvre l'a offert(e) à la vache

The goat offered it (hum/her) to the cow

[30] [POMB2] Dative-Goal cliticized (Dat-G cl)

La vache lill a remis la chèvre

The cow returned the goat to it (hm/her)

[31] [POMB3] Causative-Theme cliticized (Caus-Th cl)

Le lapin l'a fait tenu par la chèvre

The rabbit had the goat hold it (him/her)

[32] [POMB4] Causative-Causee cliticized (Caus-Cee cl)

L'éléphant lui a fait attraper la grenoulle

The elephant nade it (hım/her) catch the frog

[33] [POMB5] Causative-Reflexive Causer=Theme (Caus Refl Cer=Th)

La vache se fait saisir par le lapin

The cow got itself caught by the rabbit

[24] [POMB6] Causative-Reflexive Causee (Caus Refl Cee)

La chèvre fait se serrer la vache

The goat made the cow squeeze itself

[35] [POMB7] Causative-Reflexive Causer=Goal (Caus Refl Cer=G)

La vache se fait remettre la chèvre par le lapın.

The cow had the goat returned to it by the rabbit $/$

The cow got the rabbit to return the goat to it

[36] [POM88] Causative-Reflexive Causer=Goal, Truncated (Caus Refl Cer =G La chèvre se fait offrir le lapin

$\mathrm{Tr})$

The goat had the rabbit offered to it.

[37] [POMB9] Causative-Theme cliticized, Truncated (Caus Th $\mathrm{cl}$ )

La chèvre le fait serrer.

The goat had it (hım) squeezed

[38] [POMB 10] Causative-Reflexive Causer=Theme, Truncated (Caus Refl La chèvre se fait bousculer

Cer $=$ Th $T r$ )

The goat got itself shaken.

[39] [POMB11] Causative-Theme=Causee cliticized, Intransitive Verb L'eléphant le fait trembler.

(Caus $T h=$ Cee, Iv)

The elephant made it (hım) shake. 
[40] [POMB 12] Cleft-Object with Stylistic Inversion ( $\mathrm{CO} 2+\mathrm{SI})$

C'est le lapin qu'a flat te l'éléphant.

It was the rabbit that the elephant patted.

[41] [POMB 13] Subject-Object Relative with Stylistic Inversion (SO + SI) Le lapin qu'a gratté l'éléphant a frappé le sirigle.

The rabbit that the elephant scratched hit the monkey.

[42] [POMB14] Object-Object Relative with Stylistic Inversion (OO + SI) Le lapın a grat té la chèvre qu'a embrassée le singe.

The rabbit scratched the goat that the monkey kissed.

\subsubsection{Justification for the POMB (Clitic Pronoun Battery)}

We chose to test these sentence types for several reasons:

To further our understanding of the processing of the causative, we investigated the cliticized versions of the sentence types discussed above. What does a person know when they have full access to the lexical entry faire? He must know that there is no one-to-one correspondence between the role of causee and one particular Case. If the 'embedded' verb is intransitive, the Causee is in the accusative Case when cliticized:

(5) Le lakin l'a fait bondir.

'The rabbit it made jump.'

'The rabbit made it jump.'

However, it is in the dative if the verb is transitive:

(6) Le lapin lui a fait fiapper la vache.

'The rahbit to it made hit the cow.'

'The rabbit made it hit the cow.'

Sentences containing such clitics, [39 Causative-Theme=Causee cliticized, Intransitive Verb] 12 and [32 Causative-Causee cliticized], were compared to their full NP versions, [18] and [21] respectively. These are all instances of the faire-à or farre-inf construction. In addition, the pronominal version, i.e. (6) (or [32] ), does not induce the judgment of unacceptability of the full NP version [21]. The HAH predicts

12 For reasons which will be discussed below, the tense of the causative was changed for this sentence type and its truncated version from passé composé to present. 
that these pronominal versions should be as easy ic process as the full versions since the clitics add semaritic information ${ }^{3}$ to INFL, in sfite of the fact that they are not stiessed, which reduces their phonological sahency in comparison with Kean's P-woids

Sentence types [29 Dative-Theme cliticized] and [30 Dative-Goal cliticized] are contrasted with the above as they involve "simpler" or more canonical case assignments, 1 e THEME $=$ ACCUSATIVE and GOAL $=$ DATIVE In addition, we will contrast these with the full NP version [05 Dative].

Pronominal versions of the fatre-par constructions were also investigated. [31 Causative-Theme cliticızed] was used as a contrast to [22 Causative (Folrepar)]. (It was not possible to test this contruction with the faire-a because the cliticized theme would have had to be interpreted as manimate.)

For the sentences containing reflexive clitics, we adopted the analysis proposed in Rosen (1989) (and Grimshaw 1990) The reflexive clitıc se in French is best understood as a valency changing morpheme The external argument, or the most prominent argument within a prominence domain (= the 'subject'), is bound to (and satisfied by) one of the less prominent arguments; the latter will then have to move to Spec of IP to get Case In order to test whether this analysis was correct, we included a variety of such structures and compared them with passivized structures (discussed above), which also contain traces of movement motivated for similar reasons in the latter case, the external argument is suppressed rather than satısfied. We will make the workıng assumption that this difference between the satisfaction of the most prominent argument and its suppression will not affect the processing of these structures as reflected by acccuracy rates. We predict that causatives with reflexive clitics should be processed as well (or as poorly) as

13 Since they and the empty categories with which they are associated must form a chain consisting of a trole and one Case feature. 
"synonymous" passives. 14 The patient cannot use a linear order strategy on any of these

sentences

Truncated versions of [35 Causative-Reflexive Causer=Goal], [31

Causative-Theme cliticized], and [33 Causative-Reflexive Causer=Theme]

were included ( [36], [37] and [38] respectively). It was felt that they offered more

direct contrasts to [39 Causative-Theme=Causee cliticized, Intransitive Verb]

and that their length allowed for more varıety In addition, they eliminated the "Causee" in

the par-phrase and could thus be compared to [17 Truncated Causative].

The tense in some of the sentence types ([33],[34],[35],[36],[37],[38] and

[39]) was changed from the passe compose used elsewhere in the OMBs to the present

tense. This was necessary as a change of auxilary from avorr to être would have been

necessary for all the types which contained reflexive clitics; they would then have

contrasted more with the non-reflexive counterpart. We did not want to confound the de-

transitivizing effect of the ieflexive clitic + the causative. In most cases, this permitted a

contrast between le/se. In certain cases, la had to be used but the experimental subject

might re-segment the incoming string as "l'a fait" rather than "la fait" and thus the

additional gender cue might not even be perceived as such.

The last three sentence types involve inverted versions of sentences found in the

OMB. Cleft Object, Subject-Object Relative and Object-Object Relative. They

permit us to add diversity to the test and avoid the overuse of the causative or the clitic

pronouns. Some researchers (e.g Kall 1989) have clarmed that these inverted structures

are more frequent than their non-inverted counterparts in normal discourse; this seems

counterintuitive, but we felt that we should put it to the test. Certainly, not all similar non-

14 [34 Causative-Reflexive Causee] was also tested as it was not always clear from the linguistic literature whether this is an unacceptable structure. There are frequent examples of verbs such as se raser and se laver. This form is actually quite restricted lexically with the reflexive reading, though it seems somewhat better with the reciprocal reading with a plural NP agent of the embedded verb. 
inverted structures have acceptable inverted versions. However, they do allow a case contrast between the relative pronoun que and the qui of the Subject-Subject Relative and Object-Subject Relative, knowledge of the significance of the change in the relative pronoun is unrelated to 'lexical' propeities in these constructions.

\subsection{Subjects}

An unselected sample of nıne subjects whose mother tongue was French,' participated in this study (Unfortunately, four of the original nine could not be tested on the POMB.) The only criterion for inclusion was that they pass the pretests (see below), thus showing sufficient comprehension at the single word level Ten normal controls roughly matched for age were also tested. Subject varlables can be found in Table 32 for the total aphasic sample, Table 3.3 for the subset sample of aphasics who were tested on all three batteries and Table 3.4 for controls

15 A tenth patient withdrew from testing without having completed any of the tests. 
TABLE 3.2. PATIENT DATA-TOTAL APHASIC SAMPLE

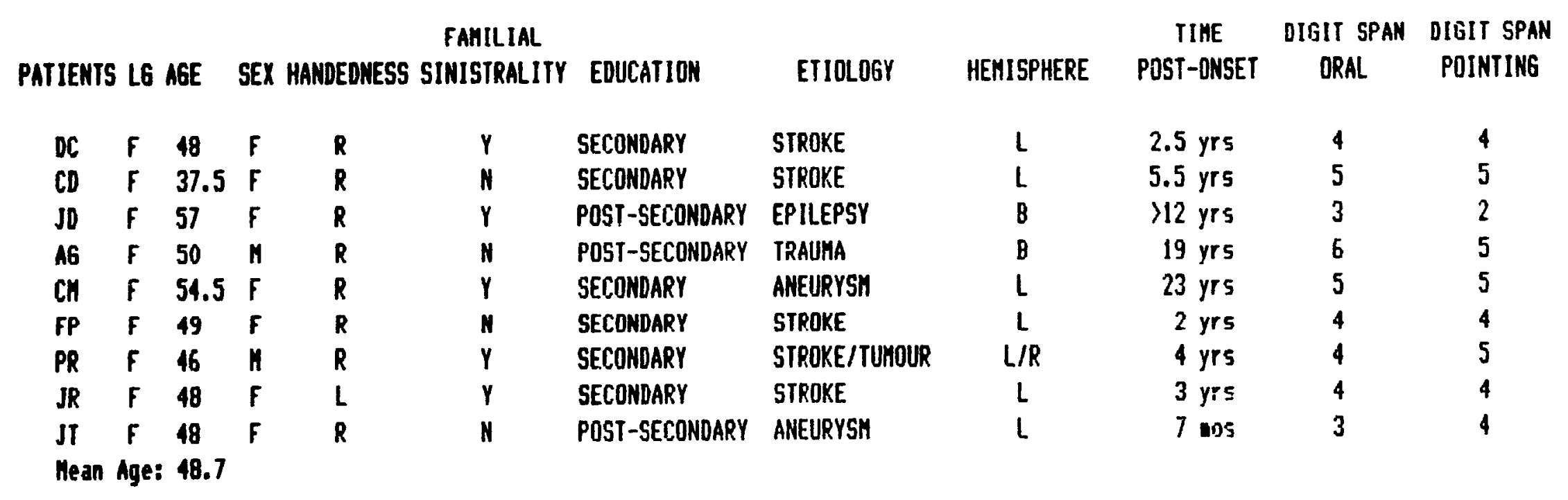


TAble 3.3. PATIENT dath-SUbSet sample

\begin{tabular}{|c|c|c|c|c|c|c|c|c|c|c|c|}
\hline PATIENTS & 16 & A6E & SEX & HANDEDNESS & $\begin{array}{l}\text { FAMILIAL } \\
\text { SINISTRALITY }\end{array}$ & EDUCATION & ETIOLDGY & HEMISPHERE & $\begin{array}{c}\text { TIME } \\
\text { POST-ONSET }\end{array}$ & $\begin{array}{c}\text { OIGIT SPAK } \\
\text { ORAL }\end{array}$ & $\begin{array}{c}\text { DIGIT SPAN } \\
\text { POINTING }\end{array}$ \\
\hline $\mathrm{XC}$ & $\boldsymbol{F}$ & 48 & $\mathbf{F}$ & $\mathbf{R}$ & $Y$ & SECONDARY & STROKE & L & 2.5 yrs & 4 & 4 \\
\hline CH & $\mathbf{F}$ & 54.5 & $F$ & $R$ & $y$ & SECONDARY & ANEURYSH & $L$ & 23 yrs & 5 & 5 \\
\hline FP & $\mathbf{f}$ & 49 & $\mathbf{F}$ & $\mathbf{R}$ & N & SECONDARY & STROKE & $L$ & 2 yrs & 4 & 4 \\
\hline PR & f & 46 & $\boldsymbol{n}$ & $\mathbf{R}$ & $Y$ & SECONDARY & STROKE/TUHOUR & $L / R$ & 4 yrs & 4 & 5 \\
\hline $\begin{array}{l}\text { JR } \\
\text { Mean }\end{array}$ & $\begin{array}{c}\text { F } \\
\text { Age: }\end{array}$ & $\begin{array}{l}48 \\
49.1\end{array}$ & $F$ & L & $Y$ & SECONDARY & STROKE & $L$ & 3 yrs & 4 & 4 \\
\hline
\end{tabular}


TABLE 3.4. CONTROL DATA

FANILIAL

CONTROLS LG AGE SEX HANDEDNESS SIMISTRALITY EDUCATION
DIGIT SPAM DIGIT SPAN

ORAL POINTING

$\begin{array}{lll}\text { POST-SECONDARY } & 7 & 6 \\ \text { POST-SECONDARY } & 7 & 6 \\ \text { ELEMEMTARY } & 5 & 5 \\ \text { POST-SECONDARY } & 6 & 5 \\ \text { ELEMEMTARY } & 5 & 5 \\ \text { POST-SECONDARY } & 7 & 8 \\ \text { SECONDARY } & 7 & 7 \\ \text { POST-SECONDARY } & 7 & 6 \\ \text { POST-SECOMDARY } & 7 & 7 \\ \text { SECONDARY } & 7 & 7\end{array}$




\subsection{Procedural Methods}

Two memory tests were given to the subject, one a digit span (I.e., correct recall of an ordered list of numbers); the other a pretest evaluating the ability to identify the animals. The sentences themselves were pseudo-randomized so that no more than two sentences of the same type followed each other

Sentences were presented auditorly and a subject's comprehension was evaluated by an object manipulation paradigm. In many ways, this paradigm is superior to a sentencepicture matching task, as possible responses are not predetermıned and/or constrained by the examiner. In the case of causatives, it would be virtually impossible to picture what the Causer has done to make the Causee perform the action of the embedded verb. Much inferencing would also have to be done by the test subjects to correctly interpret the image. For the OMBs, toy animals were used. They were maintained in a constant array (space permitting) in front of the tester. The animals specifically mentioned in the sentence being tested or which had to be provided for the truncated structures were advanced and placed in close proximity to the patient. Since the use of each animal's name is balanced across positions in the sentence, an order of presentation interpretive strategy cannot confound the results. To demonstrate a correct response, a subject had to act out all verbs including the causatives. Thus, the causative and the direct object control verbs had to be demonstrated in a similar manner; all other verbs were clear action predicates (with the exception of the copula, which cannot be demonstrated).

'Acting out' is defined as clearly demonstratıng to the tester 'who' performed the action and 'to whom' the action was done, if this is applicable.

In order to compare the Causative OMB with the regular OMB, the same method for presenting the animals to the patient was utilized, i.e. moving only those animals mentioned toward the patient before reading the sentence. 
However, a particular strategy was necessary for Truncated Passive and Truncated Causative: the anımal mentioned along with one of the other five was presented to the patient. This permitted the patients to respond correctly by.

1. having this unnamed but pragmatically likely animal do some action to the 'mentıoned' anımal.

2. choosing one of the other four anımals in the row directly in front of the tester as the agent (less appropriate but one patient did do this).

3. ignoring this 'possible' distractor and simply mentıonıng the fact that 'somebody' did the action to the correct animal.

They could also answer incorrectly by choosing the anımal mentioned as the subject and agent of an 'active' sentence, doing the action mentioned

a. to the other 'presented' animal;

b. to itself (alternatively, they could interpret the verb intransitively);

c. to one of the other animals in the unpresented array;

d. to some unspecified 'Theme'.

Given the particular nature of the pronoun OMB-- i.e. the non-reflexive pronouns do not uniquely refer to one specific anımal -- a strategy similar to the one described above was used.

The test subjects were therefore presented with:

3 animals ( 3 mentioned) for:

[35 Causative-Reflexive Causer=Goal]

[41 Subject-Object Relative with Stylistic Inversion]

[42 Object-Object Relative with Stylistic Inversion]

3 arimals ( 2 mentioned +1 non-distractor) for:

[29 Dative-Theme cliticized]

[30 Dative-Goal cliticized] 
[31 Causative-Theme cliticızed]

[32 Causative-Causee cliticized]

[36 Causative-Reflexive Causer=Goal, Truncated]

3 anirnals ( 2 mentıoned +1 distractor - always a male anımal) (contrast se/le)

[33 Causative-Reflexive Causer=Theme]

3 animals ( 1 mentioned +1 target with proper gender

+1 distractor with opposite gender)

(contrast le/la)

[37 Causative-Theme cliticlzed, Truncated]

[39 Causative-Theme=Causee clitıcized, Intransıtive Verb]

2 animals ( 2 mentioned)

[34 Causative-Reflexive Causee]

[40 Cleft-Object with Stylistic Inversion]

2 animals ( 1 mentioned +1 distractor -- always a male anımal) (contrast se/le)

[38 Causative-Reflexive Causer $=$ Theme, Truncated]

\subsection{Scoring}

For the $O M B$ and the $C O M B$, each NP in the linear string was numbered sequentially from left to right; verbs were represented by commas and a change of clause was signalled by a semi-colon. Given a neutral canonical thematic role order of Agent-Theme(-Goal) (In each clause), by convention the first slot assigned is to the Agent and so on. Therefore, the 
following sentence would be treated as:

1

Le lapın a frappé

The correct response would be

\section{2}

la vache.

$$
1,2
$$

Agent , Theme

A sentence containing a causative would be scored as follows : 1
2 3

La chèvre a fait frapper la grenoulle par la vache.

the correct reponse to which would be $1,(3), 3,2$ ( the parentheses indicating that patients were permitted to make that portion of the response verbally). This would correctly indicate that la chèvre or the goat (the Causer) made la vache or the cow (the Causee) hit la grenoulle or the frog (the Theme). In addition, to be scored as correct ( 1 as opposed to 0 ), the subject must have understood the entire sentence. No partial scores were given. Determination of whether sentences containing two action verbs were correctly interpreted disregarded certain, often idıosyncratıc, response bıases which determined whether the main or embedded verbs were acted out first. ${ }^{16}$

A slightly different scoring procedure had to be utilized for the POMB than for the other OMBs, where only full NPs were numbered. In the POMB, the reflexive and nonreflexive pronouns and with the full NPs were numbered from left to right. " $X$ " was utilized for the animal designated in Truncated structures like Truncated Passive. 17, 18

16 This is the same scoring procedure adopted in the original OMB for clause reorderings. All correct responses are encoded for each sentence type in the subjects' Summary Score Sheets.

17 The three inverted structures are not affected; as they contain only full NPs, they maintain a consistent scoring method throughout.

18 In addition, if the reader consults the Summary score sheets in the Appendix he/she will see that for each response, we coded whether or not the test subjects utilized the animal 
In addition, those sentence types that required the patient to be sensitive to gende contrasts, I.e.

\section{Causative-Theme cliticized, Truncated \\ Causative-Theme $=$ Causee cliticized, Intransitive Verb}

were scored as correct as long as a non-reflexive response was given. As stated above, the tense of the verb had been changed to permit the contrast between, le and la; all seritences containıng la are ambiguous since the heavy use of the passe compose can lead the subject to re-segment the incoming string as l'a, especially since the third person singular present tense of faire is homophonous with the past participle half of all the sentences of these types have this ambiguity. This leaves only twelve with the clear and unambiguous le clitic pronoun; responses to it were idiosyncratic, though they tended to be consistent Recall that the gender contrasts are grammatical rather than natural, the anımals are perhaps presumed to be unspecified as to their natural gender (except for la vache) In addition, at least one patient and one control thought of la grenoulle as le cra?aud ('the toad') and one person referred to la chèvre as le bouc('the billy goat'). In addition, since some subjects never used the anımals whıch were provided, these contrasts were sımply not applicable. Therefore, as long as they did not interpret the pronouns as reflexives (the only unambiguous contrast le/se) and otherwise responded correctly, their answer was scored as correct.

\subsection{Data Analysis}

For the group study, analyses of variance were performed using both subjects and

\footnotetext{
which was presented to them. Therefore, additional information is provided, e.g. $2=P$ or $2 \# P, X=P$ or $X \# P$ (in dBase 111 Plus, in which the data was recorded, \# is equivalent to 'not equal to'); $P=$ Presented Animal. Please note that the pronoun, being in INFL, Is always ' 2 '. In the case of a Truncated structure, it was found that, except in three cases overall, elther both animals presented were utilized or neither was; this seems to reside purely in the respondent's individual style and was generally consistent across tests and paradigms. Portions enclosed by parentheses were sometimes conveyed to the tester verbally rather than acted out; however it was always clear what the subject was indicating as his/her response.
} 
sentence types as units 19 in order to establish that the variance was not due to chance. In addition, a post hoc comparison procedure was then applied to verify which of the units were significantly different from each other The test utilized in all cases was the Fisher PLSD (Protected Least Sıgnifıcant Dıfference) set at a 95\% confidence level. The PLSD is a protected t-test-- protected in that its results can be accepted with confidence when the overall ANOVA is significant (Olson 1987). This post hoc test was also chosen because it was the appropriate statistic to apply given the sample size.20 Other increasingly conservative procedures would increase the likelihood of a Type 2 error, i.e. accepting the null hypothesis when in fact it should be rejected. For the individual case studies, the same criteria were used as were used by Caplan and Hildebrandt (1988. 159-162) to establish non-random performance. Briefly, as explained therein, to calculate the appropriate $x^{2}$ value $^{21}$ that would determine whether our subjects' performances were only due to chance, assumptions as to what constitutes chance must be made. Two Stages are postulated:

Stage 1 assumptions presume that the subject is choosing at random from the array of objects in front of him/her in order to act out the sentence.

Stage 2 assumptions are more restrictive since it is assumed that the subject can recall the items mentioned and is choosing randomly from this subset of the items presented.

As is evident, most of the OMBs are usually calculated under Stage 2 assumptions, since

19 All statistical procedures were performed utilizing the program Statview $512+$ from Brainpower, Inc.

20 To mitigate a Type 1 error, i.e. rejecting the null hypothesis when it should be accepted, one overall ANOVA was performed per subject group as multiple ANOVAs cannot be performed on the same data. This was in fact the more conservative approach to take as it allowed fewer of the Fisher FLSDs computed to reach statistical significance than would have been the case with multiple ANOVAs.

$21 x^{2} s$ compare observed and expected distributions of values. These Stage assumptions hel, ; us calculate the number of logically possible responses and therefore estabilsh the expected value's, i.e. 12 Total possible correct responses $-N_{\text {possibiliues }}=$ Expected value. 
subjects in most cases (except for truncated structures and many of the sentence types in the POMB) are not presented with more objects than are actually mentioned in the sentence. Whenever possible, the most restrictive assumptions are utlized in order to avoid a Type 1 error, in other words, accept ing chance performances as non-random To further avoid any possibility of a Type 1 error (since this type of c'sect manipulation paradigm permits a larger number of logically possible responses than a sentence-picture matching task, an additional test was performed The test of the significance of the difference between two independent proportions (Ferguson and Takane 1989: pp. 198-200) is performed comparing the scores a subject obtains on two sentences types with the same number of verbs the same number of logically possible responses. We can then more confidently judge whether or not the difference in performance, if there is one, is significant. 


\section{Chapter 4- Group Studies}

\subsection{Test Results}

The fcllowing chapter presents the results of all the batteries with which the experımental subjects were tested We chose to highlight the results by grouping the sentence types into relevant 'Sentence Contrasts' Only the results for the appropriate aphasic group will be presented in each case The logic of this decision resides in the fact that, to achieve generalizability of the findings, the results of the total aphasic sample on the critical sent ence types must be reported. After all, what is of interest is establishing the determinants of sentence complexity in the aphasic population as a whole. 1 Since only five patients could be tested on the $P$ (ronoun) $O M B$, the means they obtained on sentences containıng pronominal forms and the means obtained by the total group of 9 on the full NP versions could not justifiably be contrasted. However, since the apilasic samples are not independerit, we expect to find sımilar results from the statistıcal analyses performed on the data. Finally, in order to characterize aphasic comprehension deficits with structurally complex material, we must compare the performance of normals on the same materials. The aphasics' response patterns can then be viewed more accurately.

'Sentence Contrasts 1 ' is the crucial one in that it examines the accuracy rates of aphasics in the receptive processing of the French causatives, which as we have seen, subcategorize for VP rather than IP (or CP) complements. As discussed in Chapter 3 , these sentence types permit us to test our hypothesis that structural complexity in general and the additional complexity entailed by the presence of functional projections in particular categories is a major determinant of processing complexity, with increased error rates being a direct consequence of the additional hierarchical structure.

To further our understanding of the processing of these constructions, sentences

1 It is precisely because we are aware that nine subjects constitute a small sample that any further attrition to the subset of five was avoided whenever possible. 
containing pronominal clitics are compared to equivalent full NP versions of causatives as well as sımple datives in 'Sentence Contrasts 2 ' Recall that this is also a direct test of the HAH since, although prenominal clitics are in an A-bai position (I.e in INFL. --a functional head), as heads and participants in the $H$-module, they increase the saliency of INFL and are thus predicted to be correctly attended to by aphasics. 'Scntence Contrasts 3' examines reflexives in these same constructions, the claım by Grimshaw (1990) and Rosen (1989) that Romance reflexive clitics are valency-changing morphemes rathei than anaphors is tested by comparing structures containing reflexives with passive structures. According to these theoretical analyses, both structures with reflexives and those with passives are considered to involve an operation on the external argument (satisfaction for the former and suppression for the latter), with consequent identical movement of the theme to Spec of IP in order to get Case

'Sentence Contrasts 4' further examınes the comprehension of syntactic structures by testing various baseline constructions and manipulating the presence of additional thematic roles by the use of three- vs. two- place predicates (Interacting with the algument vs a-adjunct distinction); by the use of coordination (specifically, conjoined structures such as NPs, VPs, IPs and (Ps), and by the use of predication, le by the addition of relative clauses. 'Sent.ence Contrasts 5 ' compares only those structures which contain wh-trace; these may on occasion involve Styfistic Inversion. These are predicted to be in general more difficult to process due to the obligatory presence of additional CP (and IP) nodes.

\subsection{1. 'Sentence Contrasts 1'}

\subsubsection{Total Aphasic Sample}

The first set of contrasts involves 108 sentences, twelve tokens of each of nine sentence types. Three of the types are from the OMB and six are from the COMB The types being compared are the monoclausal [06 Dative Passive] and the causatives as well as 
the biclausal two-IP passivized direct object control types (intransitive and transitive embedded verb versions) and the two-CP object relatives. The causatives include those with intransitive and transitive complement verbs as well as the two with the passivized complement verbs (truncated and non-truncated versions). Table 4.1.2. contains the results obtained by all the aphasics on these sentence types. The means (and their respective Standard Deviations) are presented in descending order of accuracy. The overall accuracy rate for this set was $5864 \%$. 2 Table 41.2 also encodes all the significantly different means as determined by the PLSDs computed with the overall ANOVA. (The overall ANOVA ${ }^{3}$ with repeated measures on the sentence type factor for all OMBs for the total aphasic sample revealed a significant effect of this factor on the number of correct responses: $F(27,216)=1334, p=.0001^{\star}$. Fisher's PLSD was applied at the experimenterwise error rate of 0.05 to determine which of the means were significantly different from each other. ${ }^{4}$ )

2 The overall accuracy rate of this group on all OMBs was $64.32 \%$.

3 This statistic will only be reported on once per subject group.

4 This information for all 28 sentences can be found in Appendix A. Those relevant to the 'Sentence Contrasts' will be reported on within the text. Recall, multiple ANOVAs cannot be performed on the same data. 
Table 4.1.1. Group Results - All 9 Aphasics 'Sentence Contrasts 1'

Sentence Type

[18] Causative + Intransitive Verb

[16] Passivized Direct Object Control, intransitive Verb

[06] Dative Passive

[22] Causative (Faire-par)

[17] Truncated Causative

[11] Object-Object Relative

[09] Subject-Object Relative

[21] Causative (Faire-à)

[20] Passivized Direct Object Control + Transitive Verb
Mean SD

$12000 \quad 0$

$8.000 \quad 4.000$

$7.444 \quad 4.640$

$7.444 \quad 4.531$

$7.000 \quad 4.272$

$6.556 \quad 4.503$

$5.222 \quad 4.522$

$5222 \quad 4.206$

$4.444 \quad 4.640$

Mean: $\quad 7.037$

$[18]$

[06]

[22] [17]
[11]
[09]

[21] [20]

(Sentence types underlined by a common line do not differ on the Fisher PLSD set at a $95 \%$ confidence level; sentences not underlined by a common line do differ significantly )

With regard to the crucial sentences, we note that $[06$ Dative Passive] does not contrast with either [ 16 Passivized Direct Object Control, Intransitive Verb] or [22 Causative (Faire-par)], which in turn do not contrast with each other [06 Dative Passive] and [22 Causative (Faire-par)] which have identical means, do not contrast significantly with [ 11 Object-Object Relative]. However, [06 Dative Passive] and [22 Causative (Faire-par) do contrast significantly with [09 SubjectObject Relative], [21 Causative (Faire-à)], and [20 Passivized Direct Object Control + Transitive Verb]. [21 Causative (Faire-à)] and [09 Subject-Object Relative], which also have identical means, as well as [ 11 Object-Object Relative] and [20 Passivized Direct Object Control + Transitive Verb], do not contrast with each other. 5

5 It may be noted that [21 Causative ( Faire-à )] does not contrast with any of the biclausal structures with the same number of NPs. However, this sentence was considered by many experimental subjects to be unacceptable in its present form (i.e. with all anımate NPs); therefore, scores were depressed (the normal controls show this more clearly). We do not take this to be evidence of parallel structures though; the partial merger account may still best 
Two further issues should be discussed concerning the results. First, the [18 Causative + Intransitive Verb] was correctly responded to $100 \%$ of the tirne; in other words, despite the fact that the second $V$ precedes its Agent, the structure is no more difficult than a simple Active. Given the adoption of a linear order strategy, it would be difficult to misinterpret this sentence type. The contrastive [17 Truncated Causative] had an accuracy rate of $58.33 \%$; this structure cannot be responded to by applying a linear order stategy since the Agent of the second verb has been suppressed, and no additional information is provided by this suppressed argument which licences an a-adjunct parphrase. Even by using the severest criterion ior determining chance performance, i.e. by considering the two verbs as one unit, patients only have a 1 in 6 chance of obtaining the correct response (If we consider them as two verbs, the odds increase proportionally that their interpretation is non-random). The fact that there is such a strong bias toward [ 18 Causative + Intransitive Verb] makes their performance on the truncated structure all the more remarkable. The means of the truncated and non-truncated versions are very similar--7/12 and $7.444 / 12$ respectively. The aphasics are obviously sensitive to the argument structure of the embedded verb. 6

The second observation we would like to make is that the difference in accuracy rates between the two passivized direct object control structures is due to the additional functional category in [20 Passivized Direct Object Control + Transitive Verb]. [16 Passivized Direct Object Control, Intransitive Verb] was the type on which the patients received their second highest score in this contrastive sentence set. Once they have computed that the initial NP is not the Agent of $V_{1}$ but the Agent of $V_{2}$, why should it be

account for the construction since the VP nature of the embedded argument may mitigate the full effects of the unacceptability.

6 Recall that another difference between the farre-à and farre-par constructions resides in the prior passivization of the embedded verb before argument structure merger with faire in the latter. 
so much more difficult to interpret the complement of $V_{2}$, which after all is in unmarked canonical order in relation to its theta-assigner? The answer must lie in the branching nature of the second VP, i.e. the necessity to compute the DP complement, which then in turn must s-select its semantic head--the NP This is the only difference between these two sentence types, an analysis which posits difficulties with chain formation cannot explain their good performance with the intransitive version nor can it fully account for the transitive version being the sentence type which occasıoned their worst performance (only $37 \%$ correct). Having seemingly exhausted their processing resources, they most often fall back on a linear order strategy (62/68 errors, i.e. $91.2 \%)$.

\subsubsection{Normal Controls}

Table 4.1.2. contains the results obtained by the normals on the 9 sentence types tested. The means (and their respective Standard Deviations) are presented in descending order of accuracy. The overall accuracy rate for these contrasts was $92.03 \%$. 7 Table 4.1.2. also encodes whether the means were significantly different. (Their overall ANOVA with repeated measures on the sentence type factor revealed a significant effect of this factor on the number of correct responses: $F(41,164)=6.579 ; p=.0001^{\star}$; see Appendix A for all the Fisher's PLSD ).

7 Their overall accuracy rate on all three batteries was $92.76 \%$. 
Table 4.1.2. Group Results - 10 Controls 'Sentence Contrasts 1'

Sentence Type

[18] Causative + Intransitive Verb

[22] Causative (Farre-par)

[11] Object-Object Relative

[16] Passivized Direct Object Control, Intransitive Verb

[17] Truncated Causative

[06] Jative Passive

[20] Passivized Direct Object Control + Transitive Verb

[09] Subject-Object Relative

[21] Causative (Faire-à)
Mean SD

12.0

11.7

11.3

11.3

11.3

11.0

10.8

10.2

9.8

0

.675

.675

1.059

.949

1.054

2.044

2.440

2.573

Mean: 11.044

[18]

[22]

[17]

[06]

[20]

[09]

[21]

(Sentence types underlined by a common line do not differ on the Fisher PLSD set at a 95\% confidence level; sentences not underlined by a common line do differ significantly.)

The pattern with the controls is somewhat different than with the aphasics. With regard to the critical sentence types, although [22 Causative (Faire-par)] stıll does not contrast with either [06 Dative Passive] or [16 Passivized Direct Object Control, Intransitive Verb], it no longer contrasts with [20 Passivized Direct Object Control + Transitive Verb] either. This is no doubt due to their near ceiling performance on seven of the sentence types, on which they scored $90 \%$ or more. Their lowest score was for [21 Causative (Faire-à)] at $81.7 \%$. This result must be explaned. The poorer performance on [21] can only be due to its unacceptability. For them, this sentence type contrasts with five of the others but not with 106 Dative Passive], [09 Subject-Object Relative] and [20 Passivized Direct Object Control + Transitive Verb]. [06] has a 3,1,2 response and both [09] and [20] have 2,$1 ; 1,3$ as correct responses. Controls had a tendency to treat the Causee as a sort of locational Goal when they made an error in interpretation. 
109.

An additional overall two-factor ANOVA was calculated for Category of Subject $x$ Sentence Type (repeated measures). 8 The categorization was two level--patient vs. control. This analysis yielded the following: there was a significant main effect for type of subject $F(1,17)=14.693 ; p=.0013^{\star}$; a significant main effect for sentence type $F(27,459)=17.444 ; p=.0001^{*}$; and finally a significart interaction of the two $F(27,459)=6.287 ; p=.0001^{*}$. A factorial analysis of varıance to see which sentence types differed significantly between the patients and the controls was performed. In general terms, the only sentence types which did not contrast between the two groups were the types in which a linear order strategy would lead to the correct response.

This factorial analysis as it pertains to the present set of contrasts can be found in Table 4 .1.3. All the sentence types differed significantly between subject groups except for [18 Causative + Intransitive Verb] on which no errors were made by either.

\section{Table 4.1.3. Significantly Different Sentence Types -- Patients $x$ Controls 'Sentence Contrasts 1 '}

Sentence Type

[17] Truncated Causative

[16] Passivized Direct Object Control, Intransitive Verb

[06] Dative Passive

[22] Causative (Faire-par)

[21] Causative (Faire-à)

[20] Passivized Direct Object Control + Transitive Verb

[11] Object-Object Relative

[09] Subject-Object Relative
Fisher's PLSD

$\begin{array}{ll}F(1,17)=9.662 ; p=.0064^{\star} & 2.919^{\star} \\ F(1,17)=6.350 ; p=.022^{\star} & 2.763^{\star} \\ F(1,17)=5.587 ; p=.0303^{\star} & 3.174^{\star} \\ F(1,17)=8.664 ; p=.0091^{\star} & 3.051^{\star} \\ F(1,17)=8.389 ; p=.01^{\star} & 3.335^{\star} \\ F(1,17)=15.502 ; p=.0011^{\star} & 3.406^{\star} \\ F(1,17)=10.898 ; p=.0042^{\star} & 3.032^{\star} \\ F(1,17)=9.188 ; p=.0075^{\star} & 3.465^{\star}\end{array}$

8 See footnote 2. 
Figure 4.1. Accuracy Rates Patıents vs Controls-'Sentence Contrasts 1'

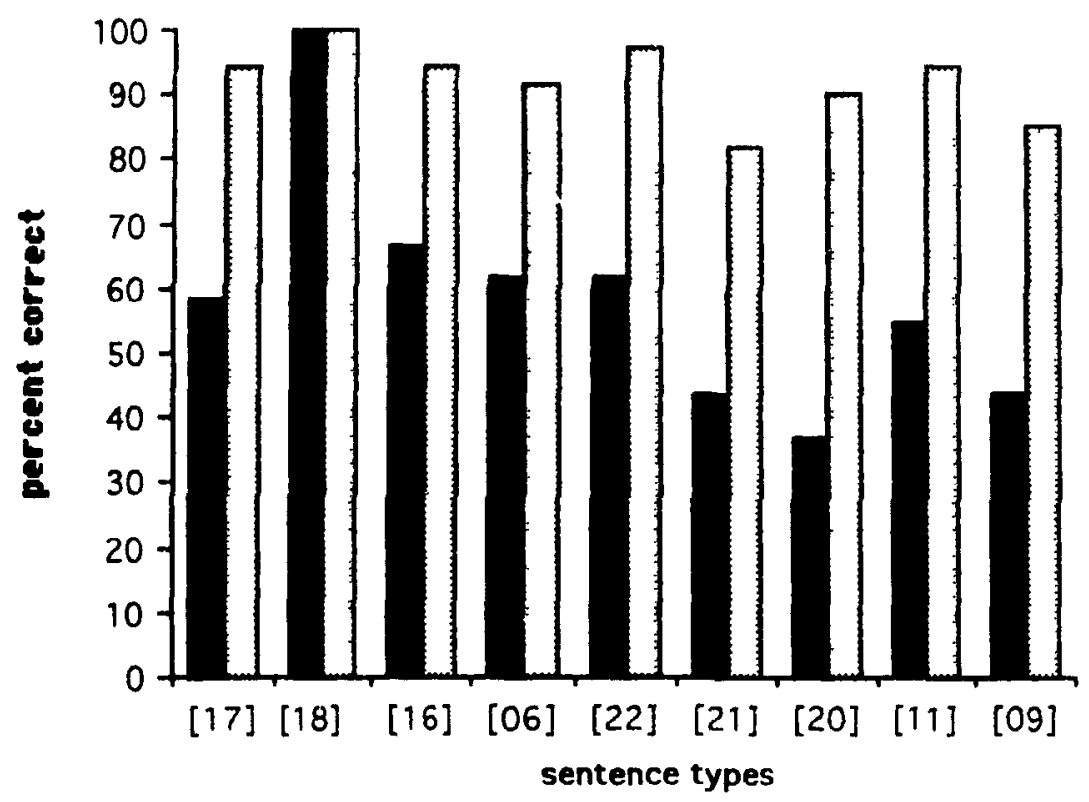

9 aphasıcs

10 controls

This set of contrasts has confirmed the prediction that a two-proposition (or one proposition + one event) structure where the event is syntactically realized as a VP such as [22 Causative (Faire-par)] is no more difficult to process than a single proposition which contains a dative verb such as [06 Datıve Passive]. We were not able to confirm this finding with [21 Causative (Faire-à)], but the control data allowed us to claim that the structure's unacceptability, rather than its complexity, accounted for the depressed scores. This same construction Faire-Inf is also instantiated in [18 Causative + Intransitive Verb] but the linear order strategy effectively obscures the role purely structural features play in sentence processing. To further our understanding of the processing of causatives, we will examine aphasics' performance on pronominal as well as full versions of these structures in 'Sentence Contrasts 2'. This will permit us to examıne sentence types in which the INFL contains more semantic information, in this case the semantic role of one of the arguments of the embedded verb (or more precisely, the merged verbs). 


\subsection{2. 'Sentence Contrasts 2'}

\subsection{1. Subset Aphasic Sample}

Table 4.2.1. contains the results obtained by the five aphasics on the 11 sentence types (132 sentences) highlighted in these contrasts. The means (and their respective Standard Deviations) are presented in descending order of accuracy. The overall accuracy rate was $69.54 \%$. 9 The table also encodes all the significantly different means established by their overall ANOVA. An ANOVA with repeated measures on the sentence type factor revealed a significant effect of this factor on the number of correct responses:

$F(41,164)=6.579 ; p=.0001^{*}$. Fisher's PLSD was applied at the experımenterwise errot rate of 0.05 to determine which of the means were significantly different from each other (see Appendix A for all the contrastive means).

Table 4.2.1. Group Results - 5 Aphasics 'Sentence Contrasts 2'

Sentence Type

[18] Causative + Intransitive Verb

[05] Dative

[29] Dative-Theme cliticized

[39] Causative-Theme=Causee cliticized, Intransitive Verb

[22] Causative (Faire-par)

[32] Causative-Causee cliticized

[30] Dative-Goal cliticized

[31] Causative-Theme cliticized

[37] Causative-Theme clitıcized, Truncated

[17] Truncated Causative

[21] Causative (Faire-à)
Mean

12.0

11.8

9.2

9.2

8.6

8.0

7.8

6.8

6.8

6.6

5.0

8.345

Mean:

[31]
$[32]$

[30]

SD

0 447

5.167

5.215

3.362

4.950

4.494

5.020

4.868

4.615

3.808

[18] [05] [39]

[22]

[17]

[21]

(Sentences types underlined by a common line do not differ on the Fisher PLSD; sentences not underlined by a common line do differ significantly, $p=.05^{\star}$.)

9 However, their overall accuracy rate on all three batteries was $62.96 \%$. 
We note that [18 Causative + Intransitive Verb] does not contrast with the pronominal versıon [39 Causative-Theme=Causee clitıcızed, Intransitive Verb] Neither of them contrasts with either [05 Dative] nor with its clitic version [29 DativeTheme cliticized]. With the exception of [18 Causative + Intransitive Verb], none of the above sontrasts with [22 Causative (Faire-par)]. Only the latter cannot be guessed at by applying a linear order strategy. The reader may have observed that, although the differences were not significant, the clitic versions [39] and [29] (which have Identical means) are lower in accuracy than the full NP types [18] and [05] respectively. This depression of the scores is due mainly to one patient (P.R.), who responded significantly below chance on every clitic and truncated structure tested $(=0 \%)$. Without his scores, the group's results on all the clitic versıons are much better:

[29] Dative-Theme cliticized

[39] Causative-Theme=Causee cliticized, Intransitive Verb

[32] Causative-Causee cliticized

[30] Dative-Goal clitıcızed

[31] Causative-Theme cliticized

[37] Causative-Theme cliticized, Truncated
$95.8 \%$ correct

$95.8 \%$ correct

$83.0 \%$ correct

$81.3 \%$ correct

$70.8 \%$ correct

$70.8 \%$ correct

These sentence types were quite well interpreted despite the indeterminacy of the reference (the minimum average score was $8.5 / 12$ ).

To return to the analysis of the group of five, sentence type [ 22 Causative (Faire-par)] and its truncated version [17] do not contrast with their clitic counterparts [31 Causative-Theme cliticized] and [37 Causative-Theme cliticized, Truncated] (which have identical means). In fact none of the types 
containing clitic pronouns contrasted with each other. [32 Causative-Causee

cliticized], the clitic version of [21 Causative (Faire-à)] did not contrast with the latter despite the anımacy problem nor did it contrast with [22 Causative (fairepar)]. The clitic versions of [22] (truncated or not, [31] and [37]) in turn did not contrast with [21 Causative (Faire-à)] though [22] itself did contrast with [21], as was the case with the aphasic sample as a whole.

The performance on [30 Dative-Goal cliticized] is somewhat depressed and it contrasts with [05 Dative] (though it does not contrast with [21 Causative (Fairea)]). As we can see above, without P.R.' s scores, [30] and [05] would probably not contrast; however, we would still like to explain why [30] is more difficult to process than [29 Dative-Theme cliticized]. The obvious reason is that linear order strategies cannot work here, since the Goal precedes the Theme. Another possible reason may be due to dialectal influences; the sentence type might be percelved as:

1

(1) Le singe. lui (1) a donné le lapın....

'The monkey, he's the one that gave the rabbit....'

I.e. with a emphatic subject and an unmentioned goal. In fact $52.4 \%$ of the aphasics' errors were of this type compared to $28.6 \%$ attributable to a linear order response.

\subsubsection{Normal Controls}

Table 4.2.2. contains the results obtained by the controls on these 11 sentence types. The means (and their respective Standard Deviations) are presented in descending order of accuracy. The overall accuracy rate was $96.52 \%$. Table 4.2.2. also encodes all the significantly different means. 
Table 4.2.2. Group Results - 10 Controls 'Sentence Contrasts 2'

Sentence Type

[05] Dative

[18] Causative + Intransitive Verb

[39] Causative-Theme=Causee cliticized, Intransitive Verb

[29] Dative-Theme cliticized

[30] Dative-Goal cliticized

[22] Causative (Faire-par)

[31] Causative-Theme cliticized

[32] Causative-Causee cliticized

[37] Causative-Theme cliticized, Truncated

[17] Truncated Causative

[21] Causative (Faire-à)
Mean SD

12.0

12.0

12.0

11.9

11.9

11.7

11.7

11.7

11.4

11.3

9.8

Mean: $\quad 11.582$

[05] [29] [22]

$[18][30] \quad[31]$

[39] [32]

[37] [17] [21]

(Sentences types underlined by a common line do not differ on the Fisher PLSD; sentences not underlined by a common line do differ significantly, $p=.05^{*}$.)

For the controls, no sentence type contrasted except for the [21 Causative (Faire-à)], which contrasted with all the others. This is due to its equivocal status, as was previously discussed. In almost all instances full NP and clitic versions of the sentence types had identıcal means. Performance on all but [21] was $94.2 \%$ or better.

An additional two-factor ANOVA was calculated for Category of Subject $\times$ Sentence Type (repeated measures). The categorization was two-level--patients (5) vs. controls (10). This analysis yielded the following results: there was a significant main effect for type of subject $F(1,13)=17.223 ; p-.0011^{*} ;$ a significant main effect for sentence type $F(41,533)=10.475 ; p=.0001^{*}$; and finally a sigr.lficant interaction of the two $F(41,533)=4.418 ; p=.0001^{\star}$. A factorial analysis of variance to see which sentence types differed significantly between the patients and the controls was performed. This information can be found in Table 4.2.3. Seven of the sentence types differed significantly between subject groups, the exceptions were [05 Dative] and [29 Dative-Theme cliticized], and [18 Causative + Intransitive Verb] and [39 Causative- 
Theme=Causee cliticized, Intransitive Verb] .

Table 4.2.3. Significantly Different Sentence Types Patients $x$ Controls 'Sentence Contrasts 2 '

Sentence Type

[30] Dative-Goal cliticized

[22] Causative (Faire-par)

[31] Causative-Theme cliticized

[21] Causative (Faire-à)

[32] Causative-Causee cliticized

[17] Truncated Causative

[37] Causative-Theme cliticized, Truncated
Fisher's PLSD

$$
\begin{array}{ll}
F(1,13)=8.916 ; p=.0105^{\star} & 2.957^{\star} \\
F(1,13)=8.447 ; p=.0123^{\star} & 2.355^{\star} \\
F(1,13)=10.111, p=.0072^{\star} & 3 .^{2} 29^{\star} \\
F(1,13)=8.49 ; p=.0121^{\star} & 3.559^{\star} \\
F(1,13)=5.81 ; p=.0315^{\star} & 3.316^{\star} \\
F(1,13)=10.26 ; p=.0069^{\star} & 3.170^{\star} \\
F(1,13)=8716 ; p=.0112^{\star} & 3.366^{\star}
\end{array}
$$

Figure 4.2. Accuracy Rates Patients vs Controls-'Sentence Contrasts 2'

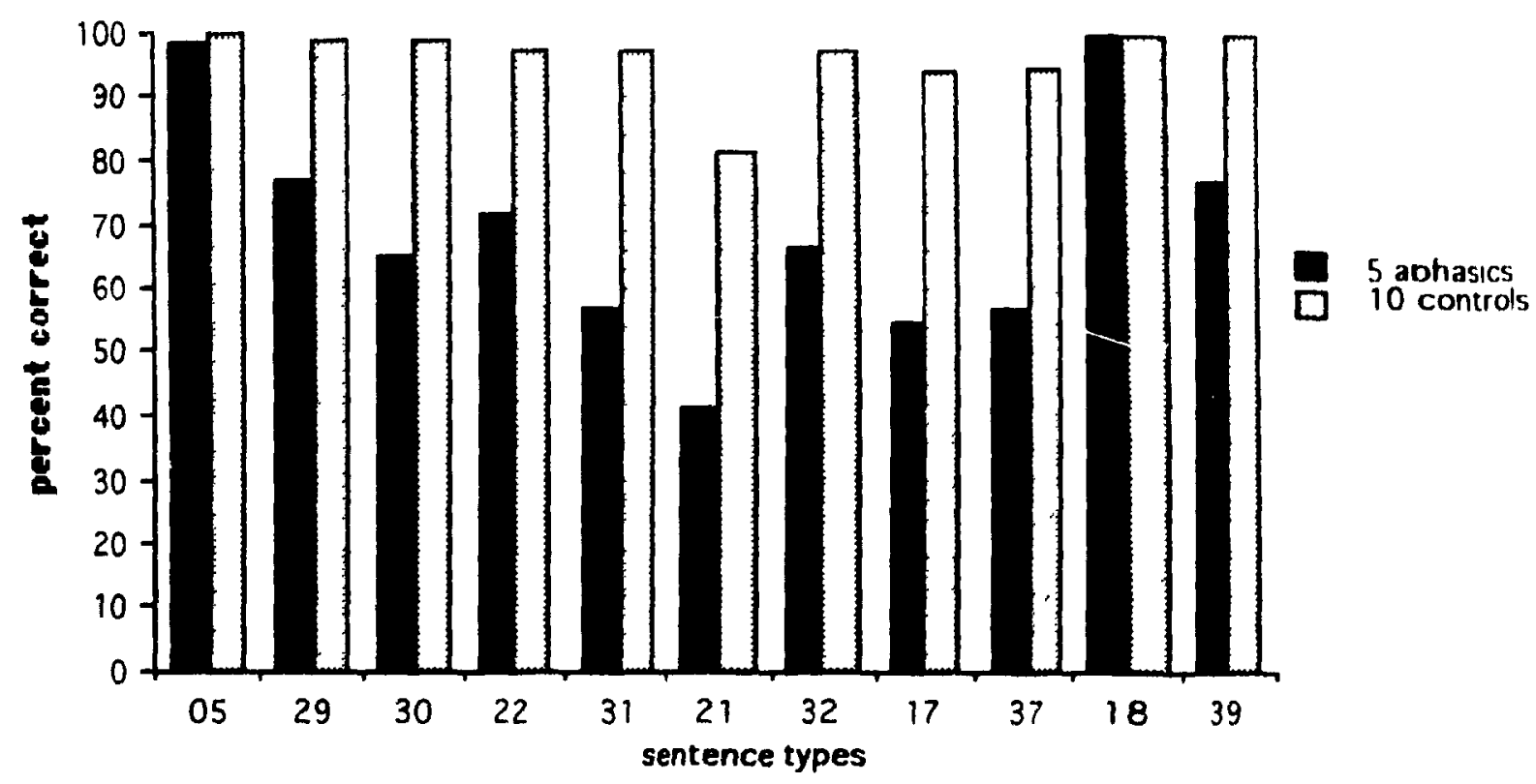

Our predictions, based on the HAH, concerning the accessibility for purposes of interpretation of an INFL signalled by a clitic chain were supported. For both the subject populations, such structures patterned with the full NP versions. The experimental subjects also demonstrated their ability to understand the grammatical clitıcized version of the problematic faire-à, thus clearly showing that their poor performance on [21] is due 
to another factor, l.e. the structure's unacceptability rather than due to the presence of additional $\mathrm{CP}$ and IP nodes.

We wanted to further examine the processing of causatives by including structures containing reflexive clitıcs. 'Sentence Contrasts 3' below describes the results we obtained.

\subsection{3. 'Sentence Contrasts 3'}

\subsubsection{Subset Aphasic Sample}

This series of contrasts consists of 96 sentences, twelve tokens of each of eight sentence types. Table 4.3.1. contains the results obtained by the five, aphasıcs. The means (and their respective Standard Deviations) are presented in descending order of accuracy. The overall accuracy rate for this group of sentences was $71.3 \%$.

\section{Table 4.3.1. Group Results - 5 Aphasics 'Sentence Contrasts 3'}

\section{Sentence Type}

[02] Passive

[33] Causative-Reflexive Causer $=$ Theme

[03] Truncated Passive

[38] Causative-Reflexive Causer $=$ Theme, Truncated

[06] Dative Passive

[36] Causative-Reflexive Causer=Goal, Truncated

[35] Causative-Reflexive Causer $=\mathrm{Goal}$

[34] Causative-Reflexive Causee
Mean $\quad$ SD

$\begin{array}{rr}10.6 & 2.074 \\ 10.4 & 2.510 \\ 9.6 & 5.367 \\ 9.4 & 5.273 \\ 9.0 & 2.345 \\ 8.4 & 4.980 \\ 7.8 & 4.764 \\ 3.2 & 4.604\end{array}$

Mean: 8.55

$[02] \quad[33] \quad[03] \quad[38] \quad[06] \quad[36] \quad[35]$

(Sentence types underlined by a common line do not differ on the Fisher PLSD set at a $95 \%$ confidence level; sentences not underlined by a common line do differ significantly.)

As predicted, none of the sentence types were significantly different from each other except for [34 Causative-Reflexive Causee], which contrasted with all other sentence types. Without the inclusion of that sentence type, no sentence type would have scored less than 
$65 \%$ correct. P.R., who is relatively good on passivized structures, still does not respond to reflexive clitics. Of the subset of patients tested on these sentence lypes, he is the only one who seemed not to understand the full NP causative constructions, 10 in his case, there are probably many interacting sentential variables which are causing the dificulty in processing. The patients' mean scores for passivized structures were almost identical to those for the equivalent se-faire constructions (e.g. [02] and [33], [0.3] and [38]), leading us to accept Rosen's account that there is a similar movement operation which necessitates the creation of a chain. Analyses that view the se as linked to a base-generated agent that is itself linked to a detransitized verb (e.g Grimshaw 1982 and Wehrli 1986) would have predicted better performances on se-fare than on passives

\subsubsection{Normal Controls}

Table 4.3.2. contains the results obtained by the controls on these same eight sentence types. The means (and their respective Standard Deviations) are presented in descending order of accuracy. The overall accuracy rate was $96.3 \%$. Table 4.3 .2 . also includes all the statistically significantly different means.

10 With the exception of [18 Causative + intransitive Verb]. 
Table 4.3.2. Group Results - 10 Controls 'Sentence Contrasts 3'

Sentence Type

[03] Truncated Passive

[38] Causative-Reflexive Causer $=$ Theme, Truncated

[02] Passive

[33] Causative-Reflexive Causer=Theme

[36] Causative-Reflexive Cause $r=$ Goal, Truncated

[35] Causative-Reflexive Causer $=$ Goal

[06] Dative Passive

[34] Causative-Reflexive Causee
Mean

$$
12.0
$$

12.0

11.8

11.8

118

11.6

11.0

10.4

Mean: $\quad 11.55$
SD

0

0

.422

.422

.422

.516

1.054

3.688

[02]

[03] [33]

$[38][36] \quad[35] \quad[06] \quad[34]$

(Sentence types underlined by a common line do not differ on the Fisher PLSD set at a 95\% confidence level; sentences not underined by a common line do differ significantly.)

It would appear that the controls show the same pattern as the patients. Without the presence of [34 Causative-Reflexive Causee], no sentence types would contrast. However, unlike the aphasics, for the controls, who as a group never score less than $87 \%$ correct, [34] does not contrast with either [35 Causative-Reflexive Causer=Goal] or [06 Dative Passive]. Without the inclusion of [34], no sentence type would have scored less than $91.7 \%$ correct. Controls were vocal in their dislike of [34]. 0.F. systematically 'repaired' the structure by clitic climbing the reflexive and attaching it to the matrix verb (thereby producing [33]); he therefore misinterpreted the structure. In most cases, the controls scored identically on passivized and reflexivized structures. 
Figure 4.3. Accuracy Rates Patients vs Controls-'Sentence Contrasts 3'

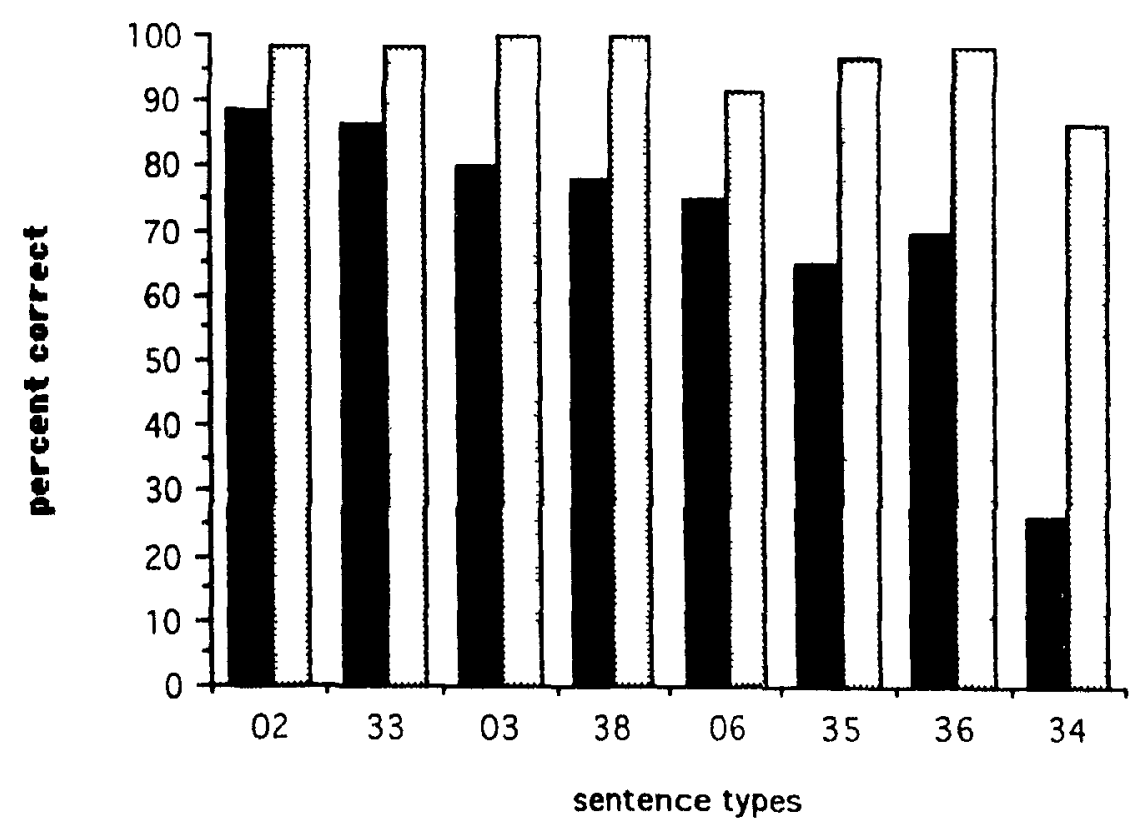

5 aphasics

10 controls

A factorial analysis of variance to see which sentence tvpes differed significantly between the patients and the controls was performed. This information can be found in Table 4.3.3.

Table 4.3.3. Significantly Different Sentence Types - Patients x Controls "Sentence Contrasts 3"

Sentence Type

[06] Dative Passive

[35] Causative-Reflexive Causer=Goal

[36] Causative-Reflexive Causer $=$ Goal, Truncated

[34] Causative-Reflexive Causee
Fisher's PLSD

$$
\begin{array}{ll}
F(1,13)=5.417 ; p=.0367^{\star} & 1.857^{\star} \\
F(1,13)=6.714 ; p=.0224^{\star} & 3.169^{\star} \\
F(1,13)=4.97 ; p=.0441^{\star} & 3.295^{\star} \\
F(1,13)=10.842 ; p=.0058^{\star} & 4.725^{\star}
\end{array}
$$

Only half of the sentence types differed significantly between subject groups. Types [02 Passive], [33 Causative-Reflexive Causer=Theme], [03 Truncated Passive], and [38 Causative-Reflexive Causer=Theme, Truncated] do not contrast.

Those sentences that contrast between subject groups are clearly those with the greater hierarchical structure, that is, those which have Goal arguments in addition to 
Themes (and the unacceptable [34]). Our prediction that the argument structure of the head, in this case the verb, determines success rates is supported. We will further explore the nature of processing costs of various structures within the same paradigm in 'Sentence Contrasts $4^{\prime}$. However, at this tıme, with regard to the results of the present set of contrasts, we may say that, although displaced elements were present in the structures tested, the lack of Spec position in the VP may account for the mitıgation of the cost of computing a non-transparent structure, with transparency being equated with phrases occupying base-generated positions (we are abstracting away from verb movement to INFL). Rosen's theoretical analysis is also supported by the empirical facts. The controls had identical means for [03] and [38] and [02] and [33]. In fact, these four sentence types did not contrast between the subject groups.

In 'Sentencf. Contrasts 3', aphasıcs obtained their highest overall mean score for a subset of the OMB paradigm and this despite the ungrammatical [34 CausativeRef'exive Causee]; without this sentence type, they would have scored $77.7 \%$ correct rather than than $71.3 \%$. Their next best overall subset mean score was in 'Sentence Contrasts 2', which tested the pronominal clitics and their interaction with causatives. The prediction that semantically more 'weighty' elements in INFL would be understood and that the sentence would be properly parsed was borne out for both types of clitıcs.

\subsection{4. 'Sentence Contrasts 4'}

\subsubsection{Obligatory vs. Optional Structural Elements}

In this set, it was decided that various structures must be tested that would contrast the optional versus obligatory presence of structure. The only obligatory elements are those which are the arguments of some predicate. All other relations are essentially optional. specifically a-adjuncts such as par-phrases, conjoined NPs (though the presence of at least one is necessary if subcategorized for), VPS, IPS and CPs, as well as clefted or relativized structures which are related to their head nouns through predication. We also 
wanted to examıne these sentence types in this light since linear order strategies so often obscure the effects of increasing sentential complexity in comprehension tasks. Witness our results for this variable computed on the OMB and the COMB in Fig. 4.4 : 11

Fig 4.4. Effect of Linear Order on Subjects' Accuracy Rates

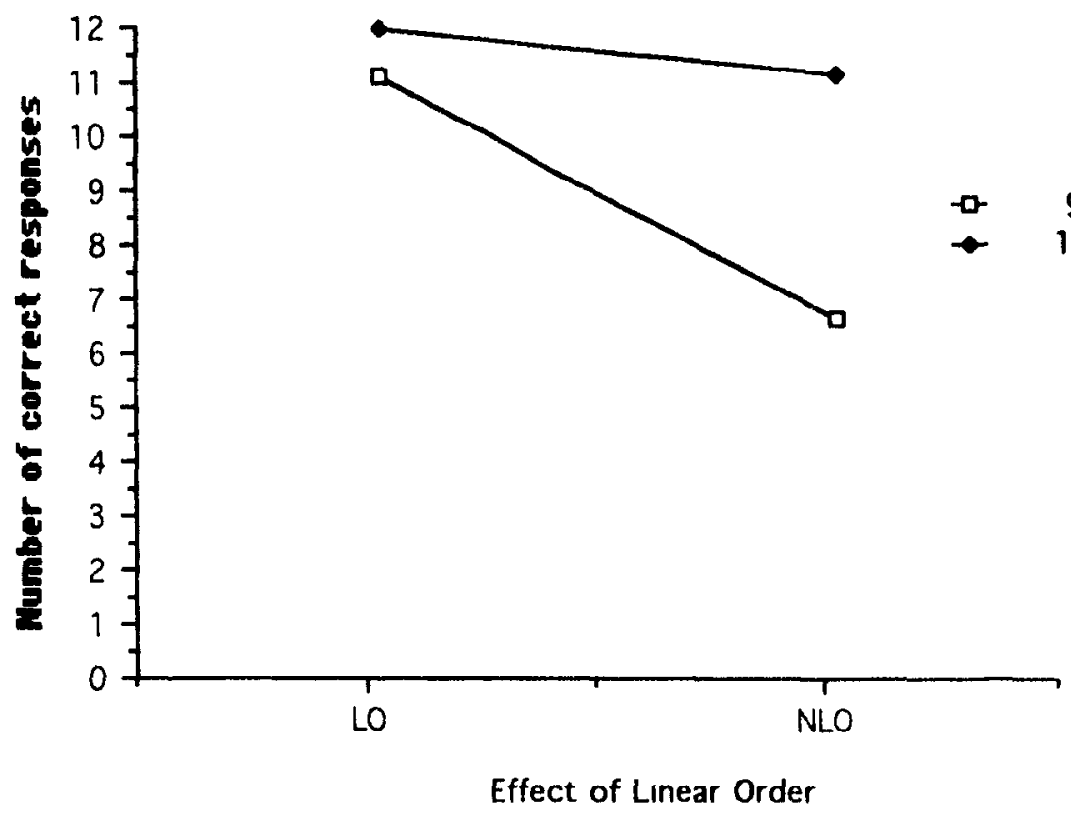

Only by carefully controlling the structural features of sentences which do nct permit the application of a linear order stategy can we truly see precisely what leads to processing breakdown in the aphasic population.

\subsubsection{Total Aphasic Sample}

Table 4.4.1. contains the results obtained by all 9 aphasics on the 20 sentence types which we contrast in this set. The means (and their respective Standard Deviations) are presented in descending order of accuracy. The overall accuracy rate was $63.8 \%$. Table 4.4.1. also encodes all the significantly different means. Appendix A.

11 For the effects of the other sentential variables presented in Table 3.1.3., see 
Table 4.4.1. Group Results .. All 9 A.phasics 'Sentence Contrasts 4'12

Sentence Type

[01] Active

[15] Direct Object Control, Intransitive Verb

[19] Direct Object Control + Transitive Verb

[13] Active Conjoined Theme

[05] Dative

[02] Passive

[14] Passive Conjoined Agent

[04] Cleft Object

[08] Conjained

[06] Dative Passive

[22] Causative (Faire-par)

[28] Conjoned Clauses 4 NPs (No Deletion) (Baselıne)

[12] Subject-Subject Relative

[27] SS Relative + Conjoined Theme

[07] Cleft-Object Dative

[21] Causative (Faire-à)

[24] Conjoined Causative

[25] Causative + Dative

[26] Causative + SS Relative

[23] Cleft-Object Causative (Farre-par)
Mean SD

$12.000 \quad 0$

11.667

11.667

11.222

11.111

9.889

8.556

8.444

8.000

7.444

7.444

7.444

7.000

7.000

6.333

5.222

3.778

3.778

2.889

2.333 .500

1.641

1.965

2.759

3.712

2.963

3.742

4.640

4.531

3.909

4.610

4.093

3.937

4.206

4.658

4.086

3.333

3.500

Mean: $\quad 7.661$

[06]

[22]

[15]

\begin{tabular}{|c|c|c|c|c|}
\hline [01] & [19] & [13] & [05] & [02] \\
\hline
\end{tabular}

[28]

[12]

[24]

[27] [07] [21] [25] [26][23]

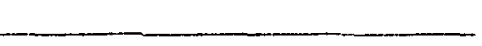

- -1.

(Sentence types underlined by a common line do not differ on the Fisher PLSD set at a 95\% confidence level; sentences not underlined by a common line do differ significantly.)

12 Since our total aphasic sample was small, an attempt was made to see if the overall results were comparable to those obtained by Caplan and Hildebrandt (1988) in their Experiment 3, which tested 49 French-speaking aphasics on nine sentence types of the OMB. In order to compare the present results with this larger sample, equivalent computations were made and confirmed the generalizability of the present results. The interested reader is referred to Appendix $A$ for this analysis. The main difference was the good performance of our subjects on Object-Subject Relative, though this may also be seen as a function of their overreliance on linear order stategies. For more on this aspect of their performance, the reader is directed to Appendix A where a complete tabulation of the total errors made by the aphasics and the controls is presented. For individuals' errors, the reader is directed to the appropriate summary score sheets in Appendix B. 
In terms of relevant statistically significant contrasts, we notice again that those structures which permit a linear order response do not contrast with each other so we cannot determine what structural relations constitute locı of difficulty. Nor do they contrast with [02 Passive]; it would appear that the base-generated nature of the more hierarchıcally complex structures is roughly equivalent to the sımpler passive, which has the added complication of movement, encoded in the NP-chain lınking the theme-subject with its trace in the VP. (Note that each of the sentences [01],[15], [19], [13], [05] and [02] contains only one inflected verb.) ${ }^{13}$

[02 Passive], though it contrasts significantly with [ 06 Dative Passive], does not contrast with its conjoined counterpart [14 Passive Conjoined Agent]. Both [02] and [14] in turn do not contrast significantly with [04 Cleft Object]; note, however, that this structure, with its two inflected verbs and two CPs, is less accurately responded to than monoclausal sentence types (due to the 1 in 2 chance of responding correctly to 104 Cleft Object], this difference is not large). In turn, these types do not contrast with [08 Conjoined]; this sentence contains two IPs, two inflected verbs and three DPs. However, it is base-generated and it seems that conjoined structures, in and of themselves, do not significantly add to processing costs; it is necessary to look at all the variables which may play a part.

The next grouping of sentence types includes those having at least three or four DPS (with the exception of [04 Cleft Object]). [08 Conjoined] and [12 Subject-Subject Relative] do not contrast with each other, nor do they contrast with [28 Conjoined Clauses 4 NPs (No Deletion) (Baseline)] or [27 SS Relative + Conjoined Theme]. In fact, [12] and [27] have identical means. In addition, they do not contrast with [06 Dative Passive] and [22 Causative (Faire-par)]. The latter, however, do not permit either a linear order or, in the case of [22], a parallel function strategy. 
Relativized and clefted structures contaıning at least three DPs do not contrast with [21 Causative (Faire-à)]. ([04 Cleft Object] does contrast with [21] though not with its dative counterpart, [07 Cleft-Object Dative]. However, the reasons for the low scores for [21] have been discussed elsewhere. The latter structure does not contrast with either [24 Conjoined Causative] or [25 Causative + Dative], which have identical means. In this case, the conjoining of the two embedded VPs seems to be equivalent in difficulty to the processing of a dative embedded verb.

The last group of sentences is comprised of four-DP sentences with the exception of [23 Cleft-Object Causative (Faire-par)] which proved to be the most difficult type to process. This type contrasts with [07 Cleft-Object Datıve]. We feel that the theme in sentence-initial position seems to violate the strong coalition (discussed in Grimshaw 1990) between the thematic and aspectual arrays which identify the Causer as the most prominent argument; the Causer's position as subject of the embedded sentence is not as salient. We find some confirmation in this in that the most frequent error type for normals $(16 / 29)$ and the second most frequent type for the aphasics in general $(27 / 87)$ was to interpret this as if it were a regular faire-par $(1,3 ; 3,2) .14$

\subsubsection{Normal Controls}

Table 4.4.2. contains the results obtained by the controls on these 20 sentence types. The means (and their respective Standard Deviations) are presented in descending order of accuracy. The overall accuracy rate was $92.8 \%$ and no sentence type was less than 70.8\% correct. Table 4.4.2. also encodes all the significantly different means.

14 The least imparred aphasics most frequently made this mistake. 
Table 4.4.2. Group Results - 10 Controls 'Sentence Contrasts 4"

Sentence Type

[01] Active

[13] Active Conjoined Theme

[05] Dative

[15] Direct Object Control, Intransitive Verb

[04] Cleft Object

[08] Conjoned

[02] Passive

[14] Passive Conjoned Agent

[19] Direct Object Control + Transitive Verb

[22] Causative (Faire-par)

[27] SS Relative + Conjoined Theme

[28] Conjoned Clauses 4 NPs (No Deletion) (Baseline)

[06] Dative Passive

[12] Subject-Subject Relative

[07] Cleft-Object Dative

[25] Causative + Dative

[24] Conjoned Causative

[21] Causative (Faire-à)

[23] Cleft-Object Causative (Farre-par)

[26] Causative + SS Relative
Mean

12.0

12.0

12.0

12.0

11.9

11.9

11.8

11.8

11.8

11.7

11.5

11.2

11.0

10.8

10.7

10.6

10.5

9.8

9.1

8.5

SD

0

0

0

0

Mean: 11.13

(Sentence types underlined by a common line do not differ on the Fisher PLSD set at a 95\% confidence level; sentences not underlined by a common line do differ significantly.)

Due to the controls' good performance on most of the sentence types, fifteen of the types do not contrast at all, contrasts beginning with [25 Causative +Dative]. The controls did better on this sentence type than on the unacceptable [21 Causative (Fairea)], [23 Cleft-Object Causative (Faire-par)] and [26 Causative + SS

Relative]. These three sentence types were not significantly different from each other.

Both [23] and [26] contain more functional categories (CPs and IPs) than [25]. The latter 
in fact does not differ significantly from either [06 Dative Passive] or [22 Causative (Faire-par)]. The controls' performance did not significantly differ on the conjoined version of [12], [27]. The sentence types which were most difficult for the aphasics were also the most difficult for the controls, although the order of accuracy of [23] and [26] is reversed.

A factorial analysis of variance to see which sentence types differed significantly between the patients and the controls was performed. This information can be found in Tables 4.4 .3 and $b$.

Table 4.4.3. a Significantly Different Sentence Types - Patients $\times$ Controls 'Sentence Contrasts 4'

Sentence Type

[02] Passive

[14] Passive Conjoined Agent

[04] Cleft Object

[07] Cleft-Object Dative

[23] Cleft-Object Causative (Faire-par)

[06] Dative Passive
Fisher's PLSD

$\begin{array}{lll}F(1,17)=4.707 ; p=.0445^{\star} & 1.859^{\star} \\ F(1,17)=7.58^{\star} ; p=.0136^{\star} & 2.486^{\star} \\ F(1,17)=13.52 ; p=.0019^{\star} & 1.983^{\star} \\ F(1,17)=9.836 ; p=.006^{\star} & 2.938^{\star} \\ F(1,17)=16.108 ; p=.0009^{\star} & 3.558^{\star} \\ F(1,17)=5.587 ; p=.0303^{\star} & 3.174^{\star}\end{array}$

Figure 4.5a Accuracy Rates Patients vs Controls-'Sentence Contrasts 4'

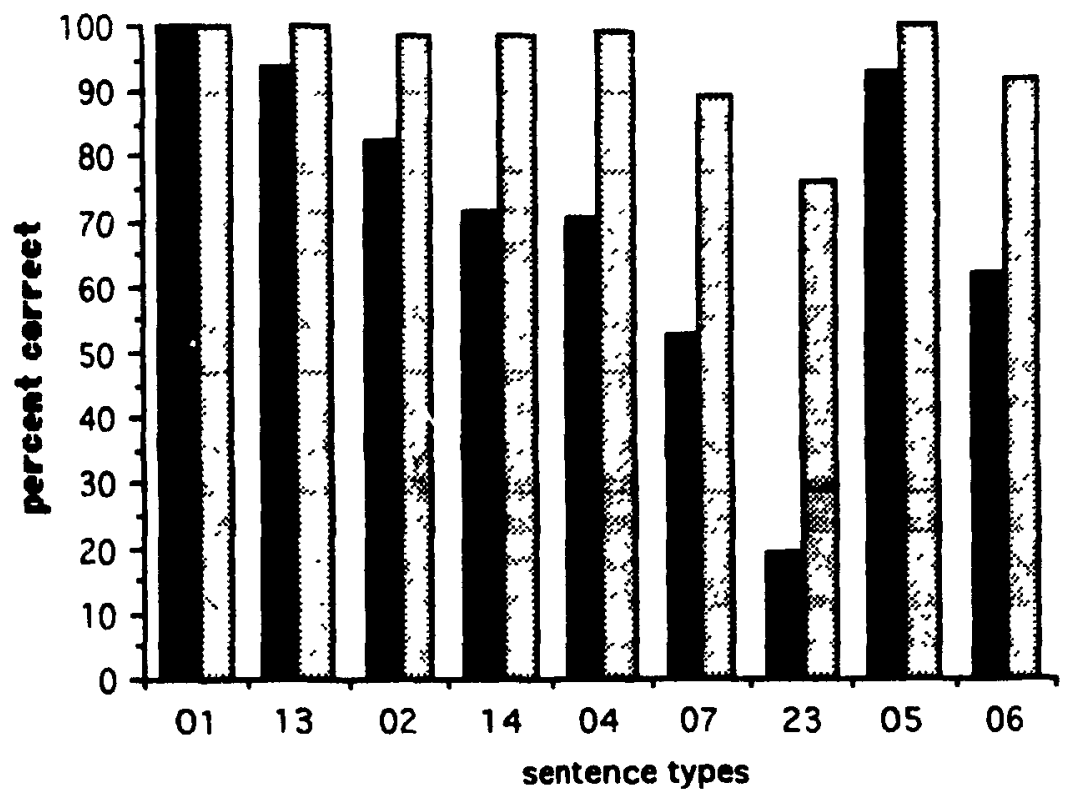

9 aphasics

10 controls 
Table 4.4.3. b Significantly Different Sentence Types - Patıents $x$ Controls Sentence Contrasts $4^{\prime}$

Sentence Type

[15] Direct Object Control, Intransitive Verb

[21] Causative (Faire-à)

[22] Causative (Faire-par)

[08] Conjoined

[28] Conjoned Clauses 4 NPs (No Deletion) (Baseline)

[12] Subject-Subject Relative

[27] SS Relative + Conjoined Theme

[26] Causative + SS Relative

[24] Conjoined Causative

[25] Causative + Dative
Fisher's PLSD

$$
\begin{array}{ll}
F(1,17)=4.474 ; p=.0495^{\star} & .333^{\star} \\
F(1,17)=8.389 ; p=.01^{\star} & 3.335^{\star} \\
F(1,17)=8.664 ; p=.0091^{\star} & 3.051^{\star} \\
F(1,17)=10.849 ; p=.0043^{\star} & 2.498^{\star} \\
F(1,17)=9172 ; p=.0076^{\star} & 2.617^{\star} \\
F(1,17)=6.006 ; p=.0254^{\star} & 3.272^{\star} \\
F(1,17)=11.774 ; p=.0032^{\star} & 2.767^{\star} \\
F(1,17)=17.932 ; p=.0006^{\star} & 2.796^{\star} \\
F(1,17)=17.66 ; p=.0006^{\star} & 3.375^{\star} \\
F(1,17)=26.035 ; p=.0001^{\star} & 2.821 \star
\end{array}
$$

Figure 4.5b Accuracy Rates Patients vs Controls-'Sentence Contrasts 4'

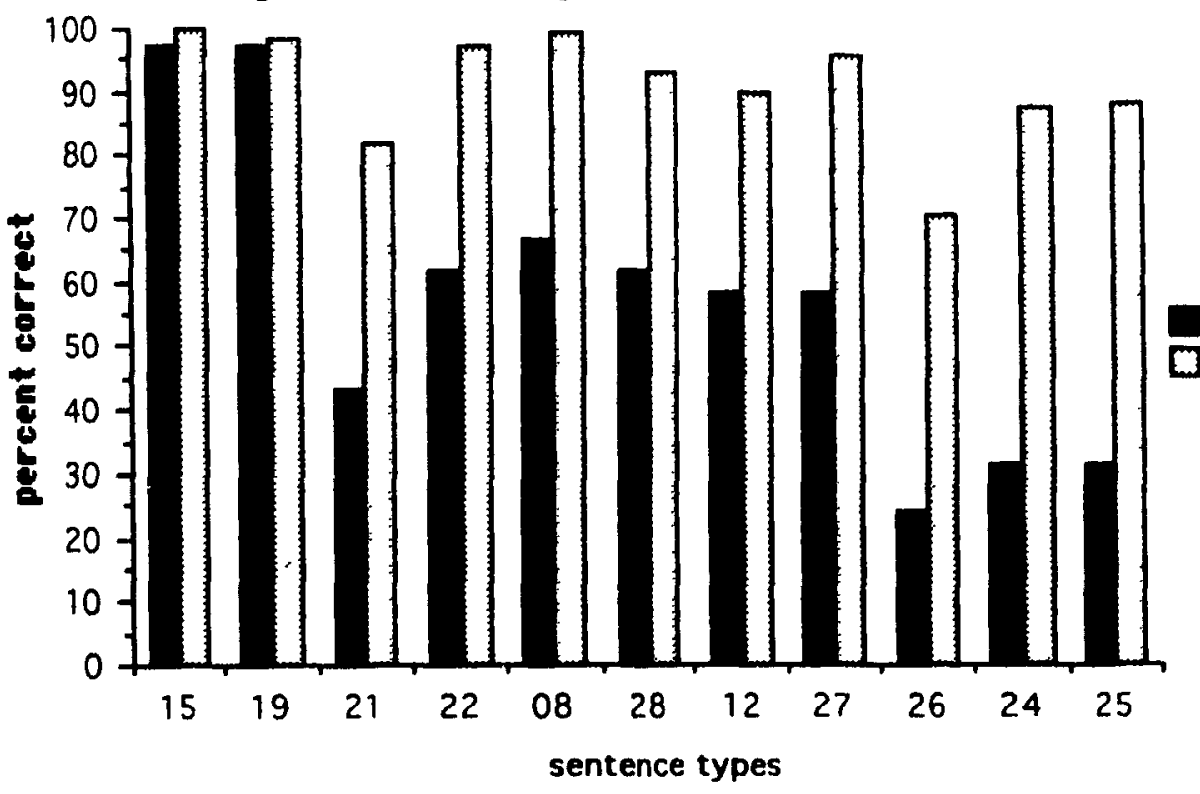

9 aphasics 10 controls

Only four sentence types did not contrast, i.e. [01 Active], [13 Active Conjoined

Theme], [05 Dative] and [19 Direct Object Control + Transitive Verb], all types where a linear order strategy would be effective. Thus, the linear order strategy camouflages the differing structural complexities of these types.

The additional hierarchical structure, i.e. nodes which permit adjunctions or conjunctions, do not seem to have the same effect on processing as do those necessary to 
represent complementation. Since theta-role assignment to arguments must proceed under government, it is clear that the nature of the relationshıp of adjunction structures and conjoined structures to their attachment site does not involve goverment and it is precisely this structural relation which increases sentential complexity. 15

\subsection{5. 'Sentence Contrasts 5 '}

\subsubsection{Subset Aphasic Sample}

The final set of contrasts in the OMB paradigm consısts of 144 sentences --12 tokens of each of 12 sentence types. The HAH predicts that, since all these sentences have at least two CPs, they will not be very well understood. Only sentences containıng wh-traces were included, as 'Sentence Contrasts 4 ' had shown that these types could be difficult to interpret. In addition to those previously discussed in the other 'Sentence Contrasts', we will also discuss [10 Object-Subject Relative] $\left(N_{1} V_{1} N_{2} V_{2} N_{3}\right)$. This is expected to be an easy structure to comprehend because a linear order strategy can be applied, i.e. $N_{1}$ acts on $\mathrm{N}_{2}$ and $\mathrm{N}_{2}$ on $\mathrm{N}_{3}$. In addition, we also will discuss inverted versions of $\mathrm{CO}_{2}, \mathrm{SO}$ and 00 relatives, which permit us to test other structures with displaced elements. Some researchers (e.g. Kail 1989) have claimed that these inverted structures are more frequent than the non-inverted versions in normal discourse; this seems counterintuitive, but it was felt that this claim should be put to the test. Certainly, not all similar structures have acceptable inverted versions. However, they do allow a case contrast between the relative pronouns que and the qui of SS and OS relatives. Such knowledge of the significance of the change in the relative pronoun is unrelated to 'lexical' properties in these constructions.

Table 4.5.1. contains the results obtained by the five aphasics on the 12 sentence

is Grodzinsky's (1990) proposal that all governed prepositions are deleted in agrammatic production is related to this but appears stipulative, since it is clear from the present data that the relation of government has widespread consequences. 
types tested. The means (and their respective Standard Deviations) are presented in descending order of accuracy. The overall accuracy rate was $45.3 \%$ (the lowest mean of the five sets). Table 4.5.1. also encodes all the significantly different means

Table 4.5.1. Group Results - 5 Aphasics 'Sentence Contrasts 5'

Sentence Type

[10] Object-Subject Relative

[04] Cleft Object

[07] Cleft-Object Dative

[27] SS Relative + Conjoined Theme

[12] Subject-Subject Relative

[11] Object-Object Relative

[09] Subject-Object Relative

[42] Object-Object Relative with Stylistic Inversion

[26] Causative + SS Relative

[40] Cleft-Object with Stylistic Inversion

[41] Subject-Object Relative with Stylistic Inversion

[23] Cleft-Object Causative (Faire-par)
Mean

10.4

8.8

7.2

7.2

7.0

6.4

5.6

3.8

3.0

2.2

2.0

1.6

Mean: 5.433

[07]

$[10] \quad[04] \quad[27]$
[12
12] [11]
[09]

[42]

[26]

[40]

[41]

[23]

(Sentence types underlined by a common line do not differ on the Fisher PLSD set at a $95 \%$ confidence level; sentences not underlined by a common line do differ significantly.)

[10 Object-Subject Relative] was the structure that was the best interpreted; however, the aphasics only scored $86.7 \%$ correct on this structure despite the facilitatıng effect of the applicability of the linear order strategy. $\mathrm{CO}_{2}$ was interpreted correctly only 73.3\% of the time. Clefted (object) structures are partıcularly difficult for the aphasıcs to interpret. The aphasics had identical means for $\mathrm{CO}_{3}$ and [27 SS Relative + Conjoined Theme]. Only OS relatives were significantly different from SS, 00 and SO, which in turn did not contrast with each other. What we do find significant is that [4200+ Stylistic 
inversion], which should have been the structure to obtain the lowest score siice it could have been perceived as an OS relative (with which it contrasts) due to the low perceptual saliency of the relative pronoun, did not contrast with the other relativized structures mentioned above. Two possible explanations are:

1- the recency effect, i.e. because it was the last proposition to be heard it was kept in memory longer.

2-the parallel function strategy: in this case, since the second DP was the affected theme of the first predicate, it was perceived as low in potency and more likely to be the patient of $V_{2}$ than its agent.

All of the other inverted structures were neither contrastive with each other nor with the most difficult of the causative structures containing ralatives and clefts.

\subsubsection{Normal Controls}

Table 4.5.2. contains the results obtained by the controls on the 12 sentence types tested. The means (and their respective Standard Deviations) are presented in descending order of accuracy. The overall accuracy rate was $84.6 \%$ (the lowest accuracy rate of all five contrastive sets). Table 4.5.2. also encodes all the significantly different means. 
Table 4.5.2. Group Results - 10 Controls 'Sentence Contrasts 5'

Sentence Type

[04] Cleft Object

[27] SS Relative + Conjoned Theme

[11] Object-Object Relative

[10] Object-Subject Relative

[12] Subject-Subject Relative

[07] Cleft-Object Dative

[09] Subject-Object Relative

[40] Cleft-Object with Stylistic Inversion

[23] Cleft-Object Causative (Farre-par)

[42] Object-Object Relative with Stylistic Inversion

[26] Causative + SS Relative

[41] Subject-Object Relative with Stylistic Inversion
Mean

11.9

11.5

11.3

11.2

10.8

10.7

10.2

9.7

9.1

8.9

8.5

8.0
SD

.316

.707

.675

1.317

1.619

1.889

2.440

4.029

3814

3.573

2.415

4.372

Mean: $\quad 10.15$

$[04]$ $[27$ $[11]$ $[10]$

(Sentence types underlined by a common line do not differ on the Fisher PLSD set at a $95 \%$ confidence level; sentences not underlined by a common line do differ significantly.)

$\mathrm{CO}_{2}$ was responded to correctly $99.2 \%$ of the time, the controls being less influenced by linear order. Normals scored better on the OO and OS relatives than on the SO and three-DP SS relatives, although none of these structures contrasted with each other [40 Cleft-Object with Stylistic Inversion] did not contrast with any structure other than its non-ınverted counterpart an! [41 Subject-Object with Stylistic Inversion]. As with tine aphasics, the three-[]P inverted relatives did not generally contrast with each other, nor did they contrast with the causatives that contained the relative and the cleft structures.

A factorial analysis of variance to see which sentence types differed significantly between the patients and the controls was performed. This information can be found in 
Table 4.5.3. Only one sentence type did not contrast--[10 Object-Subject Relative $]$, the one permittıng a linear order strategy.

Table 4.5.3. Significantly Different Sentence Types - Patients $x$ Controls 'Sentence Contrasts 5'

Sentence Type

[04] Cleft Object

[40] Cleft-Object with Stylistic Inversion

[07] Cleft-Object Dative

[23] Cleft-Object Causative (Farre-par)

[09] Subject-Object Relative

[41] Subject-Object Relative with Stylistic Inversion

[11] Object-Object Relative

[42] Object-Object Relative with Stylistic Inversion

[12] Subject-Subject Relative

[27] SS Relative + Conjoned Theme

[26] Causative + SS Relative
Fisher's PLSD

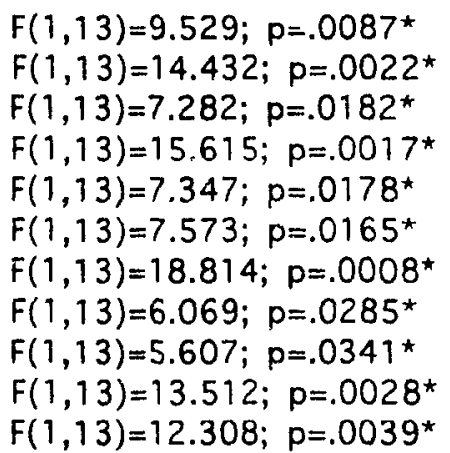

$2.170^{*}$

$4.266^{*}$

$2.802^{*}$

$4.101 *$

$3.667^{\star}$

$4.711^{*}$

$2.441^{*}$

$4.473^{\star}$

$3.467^{\star}$

$2.528^{\star}$

$3.387^{\star}$

Figure 4.6. Accuracy Rates Patients vs Controls-'Sentence Contrasts 5'

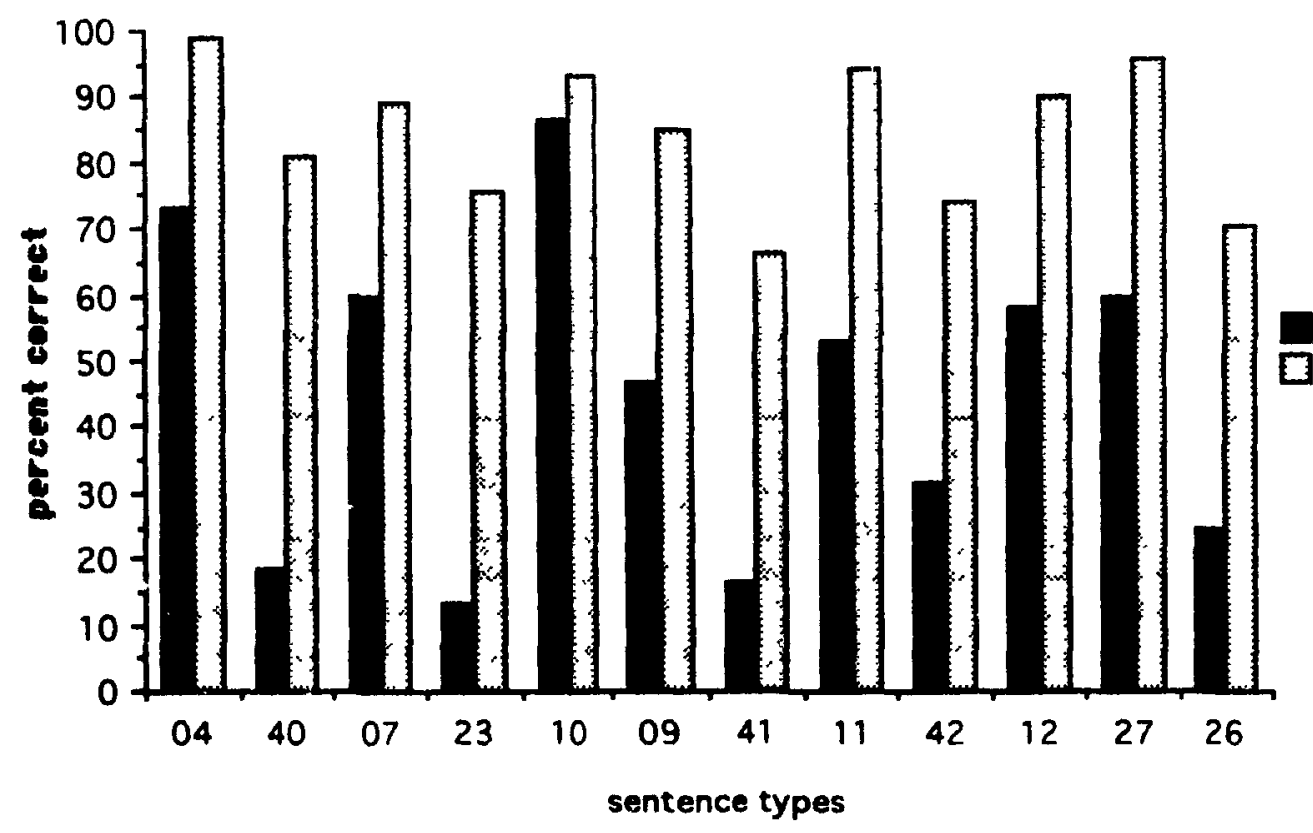

5 aphasics 10 controls

Clefted and relativized structures are more difficult to interpret than many of the other structures previously discussed. Both the aphasics and the controls obtained their lowest mean score on these contrasts. Kail's claım that inverted object relatives are more 
frequent in discourse seems difficult to maintain since one would expect a more frequent structure to be more easily understood than its less frequent but non-inverted counterpart. As we saw, non-displaced versions are more easily understood by all the test subjects. These structures which clearly contain a minımum of two CPS and two IPs led to processing difficulty, as evidenced by the higher error rates.

\subsection{The Effects of Structura! Complexity and Educational Level on Syntactic Comprehension}

Additional confirmation of the relative processing difficulty of the various sentence types we have investıgated comes rather unexpectedly from the controls' data. In computıng the repeated measures ANOVAs for the experıments, we obta ned F-values both within subject varıance and between subject variance. The latter, rather unsurprisingly for the aphasics but very surprisingly for the controls, were statistically significant. In an aphasic population, we expect this type of variance, due either to differences in the severity of the impairment or to some other idiosyncratic response bias However, how are we to account for a between-subject ANOVA showing a $F(9,410)=6.476 ; p=.0001^{*}$ in a normal population? The answer lies in the subject variables listed in Table 3.4. A twofactor ANOVA was therefore performed: Education $x$ Sentence Type (OMBs). The Education factor has three-levels and the Sentence Type is a repeated measures factor. There were main effects for Education $F(2,7)=80.632 ; p=.0001$ * and for Sentence Type $F(41,287)=10.535 ; p=.0001^{\star}$ and a significant interaction between the two $F(82,287)=7.058^{\star} ; p=.0001^{*}$. Performing a Factorial ANOVA to tease out which sentence types were contrastive for which groups (Elementary, Secondary, and PostSecondary) revealed the following:

$\begin{array}{llll}\text { Cleft-Object Dative } F(2,7)=21.467 ; p=.001^{\star} \quad & \text { E vs. PS } & 1.548^{\star} \\ & S \text { vs. PS } & 1.548^{\star}\end{array}$




\begin{tabular}{|c|c|c|c|}
\hline Subject-Object Relative & $F(2,7)=22.082 ; p=.0009^{*}$ & $\begin{array}{l}\text { E vs. } S \\
E \text { vs. PS } \\
S \text { vs. PS }\end{array}$ & $\begin{array}{l}2.421^{\star} \\
1.976^{\star} \\
1.976^{\star}\end{array}$ \\
\hline $\begin{array}{l}\text { Passivized Direct Object } \\
\text { Control + Transitive Verb }\end{array}$ & $F(2,7)=95.2 ; p=.0001^{\star}$ & $\begin{array}{l}E \text { vs. } S \\
E \text { vs. PS }\end{array}$ & $\begin{array}{l}1.032^{\star} \\
0.843^{*}\end{array}$ \\
\hline Causative ( Faire-à ) & $F(2,7)=29.437 ; p=.0004^{\star}$ & $\begin{array}{l}\text { E vs. PS } \\
S \text { vs. PS }\end{array}$ & $\begin{array}{l}1.837^{\star} \\
1.837^{\star}\end{array}$ \\
\hline $\begin{array}{l}\text { Cleft-Object Causative } \\
\text { ( Farre-par) }\end{array}$ & $F(2,7)=246.4 ; p=.0001^{*}$ & $\begin{array}{l}\text { E vs. S } \\
\text { E vs. PS } \\
S \text { vs. PS }\end{array}$ & $\begin{array}{l}1.210^{\star} \\
0.988^{\star} \\
0.988^{\star}\end{array}$ \\
\hline Causative + SS Relative & $F(2,7)=15.186 ; p=.0028^{*}$ & $\begin{array}{l}\text { E vs. } S \\
S \text { vs. PS }\end{array}$ & $\begin{array}{l}2.803^{\star} \\
2.289^{\star}\end{array}$ \\
\hline Causative-Causee cliticized & $F(2,7)=25.2 ; p=.0006^{\star}$ & $\begin{array}{l}\text { E vs. S } \\
\text { S vs. PS }\end{array}$ & $\begin{array}{l}0.632^{\star} \\
0.516^{*}\end{array}$ \\
\hline Causative-Reflexive Causee & $F(2,7)=3.373 ; p=.0943$ & E vs. PS & $5.762^{\star}$ \\
\hline $\begin{array}{l}\text { Cleft-Object } \\
\text { with Stylistic Inversion }\end{array}$ & $F(2,7)=3.929 ; p=.0718$ & E vs. PS & $6.055^{\star}$ \\
\hline $\begin{array}{l}\text { Subject-Object Relative } \\
\text { with Stylistic Inversion }\end{array}$ & $F(2,7)=24.719 ; p=.0007^{*}$ & $\begin{array}{l}\text { E vs. PS } \\
S \text { vs. PS }\end{array}$ & $\begin{array}{l}3.371^{*} \\
3.371^{*}\end{array}$ \\
\hline $\begin{array}{l}\text { Object-Object Relative } \\
\text { with Stylistic Inversion }\end{array}$ & $F(2,7)=30.485 ; p=.0004^{\star}$ & $\begin{array}{l}\text { E vs. } S \\
S \text { vs. PS }\end{array}$ & $\begin{array}{l}3.075^{\star} \\
2.511^{\star}\end{array}$ \\
\hline
\end{tabular}

The overall ANOVAs for Causative-Reflexive Causee and Cleft-Object with Stylistic Inversion only approached significance. The fact that subjects with college or university trainıng are more capable of dealing with semı-grammatical structures (Causative (Faire-à) and Causative-Reflexive Causee), while those with less education do not interpret them properly 16 casts some light on the grammaticality judgments which form the basis for important linguistic analyses.

In addition, the extreme frequency of Cleft-Subject constructions in normal discourse leads to more difficulty in discrimınating the relative pronoun. The only reason that Object-Object Relative with Stylistic Inversion was not contrastive between

16 In fact, the subject with the least schooling, O.F. (5th grade), consistently 'corrected' Causative-Reflexive Causee by 'repeating' tokens of it as if they were CausativeReflexive Causer=Theme He got them wrong because of this. 
$E$ and PS was because of O.F.'s and R.L.'s near perfect performance on them ( $92 \%$ correct), there seems to be a recency effect operating in their case, I.e. the relative pronoun is more salient in that position than it is in Subject-Object Relative with Stylistic Inversion. 17 Note also that those sentence types which did not contrast between the aphasics and the normals also never contrasted for any of the educational groups The sentence types which are less accurately processed by non-Post-Secondary normal controls are precisely those which the HAH predicts will cause processing difficulties due to their structural complexity. 18

The next chapter will present each aphasic as an individual case study We hope to show hat the responses to causatives are not random and that the statistically significant group results are not maskıng some chance individual performances.

17 Unfortunately, it will not be possible to study this factor with the aphasic population since there are no Elementary-only aphasics. This effect is mainly seen in contrasts with this group and subjects with higher levels of education. Baruzzi (1985), utilizing an Italian version of a smaller DMB, also found that years of education had an effect on accuracy in comprehending clefted object structures and object relatives. For example, University aphasics showed some of the same patterns of performance on these structures as normal controls with only an elementary education; there was thus more of a deficit when a person with more schooling had a stroke than if a less educated person who had probably never acquired the more complex syntactic structures had one.

$$
6 .
$$

18 Excluding the semı-grammatical sentences, which will be discussed further in Chapter 
136.

\section{Chapter 5-Individual Case Studies}

This chapter includes individual analyses of every aphasic who participated in our study. It is important to discuss them as individuals to insure that no idiosyncratic comprehension pattern is lost when group results are computed. In all instances, statistical analyses more appiopriate to a case study approach have been calculated and are reported on, both in this chapter, and in more detail, in Appendix B, where complete summary descriptions of eacin individual's performance can be found The nine French aphasics rather neatly divide into three groups of three, based on level of impairment. Discussion of their cases will thus be presented proceeding from least impaired group to most impaired. Finally, some individual differences among the normals will be presented.

\subsection{Aphasics without Major Comprehension Deficits}

\subsubsection{A.G.}

A.G. was a 50-year-old right-handed male who suffered a cerebral trauma as a result of a motor vehicle accident on June 9,1967 . He had a right spastic hemiplegia and cerebellar ataxia. Initıally, he was also diagnosed as having a motor aphasıa, which later e:olved into moderate to severe dysarthria.

Speech therapy results showed a net improvement in comprehension over the next two years but he continued to have such severe articulation problems as to be almost unintellıgible. His condition seems to have remained the same since that time. He has practiced very hard to articulate more clearly and during the present testing his speech was difficult to understand but became easier as tıme went by, due no doubt to my increased famillarity with his manner of speaking.

His oral digit span was six and his pointing span was five.

A.G.'s results in terms of percentage correct for the OMB sentence types can be 
found in Table 5.1.1

Table 5.1. Summary Results of Patient AG

Active

Passive

Truncated Passive

Dative

Dative Passive

Cleft-Object Dative

Subject-Object Relative

Object-Subject Relative

Object-Object Relative

Active Conjoinec' Theme

Passive Conjoined Agent

Direct Object Control, Intransitive Verb

Passivized Direct Object Control, Intransitive Verb

Causative + Intransitive Verb

Direct Object Control + Transitive Verb

Causative (Faire-par)

Conjoined Clauses 4 NPs (No Deletion) (Baselıne)

Cleft Object

Conjoined

Subject-Subject Relative

Passivized Direct Object Control + Transitive Verb

Causatıve (Faıre-à)

Truncated Causative

Cleft-Object Causative (Faire-par)

SS Relative + Conjoined Theme

Causative + Dative

Conjoined Causative

Causative + SS Relative

A.G.'s results on each sentence type were significantly above chance as computed by $x^{2 s}$ under the appropnate Stage assumptions (for each value, the reader is referred to Appendix B).

1 The tables for individual patient performances will follow the convention that the order for the sentence types is OMB before COMB then POMB. 
A.G.'s performance on the crucial sentence types of the two OMBs did not vary ;

hescored $100 \%$ correct on them all, makıng only one mistake on Passivized Direct

Object Control + Transitive Verb (for comparison of his results with those of the group, see Fig. 5.1.).

Figure 5.1. Accuracy Rate of Patient AG - 'Sentence Contrasts 1'

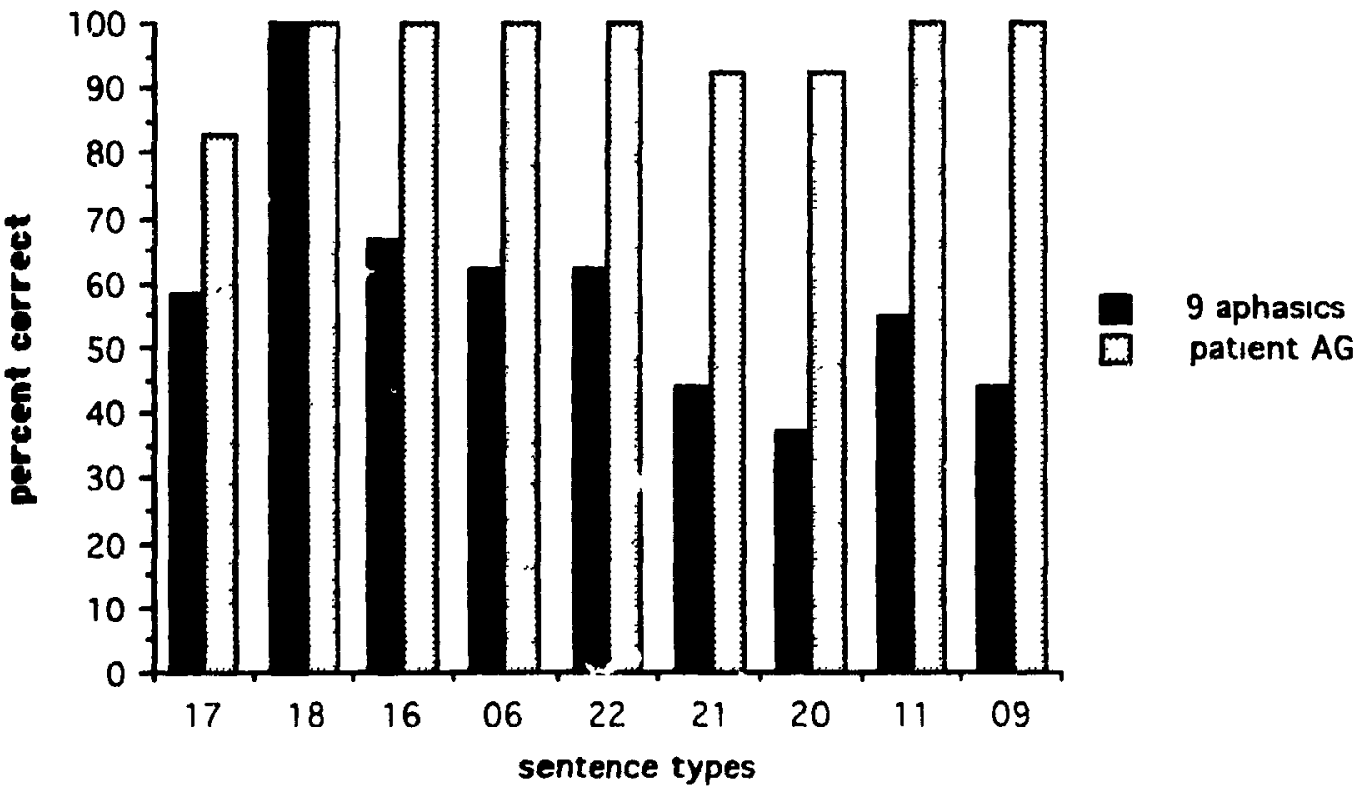

[17] Truncated Causative

[18] Causative + Intransitive Verb

[16] Passivized Direct Object Control, Intransitive Verb

[06] Dative Passive

[22] Causative (Faire-par)

[21] Causative (Faire-à)

[20] Passivized Direct Object Control + Transitive Verb

[11] Object-Object Relative

[09] Subject-Object Relative

Additionally, single-factor ANOVAs were calculated for each of the sentential variables previously isted in Table 3.1.3. 2

2 Recall that the category "number of Action Verbs" includes all non-copular verbs (this essentially affects cleft structures). "Maximum number of words" utilizes the count obtained with sentences of each type that contain the non-contracted forms of the preposition à. The linear order variable LO represents the strictest version of that view, i.e. those structures which allow a parallel function interpretation (Conjoned and the two SS Relatives) are coded NLO and 
For A.G., the number of NPs (DPs) ${ }^{3}$ had a significant effect: $F=7.96 ; p=.0007^{\star}$. His performance dimınıshed in accuracy when the sentence contained four DPs All sentence types containıng fewer than four DPs as a group contrasted significantly with the four DP sentence group by Fisher's PLSD (set at a confidence level of $95 \%$ ). Since the number of DPs in a sentence strongly correlates with the length (or maximum number of words), there is also a significant effect of sentence length $F=5.784 ; p=0086^{\star}$. Performance deteriorates mainly with the very longest sentences, those containing fourteen and fifteen words.

In additıon, the number of Action Verbs had a significant effect. $F=24.061$; $p=.0001^{\star}$, all three-action-verb sentences were the loci of his difficulties. No effect due to the number of inflected verbs was found. There was also a significant effect for the factor of linear order: $F=4.846 ; p=.0368^{\star} 4$

A.G.'s errors, enumerated in Appendix B, totalled 23/336. They are not strictly of the linear order type. Correlations of his error rate on the $O M B$ and COMB with the sentential variables confirmed and were in agreement with the single factor ANOVAs. Error rate correlated positively with number of DPs $\left(.524, p<.005^{\star}\right)$, Maximum number of words $\left(.584, \mathrm{p}<.005^{\star}\right)$; number of Action Verbs $\left(.652, \mathrm{p}<.005^{\star}\right)$; and linear order $\left(.396, p<.025^{\star}\right)$.

His performance, therefore, was similar to that of some of the normals. Only the

Causative + Intransitive Verb is counted as LO since the response is 1,$2 ; 2 \mathrm{~V}$. Aiternatives to this strictest version were calculated, however, and most patients who were affected by linear order showed this under all formulations.

3 Henceforth, we will refer to these as DPs.

4 For the group as a whole the number of NPs had a significant effect: $F=4.065$; $p=.0181^{*}$, contrasts arising between two- and three- and two- and four-NP sentences. The number of Action Vs also had a significant effect: $F=5.425 ; p=.011^{\star}$, the contrast being between three-verb sentences and one- and two-verb sentences though not between one- and two-verb sentences. As well, sentence length had a significant effect $F=3.711 ; p=.0178^{*}$, contrasts occurring between the sentences with twelve or more words and the shorter sentences; linear order: $F=28.165 ; p=.0001^{\star}$. The effect of the number of Inflected $V s$ approached but did not reach significance $F=3.711 ; p=.065$. 
very difficult sentences caused a breakdown, i.e. those with the most hierarchical structure (though he never scored fewer than $7 / 12$ correct). This is in line with the predictions of the HAH. As is even more true P.R., A.G. evidenced a dislike of interpreting both truncated structures and sentences containing pronouns with no possible intrasentential antecedents. A possible explanation for this may be lie in the fact that both patients had right hemisphere involvement, which might lead them to have difficulties in arriving at pragmatıcally appropriate interpretations. 5 In fact, despite A.G.'s effortful articulation, he would ask me at almost every token of these types 'par quip', i.e. by whom the action had been done. He chose to take on the 'Agent' role in truncated passives and causatives; that is, he chose to become the Causee who was made to perform the action on one anımal by the Causer, another anımal. A sentence type not reported on in the thesis was the Imperative + clitic pronoun $(\mathrm{N}=9)$ in the Pretest to the full NP Causative OMB, e.g. Faites le sauter 'Make hım/it jump'.6 This patient did extremely poorly on them as he kept Insistıng that there was something 'mıssing'; it appeared to me that he was interpreting the le, la, les as articles which were missing their nouns, i.e. DPs without their semantic heads. He failed to distınguish gender and number cues precısely because he miscategorized the items.

\subsubsection{C.M.}

C.M. was a 54/55-year-old right-handed female who suffered a ruptured

5 Some support for attributing this phenomenon to RH damage can be found in the case of a patient reported on in Caplan and Hildebrandt (1988): C.V., who was also extremely poor at interpreting pronouns. An EEG indicated focal slowing over both the left and ught temporal lobes; she was also diagnosed as having moyamoya syndrome which causes deterioration of the cerebral biood vessels and leads to multiple strokes.

6 In order not to offend any sensibilities, the polite form of the Imperative, 1.e. the plural, was used instead of the singular which, for purposes of contrast, would have been more appropriate. 
aneurysm about the circle of Willis on September 7, 1964 while delivering hel first and only child. The aneurysm could not be confirmed through radiographic examination Soon after, she became completely aphasic with a right hemiplegia and she became subject to epileptic seizures.

She was diagnosed as having expressive (Broca's) aphasıa, which improved with therapy. She has continued to have some word-finding difficulties until the present. C.M.'s father was a professor of French and the home atmosphere emphasized prescriptive grammar usage.

C.M. has an atypical and highly developed metalinguistic attitude to language Both her oral and pointing span were five

C.M.'s results in terms of percentage correct for all the OMBs can be found in Table 5.2 .

Table 5.2. Summary Results of Patient CM

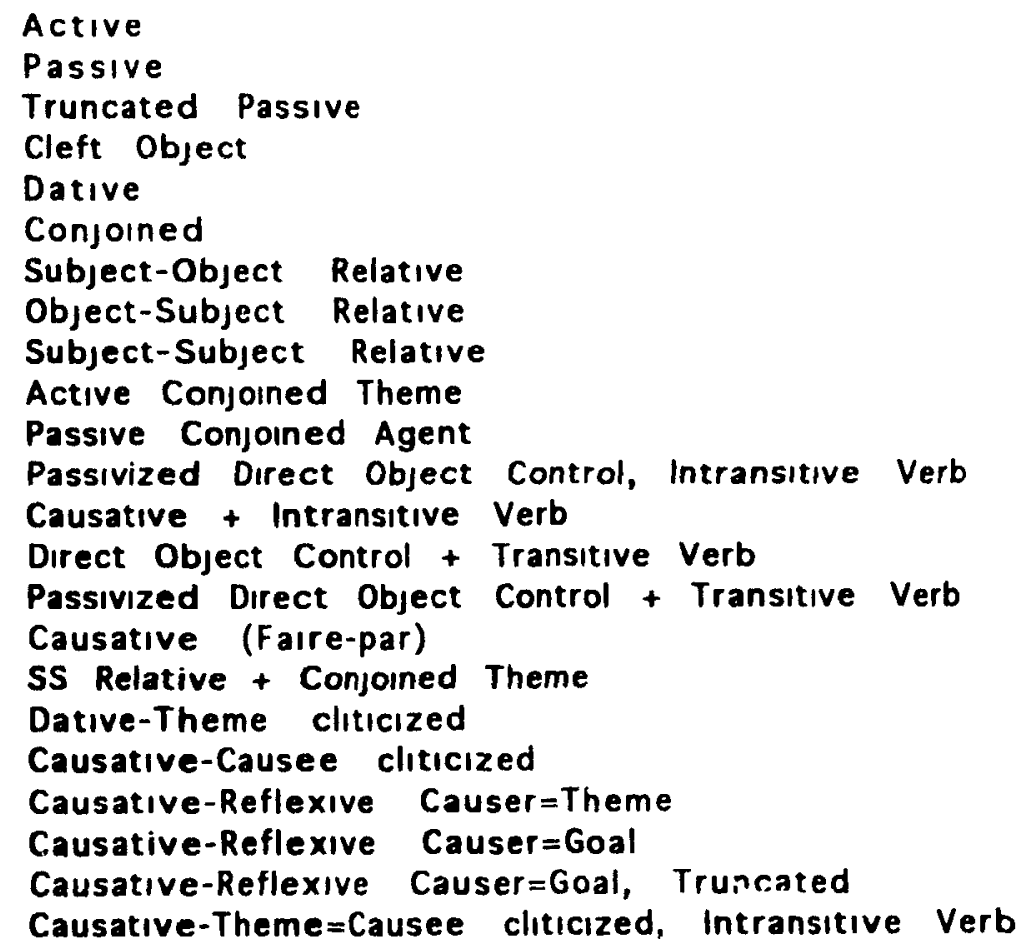


Dative Passive

Cleft-Object Dative

Direct Object Control, Intransitive Verb

Truncated Causative

Causative (Faire-à)

Causative + Dative

Conjoined Clauses 4 NPs (No Deletion) (Baseline)

Causative-Theme cliticized

Causative-Theme cliticized, Truncated

Causative-Reflexive Causer=Theme, Truncated

Object-Object Relative with Stylistic Inversion

Object-Object Relative

Conjoined Causative

Dative-Goal cliticized

Causative-Reflexive Causee

Causative + SS Relative

C.M. was the only aphasic from the original group to be tested on the

$\mathrm{P}$ (ronoun)OMB; in some senses, she served as a barometer for all further subjects as she was quite critical of the Causative-Reflexive Causee sentences, as she had been of the Causative (Faire-à) sentences, telling me that they were not correct although she could interpret them by analogy with or deduction from other forms.

All sentence types were responded to significantly above chance except for CleftObject with Stylistic Inversion, which was at chance $x^{2}=0, p=1$. Misperception of the relative pronoun is likely and since Cleft Subject sentences pattern so closely with Actives, they no longer form a part of the OMB. However, we must also keep in mind that C.M. did distinguish the relative pronoun sufficiently well on half of the tokens of this type.

C.M. responded virtually $100 \%$ correct on Passivized Direct Object Control, Intransitive Verb, Passivized Direct Object Control + Transitive Verb,and Causative (Faire-par); she made only one error on each of the following: Dative 
Passive, Cleft-Object Dative and Causative (Faire-à) (see Fig. 5.2).

Figure 5.2. Accuracy Rate of Patient CM - 'Sentence Contrasts 1'

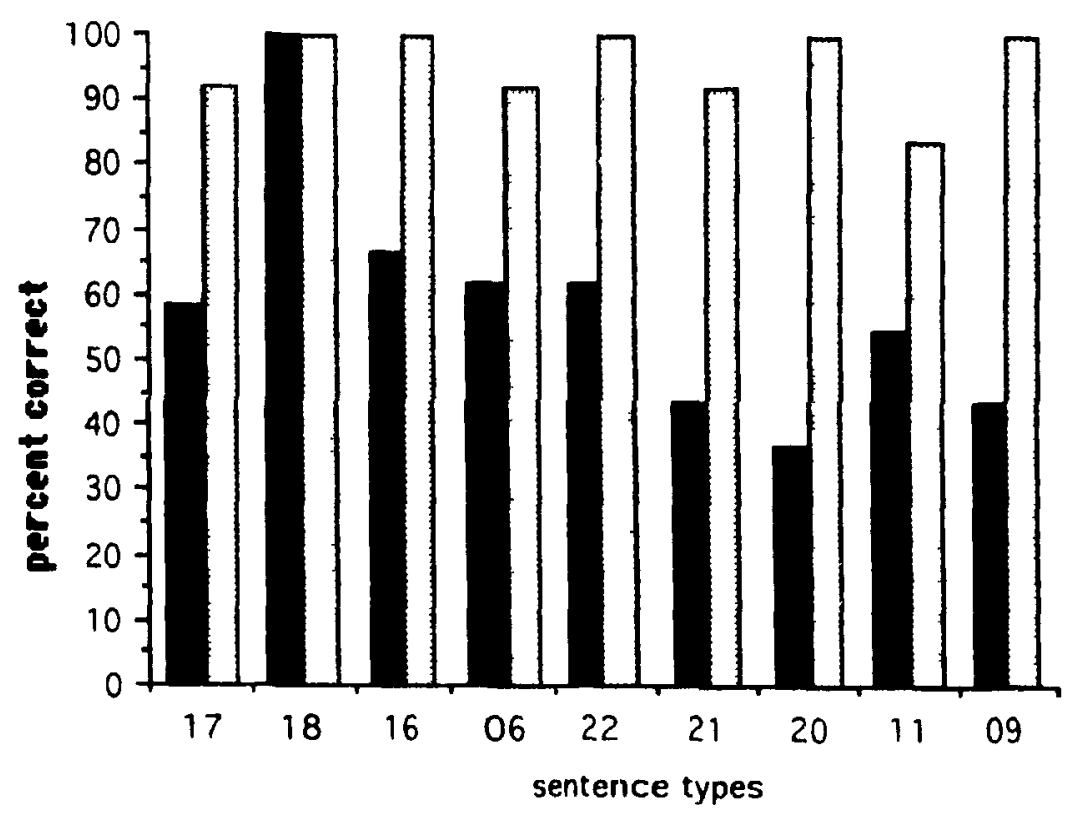

[17] Truncated Causative

[18] Causative + Intransitive Verb

[16] Passivized Direct Object Control, Intransitive Verb

[06] Dative Passive

[22] Causative (Faire-par)

[21] Causative (Faire-à)

[20] Passivized Direct Object Control + Transitive Verb

[11] Object-Object Relative

[09] Subject-Object Relative

A sentence type she found particularly difficult was Cleft-Object Causative (Fairepar). She tended to interpret the sentence as a Causative (Faire-par) which is odd because there can be no Cleft-Subject Causative sentence, i.e. one in which a NP immediately follows the relative pronoun qui.

Single-factor ANOVAs showed no significant effect for either number of DPs or linear order; the effect of the number of Inflected Vs approached but did not quite reach significance: $F=3.657 ; p=.0669$. This is directly linked to her relative difficulty with cleft sentences. Recall that these are structures with additional CP nodes. In addition, her 
scores were such that the effect of the number of Action Vs almost reached significance:

$F=3.313 ; p=.0529$, one-verb sentences being significantly easier than those with three. No difference was noted between one- and two- or two- and three-verb sentences. She did not have an effect for Maxımum number of words, though individual Fisher's PLSD (set at a 95\% confidence level) revealed some effects of thirteen- and fifteen-word sentences as compared to nine-, ten- and eleven-word counterparts.

Correlation coefficients were computed between her error rates and the first 28 OMB sentence types.7 Error rates correlated significantly for the following sentential variables: number of Action Vs (.424, p<.05); number of Inflected Vs (.351, p<.05); and Maxımum number of words $(.442, p<.01)$.

\subsubsection{J.T.}

J.T. was a 46-year-old right-handed female who on August 22, 1985 suffered a severe subarachnord hemorrhage from an ophthalmic artery aneurysm. A four vessel angiogram showed a left carotid ophthalmic aneurysm and a left cavernous carotid aneurysm. Surgery was successfully performed on September 11, 1985, and this consisted of a left pterional cranıotomy and microscopic clipping of the left ophthaimic bifurcation aneurysm under hypotension and general anesthesia. After a repeat angiogram to verify the results of the surgery, the patient developed a global aphasıa with right hemiparesis. Her aphasıa resolved into nominal aphasia and dyslexia and dysgraphia. She reported having difficulty writıng 'certain words' on paper, though she clamed to know them in her head. As a special education teacher, these problems were of great concern to her.

As of the end of February 1986, she still presented with a residual aphasia

7 In order to more accurately compare the effects of these variables across all subjects, only those for the first 28 sentences were calculated, since all subjects were tested with these. The groups' scores were also computed in the same way (see footnote 4); this holds for both the ANOVAs and the correlations, though only the group's ANOVAs are reported. 
characterized by word-findıing difficultıes, phonemic paraphasıas, alexia, very signiticant agraphia and mild comprehension problems. She was receiving speech therapy during the course of the present testıng. Unfortunately, the speech therapy reports were unavalable.

Her oral digit span was three and her pointing span was four.

J.T.'s results in terms of percentage correct for the OMB sentence types can be found in Table 5.3.

Table 5.3. Summary Results of Patient JT

$\%$ Correct

Active

100

Passive

Dative

Conjoined

Object-Object Relative

Subject-Subject Relative

Active Conjoined Theme

Direct Object Control, Intransitive Verb

Truncated Causative

Causative + Intransitive Verb

Direct Object Control + Transitive Verb

SS Relative + Conjoined Theme

Truncated Passive

92

Passive Conjoined Agent

Passivized Direct Object Control, Intransitive Verb

Conjoined Causative

Cleft Object

Dative Passive

Causative (Faire-par)

Object-Subject Relative

Causative (Faire-à)

Conjoined Clauses 4 NPs (No Deletion) (Baselıne)

Passivized Direct Object Control + Transitive Verb

Causative + Dative 
J.T.'s performance on the crucial sentence types reveals the typical pattern for the group (see Fig. 5.3.)

Figure 5.3. Accuracy Rate of Patient JT - 'Sentence Contrasts 1'

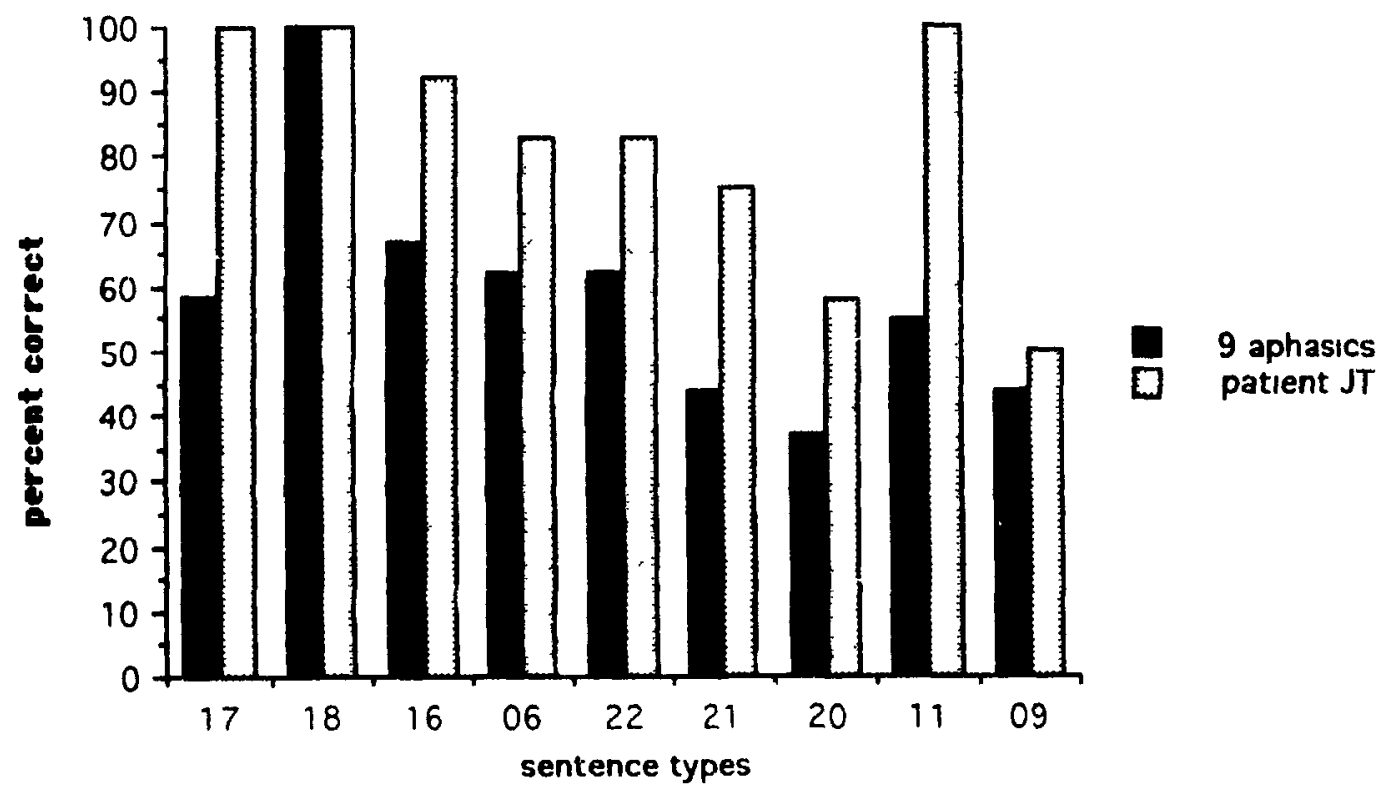

[17] Truncated Causative

[18] Causative + Intransitive Verb

[16] Passivized Direct Object Control, Intransitive Verb

[06] Dative Passive

[22] Causative (Faire-par)

[21] Causative (Faire-à)

[20] Passivized Direct Object Control + Transitive Verb

[11] Object-Object Relative

[09] Subject-Object Relative

She scored $83 \%$ on both Dative Passive and Causative (Faire-par), 92\% on Passivized Direct Object Control, Intransitive Verb; $100 \%$ correct on Dative but only 75\% correct on Causative (Faire-à) and, crucially had a much lower accuracy on Passivized Direct Object Control + Transitive Verb $-58 \%$ correct. Object-Object Relatives were correctly interpreted $100 \%$ of the time (as were 
Subject-Subject Relative and SS Relative + Conjoıned Theme). However, she had more difficulty with clefted structures as well as Subject-Object Relative, I.e those structures where the initial NP is not the agent of $V_{1}$. This explanation seems more adequate than simply invoking a parallel function heuristic (although her difficulty with Object-Subject Relative does seem to favour such an analysis).

All her responses yielded significantly above chance $x^{2}$ values under the appropriate Stage assumptions.

The contribution that the verb farre can make in helping the listener 'chunk' the Incoming material can be seen in this patient's accuracy with Conjoined Causative-92\% correct (one IP). These sentences cannot simply be interpreted with a linear order heuristic: $(1,(4) ; 4,2 ; 4,3)$. Recall that this patient has the rather limited oral digit span of only three. Her lower scores are in the direction predicted by the HAH, I.e. with clefts and relatives (two CPs).

Single-factor ANOVAs on the OMBs revealed no significant effect for number of either NPs, Action Vs, or Inflected Vs There was a significant effect for Maximum number of words: $F=3.986 ; p=.0061^{\star}$, problems beginning to surface at twelve-word sentences. When we consider her reduced oral span $(=3)$, her performance is all the more remarkable. There was no effect based on the linear order varıable. 8

J.T. made 58/336 errors on the OMBs. Her error pattern was such that only clefted structures induced an erroneous linear order strategy. As with C.M., however, her most frequent mistake with Cleft-Object Causative (Faire-par) was interpreting it as a Causative (Faire-par) (7/9 times). In effect, cleft structures are examples of the creation of additional categories without the addition of propositional content. Correlation

8 One of the other methods of coding this variable discussed previously, 1 e. coding $(1,2 ; 1,3)$ responses as $L O$, does reveal such an effect: $F=7.428 ; p=.0113^{\star}$. This seems to be linked to her occasional adoption of a parallel function strategy, witness her perfect performance on all structures that permit this. Her error patterns are predominantly of this kind for $S O=4 / 6$ errors and for $O S=1 / 3$ errors. 
coefficients computed between her error rate on the OMBs and the sentential variables were significant for the following. number of DPs $(.375, p<.025)$; Maximum number of words $(.492, p=<.005)$, and linear order $(.335, p<.05)$ they approached significance for Inflected Vs (effect of cleft structures) $(.304, p>.05)$

\subsection{Aphasıcs with Some Comprehensıon Deficits}

5.2. 1. D.C.

D.C. was a 48-year-old right-handed female who suffered a cerebrovascular accident on October 19,1986 . The diagnosis was a complete occlusion of the left internal carotid artery. An angıogram also showed a problem with the subclavian artery radiographically, though it seemed asymptomatic. In addition, a certain degree of stenosis of the right internal carotıd and the right subclavian was evident. Examınation at that time led to a diagnosis of Broca's aphasıa with phonetic disintegration, a mild right Vilth nerve central palsy and a monoparesis of the right arm more distal than proximal.

Speech therapy reports in 1987 revealed word-finding difficulties, and the patient did not initiate conversation She continued to have some difficulty with palatal consonants and produced some phonetic errors. Her reading aloud had improved and fewer paralexias were made. Her undeıstanding of written material was confined to global comprehension of a short text. Her auditory comprehension improved though the deficit in this, area had never been severe. Seven of eight commands were correctly executed while only five of eight had been at the initial evaluation. She had by this tinie shown a significant improvement on the fifth section of the Token Test $9: 18 / 22(+11)$.

Her written performance had improved as well. She could use her dominant hand and her writing was satisfactory. She had not written very much pre-onset and had been prone to making mistakes. She could write high frequency words and simple sentences to

9 A standardized aphasia test used to evaluate receptive disturbances (DeRenzi and Vignolo 1962). 
dictation without errors. Speech therapy was interrupted by further health problems which necessitated major surgery.

When I saw the subject, she exhibited the type of speech characterized by the therapist but to a lesser degree. Her digit span was four for both oral and pointing.

D.C.'s results in terms of percentage correct for the OMBs can be found in the Table

Table 5.4. Summary Results of Patient DC

$\%$ Correct

Active

Truncated Passive

Dative

Active Conjoined Theme

Direct Object Control + Intransitive Verb

Causative + Intransitive Verb

Direct Object Control + Transitive Verb

Dative-Theme cliticized

Causative-Theme cliticized,Truncated

Causative-Reflexive Causer $=$ Theme, Truncated

Causative - Theme $=$ Cause chiticized, Intransitive Verb

Dative Passive

Passive Conjoined Agent

Causative-Reflexive Causer $=$ Theme

Cleft Object

Conjoined

Subject-Subject Relatives

Causative (Faire-par)

Cleft Object-Dative

67

Object-Subject Relatives

Passivized Direct Object Control + Intransitive Verb

Conjoined Clauses 4 NPs (No Deletion) (Baseline)

Dative-Goal cliticized

Causative-Reflexive Causer=Goal , Truncated

Causative-Causee cliticized

Causative Reflexive Causer $=$ Goal 
Object-Object Relatives 50

Causative (Faire-à)

SS Relative + Conjoined Theme

Causative-Reflexive Causee

Subject-Object Relatives

Truncated Causative

Causative-Theme cliticized

Object-Object Relative with Stylistic Inversion

Passivized Direct Object Control + Transitive Verb

Cleft-Object Causative (Faire- Par)

Conjoined Causative

Causative + SS Relative

Cleft-Object with Stylistic Inversion

Causative + Dative

Subject-Object Relative with Stylistic Inversion

D.C.'s performance on most sentence types was non-random except for Cleft

Object, which was at chance on Stage 2 assumptions.

Her performance on the critical sentences demonstrated statistically significant differences in the expected direction (see Fig. 5.4.). 
Figure 5.4. Accuracy Rate of Patient DC - 'Sentence Contrasts 9'

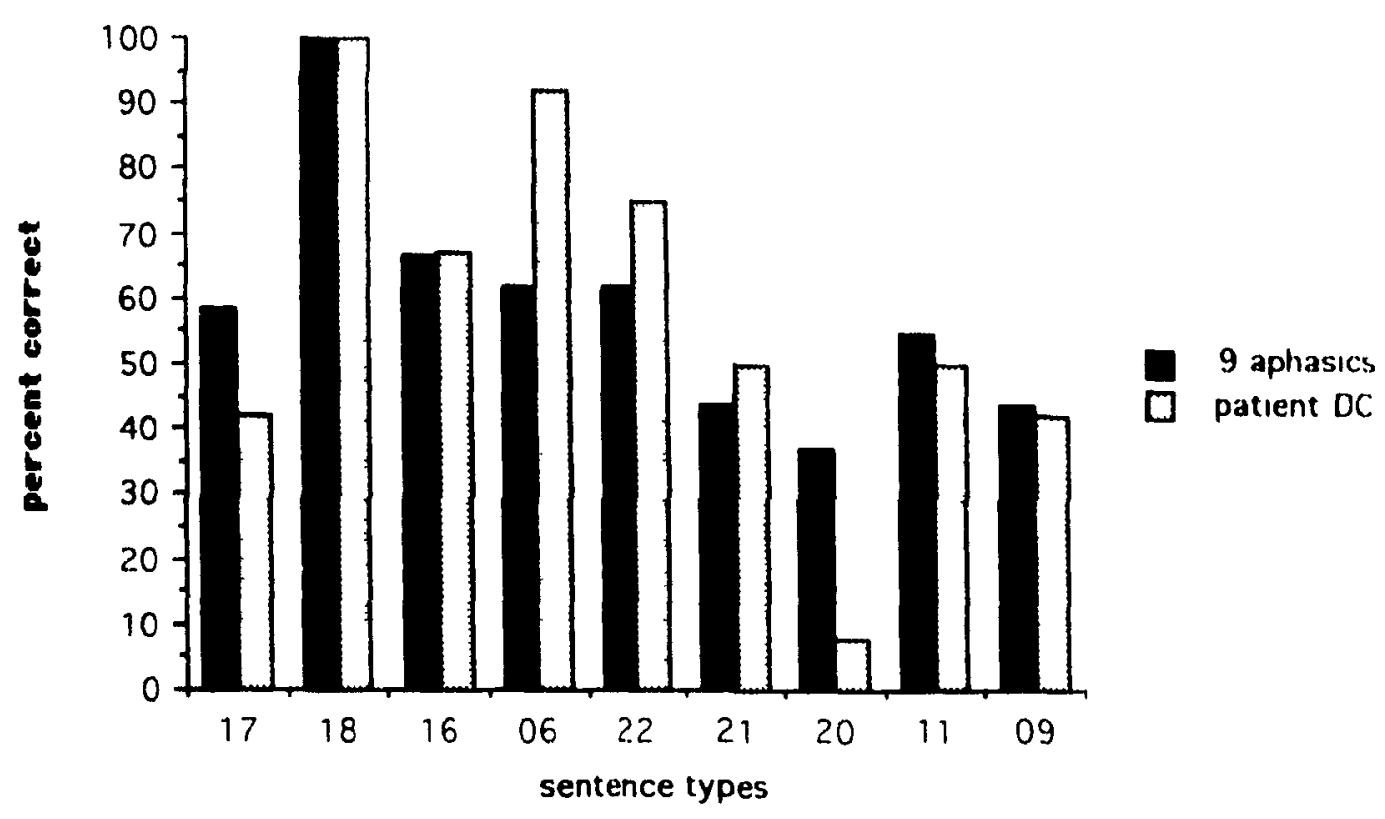

[17] Truncated Causative

[18] Causative + Intransitive Verb

[16] Passivized Direct Object Control, Intransitive Verb

[06] Dative Passive

[22] Causative (Faire-par)

[27j Causative (Farre-a)

[20] Passivized Direct Object Control + Transitive Verb

[11] Object-Object Relative

[09] Subject-Object Relative

Notice that she scores better than the group means for Dative Passive and Causative

(Faire-par) and Causative (Faire-à) (though only very marginally so for the last

type ). She also scores lower, however, for Object-Object Relative and Subject-

Object Relative and even more markedly, for Passivized Direct Object Control +

Transitive Verb. We assume that her performance on the latter is directly related to the

fact that the relativized structures are predications while the control verb takes an event complement.

The test of significance of the difference between two independent proportions

(Ferguson and Takane, 1989) revealed that Dative Passive and Causative (Faire- 
par) were not significantly different from each other $(p=.273310)$; however, Dative and Datıve Passive were significantly different from Causative (Faire-à) $\left(p=.0047^{\star}\right.$ and $p=.0247^{\star}$ respectively). Causative (Faire-par) did not differ significantly from

Passivized Direct Object Control, Intransitive Verb $(p=.6534)$ nor from Object-Object Relative or Causative (Faire-à) (both $p=.2059$ ); however, there was a significant difference from Passivized Direct Uiject Control + Transitive Verb and Cleft-Object Causative (Faire-par) (under the original assumptions) (both $\left.\mathrm{p}=.0009^{\star}\right)$. In addition, Cleft-Object Dative differed significantly from CleftObject Causative (Faire-par) $\left(p=.0032^{\star}\right)$.

Her responses to the POMB revealed better performances on structures which allowed a linear order strategy to be employed; for example, Dative-Theme clitıcized was significantly different in terms of accuracy than Dative-Goal cliticized ( $p=$ $\left..0285^{\star}\right)$. The differences between Causatıve-Causee clitıcized and CausativeTheme cliticized were not significant $(p=.0977)$.

Single-factor ANOVAs performed on the full-NP OMB batteries (OMB and COMB) revealed a significant effect for the number of DPs: $F=4.499 ; p=.0122^{\star}$ problems originating at four DP sentences. Sentence length was also a significant factor: $F=3.08$; $p=.02^{\star}$, the locus of difficulty beginning at thiteen-word sentences. The number of Action Vs was also highly relevant: $F=10.372 ; p=.0005^{\star}$. In terms of Action Vs, the group of sentence types containing only one such verb differed from those containing more than one, while those contaınıng two differed from those containing three. There was no significant effect for number of Inflected Vs. The linear order variable yielded a significant effect: $F=9.314 ; p=0052^{\star}$

10 In order to compare these sentence types an additional $\chi^{2}$ value had to computed for the Causative (Faire-à), Causative (Faire-par) and Cleft-Object Causative (Fairepar). Assuming that the causative is processed as one verb, this would in fact further constrain what would count as non-random performance. On these assumptions, all aphasics' performance on these sentence types continued to be non-random except for F.P.'s response on Cleft-Object Causative (Faire-par), which was then at chance levels. 
D.C.'s errors were predominantly of the linear order type, though interestingly, on Cleft-Object Causative (Faire-par), she made as many errors using a linear order strategy (5/12) as she did with the pattern we first saw with C.M. and J.T (5/12), i e interpreting the structure as if it were a simple Causative (Faire-par) As to correlations between her error rates on the OMB and COMB and the sentential variables associated with them $(118 / 336)$, we find $.570, p<.005^{\star}$ for number of DPs, .667 , $p<.005^{\star}$ for number of Action Vs; .330, p<.05* for number of Inflected Vs, 702,p<.005* for sentence length, $.514, p<.005^{\star}$ for linear order

\subsubsection{F.P.}

F.P. was a 49-year-old right-handed female who suffered a cerebrovascular accident on October 6,1986. A CT-scan revealed an ischemic attenuation of the area supplied by the left sylvian artery. The diagnosis of a left hemisphere CVA with a right hemiparesıs and expressive (Broca's) aphasıa was made

Speech therapy reports in 1986 stated that the patient was initially mute but soon began to be able to converse adequately with the therapist Her oral comprehension was better on concrete than abstract words and she had some difficulty with spatial expressions. Shorter, simpler sentences were easier for her to understand (no relative clauses or conjunctions). The subject had trouble integrating more complex material or could only understand a subset or part of the material. Word order was often a determinant of success or failure in understanding arguments in a clause.

Oral expression was good, although word-finding difficulties were still present. Uncorrected phonemic paraphasias were sometımes present. She had great difficulty remembering numbers, which upset her as she had worked as an accountant in a bank prestroke.

Reading was possible though she evidenced some slight difficulties with sentences At first, she had trouble identifying numbers. Mathematical operations were slow and not 
always accurate. The therapist diagnosed a posterior (some contradiction with earlier diagnosis) aphasia with dyscalculia. The patient made good and steady progress in all aspects.

At the time of testing, the patient still suffered from a right hemiparesis and had some word-finding difficulties. Both her oral and pointıng digit spans were four.

F.P.'s results in terms of percentage correct for the OMBs can be found in Tabie 5.5 .

Table 5.5. Summary Results of Patient FP

$\%$ Correct

Active

100

Truncated Passive

Cleft Object

Dative

Active Conjoined Theme

Direct Object Control, Intransitive Verb

Causative + Intransitive Verb

Direct Object Control + Transitive Verb

Causative-Causee cliticized

Causative-Reflexive Causer $=$ Theme

Causative-Reflexive Causer $=$ Goal, Truncated

Causative-Reflexive Causer=Theme, Truncated

Passive

Passive Conjoined Agent

Truncated Causative

Conjoined Clauses 4 NPs (No Deletion) (Baseline)

Dative-Theme cliticized

Causative-Reflexive Causer $=$ Goal

Conjoined

83

Object-Subject Relative

Object-Object Relative

Subject-Subject Relative

SS Relative + Conjoined Theme

Dative-Goal cliticized

Causative-Theme=Causee cliticized, Intransitive Verb

Cleft-Object Dative

Passivized Direct Object Control, Intransitive Verb

Causative (Faire-par)

Causative-Theme cliticized 
155.

Dative Passive

Subject-Object Relative

$\begin{array}{ll}\text { Causative-Theme cliticized, Truncated } & 50\end{array}$

Conjoined Causative

Causative + SS Relative

Cleft-Object with Stylistic Inversion

Causative (Faire-à)
Cleft-Object Causative (Faire-par)

Causative + Dative

Passivized Direct Object Control + Transitive Verb

Subject-Object Relative with Stylistic Inversion

F.P.'s responses are non-random under the appropriate Stage assumptions, except

In the following cases: Causative + Dative , where the $\chi^{2}$ value is $210.322, p=.1609$;

Cleft-Object with Stylistic Inversion, $x^{2}=3, p=.0833$; and Cleft-Object

Causative (Faire-par), when the causative is treated as one verb, $\chi^{2}=10, p=.0752$.

Her responses to the critical sentences are, however, in the expected direction (see Fig.

5.5). 
156.

Figure 5.5. Accuracy Rate of Patient FP - 'Sentence Contrasts 1'

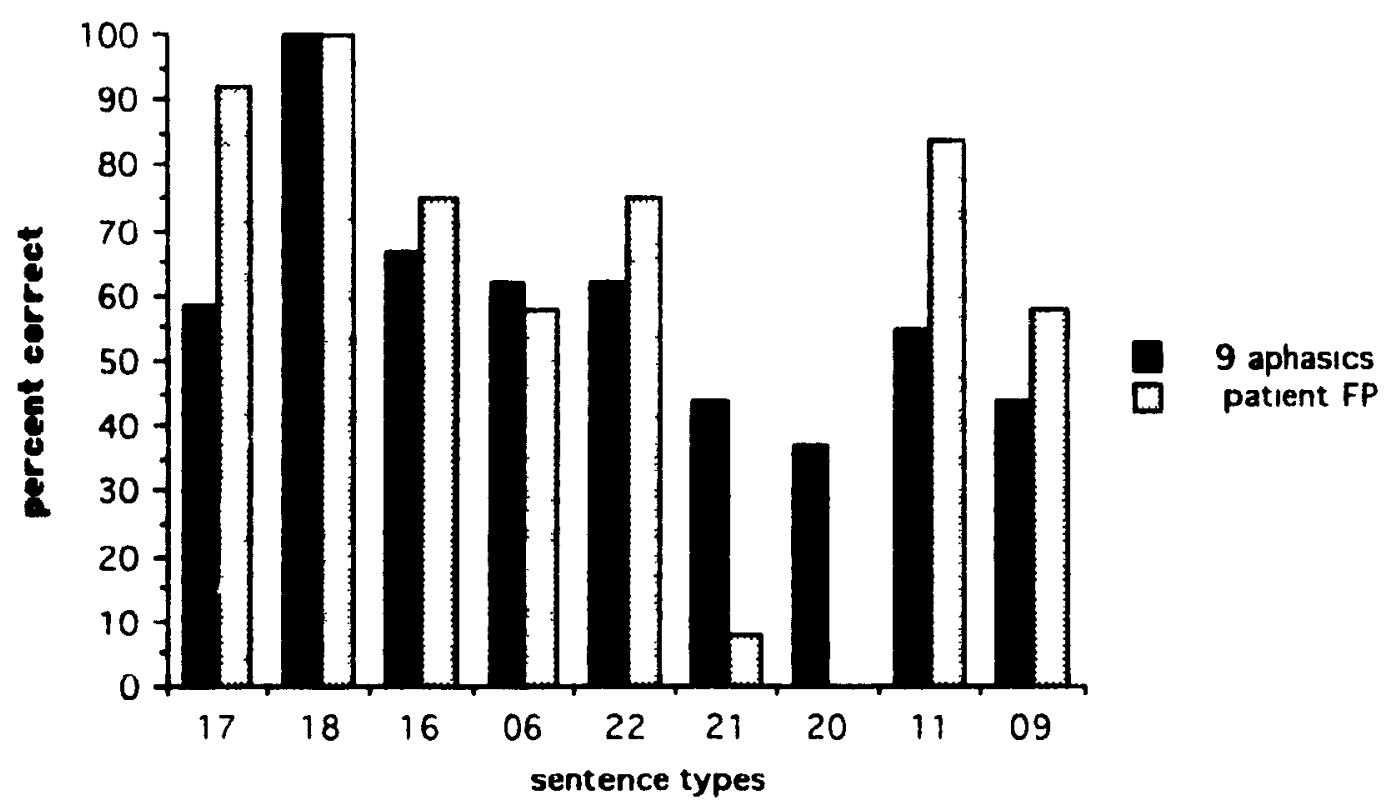

[17] Truncated Causative

[18] Causative + Intransitive Verb

[16] Passivized Direct Object Control, Intransitive Verb

[06] Dative Passive

[22] Causative (Faire-par)

[21] Causative (Faire-à)

[20] Passivized Direct Object Control + Transitive Verb

[11] Object-Object Relative

[09] Subject-Object Relative

Her accuracy is the same for Passivized Direct Object Control, Intransitive Verb and Causative (Faire-par): she scores $75 \%$ correct on these sentence types--in fact, her performance is $17 \%$ better on these types than on Dative Passive, though this is not significantly different. She also, somewhat atypically, performs better on Object-Object Relative than on all these sentence types, 83\% correct. However, both Passivized Direct Object Control, Intransitive Verb and Causative (Faire-par) do contrast significantly with Passivized Direct Object Control + Transitive Verb $\left(p=0001^{\star}\right)$ as well as with Causative (Faire-a) $\left(p=.0009^{\star}\right)$. In addition, accuracy on Causative + Intransitive Verb and Truncated Causative was high: 100\% correct and $92 \%$ correct respectively. This patient can be said to have retained intact the lexical 
information encoded with the verb faire.

Single-factor ANOVAs were performed on her results. Number of OPS falled to achieve sıgnificance: $F=2499 ; p=.0838$. There was no effect for elther Inflected Vs or sentence length (though a Fisher's PLSD set at a confidence level of 95\% revealed some significant effects, primarily with thirteen-word sentences). There was a significant effect for the linear order variable; $L O$ revealed a $F=8.072, p=.0086^{\star}$. There was also an effect for number of Action Vs which was highly significant $F=3.676 ; p=0399^{*}$, the difference obtaining between one- and three-verb sentences only

F.P. made $98 / 336$ errors on the $C O M B$ and the $O M B$, mostly of the linear order type. In addition, her performance on Cleft-Object Causative (Faire-par) mirrored D.C.'s in that five errors were 1,2;2,3 and four showed the same error made by C.M., J.T., and D.C., I.e. 1,3;3,2 or the response appropriate to Causative (Faire-par). These results clearly support the $\mathrm{HAH}$, as the clefted version of the causative has two CPs. Correiation coefficients between error rates and sentential variables were significant for the following: number of DPs $\left(.477, p<.01^{*}\right)$; number of Action Vs $\left(.473, p<.01^{*}\right)$; sentence length $\left(.593, p<.005^{\star}\right)$; and linear order $\left(.487, p<.005^{\star}\right)$. No correlation was found for number of Inflected Vs.

\subsubsection{L.R.}

J.R. was a 46-year-old left-handed female who suffered a cerebrovascular accident on December 8, 1985. Diagnosis was of a left hernusphere CVA in the perisylvian region. CTscan revealed a deep ischemic attack of the nuclei and the internal capsule. Initially, she presented with a right hemiparesis and speech difficulty.

Speech therapy reports stated that she had a mild Broca's aphasia with a mild dysarthria which caused her to sound as if she had a foreign accent. Her voice also had a raucous quality which turned out to be due to polyps on her left vocal cord; these were 
158.

removed by a polypectomy on November 4,1986 . She appeared to have no comprehension difficultıes. She contınued to have mild word-finding difficultıes and tired easily when reading. Her condition improved fairly rapidly. The patient did not go to a convalescent hospital but went directly home.

When I tested this subject, she no longer evidenced any hemiparesis. Outwardly, she seemed completely recovered. The subject herself stated that, if overly tired in the evenings, she often cannot speak and her family has adjusted to this and allows her to rest. Formal testing revealed some limitations to her comprehension and memory. Her oral and pointing spans were both four.

J.R.'s results in terms of percentage correct for the OMB sentence types can be found in Table 5.6 .

Table 5.6. Summary Results of Patient JR

\% Correct

Active

100

Truncated Passive

Dative

Object-Subject Relative

Active Conjoined Theme

Direct Object Control, Intransitive Verb

Causative + Intransitive Verb

Direct Object Control + Transitive Verb

Causative-Reflexive Causer $=$ Theme, Truncated

Causative-Theme=Causee cliticized, Intransitive Verb

Dative-Theme cliticized

92

Dative-Goal cliticized

Causative-Theme cliticized

Causative-Reflexive Causer $=$ Theme

Causative (Faire-par)

83

Causative-Reflexive Causer=Goal, Truncated

Passivized Direct Object Control, Intransitive Verb

Causative-Causee cliticized

Causative-Reflexive Causer $=$ Goal 
Passive

Causative + Dative

Causative + SS Relative

Cleft-Object with Stylistic Inversion

Subject-Object Relative with Stylistic Inversion

Cleft-Object Causative (Faire-par)

J.R.'s performance contrasted sharply with her seemingly unımpared production.

In the OMBs, Passive, Cleft Object and Causative + Dative were responded to at

chance levels. As we will see below, this patient has difficulties with empty categories. 11

11 The very real effect that empty categories play in sentence processing has been the focus of much work within parsing theory. It is beyond the scope of this thesis, however, to fully examine the impact of each type of empty category--wh-trace, NP-trace, PRO and pro--on our subjects' sentence comprehension. Such an investigation will be part of future work interested readers should consult Hildebrandt (1986) and Caplan and Hildebrandt (1988) for discussions of precisely this topic, looking more specifically at such categories in English. 
160.

With reference to the crucial sentences, see Fig.5.6..

Figure 5.6. Accuracy Rate of Patient JR - 'Sentence Contrasts 1'

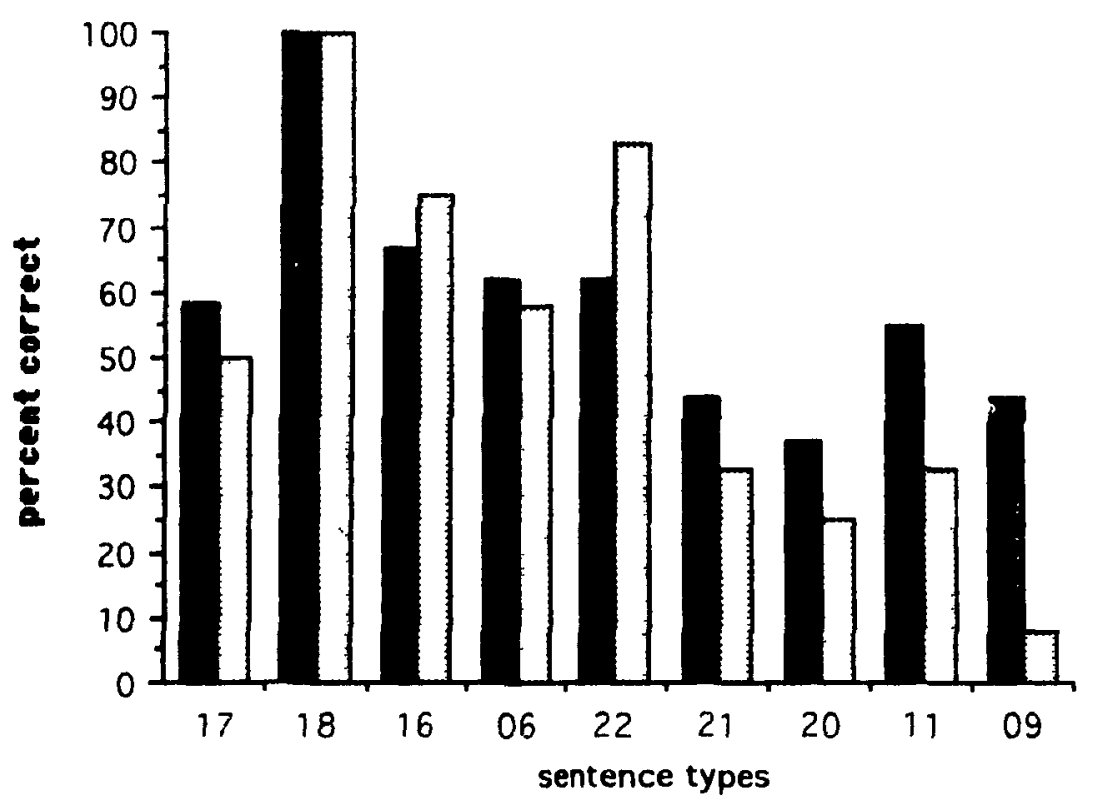

[17] Truncated Causative

[18] Causative + intransitive Verb

[16] Passivized Direct Object Control, Intransitive Verb

[06] Dative Passive

[22] Causative (Faire-par)

[21] Causative (Faire-à)

[20] Passivized Direct Object Control + Transitive Verb

[11] Object-Object Relative

[09] Subject-Object Relative

Her score is above the group's mean for Causative (Faire-par). Her scores are lower

for Causative (Faıre-à), Passivized Direct Object Control + Transitive

Verb, Object-Object Relative and Subject-Object Relative.

J.R. scores best at Causative (Faire-par)--83\% correct; she scores $75 \%$

correct on Passivized Direct Object Control, Intransitive Verb; 58\% correct on Dative Passive; $33 \%$ correct on Object-Object Relative and Causative (Fairea); only $25 \%$ correct on Passivized Direct Object Control + Transitive Verb; and $8 \%$ correct on Subject-Object Relative. The difference between Dative (100\%) and Causative (Faire-à) is significant on the SDTIP $\left(p=.0005^{\star}\right)$. There is no such 
difference with Causative (Faire-par); in fact, there is no difference between Causative (Faire-par) and either Passivized Direct Object Control, Intransitive Verb or Dative Passive. There is a significant difference between Causative (Faire-par) and both Object-Object Relative and Causative (Fairea) $\left(p=.013^{\star}\right)$, as well as between Causative (Faire-par) $\left(p=0041^{*}\right)$ and SubjectObject Relative $\left(p=.0002^{\star}\right)$. Her performance on Cleft-Object Dative is also significantly different from Causative (Faire-par) $\left(\mathrm{p}=.035^{\star}\right)$. Her performance on Cleft-Object Causative (Farre-par) (0\%) is significantly below chance, $\chi ?=$ $248.486 ; p=.0001^{\star}$.

In addition, we would draw the reader's attention to the fact that this subject is more accurate in her responses to the Causative + Reflexive clitic variants of certain thematic orders; for example, she scores $92 \%$ on Causative-Reflexive Causer $=$ Theme but only $58 \%$ on Passive, $75 \%$ on Causative-Reflexive Causer $=$ Goal and $58 \%$ on Dative Pássive. However, she scores identically on Truncated Passive and Causative-Reflexive Causer=Theme, Truncated-$100 \% .12$ It must be concluded that the verb faire is anding her to not apply her preferred linear order strategy. It would appear that the presence of se and faire in the matrix INFL allows her to immediately assign a non-agentive thematic role to the DP in the Spec of IP Single-factor ANDVAs were performed on her responses to the first 28 sentence types of the OMBs. There was a significant effect for number of DPs ( $F=4.575$; $\left.p=.0114^{\star}\right)$, the difficulty arising with four-DP sentences, which contrasted with each of the other types. The effect for number of Action Vs yielded $F=4.251 ; p=.0258^{\star}$, the difference arising between one- and three-verb sentences. This patient is the only one who had a significant effect due to the number of Inflected $V s\left(F=6.912 ; p=.0142^{\star}\right)$, the

12 While the difference between Causative-Reflexive Causer=Theme and Passive approaches significance $(p=.0593)$, there are no statistically significant differences between these sentence types. However, we feel they are suggestive. 
difference between one- and two-Inflected-verb sentences being significant on a Scheffé Ftest $=6912^{*}$ (at the 0.05 level) Coupled with her extremely poor performance on sentences containing NP and wh-trace, this can be seen as a rather specific problem with functional categories such as IP and CP Sentence length was also significant $(F=2.642$; $\left.p=.0375^{\star}\right)$, contrasts arising with thirteen+-word sentences. Finally, linear order also was highly determınative for this subject. $F=21.045 ; p=.0001^{\star}$.

$J R$ made $154 / 336$ errors on the OMB and the COMB. Her most frequent error type was caused by her use of the linear order strategy. Correlation coefficients were calculated between her error rate and the sentential variables The rate correlated .588, $\mathrm{p}<005^{*}$ with number of DPs, .489, $p<005^{\star}$ with number of Action Vs, .458, $p<.01^{\star}$ for number of Inflected Vs, 735, $p<005^{*}$ for sentence length, .669, $p<005^{*}$ for linear order

J.R.'s difficulties seem to reside in structures which contain moved elements, e $\mathrm{g}$ passives, or which have traces which must be governed from an A-bar position in CP, e.g relatives. Indeed this subject's performance also breaks down when there is more than one inflected verb in a sentence Recall that in the latest versions of the theory it is presumed that, in French, verbs must move to INFL to get. Tns. In other words, all government of traces whether, NP-trace, wh-trace or verbal $t$, seems to be affected However, it is important to note her good performance (never $\quad s_{\text {. }}$. tan $9 / 12$ correct) with pronominal clitics (we have already noted this with reflexives) Though she clearly has a problem with INFL, she can correctly parse the structure when a thematic role is able to be identified there. These are exactly the results predicted by the $\mathrm{HAH}$.

\subsection{Aphasics with Major Comprehension Deficits}

5.3.1. C.D.

C.D. was a 37-year-old right-handed female who suffered a cerebrovascular accident on December 1,1980 . The diagnosis was of an embolism in the middle cerebral 
artery, possibly cardiac in origin An electrnencephalogram showed maximal cortical dysfunction centro-temporally with a slight associated subcortical involvement Neurological examınation revealed a right hemiparesıs, right spastic hemiplegia, a right homonymous hemianopsia and a mixed aphasia, predominantly moto in nature

Speech therapy reports in 1981 showed slow but steady progress in the four language modalities An expressive and receptive deficit in logico-grammatical formulation was present although the patient compensated adequately for this At the end of therapy in 1982, she still showed difficulty in remembering written texts

On November 16,1985, she again suffered a mild left hemisphere CVA There was no evidence of an embolism so a diagnosis of a pathology of the local arterial wall was made She presented with a severe right hemiplegia and an expressive aphasia

When I s.lw the subject over a period of several months, she appeared to be in a stable condition. She was not at that time following a course of speech therapy Her digit span was five for both oral and pointing. ${ }^{12}$

C.D.'s results in terms of percentage correct for the OMBs can be found in Table 5.7.

Table 5.7. Summary Results of Patıent CD

$\%$ Correct

Active 100

Truncated Passive

Direct Object Control, Intransitive Verb

Causative + Intransitive Verb

Dative

92

Active Conjoined Theme

Direct Object Control + Transitive Verb

Object-Subject Relative

75

13 Note that her digit span is better than those of the moderately impaired aphasics and that of J.T. from the least impaired group. 
C.D.'s performance was at chance for the following sentence types: Passive $\left(\chi^{2}=.333, p=.5637\right)$ and Cleft Object $\left(\chi^{2} 0, p=1\right)$. All other sentences were nonrandom, either significantly better or worse than chance; with visual inspection of the $\chi^{\text {? }}$ values revealing the nature of the non-chance performance.

C.D. was very aware of her deficits, stating explicitly that, as soon as more than two anımals were put before her (or mentıoned in the sentence), she could no longer interpret the structure correctly. She would only succeed when a strictly linear order would yield the correct response, e.g. Dative, Active Conjoined Theme, Direct Object Control + Transitive Verb (92\%), and Object-Subject Relative (75\%). As previously stated, her performance on Passives was no better than chance, with the reversal of 
normal thematic order obviating the advantage of having only two DPs However, her performance on Truncated Passive was 100\%, we would therefore suspect that this patient treated these as lexical rather than syntactic passives Her performance on Truncated Causative, 50\%, was significantly above chance $(y:=151.516$, $\left.p=.0001^{*}\right)$; even were the causative considered as one verb, this would be nonrandom Recall that this sentence cannot be interpreted utilising a linear order strategy $(1,(X) ; X, 2)$; in other words, some non-mentioned Causee must, through the Causer's agency, perform an action on $N_{2}$ Due to this patient's difficulties with sentences with three overt DPs, Dative Passive, Subject-Object Relative, Causative (Faire-par), and Cleft-Object Causative (Faire-par) were all incorrectly interpreted, she scored $0 \%$ on them all Causative (Faire-à), Passivized Direct Object Control, Intransitive Verb, and Passivized Direct Object Control + Transitive Verb were all at $8 \%$ accuracy, Cleft-Object Dative and Object-Object Relative at $16 \%$ None of these sentence types are significantly different from each other (see Fig 5 7.) 
166.

Figure 5.7. Accuracy Rate of Patient CD - 'Sentence Contrasts I'

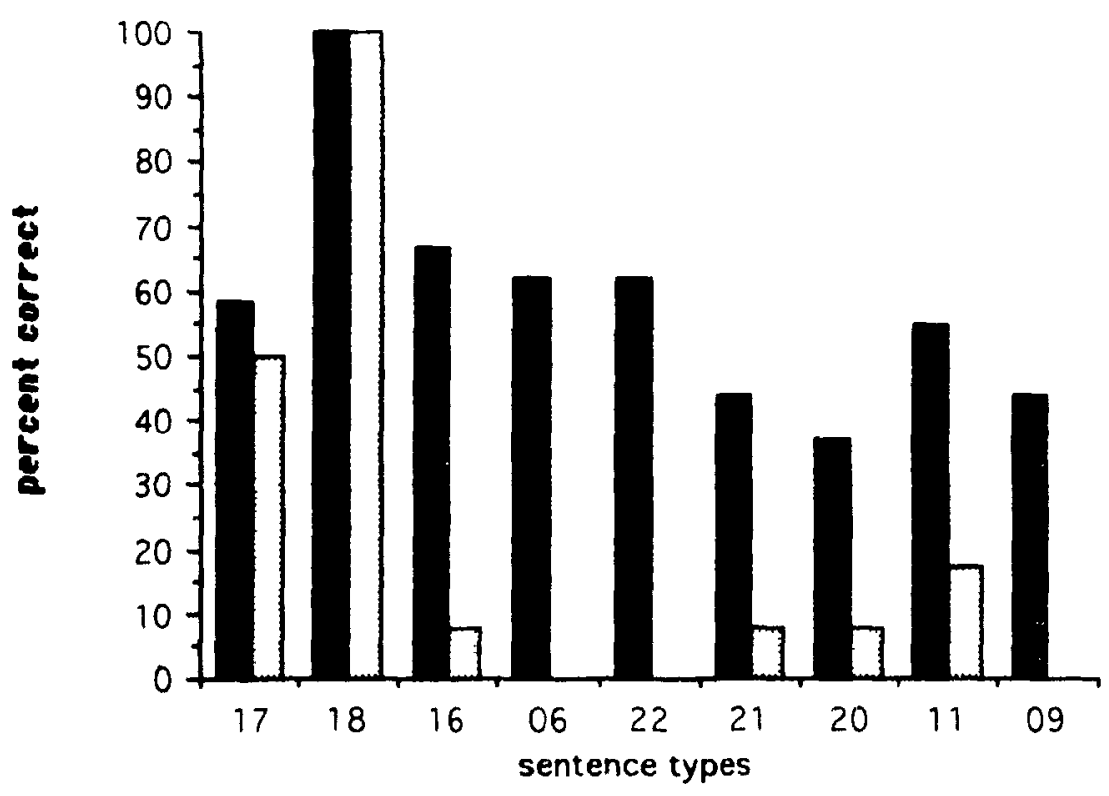

9 aphasıcs

patient CD

[17] Truncated Causative

[18] Causative + Intransitive Verb

[16] Passivized Direct Object Control, Intransitive Verb

[06] Dative Passive

[22] Causative (Farre-par)

[21] Causative (Faire-à)

[20] Passivized Direct Object Control + Transitive Verb

[11] Object-Object Relative

[09] Subject-Object Relative

We would draw the reader's attention .o the poor performance on cleft-object and object relatives. Her scores on Subject-Subject Relative and SS Relative + Conjoined Theme are higher, the latter being statistically significantly different from SubjectObject Relative, Causative (Faire-par), and Cleft-Object Causative (Fairepar) $\left(.0285^{\star}\right.$ on the SDTIP).

Single-factor ANOVAs were performed on her scores and the sentential variables. The number of DPs was significant $\left(F=3.294 ; p=.0377^{\star}\right)$ the Fisher PLSD (at the 0.05 level of significance) revealing a difference between one and four DPs $\left(9.168^{\star}\right)$, between two and three $\left(3.831^{\star}\right)$, and between two and four $\left(4.9^{\star}\right)$. There was no simple effect for either number of Action Vs ( $F=2.2889 ; p=.0738)$ or Inflected $V_{s}(F=2.209 ; p=.1492)$ 
Sentence length was a determinant of accuracy $\left(F=2708, p=0341^{\star}\right)$, problems arising when the sentence contained 10 words or more Linear order also played an important role $\left(F=34928, n=0001^{\star}\right)$ When the combined effects of number of DPs and LO were calculated, main effects of DPS and $L O$ were also found, although there was no interaction In addition, when the combined effects of number of Inflected Vs and LO were calculated. there were main effects for both factors $432, p=0485^{*}$ for inflected $V_{s}$ and $223 ? 3$. $\mathrm{p}=.0001^{\star}$ for $\mathrm{LO}$, although there was no interaction Clefted structures are a problem for this patient, but within the total picture of her deficits, they have less of an effect than other factors such as number of DPs and number of words

C.D. made $195 / 336$ errors on the OMBs, mostly of the linear order kınd With four DP sentences, this may produce $1,2,2,3,3,4$ responses or $1,2+3 ; 2+3,4$ In addition, her errors do not always respect the proper number of arguments a verb has, e.g Dative may be responded to as $1,2,1,3$ or relatives may be treated more like Datives Correlation coefficients were calculated between her error rate and the sentential variables yielding the following significant values: $.527^{\star}, p<.005^{\star}$ for number of DPs, $428, p<025^{\star}$ for number of Action Vs; .711, p<.005* for sentence length; .757, $p<005^{*}$ for linear order.

\subsubsection{J.D.}

J.D. was a 57-year-old right-handed female with a complex neurologic history She suffers from multiple sclerosis (which has probably caused white matter lesions in both hemispheres), and eplepsy (focalized in the left Rolandic area). In 1963, she was hospitalized for neurological signs stemming from a polysystemic involvement of the central nervous system, which was diagnoscd as probably being multıple sclerosis. In 1974, she was again hospitalized with a left peripheral vestibular syndrome with nystagmus. Neurological examınation revealed many abnormal sıgns diagnosed as left homonymous quadranopsia. A tumour or parietal epılepsy was suspected. In August 1974, a nevrectomy of the eighth pair of cranial nerves was performed to control the attacks. In 
December 1974, she had a labyrinthectomy to verify the completeness of the previous nevrectomy. An electroencephalogram showed the possibility of a mild cortical involvement In the left fronto-temporal region

In March 1977 she was tested at the Mayo Clinic in Rochester, however, due to the complexity of the case, a more exact diagnosis could not be made In June 1977, Hopital Notre-Dame diagnosed epilepsy in the left primary motor area. In 1978, she had meningitis (which was probably bilateral) and subsequent to this suffered from speech problerns. She spoke five languages before her neurological problems but lost all but hei mother tongue, French

Speech therapy reports in 1978 showed severe word-finding problems (I.e. in French). Repetition elicited phonemic transtormations with multiple 'conduites d'approche' In narrative discourse, the subject made many paragrammatısms. Reading exhibited parallel deficits, i.e. It was slow and effortful with a moderate dyslexia The subject had word-finding difficulties in writing, exhibitıng a dysorthographia. Oral comprehension in context was good but Pierre Marie's test was not performed in the proper order. Comprehension of an auditorly presented text was poor as memory load Increased. She performed poorly on the Token Test as well

Comprehension of simple material was considered adequate but, as in the neuropsychological examination, the subject had a significant memory deficit. Oral expression was slow, hesitant, with many aborted sentences due to the word-finding difficulties. A tentative diagnosis of conduction aphasia with involvement of a frontal lesion was made at the time.

A temporal cranıotomy and a partial cortectomy were performed on March 20, 1980. Subsequently, she received additional speech therapy although her difficulties were much the same as they had been. Oral expression was hesitant with many phonemic paraphasias especially in repetition. The patient used many circumlocutions as a compensatory stategy for her word-finding diffıculties. In oral comprehension she 
continued to exhibit deficits in all auditorly presented material as length and complexity Increased. The Token Test results were poor as soon as three elements were introduced Both expressive and receptive aspects of the written language were now totally impaired She was tentatively diagnosed at that tıme as a case of Wernicke's aphasia (type 111). predominantly in the written modalities She received therapy over the next three years and her deficits in the written modalities improved and her condition stabilized somewhat

At the time of her participation in this research, she cont inued to have memoryrelated problems Hesitant speech, word-finding difficulties and severe comprehension problems persisted Her oral digit span was three while her pointing span was two J. D.'s results in terms of percentage correct for the OMBs can be found in Table 5.8.

Table 5.8. Summary Results of Patient JD

\% Correct

$\begin{array}{lr}\begin{array}{l}\text { Active } \\ \text { Causative + Intransitive Verb }\end{array} & 100 \\ \text { Direct Object Control, Intransitive Verb } & 92 \\ \text { Direct Object Control + Transitive Verb } & 83 \\ \text { Object-Subject Relative } & 75 \\ \begin{array}{l}\text { Active Conjoined Theme } \\ \text { Dative }\end{array} & 58 \\ \begin{array}{l}\text { Passive } \\ \text { Cleft Object } \\ \text { Conjoined }\end{array} & 50 \\ \end{array}$

$\begin{array}{ll}\text { Truncated Passive } & 25\end{array}$ 
Subject-Subject Relative

Passive Conjoined Agent

Passivized Direct Object Control, Intransitive Verb

Truncated Causative

Causative (Faire-par)

Cleft-Object Dative

Subject-Object Relative

Object-Object Relative

Causative (Faire-à)

Causative + Dative

SS Relative + Conjoined Theme

Dative Passive

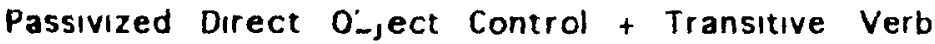

Cleft-Object Causative (Faire-par)

Conjoined Causative

Causative + SS Relative

Conjoined Clauses 4 NPs (No Deletion) (Baseline)

J.D.'s performance was at chance levels for the following: Passive, Truncated

Passive, Cleft Object, Dative Passive, Cleft-Object Dative. All other sentence types were significantly different from chance.

On the crucial sentences, see Fig.5.8. 
Figure 5.8. Accuracy Rate of Patient JD - 'Sentence Contrasts 1'

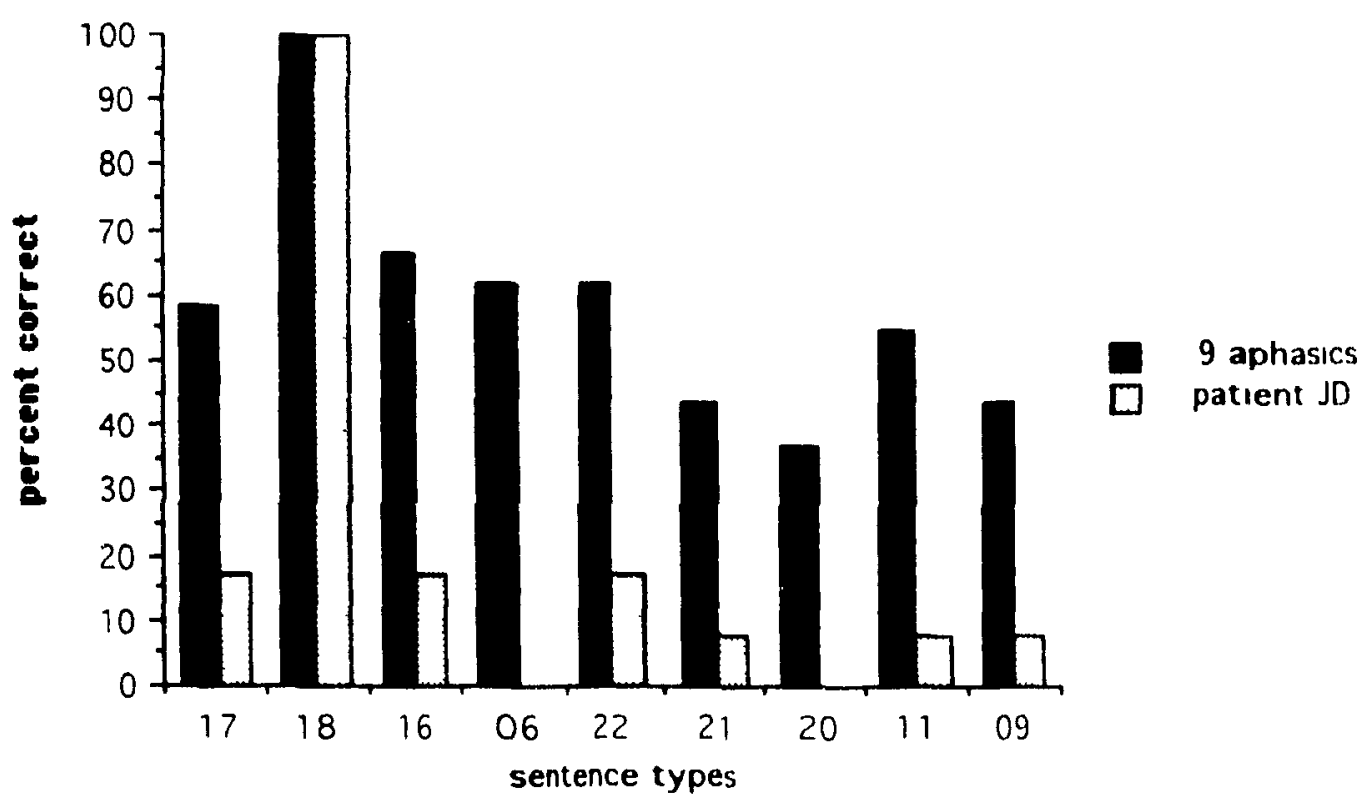

[17] Truncated Causative

[18] Causative + Intransitive Verb

[16] Passivized Direct Object Control, Intransitive Verb

[06] Dative Passive

[22] Causative (Faire-par)

[21] Causative (Faire-a)

[20] Passivized Direct Object Control + Transitive Verb

[11] Object-Object Relative

[09] Subject-Object Relative

Her performance was so imparred that no meaningful contrasts could be made. She scored

$17 \%$ for Passivized Direct Object Control, Intransitive Verb, and Causative

(Faire-par); $8 \%$ for Cleft-Object Dative, Subject-Object Relative, Object-

Object Relative, and Causative (Faire-à); and finally $0 \%$ on Dative Passive,

Passivized Direct Object Control + Transitive Verb, and Cleft-Object

Causative (Faire-par), Her responses to four $D^{D}$ sentences degenerated at times to an order of presentation strategy which she had not previously demonstrated and is only ever seen in severely impaired subjects.

Single-factor ANOVAs were computed between her scores on the OMBs and on the sentential variables. There were significant effects for the following: number of DPS 
$\left(F=3811 ; p=.023^{\star}\right)$, contrasts occurring between two- and three- as well as two- and four- DP sentences, and linear $\operatorname{order}\left(F=39.86 ; p=.0001^{\star}\right)$. In addition, in a 2-factor ANOVA between number of DPs and LO, main effects were found for both factors: DPs:

$F=20.226 ; p=.0001^{*}$ and $L O: F=65.829 ; p=.0001^{*} A$ significant interaction was also found: $F=4.5 ; p=.0137^{\star}$. A 2-factor ANOVA was also computed for number of Inflected Vs and LO; again, main effects for the factors were found and there was a significant Interaction (Infl.Vs: $F=6741 ; p=.0158^{\star} ; L 0: F=25.646 ; p=.0001^{\star}$, and $A \times B: F=4.876$; $\left.p=.037^{\star}\right)$. In fact, her highest scores were all for sentential structures which allowed a linear order strategy. Differences among these were due to sentential complexity and length.

There were no simple effects for number of Action Vs or Inflected Vs, nor were there effects for sentence length as a whole. 14 It would appear that this patient was too Imparred to show such variances in her performance on these variables.

J.D. made 235/336 errors on these sentence types. Correlation coefficients were calculated between her error rates and the sentential variables, the following being statıstıcally significant: number of DPs $\left(479, p=.005^{\star}\right)$; maximum number of words $\left(.629, p<.005^{\star}\right)$; linear order $\left(778, p<.005^{\star}\right)$.

\subsubsection{P.R.}

P.R. was a 46-year-old right-handed male who suffered a cerebrovascular accident on February 7,1985 . The diagnosis was a left hemisphere perisylvian thrombosis. CTscan also revealed a significant focal ischemia in the region of the central nuclei, the internal capsule and the left temporal lobe. It occurred only hours before the subject was due to be operated on to remove a large atypical benign meningioma from the frontoparietal region of the right hemisphere. He exhibited a moderately severe right spastic

14 Though shorter sentences did contrast with the medium-length sentences on the Fisher PLSD. 
hemiplegia and mixed aphası. The surgery was performed on schedule and the ent ire tumour was successfully removed.

On October 25, 1985, the patient underwent a right fronto-parietal cranioplasty to reparr a defect in the bone. An acrylic flap was fixed into position to replace the bone flap removed for analysis during the craniotomy

Speech therapy reports stated that the patient could hardly speak Comprehension was sufficient for simple words and for simple sentences in context The patient could not be tested further. He could not read at all. He was evaluated as having Broca's aphasia Subsequently, he made some progress and could repeat four-syllable words and simple sentences.

- At tıme of testing, he still had the hemiparesis and some word-finding difficulties.

His oral digit span was four and his pointing span was five 15

P.R.'s results in terms of percentage correct for the OMB sentence types can be found in Table 5.9.

Table 5.9. Summary Results of Patient PR

$\%$ Correct

Active 100

Causative + Intransitive Verb

Direct Object Control + Transitive Verb

Passive

Dative

Active Conjoined Theme

Direct Object Control, Intransitive Verb

Object-Subject Relative

83

Dative Passive

67

Passivized Direct Object Control, Intransitive Verb

15 Again, please note the digit span is lower than normal (approx. 7) but better than those of many subjects in the less impaired groups. 
Causative-Reflexive Causer $=$ Theme

P.R.'s performance was at chance for Cleft Object. Other sentences demonstrated non-random performance.

On the crucial sentences, see Fig.5.9. 


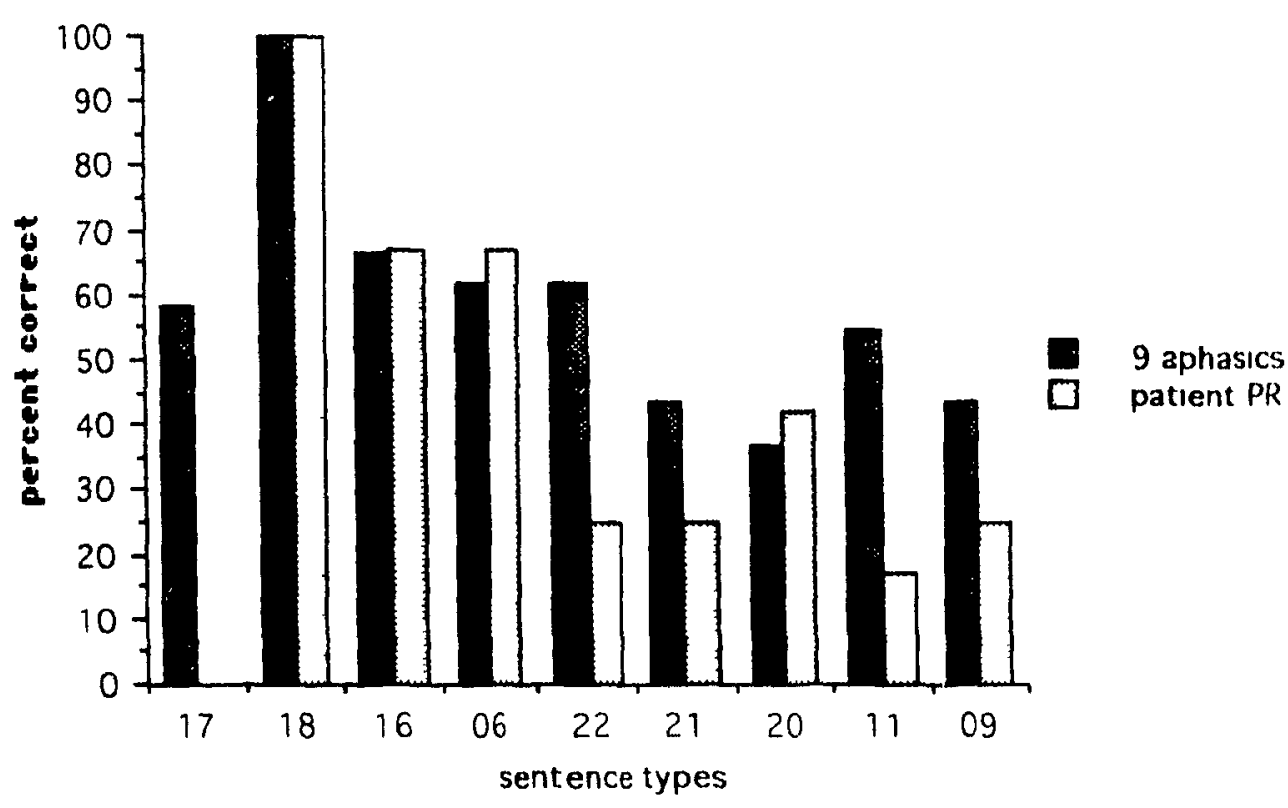

[17] Truncated Causative

[18] Causative + Intransitive Verb

[16] Passivized Direct Object Control, Intransitive Verb

[06] Dative Passive

[22] Causative (Farre-par)

[21] Causative (Farre-à)

[20] Passivized Direct Object Control + Transitive Verb

[11] Object-Object Relative

[09] Subject-Object Relative

P.R. performed as well on Datıve Passive as on Passivized Direct Object Control, Intransitive Verb--67\% correct. This is $25 \%$ better than his scores for Passivized Direct Object Contral + Transitive Verb $-42 \%$ correct. This in turn is $17 \%$ higher than his scores for Cleft-Object Dative, Subject-Object Relative, Causative (Farre-à), and Causative (Faire-par) and 25\% better than his performance on Object-Object Relative. He shows significantly different accuracy on Dative Passive and Causative (Faire-par), a very different pattern than is exhibited by the other subjects (SDTIP $p=.0405^{\star}$ ). The difference between Passivized Direct Object Control + Transitive Verb and Causative (Faire-par) is not large enough to reach significance. 
P. R. is better at passivized structures than at structures that contain wh-trace. If we compare Passive with Cleft Object, we find a difference of $42 \%$, were the score for Cleft Object not at chance, we could perform the SDTIP, which would yield a significant difference, $p=.0247^{\star}$. The difference between Dative Passive and Cleft-Object Dative is again 42\%; since both are different from chance, the SDTIP yields a significant difference, $p=.0405^{\star}$.

Interestingly, considering his problem witi, wh-trace, PR is better at SS Relative + Conjoined Theme than at Subject-Subject Relative (42\% vs. 17\%). It would appear that the additional 'weight' in the subordinate clause helps the subject better segment the incoming string. ${ }^{16}$ P.R. is very impared with two-CP sentences. This was what was predicted by the HAH. The only two types to which he responds with any accuracy are those which allow a linear order interpretive strategy

This subject shows another very idiosyncratic response pattern. All truncated structures yielded $0 \%$ correct. Whether he completely misunderstood them or simply rejected them for pragmatic reasons could not be determıned with this paradigm; perhaps testing with a sentence-picture matching protocol could tease out the pragmatic factor. In addition to this behaviour, all sentences with clitics in the POMB were equally ignored; only Causative-Reflexive Causer $=$ Theme, the one most resembling a passive, obtained a score as high as $6 / 12$. He almost performed at the same level for Passive Conjoined Agent (42\%);17 again, this sentence type shows the same reversal of thematic role order. However, in almost all the other cases, this patient was extremely poor with c!ıtics. This problem with clitics and the problem with truncated forms seem to point to the right hemisphere damage being to blame. Recall that, although A.G.'s

16 Prosodic factors no doubt play a factor here.

17 Within another paradigm, which could not be reported on in this thesis, ne did perform at this level with a sentence type which requires that a pronoun be interpreted as coreferential with the first NP of the sentence. The antecedent is therefore present in the discourse. 
performance was in general very good, he did not like truncated structures either; no doubt he had bilateral damage due to his automobile accident.

Single-factor ANOVAs were computed on his scores on the OMB and the COMB and the sentential variables. He showed no significant effect due to number of DPs (though it approached significance, $F=2.78 \hat{0} ; p=.0625$ ). There was no effect due to number of Action Vs, though again it approached significance $(F=2.917 ; p=.0727)$; there was almost an effect due to number of Inflected $V_{s}(F=3.428 ; p=.0755)$ (this is probably linked to his problem with wh-trace). There was no overall effect for sentence length, but there was for the linear order variable $\left(F=39.871 ; p=.0001^{\star}\right)$. A 2-factor ANOVA of Infl. Vs $\times$ LO yielded main effects for the two factors $\left(F=4.561 ; p=.0431^{*}\right.$ and $F=31.812 ; p=.0001^{*}$ respectively).

P.R. made $183 / 336$ errors on these sentence types. His error rate did not correlate with the number of DPs though it did with the number of Action Vs $\left(.416, p<.025^{\star}\right)$ and the number of Inflected Vs $\left(.341, p<.05^{\star}\right)$. Correlation coefficients were significant for sentence length $\left(.418, p<.025^{\star}\right)$ and linear order revealed its influence as well $(.778$, $p<.005^{\star}$ ). Many of his erroneous responses used a linear order strategy (see Appendix B).

\subsection{Normal Controls}

Single-factor ANOVAs were calculated for each of the 10 controls with relation to the effect that the various sententral variables played in determining their accuracy. Due to the near ceiling performance of most of the controls, most simple effects were not evidenced. Two-factor ANOVAs, however, showed some main effects. For C.D.2, an Infl. Vs $x$ LO yielded a significant effect for infl. Vs $\left(F=4.77 ; p=.039^{\star}\right)$. D.P. and F.T. showed a similar pattern though their results did not actually reach significance. C.V. had no main effect for Intl. Vs but the influence of linear order approached significance. M.J. showed a main effect of number for DPs in a DP $\times$ LO contrast $\left(F=7.621 ; p=.0012^{\star}\right)$. 
L. N. 18 showed a simple effect for number of Action Vs $\left(F=9.768 ; p=.0007^{\star}\right)$, three-verb sentences contrastıng with one- and two-verb ones, R.L. had a significant effect for linear order. $F=6.139, p=.02 * 0 F$. demonstrated the most interesting pattern on linear order, $F=4.925 ; \mathrm{p}=.0354^{\star}$. There was also a variable we have not previously discussed, one we have named 'Agent First'; sentences were coded as possessing this variable if the first action to be enacted was to be performed by $N_{1}$. No subject (patient or control) other than O.F. showed any effect for this factor, his scores reached $F=5.715$, $\mathrm{p}=.0244^{\star}$. This is the experimental subject with the least education (5th grade) and it is hard not to conclude that there is a causal relationship. (For the reader's convenience, summary results of O.F., R.L., and L.N. are included in Appendix B.)

Further implications of the results of both the group studies and the individual cases for understanding sentence comprehension in relation to the Head Accessibility Hypothesis and for pursuing the linguistic analysis of French Causatives will be discussed in the final chapter.

18 L.N. showed atypically poor performance for her education level for sentence types such as Subject-Object Relatives. We could not rule out the possibility of a hearing loss. Upon questioning, we discovered that the woman was Acadian and that she spoke Spanish, having lived for 10 years in South America. In fact, at the time of testing she was boarding a recent immigrant frcm South America. Whether these factors account for the discrepancies in her performance is an open question which calls for further exploration. Her poor performance on Causative (Faire-a) may be due in part to the interlingual ambiguity of the cue for her. In Spanısh, all animate direct objects are preceded by a. 


\section{Chapter 6- General Discussion}

6.1. Comprehension of Causatives and its Implication for the Understanding of Aphasic Comprehension

\subsubsection{The Processing of VP Complements vs. IP Complements}

The central hypothesis of the thesis was that, as causatives (faire-par in particular) have VP complements, subjects' results (number of correct responses) for these structures would pattern with Dative Passives and not with Passivized Direct Object Control + Transitive Verb structures. As a group, the subjects performed 62\% correct on both Dative Passive and Causative (Faire-par) and only $37 \%$ correct on Passivized Direct Object Control + Transitive Verb. It would seem that our prediction was confirmed. These sentence types hold the number of overt DPs constant (three). None, rermit a linear order strategy. There is some slight difference in the number of words' Dative Passive $=11$, Causative (Faire-par) $=10$, and Passivized Direct Object Conirol + Transitive Verb $=12$. However, the difference between Dative Passive and Causative is that the Causative is missing the preposition à. We are therefore not talking about a major lexical category (on the view that à is only a case marker). Between the Causative and the Control structure, the only differences are the additional été and à in the Control structure. Between Dative Passive and the Control structure, the difference is that the latter has an additional verb. In fact, it is with the Passivized Direct Object Control, Intransitive Verb that the group's results on Dative Passive and Causative (Faire-par) tally (66.67\% correct). Although it has the same number of words as the Causative, it has only two DPs, one fewer than the other three types; however, it has the same number of IPs as the other Control structure, I.e. one more than the Dative Passive and the Causative (Faire-par).

Naturally, countıng only the overt DPs is insufficient. Dative Passive and 
Passivized Direct Object Control, Intransitive Verb and Passivized Direct Object Control + Transitive Verb contain an NP trace. In addition. the two latter structures contain PRO Under some iecent analyses of passives, they may also be considered to have a PRO in the VP which is coindexed with the adjunct by-phrase (Gulfoyle,1990). It is difficult to quantify the level of difficulty of the combination of overt lexical NPs + empty categories Some other structures can also be compared which have an antecedent governing from an $A^{\prime}$-position rather than from an A-position as with passivized structures, e.g. Cleft-Object Dative (response: $2,1,3$ ) and Object-Object Relative $(1,2 ; 3,2)$. The group responded $52.8 \%$ correct and $54.6 \%$ correct respectively (both types have three DPs and one wh-trace); this is still below their performance on Causative (Faire-par). ${ }^{1}$

Group results may at times obscure individua! deficits and for that reason each patient's results were analyzed on a case-by-case basıs. Four of the patients showed the same significant differences between these sentence types as were revealed by the group as a whole--J.T., 2 D.C., F.P. and J.R. Two other patients' performances were at ceiling for these sentences: A.G. scored $100 \%$ on all of these except for makıng one mistake on Passivized Direct Object Control + Transitive Verb and C.M had perfect scores P.R. showed better performance on Dative Passive and Passivized Direct Object Control, Intransitive Verb (both $67 \%$ correct) than on Passivized Direct Object Control + Transitive Verb (42\% correct). He performed poorly on both versions of the Causative (both $25 \%$ correct). However, the SDTIP cannot be applied to all of these sentence contrasts; in most cases the differences between the ones that can be compared are

1 This is in reference to full NPs only. Clitics are in $A^{\prime}$-positions and the aphasics' performance on the clitic version of faire-par was poorer than for the full NP version $(56.7 \%$ vs. $71.7 \%$ respectively).

2 Although J.T. did score $25 \%$ more accurately on Causative (Faire-par) than 
not significant The one contrast that can be made under a re-calculation of the causatives reveals that he is significaritly more accurate when responding to Dative Passive than to either causative This might lead one to believe that the reason for the difference in his performance lies in the lexical entries of the verbs involved If, as we assume, he has little problem with the subcategorization frames of three-place predicates per se, he must be experiencing difficulty because faire subcategorizes for a VP complement, entailing the presence of an additional VP-Internal 'Agent', whether expressed or implicit. It may be the case that the semantic specification of faire is too general for P.R., hence the better performance with the more explicit control verbs forcer and inciter. It cannot simply be that he has lost the concept of 'causality', possibly due to the right hemisphere Involvement; otherwise, his performance on the verbs of obligatory control would have been worse, or might have shown the pattern exhibited by the group. The last two patients, C.D. and J.D., score sc poorly on all these sentence types that no meanıngful comparisons are possible.

We feel that the approach taken in this thesis has demonstrated the relationship between a group study approach and case studies Demonstrably, some patients' performances are either too good or too bad to reveal which sentence types are more complex, whether on linguistic or processing grounds. However, the majority of the patients will mirror the group's performance as they do not constitute independent samples. Additionally, although some of the contrasts could not be fully compared statistically, we examıned the case of one patient whose performance contrasted with the group's for reasons we could explain on linguistic grounds, and this information was recoverable by the rase approach.

\section{1.2. The Intactness of the Lexical Representation of Eaire}

What is it that a person knows when he can interpret a Causative (Faire-par)? (Two-thirds of our aphasic sample scored $\geq 9 / 12$; one-third $1 / 3$ scored $\leq 3 / 12$; no 
control scored less than 10)

The Causative + Intransitive Verb (an instance of the Falle-inf contructinn) was invariably answered correctly $(100 \%)$ by all French experımental subjects in English, this sentence type would permit a lineat order strategy, but in Fiench the one who performs the 'action' is in what would appear to be object position Howevel, with a VPInternal-subject analysis, the NP is still in subject position, although it is 'affected' by the 'Causer' or matrix subject

This sentence type was contrasted with Truncated Causative (this was responded to $94 \%$ correctly by the controls) The patients' score dropped to $58.33 \%$ correct which, although significantly above chance (since the three participants must be identified), can be accounted for by the strong bias to treat the explicit Theme of the embedded verb as the Agent, in some ways, they seem to be interpreting the structure as having a pro in object position. ${ }^{3}$ (How legitımate it would be to accept analyses which have posited just such a pro In italian--see, for example, Rizzı (1988)-- is presently unclear, this certainly merits further study.) As a group, if Causatives were not understood, the Truncated Causative would be $0 \%$ correct. In fact one patient (C.D.) who scored 0 on Causative (Faire-par) actually scored $50 \%$ correct on the truncated version; the ditference is statistically significant (SDTIP, $p=.0047^{\star}$ ). This patient also scored significantly better on Truncated Passive than on the full NP version (SDTIP, $p=.012^{\star}$ ), but any explanation that would involve treating the truncated version of this latter structure as a lexical passive surely cannot be generalized to the Truncated Causative. This patient therefore has retained some knowledge of the syntactic consequences of the subcategorization requirements of faire, though her consciously perceived difficulty with three-overt-NP (DP) sentences p' ecludes her from responding to the full form correctly. (Note that it cannot be a psychological block at the mere presentation of three animals in

3 Obviously, since this would be a governed position, this ec could not be PRO. 
the array since the Truncated Causative requires just such an array.) The two other subjects who did not understand the causative, J.D. and P.R, demonstrated that they are not sensitive to the difference between truncated and non-truncated sentence types. Of those six patients who scored well on the Causative (Faire-par), two did only half as well on the truncated version as on the causative containing the intransitive verb (D.C. and J.R.), while the remaining four performed almost as well on both types.

Similarly, when a person has an intact representation of the lexical entry for faire, he must understand the difference between Causative-Theme=Causee cliticized, Intransitive Verb (2 animals)--76 67\% correct--ana Causative-Theme clitıcızed, Truncated ( 3 anımals) $--56.67 \%$ correct.

D.C. C.M. F.P. P.R. J.R.

Causative-Theme=Causee cliticized, $100 \% 100 \% 83 \% \quad 0 \% \quad 100 \%$ Intransitive Verb Causative-Theme cliticized, Truncated $100 \% \quad 92 \% \quad 50 \% \quad 0 \% \quad 42 \%$

Of the five subjects who could be tested, only one (P.R.) was among those who scored poorly on the Causative (Faire-par), again, he cannot properly interpret structures containing this verb and this is compounded by his problems with unspecified reference. J.R.'s performance on Causative-Theme cliticized, Truncated parallels her difficulty with the full NP trunczed version previously aiscussed.

What else must a person understand about Causatives? They must be able to distinguish the interpretation of le and lui in dative and causative sentences. 
184.

Group: Dative-Theme cliticized

Dative-Goal clitıcized

Causative-Theme cliticized

Causative-Causee cliticized 4 $76.67^{\circ}$ o correct

$6500 \%$ correct

$5667 \%$ correct

$66.67 \%$ correct

Both the Dative-Theme cliticized and the Causative-Causee cliticized can be well interpreted by the linear order heuristic (Interpretive strategy); however, note that Dative-Goal cliticized (which cannot be so interpreted) and Causative-Causee cliticized are responded to with the same degree of accuracy The same Case-assigning mechanism seems to be operational here despite the difference in the thematic roles that must be played out. The drop in performance we note in Causative-Theme cliticized may be due to the fact that the accusative clitic is used to represent elther the Causee or the Theme in the appropriate structures Some dialects or idiolects appear to permit the use of the accusative clitic as Causee even in structures with an embedded transitive verb This sentence type is misinterpreted despite the presence of the par-phrase identifying the Causee. For those for whom the accusative clitic is more ambiguous, there are therefore three possible Agents within the sentence, which provides increased opportunities for misinterpretation

The group scores are substantially lowered by P.R.'s inability to correctly interpret pronouns on this task. If we recalculate the group's results without P.R.'s, we obtain:

Datıve-Theme clitıcızed

Dative-Goal cliticized

Causative-Theme cliticized

Causative-Causee clitıcızed
$95.8 \%$ correct

$81.3 \%$ correct

$70.8 \%$ correct

$83.0 \%$ correct

These sentence types were quite well interpreted despite the indeterminacy of the

4 This is an instance of faire-à since the Causee cannot surface as a dative clitic when it has been suppressed. 
185.

reference (the mınımum average score was $85 / 12$ ) These results were predicted by the HAH. Despite the non-stressed nature of clitics, they are well comprehended Their presence adds saliency to the INFL to which they have been adjoined According to other structural account, sentence types containing clitics should be unavallable. Only the HAH accurately predicts the attested performance and explains the reasons for it

\subsubsection{Interpretation of the Reflexive Pronoun Se}

The reflexive pronoun is generally well understood. No completely acceptable structure containing the reflexive pronoun scored less than $65 \%$ correct (the CausativeReflexive Causee is discussed below in the section on 'ungrammatical' structures) The use of se in causative structures is also well interpreted; the preferred reading is that se + faire is equivalent to a passive, before testing, it had been our hypothesis that this would be the case. 5

Causative-Reflexive Causer $=$ Theme

Passive

Truncated Passive

Causative-Reflexive Causer $=$ Theme, Truncated

Causative-Reflexive Causer $=$ Goal, Truncated

Causative-Reflexive Causer $=$ Goal

Dative Passive
$86.67 \%$ correct

$88.33 \%$ correct

$80.00 \%$ correct

$78.33 \%$ correct

$70.00 \%$ correct

$65.00 \%$ correct

$75.00 \%$ correct

Certainly se seems to have a valency-changing effect on the verb with which it is associated; the existence of 'lexicalized' se $+V_{1}$ e.g. s'agenouiller 'to kneel', makes

5 There is the alternate reading which carries with it the sense that the sentential subject may be somewhat responsible for what happens to him. This nuance does not alter the fact that a reversal of thematic roles must be acted out. The testing of other causative structures may also induce or introduce a bias toward such a reading. 
'intransitive' readings likely. However, the ad' ition of se creates unaccusatives not unergatives As we have seen in Chapter 2, the linguistic analysis proposed in Grmshaw (1990) and integrated into an analysis of Romance causatives by Rosen (1989) clatms that it attaches to the argument structure of a verb and satisfies the external argument, as well as lexically binding the internal argument When projected to the level of the phrase structure, this will have the same consequences as passivization the Theme (or Goal) argument will have to move into subject position, with causatives, this will normally be the matrix subject position

One patient 'repeated' 6 Le singe se fait frapper par le lapın as Le singe a ete frappc par Je Japın, another 'repeated' La grenoulle que la chevre a serree a chatoulle le singe as La grenouille se fait serrer par la chevre, et a chatouille le singe, and another patient 'repeated' L'elephant a fait gratter la grenoulle as La grenoulle s'est falt gratter in all cases, after providing these paraphrases, they interpreted the structure correctly Recall that, when the test was designed, the tense of farre was changed from passe compose to the present for these sentences in order not to bias the test subjects toward this reading by the presence of être as auxiliary However, it would appear that the bias is inherent in the structure. These constructions with se + faire are in INFL As with the pronominal clitics, the reflexive clitics are well processed Their presence alerts the experimental subject to the fact that the DP in Spec of IP cannot be an Agent, which is the usual default interpretation.

\subsection{Interpretation of the Semi-Grammatical Causative (Faire-à) and Causative-Reflexive Causee}

Causative (Faire-à) caused an increase in the error rate, with many lineat order errors. The five patients who performed all the tests scored $41.67 \%$ correct on these structures, a large drop from their $71.67 \%$ correct for Causative (Faire-par). 
The structure, as designed for this test, is not fully acceptable The controls scored $8167 \%$ correct on Causative (Faire-à) but $975 \%$ on Causative (Faire-par); only the scores of controls with higher levels of education did not show this drop in accuracy However, it is difficult to convey the reactions that most of the experimental subjects had after the sentences were read. There was much grımacing, requests for repetitions of the first few tokens of the type, explirit indications that they would substitute par for à and so on These reactions do not have exactly the same character as those we see when the stımulus is either very long or very complex. Many theorists have farled to discuss the fact that these constructions are not acceptable The Theme of the embedded verb must be inanimate or the structure seems peculiar. 7 Note that the embedded verbs normally have no such restriction. frapper may take either an inanimate or an anımate object, e $g$ frapper le mur or frapper Pierre We know that there are anımacy restrictions for the other arguments of the causative construction Normally the Causee must be animate to be used in the Causative (Faire-a) construction, if it is not, then the Causative (Faire-par) must be used.

(1) * J'aı fait ınonde les prés a l'eau de la riviere 'I made the water from the river flood the meadows.'

(2) J'aı fait ınonde les prés par l'eau de la rivière.

'I had the meadows flooded by the water from the river.'

Milner $(1982)^{8}$ has clamed that this is linked to the selectional restrictions of the verb faire, e.g.:

(3) J'al fait des méchancetés à Paul.

'I did malicious things to Paul.'

The Theme here is normally inanımate and the Goal anımate. This is exactly the same

1 Kayne (1975) discussed some of these anımacy restrictions.

8 These three examples are taken from Milner (1982: p. 151). We have provided the English glosses 
restriction we see with the causative To borrow some concepts from Saksella (1982) concerning 'affectedness', we would propose that the NP in the PP complement in (3) is animate and affected while the theme is not affected In the farre-a construction, when the object of the embedded transitive verb is inainmate, the sentence is grammatical However, when it is animate there will be a conflict since the Theme of transitive verbs is normally 'affected' or suffers a change of state, there thus appears to be a constraint agaınst two [+anımate/+affected] full NP complements The a-adjunct par-phrase NP is not considered [+affected], at least not in the same way as the Causee in a falle-à causative, which is normally viewed as lacking control over its actions (cf Cannings and Moody 1978, Hyman and Zımmer 1976) The adjunct NP need not be specified for anımacy and the constraint is no longer applicable to the Theme of the embedded verb because it is now impossible to have iwo [+affected] complements in this construction, given that the Causee-argument has been suppressed. This additional selectional restriction imposed on the embedded verb by faire is an additional argument for considering that there is no IP complement to faire in these cases Such restrictions can be accommodated in Rosen's analysis by stipulating that the Lexical Conceptual Structure is changed for this complex predicate. (Even an analysis such as Stoweii's (1983) claims that a governing verb can Impose semantic restrictions on the verb of a Small Clause complement, i e a clause with no IP node.) We cannot see how a biclausal analysis could account for this phenomenon As for the processing of the Causative (Faire-à) sentences used in this test, even though they are of questionable status grammatically, patients scored somewhat better on Causative (Faire-à) $(9=43.52 \% ; 5=41.67 \%)$ than on Passivized Direct Object Control + Transitive Verb $(9=37 \% ; 5=35 \%)$, while the reverse pattern can be seer with the controls. Causative (Faire-à) $=81.67 \%$ and Passivized Direct Object Control + Transitive Verb $=90 \%$ correct An interesting error that was made was to treat the Causee as a goal in the sense of location, with à apparently being treated as vers or 'towards'. This rather curıously echoes the analysis of Cannıngs and Moody (1978) 
who analyzed the construction as evidencing deictic orientation or 'motion towards' the causee.

The Causative-Reflexive Causee also led to misinterpretations. Although Kayne (1975) and Rosen (1989) state that the structure should be grammatıcal, this test shows clearly that there are lexical restrictions. A typical example in Kayne would have a psych-noun in the matrix subject position, which describes the causee's state, e.g.:

(4) La crainte du scandale a fait se tuer le frère du juge.

'Fear of scandal made the brother of the judge kill hırrself.'

$$
\text { (Kayne 1975: } 404 \text {,ex. (4D)) }
$$

Rosen and many others use examples like se laver and se raser; all these verbs can be translated into Englisin with no reflexive at all. (One of the controls, C.D.2, explicitly stated that only se gratter or 'to scratch' seemed right in this structure.) Italian does not permit anything to come between the causative and the embedded verb; however, the preferred interpretation is the reflexive one, as in English.

Subjects tended either to decode the structure as if it were a puzzle or to have the subject 'displace' the se to pre-complex position, i.e. In front of faire, in 'iepeatıng' the sentence, while also adding a par to a produce Causative-Reflexive Caus $=r=$ Theme structure. Naturally, they then misinterpreted the sentence (recall that control O.F. always did this). Of the patients, only C.M., who has a very metalinguistic attitude to French, scored well on these types. Controls with non-Post-Secondary education did poorly on the Causative (Faire-à), though only the subject with the least education did not score well on Causative-Reflexive Causee. Both patıents and controls utilized 'repair' strategies on both of these sentence types (even though this did not always lead to improved scores). Repainng ungrammatical sentences is more typically seen in grammaticality judgment tasks (e.g. Wulfeck 1987). Since in a comprehension task no verbal response need be made, it is perhaps significant that so many of the experimental subjects spontaneously did produce one. 


\subsection{Structures with Stylistic Inversion}

These structures were among the most difficult tested (recall that both experımental groups obtained their lowest overall means in 'Sentence Contrasts 5'). The patients (and control O.F., for example) scored better on Object-Object Relative with Stylistic Inversion (three DPs + Wh-trace) (3167\% correct) than on the CleftObject with Stylistic Inversion (two DPs+ Wh-trace) (1833\%). Misinterpreted 0Os become OSs, which had the best results of all the relatives $(5=86.67 \%$ correct $)$. Cleft Objects, if misinterpreted, become Cleft Subjects, which are not tested by the $\mathrm{OMB}$ as patients scored as well on them as on simple Actives in the very earliest versions of the test. Of all the inversion structures, normals as a group performed best on CleftObject with Stylistic Inversion $(80.83 \%$ correct vs. $74.17 \%$ on Object-Object Relative with Stylistic Inversion.) 9 The most misınterpreted structure was the Subject-Object Relative with Stylistic Inversion, patients scoring $16.67 \%$ correct. SS, with which it could be confused as a type, was $58.33 \%$ correct. I have discussed these results with some French speakers and have been told that the I in quil is often dropped in speech, making the structures with inversions homophonic with subject relatives. In addition, the relative pronouns, even when well articulated may be difficult to discriminate. There are therefore both productive and receptive reasons for them to be difficult to process.

\subsection{The Significance of the Four DP Sentences.}

Contrary to the expectation that these sentences would be harder to process than three-DP sentences, it was a three-DP Causative structure that was the worst interpreted,

9 There may be a particular facilitative effect in French for 0 - 0 relatives in general, Patient R.L., the one francophone case study reporteo in Caplan and Hildebrandt (1988), scored best on these relatives and worst on S-O in both testing sessions. The relative pronoun que may be more salient in that position. One cannot dismiss a parallel function strategy in terms of Grimshaw's prominence theory, it may be conceptually easier to think of the Theme as the less prominent argument in both domains--that of the matrix and that of the embedded verb. 
as demonstrated in 'Sentence Contrasts 5'. The group's score for Cleft-Object Causative (Faire-par) was $19.44 \%$ for all 9 and $13.33 \%$ for the subset of 5 (the controls scored $75.83 \%$ correct). The structure contains three-DPs + Wh-trace + causative verb; obviously this is much too complex. Those patients who had evidenced comprehension deficits used a linear order strategy to decode the sentence However, what is most interesting is that the patients with relatively intact comprehension abilities and the controls most often made the mistake of interpreting the structure as if it were a Causative (Faire-par). Therefore, we find further confirmation of the HAH which predicts that lexical properties of a head may signal a non-linear order bias; in most situations with a causative, the chosen answer would have been correct. This is another case where tirree agerits seem to be competing the head of the relative clause seems to be in the focused position; the DP immediately preceding the causative verb should retain some of its 'potency' and the final DP is preceded by a par. Clefted structures in general were consistently among the worst interpreted by patients and controls alike.

All four-DP sentences containing the causative were fairly difficult for the patients: Conjomed Causative $=31.48 \%$ (though three patients scored $\geq 8$ ) (controls $=87.5 \%) ;$ Causative + Dative $=31.4 \%$ (though three scored $\geq 7$ ) (controls $=88.33 \%)$; Causative + SS Relative (I.e. Causative + Wh-trace + four DPs) $=23.17 \%$ correct (two scored $\geq 7$ ) (controls $70.83 \%$ ). This last structure is extremely complex in French, although the grade-school-educated controls did better than the two high-school-educated ones. The lexical entry for faure cannot help to group the words into phrases in the face of such a lack of transparency. An interesting response strategy which surfaced was that some controls quickly interpreted the sentence-final relative clause first, seemingly to get it out of the way, then responded to the causative structure.

The French patients were often able to interpret sentences with four DPs. Notably, they scored $62 \%$ on Conjoined Clauses 4 NPs (No Deletion) (Baseline) and 
$58.33 \%$ on SS Relative + Conjoined Theme. In fact, patients found this last structure no harder than Subject-Subject Relative $=58.33 \%$. It is fair to say that conjoined DPS seem not to add much difficulty to a structure; this was demonstiated in 'Sentence Contrasts 4'. (The adaptive strategy which emerged for four DP sentences was a linear order one' $1,2+3 ; 2+3,4$ !. The argument structure of the verb. 1.e the number of theta-roles it normally assigns, seems to be the more decisive factor in predicting processing load Conjunctions are, in fact, one of the functional categories produced by agrammatics, witness Goodglass and Menn (1985) for English, Feyeressen (1985) for French, Kamıo $(1984,1985)$ for Japanese. It would appear that a copy of an identical category elther by conjunction or adjunction, does not ental the same processing cost as complementation by a different type of category. Perhaps this is part of the reason for the relatively good performances on causatives, ı.e. on the analysis of a partıal merger of the argument structures, a VP takes another VP as its complement. Uitımately, it is no doubt the government relation that holds between a head and its co:nplement that is the locus of syntactic complexity.

In addition, in contrasting Conjoıned Clauses 4 NPs (No Deletion) (Baseline) $=62 \% 10$ and SS Relative + Conjoined Theme $=58.33 \%$, the subjects seemed quite sensitive to the addition of the complementizer qui, which was the only overt element that differentiated these two sentence types 11 . Certain functional categories can thus be attended to.

10 Although this sentence type contains at least two CPs, the linear order strategy will aid interpretation.

11 A similar finding was reported by Caplan and Hildebrandt with patient R.L., who appeared sensitive to the difference between the qui of S-S relatives and the et of the Conjoined sentence types, performing consistently better on the Conjoined even though they require the same response $(1,2 ; 1,3)$. 


\subsection{Extensions of the Head Accessibility Hypothesis}

Thus far, we have restricted discussion of the HAH to the syntactic domain. Because the model of grammar assumed withın this thesis locates inflectional morphology within the syntactic component, we were able to demonstrate that the HAH accounted for the presence or absence of these spell-outs of phi-features, I.e. agreement, case, tense, etc. The HAH clearly generalizes to the domains of derivational morphology and phonology as well. This is so because the construct head is used at all levels of the grammar. The HAH therefore permits us to deal with the derivational morphological patterns seen in agrammatism. We have only briefly mentioned a characteristic that is often found as part of the symptom complex, i.e the nominalization of verbs. Recall that Kean's hypothesis stated that derivational affixes (as P-clitics) tended to be omitted in agrammatism. Now, we have seen that syntactic category membership differentially affects agrammatic retention. Derivatıonal suffixes determine the syntactic categories of the stems to which they are affixed. Marshall and Newcombe (1966) and Marshall, Newcombe and Marshall (1970) have demonstrated the claim--long made in t,ie literature (see Marshall and Newcombe (1966) for further references)-- that nouns are retained better than adjectives and adjectives better than verbs in a deep dyslexic subject (G.R.) who evidenced 'telegrammatıc speech', ı.e. he was also agrammatıc. 12 In reading tasks, wrong responses tended to be nouns when the stımulus word was either a noun or a verb. Ninety percent of the verbs were read as nouns and ninety percent of the misread nouns had other nouns substituted for them. Whitaker's (1972) non-fluent patient (F.W.) also produced many deverbal nouns instead of the intended verb targets, as in (5):

\section{(5)}

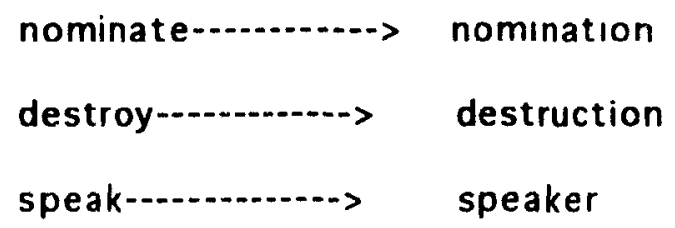

12 There is a high though not perfect correlation between the syndromes of deep dyslexia and agrammatism. 
Patterson (1980) reported the derivational paralexias of deep dyslexic patients Twothirds of the patients' errors consisted of suffix deletions, as in (6a) and suffix substitutions, as in $(6 b)$
a. soloist -..........-. solo
b. projection--...-.-.) projector
c. contain--...-..--> container
d. applaud-..........-> applause

Surprisingly, however, one-third of the errors consisted of suffix additions, as in $(6 \mathrm{c})$, or simply changes in part of speech, e g (6d). Of the major lexical categories, verbs wete particularly likely to be incorrectly produced, a bias towards producing concrete Imageable nouns and adjectives was demonstrated in her results. ${ }^{13}$

These findings cannot be explained by Kean's hypothesis, ${ }^{14}$ since the tested items were all phonological words We are led to the conclusion that, contrary to her predictions, nominalizing suffixes seem to contribute to a word's potential for retention, and their loss may place the non-nominal base in 'processing jeopardy' as it were in other cases, where a noun is the base of some derivational process, we would expect that any affix which changes this preferentially processed base to another syntactic category (Adj or V) would be less retained, perhaps even in spite of semantic non-transparency There must then be an interaction between the syntactic category of the base, the syntactic features associated with a given affix and its subcategorization requirements.

For severely afflicted agrammatics, the noun phrase may be the most complex structure possible. We have argued throughout this thesis (see also Gendron 1986) that

13 Though these findings are from reading tasks, other patients reported by Whitaker (1972)--K.T. and W.L.--made comparable errors on naming tasks: decide-> decision; conceal-> concealment. Unfortunately, F.W. could only be tested in the reading modality.

14 Additional evidence that Kean's analysis cannot be maintained can be found in Kehayla (1984), who showed that what determined retention of derivational affixes was a complex interplay between the semantic transparency of the affixes and the nature of the boundary with which they were associated. 
the NP is easier to process for anterior aphasics because it is the only category that need not subcategorize for anuther. It is inherently intransitive, its complements always optional A compensatory strategy that aphasics may utilize to circumvent their expressive difficulties is to use underived nouns and noun-formıng suffixes (e.g. in English, the agentive -er) attached to the appropriate categories to mımıc some aspects of a sentential structure. In fact, a dyslexic patient of Marshall, Newcombe and Marshall's (1970) made a consıderable number of addition errors in reading, producıng -er nominals for the related verb stımulı. Agrammatics might be considered to be exploitıng the referential uses of nouns.

Consıder the following example (adoptıng Williams' (1981b) notation): in the case of the suffix -er, the external argument $R$ of baker, for example, would be equated to the Actor theta-role of the verbal stem:

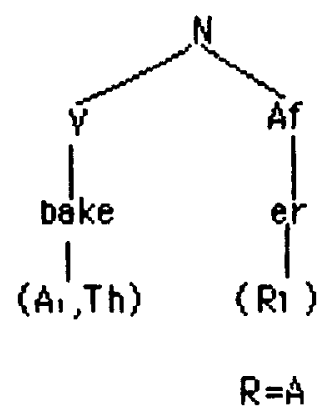

The whole would stand for: The man (or the one) who bakes. This process has the advantage of taking place in the Lexicon. Feyereisen's (1985) case (Mrs.V), who used an "Infer [sic] rather than specify" strategy, described a scene in which a man holdıng a fishing pole was walkıng towards the river simply as un pêcheur 'a fisherman'. Studies by Danly and Cooper (as cited in Foldı, Cicone, and Gardner 1983) have shown that so-called monotonic telegrammatic utterances show melodic contours appropriate to declarative sentences. By examining the respıration patterns of Broca's aphasıcs, Schönle (1979) (also cited in Foldi et al. 1983) showed that they were attempting to encode connected discourse and not merely unrelated word lists. 
The other linguistic accounts cannot explain the addition of affixes, e.c: nominalizations Our claim that the Head Accessibility Hypothesis generalizes to the morphological domain could in future research work be tested in languages that have morphological causatives. 15

The construct head also finds an application in phonology, where it is referred to as nucleus. It is beyond the scope of this thesis to fully deal with phonological complexity (see Blumstein (1988-214-220) for further discussion) Suffice it to say that the basic unmarked syllable structure is $\mathrm{CV}$, i e the syllable licences a non-branching onset (no consonant clusters) and a non-branching rhyme (no coda), which then rewrites as the nucleus. The concept of phonological salience may be linked to sonority, i e. loudness The maxımally sonorous segment is the nucleus, with a consequent loss of sonority as one moves further away from that position. Phonological errors found across all aphasic types 16 are those of syllable simplification in that the target tends to be reduced to CV. When substitution errors occur, they, like the morphological errors previously discussed, tend to involve at most one erroneous feature. This demonstrates non-random and principled misselections. The aphasics seem to have the correct target in mind but to have trouble in either access or execution.

An interesting fact which intersects the morphosyntactic and phonological domains is that syllabic inflectional affixes are better retained than non-syllabic ones. There is ample evidence of this in the literature. It is true for English in tasks of production and comprehension of the syllabic plural, for example Kehayia (1990). In addition, it has also been demonstrated in comprehensıon in Hungarıan (Osmán-Ságı and MacWhınney 1991 cited in Bates and Wulfeck 1989) that an accusative form containıng a strong vowel is

15 The Causative tests developed in this thesis were initially inspired by work by Ammon and Siobin (1979), who tested children's comprehension of causatives in English, Italian, SerboCroatıan and Turkısh. Aphasıc data from Turkısh or Japanese would be invaluable for further investigating the role of the lexical processes in the building-up of syntactic structure

16 These errors are also reported in the developmental literature. 
better attended to by both fluent and non-fluent aphasics (e.g. macska't 'cat-accusative' vs. mókus-t 'squirrel-accusative'). A likely explanation is that they are generally more salient There is a vowel nucleus which is the head of the syllable; it may also at tink 'bear stress In addition, re-syllabification often occurs and, if the ster. ends with a consonant, this element may become the onset of a vowel-ınitial affix, thereby also simplifying the stem-final rhyme Non-syllabic affixes are not headed in this sense, tending to act as codas or appendices to the final syllable of the stem, complicating its structure.

The HAH is constrained to only permit reference across linguistic levels through the notion of head 17 Various other theorists have also ment:oned this interactive aspeci; for example, Garman $(1982,1990)$ discusses how phonology (syllabicity), word class, and syritactic level interact to explain agrammatics' retention of inflectional morphology alone. Our account generalizes to derivational affixes and phrase structure as well and does so in a principled way.

\subsection{Conclusion}

We have presented a detalled analysis of aphasics' comprehension of the complex predicate causative verb. The hypothesis that the lexical properties of the French verb in this case entall something akın to a partial merger of two verbs' argument structures was supported not only by the group results but by individual case studies. Additionally, we have shown that it is unlikely that there is an elaborated or even defective IP node between the verbs in the French case, given subjects' responses to obvious case of CPs (and consequently of IPs), I.e. clefted structures and the Passivized Direct Object Control

+ Transitive Verb. We have extended Rosen's (1989) analysis of the Causative (Faire-à), which now accounts for the unacceptability of the structure as a function of

17 In morphology and syntax, $[+N]$ categories are more accessible for structural reasons. In phonology, structural reasons privilege the feature [+voc] since this will determine what can count as a nucleus and the position any given segment may hold in the syllable. 
the anımacy of the embedded Theme.

Finally, our re-interpretation of the closed -class hypothesis within a stuctly Government-Binding framework has permitted us to parsimoniously account fol the pattern of syntactic expressive and receptive deficits in agrammatisn and paragrammatism cross-linguistically We locate the primary deficit in the categorial status of the heads of projections (whether on the syntactic level or the morphological level) and the categorial status of the complements these heads require to satisfy constraints of well-formedness. We assume that, as a head, an element acquires structural prominence and is therefore more salient Structural complexity is thus defined in a purely hierarchical fashion at all linguistic levels; branching structures are more difficult to process than non-branching ones. The relation of government, which is defined as the relation holding between a head and its complements, plays a crucial role Languagespecific features can clearly, and in many cases redundantly, aid an impaired subject by makıng functional heads more salient, thereby at tımes cırcumventıng or minumizing receptive difficulties.

Ease of processing is defined as the syntactic transparency of thematic role order (which in the case of the causative may be item-specific), I.e. D-structure positions--'a pure representation of GF-theta' maintained throughout the derivation Chain formations, whether caused by movement of maximal projections or of governed heads, are the loci of difficulty since the landing site for the moved element may not be avalable due to the increased processing load the construction of such structures entals (e.g. branching maximal and intermediate projections of functional categories). Our approach has the advantage of unifying what appeared to be disparate phenomena--problems with chain formations (NP and wh- movement) and the difficulty caused by inflectional morphology -into one by adoptıng Pollock's (1989) hypothesıs that the verb must move to INFL to get Tense, creating a verbal chain. This explains why infinitives, which need not move, are often default forms. 
The Head Accessibility Hypothesis is to be preferred to other hypotheses that have been proposed since it can account for a larger body of data, is not modality-specific and cuts across linguistic domains it allows us to account for processing difficulty by locating the initial problems with lexical retrieval of both lexical and, especially, functional categories which, under new assumptions, head their own projections. The head of a phrase dictates the nature of its complements. In addition, its properties will dictate the presence or absence of Specifier positions, sister(s) to one of the head's projections, usually an intermediate level one. If, as Chomsky has recently suggested (1992), subject-verb agreement and Case reduce to instances of Spec-head agreement, the pivotal role played by both phrasal heads and Specifier positions cannot be ignored in future research work, we hope to investigate the nature of this agreement in languages with overt case inflections. 


\section{REFERENCES}

Abney, S 1986. Functional elements and lisencing. Paper presented at GLOW, Gerona, Spain.

Aissen, J 1974. Verb raisıng. Linguistic Inquiry $5 \quad 325-366$

Aissen, J. 1979. The Syntax of Causative Constructions New York. Garland Publishıng

Ammon, M. S and Slobin, D. I. 1979. A cross-lınguistic study of the processing of causative sentences Cognition 7. 3-17.

Baker, M. C. 1985. Incorporation A Theory of Grammatical Function Changing Unpublished doctoral dissertation, MIT, Cambridge, Mass

Baker, M. C. 1988. Incorporation. A Theory of Grammatical Function Changing Chicago The University of Chicago Press

Baruzzı, A. L. 1985 Effects of Degree of Literacy on Syntactic Comprehension in Normal and Aphasic Populations Unpublished Master's thesis, McGill University, Montreal

Bates, E., Chen, S, Tzeng, O., LI, P. and Opıe. M 1991 The noun-verb problem in Chınese aphası. Braın and Language 41. 203-233

Bates, E., Friedericı, A and Wulfeck, B. 1987a. Grammatical morphology in aphasia Evidence from three languages. Cortex 23 545-574.

Bates, E., Friederici, A and Wulfeck, B 1987b Sentence comprehension in aphasıa. a cross-lınguistic study Brain and Language $32 \quad 19-67$

Bates, E., Friedericı, A., Wulfeck, B. and Juarez, L. 1988. On the preservation of word order in aphasıa Cross-linguistic evidence. Brain and Language 33 323-364

Bates, E., Hamby, S. and Zurif, E. 1983 The effects of focal brain damage on pragmatic expression. Canadian Journal of Psychology 37: 59-84

Bates, E. and Wulfeck, B. 1989. Crosslınguistic studies of aphasia. In B. MacWhinney and E. Bates (eds.), The Cross-Linguistıc Study of Sentence Processing (pp. 328-371). New York: Cambridge University Press.

Berndt, R. S. and Caramazza, A. 1981. A re-definition of Broca's aphasia. Applied Psycholinguistics 1. 225-278.

Bever, T. G. 1970. The cognitive basis for linguistic structures. In J R. Hayes (ed.), Cognition and the Development of Language (pp. 279-362) New York: John Wiley \& Sons.

Bhatnagar, S. and Whitaker, H. A. 1984. Agrammatism in inflectional bound morphemes: a case study of a Hindi-speakıng aphasic patient. Cortex 20. 295-301

Blake, B. J. 1990. Relational Grammar. London: Routledge. 
Blake, B J. 1990 Relational Grammar London. Routledge

Blumsteın, S. E. 1988. Neurolinguistics: an overview of language-braın relations in aphasıa In F J Newmeyer (ed) Linguistics The Cambridge Survey: III Language Psychological and Biological Aspects (pp 210-236) Cambridge: Cambridge University Press

Bradley, D, Garrett, M and Zurif, E 1980 Syntactic deficits in Broca's aphasia.In D. Caplan (ed.), Biological Studies of Mental processes (pp. 269-286). Cambridge, Mass.: MIT Press.

Burzıo, L 1986. Italian Syntax: A Government-Biriding Approach. Dordrecht: D. Reidel.

Butler, S. L., Caplan, D. and Waters, G S.1988. Characteristıcs of syntactic comprehension deficits following closed head injury. Paper presented at Academy of Aphasıa, Montreal, October, 1988

Butterworth, B., Panzerı, M, Semenza, C. and Ferierı, T. 1990 Paragrammatisms: A longitudinal study of an Italian patient. Language and Cognitive Processes 5: 115-140.

Cannings, $P$ and Moody, M. D. 1978 A semantic approarh to causation in French. Lingvistıcae Investigationes 11: $331-362$

Canzanella, M A. 1990. A Study of Prepositions in Aphasia: Experımental Results and their Theoretical Implications Unpublished Master's thesis, McGill University, Montreal.

Caplan, D. 1983a A note on the "word order problem" in agrammatism. Brain and Language 20: $155-165$.

Caplan, D. 1983b Syntactic competence in agrammatism: a lexical hypothesis In $M$. Studdert-Kennedy (ed.), Psychology of Language (pp. 177-187). Cambridge, Mass.: MIT Press.

Caplan, D. Baker, C. and Dehaut, F. 1985. Syntactic determınants of sentence comprehension Cognition 21: 117-175.

Caplan, D. and Hildebrandit, N. 1988. Disorders of Syntactic Comprehension. Cambridge, Mass.: MIT Press.

Caramazza, A. and Zurif, E. 1976. Dissociation of algorithmic and heuristic processes in language comprehension: Evidence from aphasis. Brain and Language 3: 572-582.

Caramazza, A. and Micelı, G. 1991. Selective impairment of thematic role assignment in sentence processing. Brain and Language 41: 402-436.

Chornsky, N. 1970. Remarks on nominalisation. In R. Jacobs and E. Rosenbaum (eds.), Readings in English Transformational Grammar (pp. 184-221). Waltham, Mass.: Ginn and $\mathrm{Co}_{0}$

Chomsky, N. 1982 Lectures on Government and Binding: The Pisa Lectures. 2nd rev. ed. Dordrecht; Foris. 
Chomsky, N. 1986. Barriers Cambridge, Mass. MIT Press.

Chomsky, N 1989 Some notes on economy of derivation and repiesentation MIT Working Papers in Linguistics 10: 43-74.

Chomsky, N. 1992. A minımalist program for linguistic theory Unpublished typescript, MIT.

Chomsky, N. and Lasnik, H. 1977. Filters and control Linguistic Inquiry 8. 425-504.

Comrie, B. 1976 The syntax of causative constructions. Cross-language similarities and divergences. In M. Shibatani (ed), Syntax and Semantics 6: the Grammar of Causative Constructions (pp. 261-312). New York: Academic Press.

Comrie, B. 1981. Language Universals and Linguistic Typology Oxford Basil Blackwell

Cook, V. J. 1988. Chomskj's Universal Grammar An Introduction. Oxford Basil Blackwell

Cooper, W. E and Zurif, E. 8. 1983. Aphası: Information processing in language production and reception. In B. Butterworth (ed.), Language Production Vol. 2: Development, Writing and other Language Processes (pp 225-256) London. Academic Press.

De Bleser, R. and Bayer, J. 1985. German word formation and aphası. The Linguistic Review 5: 1-40.

De Bleser, R. and Bayer, J. 1988. On the role of inflectional morphology in agrammatism In M. Hammond and M. Noonan (eds.). Theoretical Morphology ( $p p$ 45-69) New York Academic Press.

De Bleser, R., Bayer, J. and Luzzattı, C. 1990. Patterns of morphosyntactic impairment and preservation: a morpholexical approach. Paper presented at TENNET 1, Montreal, May, 1990.

De Renzı, E. and Vignolo, L. 1962. The Token Test: A sensitive test to detect receptive disturbances in aphası. Brain 85: 665-678.

Di Sciullo, A. and Willams, E. 1987. On the Definıtion of Word. Cambridge, Mass.: MIT Press.

Farrell, G. 1985. Compensatory Mechanısms in Aphasıa: Production of Syntactic Forms that Express Thematic Roles. Unpublished Master's thesis, Mc Gill University, Montreal.

Fay, D. and Cutler, A. 1977. Malaptopisms and the structure of the mental lexicon. Linguistic Inquiry 8: 505-520.

Ferguson, G. A. and Takane, Y. 1989. Statistical Analysis in Psychology and Education. 6th edition. New York: McGraw-Hill Publishing Company. 
Feyereısen, P. 1985. How do aphasic patıents differ in sentence production? Unpublished typescript, Université de Louvain.

Foldi, N. S., Cicone, M. and Gardner, H. 1983. Pragmatic aspects of communication in brain-damaged patients. in S. J Segalowitz (ed.), Language Functions and Brain Organızatıon ( $p p$ 51-86) New York: Academıc Press.

Frazıer, L. 1988. Grammar and language processing. In F. J. Newmeyer (ed.) Linguistics: The Cambridge Survey: II Linguistic Theory Extensions and Implications (pp. 15-34). Cambridge: Cambridge University Press.

Fukui, N. 1986. A Theory of Category Projection and its Applications. Unpublished doctoral dissertation, MIT, Cambridge, Mass.

Fukui, N. and Speas, M. 1986. Specifiers and projection. MIT Working Papers in Linguistics 8: 128-172.

Garman, M. 1982. Is Broca's aphasıa a phonological deficit? In D. Crystal (ed.), Linguistic Controversies (pp. 152-179). London: Edward Arnold.

Garman, M. 1990. Psycholınguistics. Cambridge: Cambridge University Press.

Garnhain, A. 1985. Psycholinguistics: Central Iopics. London: Methuen.

Garrett, M. F. 1990. Sentence processing. In D. N. Osherson and H. Lasnik (eds.) Language: An Invitation to Cognitive Science. Volume 1 (pp. 133-175). Cambridge, Mass.: MIT Press

Gendron, J. 1983. A re-examination of Smith and Mimica's "Agrammatism in a caseinflected language: Comprehension of agent-object relations". Unpublished typescript, McGill University.

Gendron, J. 1986. Examınıng argument structure in order to explaın agrammatic phenomena. McGill Working Papers in Linguistics 3.2: 33-50.

Gıorgı, A. and Longobard, G. 1991. The Syntax of Noun Phrases: Configuration, Parameters and Empty Categories. Cambridge: Cambridge University Press.

Goodall, G. 1987. Parallel Structures in Syntax: Coordination, Causatives and Restructuring. Cambridge: Cambridge University Press.

Goodglass, H. 1976. Agrammatism. In H. Whitaker and H. A. Whitaker (eds.), Studies in Neurolınquistics 1 (pp. 237-260). New York: Academic Press.

Goodglass, $H$. and L. Menn. 1985. Is agrammatism a unitary phenomenon? In M. Kean (ed.), Agrammatısm (pp. 1-26). Orlando: Academic Press.

Grımshaw, J. 1979. Complement selection and the lexicon. Linguistıc Inquiry 10: 279-326. 
Grimshaw, J. 1981. Form, function, and the Language Acquisition Device. In C. L. Baker and J. J. McCarthy (eds.), The Logical Problem of Language Acquisition (pp 165182). Cambridge, Mass.: MIT Press.

Grimshaw, J. 1982. On the lexical representation of Romance reflexive clitics. In I. Bresnan (ed.), The Mental Representation of Grammatıcal Relations (pp. 87-148). Cambridge, Mass.: MIT Press.

Grimshaw, J. 1990. Argument Structure. Cambridge, Mass.: MIT Press.

Grodzinsky, Y. 1984. The syntactic characterization of agrammatısm. Cognition 16: 99-120.

Grodzınsky, Y. 1990. Theoretıcal Perspectives on Language Deficıts. Cambridge, Mass.: MIT Press.

Guastı, M. T.1990. The 'Faire-Par' construction in Romance and in Germanic. In A L. Halpern (ed.), The Proceedings of the Ninth West Coast Conference on Formal Linguistics (pp. 205-218), Stanford: CSLI ( Stanford Linguistics Association).

Guilfoyle, E. 1990. Functional Categories and Phrase Structure Parameters. Unpublished doctoral dissertation, McGill University, Montreal.

Guilfoyle, E. and Noonan, M. 1988. Functional categones and language acquisition. Paper presented at the Boston University Conference on Language Development 13

Hagiwara, H. 1985. Syntactic deficits in sentence comprehension in Japanese aphasics. Unpublished typescript, McGill University, Montreal.

Hagiwara, H. 1987. Sentence Comprehension Disturbances in Japanese Aphasics. Unpublished doctoral dissertation, McGill University, Montreal.

Hagiwara, H. and Caplan, D. 1990. Syntactic comprehensıon in Japanese aphasics. Braın and Language 38: 158-170.

Heilman, K. M. and Scholes, R. J. 1976. The nature of comprehension errors in Broca's, conduction, and Wernicke's aphasics. Cortex 12: 258-265.

Higginbotham, J. 1985. On semantics. Linguistic Inquiry 16: 547-593.

Hildebrandt, N. 1986. A Linguistically-Based Parsing Analysis of Aphasics' Comprehension of Referential Dependencies. Unpublished doctoral dissertation, Mc Gill University, Montreal.

Hyman, L. and K. Zımmer. 1976. Embedded topic in French. In C. Li (ed.), Subject and Topic (pp. 191-211). New York: Academic Press.

Jackendoff, J. 1985. Believing and intending: Two sides of 'he same coin. Lingusstıc Inquiry 16: $445-460$. 
Jarema, G. and Kehayı, E. 1990. Imparment of inflectional morphology and lexical storage. Unpublished typescript, Centre de Recherche du Centre Hospitalier Côte-des-Neıges, Montreal.

Kail, M. 1989. Cue valıdity, cue cost, and processing types in sentence comprehension in French and Spanish. In B. MacWhinney and E. Bates (eds.), The Crosslinguistic Study of Aphasıa (pp. 77-117). New York: Cambridge University Press.

Kamıo, A. 1984. A linguistic analysis of three Japanese agrammatıcs' speech. Unpublished typescript, University of Tsukuba and Harvard-Yenching Institute.

Kamıo, A. 1985. Agrammatism and linguistic theory: Toward a grammatical characterization of agrammatic syndromes. Unpublished typescript, University of Tsukuba and Harvard-Yenching Institute.

Kayne, R. S. 1975 French Syntax: The Transformatıonal Cycle. Cambridge, Mass.: MIT Press.

Kayne, R. S. 1989. Null subjects and chitic climbing. In O. Jaeggli and K. J. Safir (eds.), The Null Subject Parameter (pp. 239-261). Dordrecht: Kluwer.

Kean, M. 1977. The linguistic interpretation of aphasic syndromes: Agrammatism in Broca's aphasia: An example. Cognition 5: 9-46.

Kean, M. 1978. The linguistic interpretation of aphasic syndromes. In E. Walker (ed.), Explorations in the Biology of Language (pp. 67-138). Muntgomery, Vt.: Bradford Books.

Kean, M. 1980. Gramrnatica! representations and the description of linguıstic processing.In D. Caplan (ed.), Biulogical Studies of Mental Processes (pp. 239-268). Cambridge, Mass.: MIT Press.

Kehayia, E. 1984. Morphological 'nvestıgations of Agrammatism. Unpublished Master's thesis, McGill University, Montreal.

Kehayı, E. 1990. Morphological Defisits in Agrammatıc Aphasia : A Comparative Study. Unpublished doctoral dissertation, McGill University Montreal.

Kilbourn, K. 1991. Selective impairment of grammatical morphology due to induced stress in normal listeners: Implications for aphasia. Brain and Language 41: 275-288.

Kolk, H. J. 1978. Judgement of sentence structure in Broca's aphasia. Neuropsychologia 16: 617-625.

Kolk, H. J. and van Grunsven, M. J. F. 1985. Agrammatısm as a variable phenomenon. Cognitive Neuropsychology 2: 347-384.

Koopman, H. and Sportiche, D. 1988. Subjects. Unpublished typescript, UCLA.

Lamontagne, G. and Travis, L. 1986. The Case Filter and the ECP. McGill Working Papers in Linguistics 3.2: $51-75$. 
L.apointe, S. 1983. Some issues in the linguistic description of agrammatism. Cognition 14: $1-39$.

Lapointe, S. 1985. A theory of verb form use in the speech of agrammatic. Brain and Language 24: 100-155.

Larson, R. 1988. On the double object construction. Linguistic Inquiry. 19: 335-392

Lebeaux, D. 1988. Language Acquisition and the Form of Grammar. Unpublished doctoral dissertation, University of Massachusetts, Amherst

Linebarger, M. C. 1989. Neuropsychological evidence for linguistic modularity. In G N. Carison and M. K. Tanenhaus (eds.), Linguistic Structure in Language Processing (pp. 197-238). Dordrecht: Kluwer.

Linebarger, M. C., Schwartz, M. F. and Saffran, E. M. 1983 Sensitivity to grammatical structure in so-called agrammatic aphasics. Cognition 13. 361-392.

Luria, A. A. 1975. Two kınds of disorders in the comprehension of grammatical constructions. Lillguistics 154/5, 47-56.

MacWhınney, B., Osmán-Ságı, J. 1991. Inflectıonal markıng in Hungarıan aphasıcs Braın and Language 41: 165-183.

MacWhınney, B., Osmán-Ságı, J. and Slobın, D. I. 1991. Sentence comprehensıon in aphasıa in two clear case-markıng languages. Brain and Language 41. 234-249.

Magnúsdóttır, S. and Thráınsson, H. 1990. Agrammatısm in Icelandıc: Two case studies. In L. Menn and L K Obler (eds.), Agrammatic Aphası: Cross-language nar: ative sourcebook. Vol. 1. (pp. 443-543). Philadelphia. John Benjamıns

Manzını, M. 1983. Restructuring and Reanalysıs. Unpublished doctoral dissertation, MIT, Cambridge, Mass.

Marshall, J. C. 1977. Disorders in the expression of language. In J. Morton, and J. C. Marshall (eds.), Psycholınguistics Series Vol.1 (pp. 125-160). London: Elek.

Marshall, J. C. and Newcombe, F. 1966. Syntactic and semantic errors in paralexia. Neuropsychologia 4: 169-176.

Marshall, M., Newcombe, F., and Marshall, J. C. 1970. The microstructure of word-finding difficulties in a dysphasic subject. In G. B. Flores d'Arcais, and W. J. M. Levelt (eds.), Advances in Psycholınguistics (pp. 416-426). Amsterdam: North Holland Publishing Co.

Menn, L. and Obler, L. K. (eds.).1990. Agrammatıc Aphasıa: Cross-language narrative sourcebook (3 vols.). Philadelphıa: John Benjamıns.

Miceli, G., Mazzucchi, A. 1990. Agrammatism in Italian: Two case studies. In L. Menn and L. K. Obler (eds.), Agrammatic Aphasia: Cross-language narrative sourcebook Vol. 1 (pp. 717-816). Philadelphı: John Benjamıns. 
Micelı, G., Mazzucchı, A., Menn, L. and Goodglass, H. 1983. Contrastıng cases of Italian agrammatic aphasia without comprehension disorder. Brain and Language 19: 65-97.

Miceli, G., Silveri, C., Villa, G. and Caramazza, A. 1984 On the basis for the agrammatic's difficulty in producing main verbs. Cortex 20: 207-220

Milner, J. Y. 1982. Ordres et raisons de langage. Parıs: Edıtions du Seuil.

Myerson, R. and Goodglass, H. 1972. Transformational grammars of aphasic patients. Language and Speech 15: 40-50.

Olson, C. L. 1987. Statıstıcs: Makıng Sense of Data. Boston: Allyn and Bacon, Inc.

Ouhalla, J. 1990. Null subjects and word order in agrammatısm. Unpublished typescript, Queen Mary and Westfield College, London University.

Ouhalla, J. 1991. Functional categories and the Head parameter. Paper presented at Glow, Leiden.

Patterson, K. 1980. Derivatıonal errors. In M. Coltheart, K. Patterson and J. C. Marshall (eds.), Deep Dyslexıa (pp. 286-306). London: Routledge and Kegan Paul.

Pierce, A. 1989. On the Emergence of Syntax: A Crosslinguistıc Study. Unpublished doctoral dissertation, MIT, Cambridge, Mass.

Pollock, J. Y. 1989 Verb Movement, UG and the structure of IP. Linguistic Inquiry 20: 365-424.

Radford, A. 1990. Syntactic Theory and the Acquisition of English Syntax: The Nature of Early Child Grammars of English. Oxford: Basıl Blackwell.

Reed, L. 1990a. Biclausality, barriers, and the French causative construction. Cahiers Lunguistiques d' Ottawa 18· 79-93.

Reed, L. 1990b. Adjunction, $X^{\circ}$ movement, and verbal government chains in French causatives. MIT Working Papers in Lingunstics 12.

Reed, L.1990c. Two Issues in the semantic interpretation of Eaire-Infinitive: Argument structure and direct vs. indirect causation. Unpublished typescript, University of Ottawa.

Reed, L. 1991. The thematic and syntactic structure of French causatives. Unpublished typescript, University of Ottawa.

Rizzi, L. 1985. Two notes on the linguistic interpretation of Broca's aphasia. In M. Kean (ed.), Agrammatısm (pp. 153-164). Orlando: Academic Press.

Rizzi, L. 1986. Null objects in Italian and the theory of pro. Linguistıc Inquiry 17: $501-557$.

Rizzı, L. 1990. Relativızed Minımality. Cambridge, Mass.: MIT Press. 
Rochette, A. 1988. Semantıc and Syntactic Aspects of Romance Sentential Complementation Unpublished doctoral dissertation. MIT, Cambridge, Mass.

Rosen S T. 1989. Argument Structure and Complex Predicates Unpublished doctoral dissertation, Brandess University

Rosenberg, B. E., Zurif, E., Brownell, H., Garrett, M. and Bradley, D 1985. Grammatical class effects in relation to normal and aphasic sentence processing Brain and Language 26: $287-303$.

Rouveret, A. and Vergnaud, J. R. 1980 Specifying reference to the subject. French causatives and conditions on representations Linguistic Inquiry 11 : 97-202.

Saffran, E. M., Schwartz, M. F. and Marın, O. S. M. 1980. The word order problem in agrammatism: II production. Brain and Language 10· 263-280.

Saksena, A. 1982. Topics in the Analysis of Causatives. Berkeley University of California Press.

Schwartz, M. F., Linebarger, M. C., Saffran, E M. and Pate, D. S 1987. Syntactic transparency and sentence interpretation in aphasia. Language and Cognitive Processes 2: $85-113$.

Schwartz, M. F., Saffran, E. M. and Marın, O. S. 1980. The word order problem in agrammatısm: I comprehension. Brain and Language 10. 249-262.

Smith, S. D. and Mimica, I. 1984. Agrammatism in a case-inflected language Comprehension of agent-object relations. Brain and Language 21. 274-290.

Speas, M. J. 1990. Phrase Structure in Natural Language. Dordrecht Kluwer.

Sportiche, D. 1988. A theory of floating quantifiers and its corollaries for constituent structure. Linguistic Inquiry 19: 425-449.

Stowell, T. 1983. Subjects across categories. The Linguistıc Review 2: 285-312.

Stark, J. A. and Dressler, W. U. 1990. Agrammatism in German: Two case studies. In L. Menn and L. K. Obler (eds.), Agrammatic Aphasia: Cross-language narrative sourcebook. Vol. 1 (pp. 281-441). Philadelphra: John Benjamins.

Tissot, R., Mounin, G. and Lhermitte, F. 1973. L'Agrammatısme: Étude neuropsychologıque Brussels: Charles Dessart.

Traill, A. 1970. Transformational grammar and the case of the Ndebele-speakıng aphasic. Journal of the South African Logopedic Society 17: 48-66.

Travis, L. 1983. Evidence for grammar in agrammatıc speech: Reply to Grodzınsky. Unpublished typescript, MIT. 
Tzeng, O. J. L., Chen, S. and Hung, D. L. 1991. The classifier problem in Chinese aphasıa. Brain and Language 41: 184-202.

Wehrli, E. 1986. Or, some properties of French clitic se in H. Borer (ed.), The Syntax of Pronominal Clitics. Syntax and Semantics 19 (pp. 263-283). New York: Academic Press.

Whitaker, H A. 1972. Unsolicited nominalizations by aphasıcs: the plausibility of the Lexicalıst model. Linguistics 78: 62-71.

Williams, E. 1980. The French causative construction. Unpublished typescript, University of Massachusetts, Amherst.

Williams, E. 1981 a. On the notions of 'lexically related' and 'head of word'. Linguistic Inquiry 12: $245-274$.

Williams, E. 1981b. Argument structure and morphology. The Linguistic Review 1: $81-114$

Willıarns, E. 1983. Agaınst small clauses. Linguıstıc Inquiry 14: 287-308.

Wulfeck, B. 1987. Sensitivity to Grammaticality in Agrammatic Aphasia : Processing of Word Order and Agreement Violations. Unpublished doctoral dissertation, University of Calıfornia.

Zıngeser, L. and Berndt, R. S. 1990. Retrieval of nouns and verbs in agrammatism and anomı. Brain and Lanquage 39: 14-32.

Zubizarreta, M. L. 1982. On the Relationship of the Lexicon to Syntax. Unpublished doctoral dissertation, MIT, Cambridge, Mass.

Zubizarreta, M. L. 1985. The relation between morphophonology and morphosyntax : the case of Romance causatives. Linguistic Inquiry 16: 247-289.

Zurif, E. 1990. Language and the brain. In D. N. Osherson and H. Lasnik (eds.) Language: An Invitation to Cognitıve Science. Volume 1 (pp. 177-198). Cambridge, Mass.: MIT Press. 
210.

I

APPENDICES 
211 .

APPENDIX A

Summary of Group Results 
Table A.A.1.1. Raw Scores, Means, and Percent CorrectTotal Aphasic. Sample-OMBs

\begin{tabular}{|c|c|c|c|c|c|c|c|c|c|c|c|c|}
\hline & SMIEx TAF & $x$ & $\infty$ & $D$ & No & $a$ & $\mathbb{P} \mid 1$ & $\mathbf{R}$ & $\sqrt{2}$ & $\pi$ & $\operatorname{Mnn}(9 N)$ & scarret (9N) \\
\hline 11 & $a+1$ & 12 & 121 & 12 & 12 & 12 & 12 & 12 & 12 & 12 & 12000 & 100000 \\
\hline 2 & ars & 12 & 7 & 5 & 12 & 12 & II & 11 & 7 & 12 & 9809 & 20.07 \\
\hline 3 & 0,0 & 12 & 12 & 3 & 12 & 12 & 12 & 0 & 12 & 11 & 9.50 & 7950 \\
\hline 4 & ary & 9 & 6 & 5 & 11 & 12 & 12 & 6 & 5 & 10 & 8.44 & 70,50 \\
\hline s) & ares & 12 & II & 6 & 12 & 12 & 12 & 11 & 12 & 12 & 11.111 & $x 58$ \\
\hline 6 & $a x$ & II & 0 & 0 & 12 & 12 & -7 & 8 & 7 & 10 & 7.44 & 620167 \\
\hline 7 & $\cos \theta$ & 8 & 2 & 1 & 12 & 11 & 9 & 3 & 5) & 6 & 6.333 & 52.78 \\
\hline 8 & $a$ & 9 & 6 & 5 & III & 12 & 10 & 1 & 6 & 12 & 8.000 & 66.67 \\
\hline 9 & 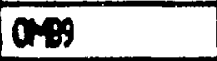 & 5 & 0 & 1 & 12 & 12 & 7 & 3 & $\pi$ & 6 & 520 & 43519 \\
\hline 10 & ansio & 8 & 9 & 9 & 12 & 12 & 10) & 10 & 12 & 9 & 10.111 & 829 \\
\hline 11 & andi & 6 & 2 & 1 & 12 & 10 & 10 & 2 & 4 & 12 & 6206 & 5150 \\
\hline 12 & aصil2 & 9 & 3 & 2 & III & 12 & 10 & 2 & 2 & 12 & 7000 & 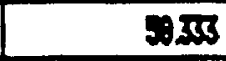 \\
\hline 18 & aed18 & 12 & III & 7 & 12 & 12 & 12. & II & 12 & 12 & 11200 & 8.519 \\
\hline 14 & and14 & 11 & 5 & 2 & 12 & 12 & II) & 5 & 8 & 11 & 858 & $712 x$ \\
\hline 15 & $a$ & 12 & 12! & 11 & 12 & 11 & 12 & 11 & 12 & 12 & 1160 & $n m$ \\
\hline 16 & $\infty$ & 8 & 11 & 2 & 12 & 12 & 9 & 8 & 9 & 11 & 8000 & 6667 \\
\hline 17 & $c_{108}$ & 5 & 6 & 2 & 10 & 11 & 11) & 0 & 6 & 12 & 7000 & 58.563 \\
\hline 18 & caras & 12 & 12) & 12 & 12 & 12 & 12 & 12 & 12 & 12 & 12000 & 10000 \\
\hline 19 & ans & 12 & II & 10 & 12 & 12 & 12) & 12 & 12 & 12 & 11607 & $\pi m$ \\
\hline 20 & and & 1 & 1 & 0 & 11 & 12 & 0 & 5 & 3 & 7 & 4.414 & 5708 \\
\hline (x) & $\operatorname{arns}$ & 6 & 1 & 1 & 11 & 11 & 1 & 8 & 1 & 9 & 520 & 4519 \\
\hline 2 & $\cos x$ & 9 & 0 & 2 & 12 & 12 & 9 & 3 & 10 & 10 & 7.44 & 02057 \\
\hline 23 & $a$ & 1 & 0 & 0 & 10 & 6 & 1 & 0 & 0 & 3 & 2330 & 19.4 .4 \\
\hline 24 & 00010 & 1 & 0 & 0 & 8 & 10 & 4 & 0 & 0 & 11 & 3.70 & 31.01 \\
\hline 25 & arell & 0 & 2 & 1 & 9 & 11 & 1 & 2 & 1 & \begin{tabular}{|l|}
7 \\
\end{tabular} & 2.76 & 8181 \\
\hline$x$ & are12 & 1 & 0 & 0 & 7 & 9 & 1 & 0 & 1 & 4 & 2809 & 24074 \\
\hline$\pi$ & carsis & 6 & 4 & 1 & 10 & 12 & 10 & 3 & 3 & 12 & 7000 & 9030 \\
\hline 2 & arels & 8 & 5 & 0 & 12 & 11 & III & 7 & 4 & 9 & 7.44 & 02187 \\
\hline
\end{tabular}


213.

Table A.A.1.2. Group Results- All 9 Aphasics (OMBs)

Sentence Type

[01] Active

[18] Causative + intransitive Verb

[15] Direct Object Control, Intransitive Verb

[19] Direct Object Control + Transitive Verb

[13] Active Conjoined Theme

105] Dative

[10] Object-Subject Relative

[02] Passive

[03] Truncated Passive

[14] Passive Conjoined Agent

[04] Cleft Object

[08] Conjaned

[16] Passivized Direct Object Control, Intransitive Verb

[06] Dative Passive

[22] Causative (Farre-par)

[28] Conjoined Clauses 4 NPs (No Deletion) (Baseline)

[12] Subject-Subject Relative

[17] Truncated Causative

[27] SS Relative + Conjoined Theme

[11] Object-Object Relative

[07] Cleft-Object Dative

[09] Subject-Object Relative

[21] Causative (Faire-à )

[20] Passivized Direct Object Control + Transitive Verb

[24] Conjoined Causative

[25] Causative + Dative

[26] Causative + SS Relative

[23] Cleft-Object Causative ( Farre-par )
Mean SD

12.000

12.000

11.667

11.667

11.222

11.111

10.111

9.889

9.556

8.556

8.444

8.100

8.000

7.444

7.444

7.444

7.000

7.000

7.000

6.556

6.333

5.222

5.222

4.444

3.778

3.778

2.889

2.333

0

0

.500

.707

1.641

1.965

1.537

2.759

4.640

3.712

2.963

3.742

4.000

4.640

4.531

3.909

4.610

4.272

4.093

4.503

3.937

4.522

4.206

4.640

4.658

4.086

3.333

3.500

Mean $\mathrm{OMB}+\mathrm{COMB} \quad 7.718$ 
Table A.A.1.3. Significantly Different Sentence Types-

Total Aphasic Sample-OMBs

$\begin{array}{llllllllllllllllllllllllllll}0 & 0 & 0 & 0 & 0 & 0 & 0 & 0 & 0 & 1 & 1 & 1 & 1 & 1 & 1 & 1 & 1 & 1 & 1 & 2 & 2 & 2 & 2 & 2 & 2 & 2 & 2 & 2\end{array}$

01

$\begin{array}{llllllllllllllllllllllllllll}1 & 2 & 3 & 4 & 5 & 6 & 7 & 8 & 9 & 0 & 1 & 2 & 3 & 4 & 5 & 6 & 7 & 8 & 9 & 0 & 1 & 2 & 3 & 4 & 5 & 6 & 7 & 8\end{array}$

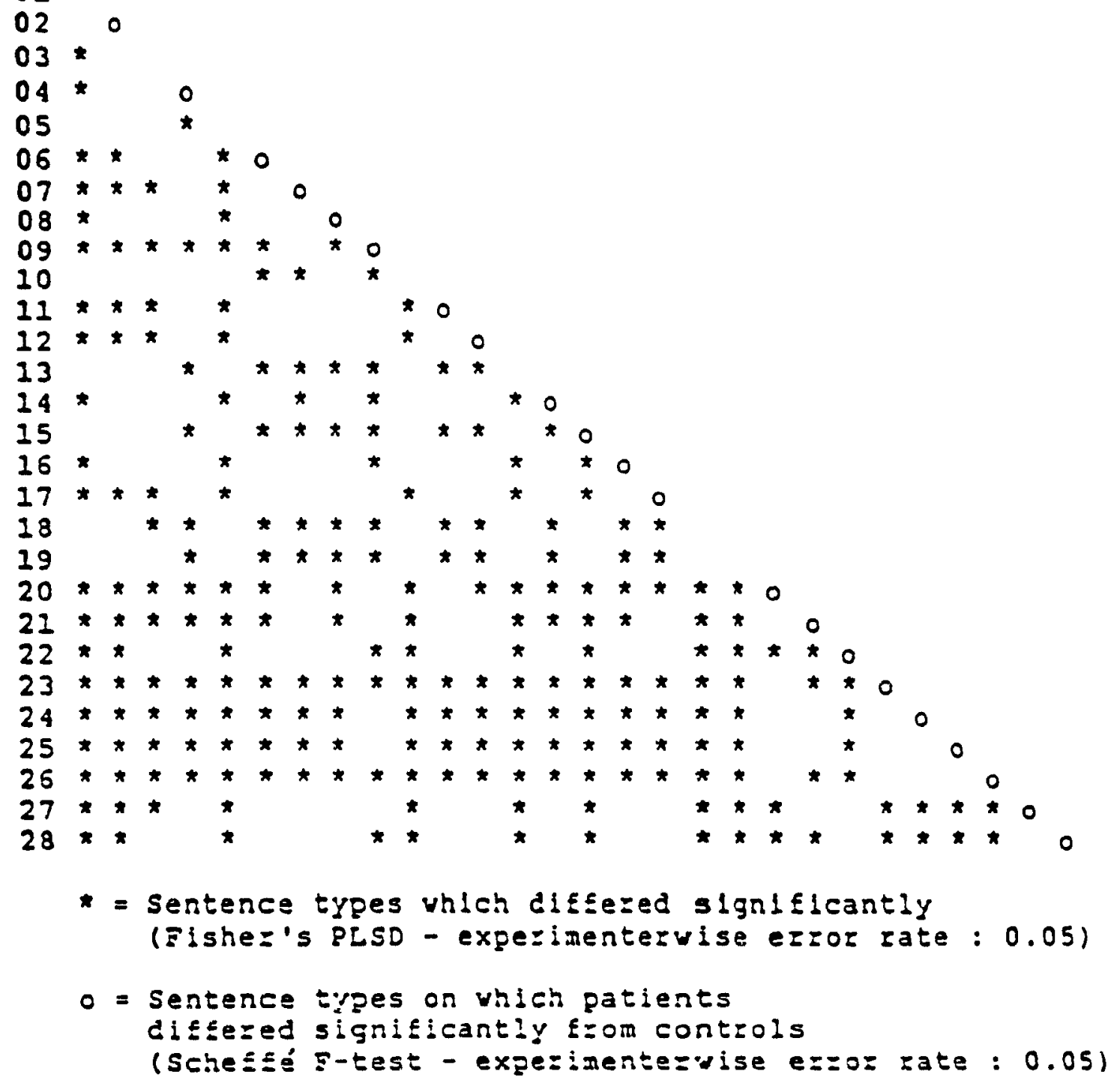


Table A.A.2.1. Raw Scores, Means, and Percent CorrectSubset Aphasic Sample-OMBs

\begin{tabular}{|c|c|c|c|c|c|c|c|c|}
\hline & SEKTEKCE TYPE & $x$ & $\mathrm{CM}$ & IP & $P R$ & $\mathbb{R}$ & $\operatorname{Min}(5 A)$ & 8 Correct (5A) \\
\hline 11 & aMB 1 & 12 & 12 & 12 & 12 & 12 & 12.000 & 100.000 \\
\hline 2 & OMB2 & 12 & 12 & 11 & 11 & 7 & 10.600 & 88.333 \\
\hline 3 & 0793 & 12 & 12 & 12 & 0 & 12 & 9600 & 80000 \\
\hline 4 & 0.484 & 9 & 12 & 12 & 6 & 5 & 8.800 & 73.333 \\
\hline 5 & aris & 12 & 12 & 12 & 11 & 12 & 11.800 & 98.333 \\
\hline 6 & $0+86$ & III & 12 & 7 & 8 & 7 & 9.000 & 75.000 \\
\hline 7 & 01487 & 8 & 11 & 9 & 3 & 5 & 7200 & 60.000 \\
\hline 8 & 0456 & 9 & 12 & 10 & 1 & 6 & 7.600 & 63.333 \\
\hline 9 & a+189 & 5 & 12 & 7 & 3 & 1 & 5.600 & 46.667 \\
\hline 10 & $0+10$ & 8 & 12 & 10 & 10 & 12 & 10.400 & 86.667 \\
\hline 11 & Orisil & 6 & 10 & 10 & 2 & 4 & 6400 & 53.333 \\
\hline 12 & 01812 & 9 & 12 & 10 & 2 & 2 & 7.000 & 58.333 \\
\hline 13 & arsis & 12 & 12 & 12 & III & 12 & 11.800 & $98 . \overline{333}$ \\
\hline 14 & OMP14 & 11 & 12 & 11 & 5 & 8 & 9.400 & 78.333 \\
\hline 15 & compl & 12 & II & 12 & 11 & 12 & 11.600 & 9.667 \\
\hline 16 & Contin2 & 8 & 12 & 9 & 8 & 9 & 9.200 & 76.667 \\
\hline 17 & cams3 & 5 & 11 & III & 0 & 6 & 6.600 & 55.000 \\
\hline 18 & COMB4 & 12 & 12 & 12 & 12 & 12 & 12.000 & 100.000 \\
\hline 19 & Contros & 12 & 12 & 12 & 12 & 12 & 12.000 & 100.000 \\
\hline 20 & ans & 1 & 12 & 0 & 5 & 3 & 4.200 & 35.000 \\
\hline 21 & cor187 & 6 & 11 & 1 & 3 & 4 & 5.000 & 41.667 \\
\hline 22 & Canb8 & 9 & 12 & 9 & 3 & 10 & 8.600 & 71.667 \\
\hline 23 & cominos & 1 & 6 & 1 & 0 & 0 & 1.600 & 13.333 \\
\hline 24 & 004810 & 1 & 10 & 4 & 0 & 0 & 3.000 & 25.000 \\
\hline 25 & Carbil & 0 & 11 & 1 & 2 & 1 & 3.000 & 25.000 \\
\hline 26 & 041812 & 1 & 9 & 4 & 0 & 1 & 3.000 & 25.000 \\
\hline 27 & ando13 & 6 & 12 & 10 & 5 & 3 & 7.200 & 60.000 \\
\hline 28 & Coribis & 8 & III & 11 & 7 & 4 & 8.200 & 68.353 \\
\hline 29 & Porol & 12 & 12 & III & 0 & II & 9.200 & 76667 \\
\hline 30 & PON182 & 8 & 10 & 10 & 0 & III & 7.800 & 65.000 \\
\hline 31 & porns & 3 & 11 & 9 & 0 & 11 & 6.800 & 56.667 \\
\hline 32 & POMPA & 7 & 12 & 12 & 0 & 9 & 8.000 & 66.667 \\
\hline 33 & Poribs & III & 12 & 12 & 6 & 11 & 10.400 & 8.667 \\
\hline 34 & POMLO & 6 & 10 & 0 & 0 & 0 & 3.200 & 26.667 \\
\hline 35 & Porvo? & 7 & 12 & 11 & 0 & 9 & 7.800 & 65.000 \\
\hline 36 & $P Q 480$ & 8 & 12 & 12 & 0 & 10 & 8.400 & 70.000 \\
\hline 37 & porbs & 12 & II & 6 & 0 & 5 & 6.800 & 56.667 \\
\hline 38 & Pr.s10 & 12 & III & 12 & 0 & 12 & 9.400 & 70.335 \\
\hline 39 & Pribll & 12 & 12 & 10 & 0 & 12 & 9.200 & $x .667$ \\
\hline 40 & Poina12 & 1 & 6 & 3 & 0 & 1 & 2.200 & 18.333 \\
\hline 4 & Poris13 & 0 & 7 & 0 & 2 & 1 & 2.000 & 16.667 \\
\hline 42 & Ponold & 3 & III & 3 & 0 & 2 & 3.800 & 31.667 \\
\hline
\end{tabular}


Table A.A.2.2. Group Results- 5 Aphasics (OMBs)

\begin{tabular}{|c|c|c|}
\hline Sentence Type & Mean & SD \\
\hline [01] Active & 12.0 & 0 \\
\hline [18] Causative + Intransitive Verb & 12.0 & 0 \\
\hline [19] Direct Object Control + Transitive Verb & 12.0 & 0 \\
\hline [05] Dative & 11.8 & .447 \\
\hline [13] Active Conjoined Theme & 11.8 & 447 \\
\hline [15] Direct Object Control, Intransitive Verb & 11.6 & .548 \\
\hline [02] Passive & 10.6 & 2.074 \\
\hline [10] Object-Subject Relative & 10.4 & 1.673 \\
\hline [33] Causative-Reflexive Causer $=$ Theme & 10.4 & 2.510 \\
\hline [03] Truncated Passive & 9.6 & 5.367 \\
\hline [14] Passive Conjoined Agent & 9.4 & 2.881 \\
\hline [38] Causative-Reflexive Causer=Theme, Truncated & 9.4 & 5.273 \\
\hline [16] Passivized Direci Object Control, Intransitive Verb & 9.2 & 1.643 \\
\hline [29] Datıve-Theme clitıcized & 9.2 & 5.167 \\
\hline [39] Causative-Theme=Causee cliticized, Intransitive Verb & 9.2 & 5.215 \\
\hline [06] Dative Passive & 9.0 & 2345 \\
\hline [04] Cleft Object & 8.8 & 3.271 \\
\hline [22] Causative (Faire-par) & 8.6 & 3.362 \\
\hline [36] Causative-Reflexive Causer=Goal, Truncated & 8.4 & 4.980 \\
\hline [28] Conjoined Clauses 4 NPs (No Deletion) (Baselıne) & 8.2 & 2.950 \\
\hline [32] Causative-Causee cliticized & 8.0 & 4.950 \\
\hline [30] Dative-Goal cliticized & 7.8 & 4.494 \\
\hline [35] Causative-Reflexive Causer=Goal & 7.8 & 4.764 \\
\hline [08] Conjoined & 7.6 & 4.278 \\
\hline [07] Cleft-Object Dative & 7.2 & 3.194 \\
\hline [27] SS Relative + Conjoined Theme & 7.2 & 3.701 \\
\hline [12] Subject-Subject Relative & 7.0 & 4.690 \\
\hline [31] Causative-Theme cliticized & 6.8 & 5.020 \\
\hline [37] Causative-Theme cliticized, Truncated & 6.8 & 4.868 \\
\hline [17] Truncated Causative & 6.6 & 4.615 \\
\hline [11] Object-Object Relative & 6.4 & 3.578 \\
\hline [09] Subject-Object Relative & 5.6 & 4.219 \\
\hline [21] Causative ( Faire-à ) & 5.0 & 3.808 \\
\hline [20] Passivized Direct Object Control + Transitive Verb & 4.2 & 4.764 \\
\hline [42] Object-Object Relative with Stylistic Inversion & 3.8 & 4.207 \\
\hline [34] Causative-Reflexive Causee & 3.2 & 4.604 \\
\hline [24] Conjoned Causative & 3.0 & 4.243 \\
\hline [25] Causative + Dative & 3.0 & 4.528 \\
\hline [26] Causative + SS Relative & 3.0 & 3.674 \\
\hline [40] Cleft-Object with Stylistic Inversion & 2.2 & 2.387 \\
\hline [41] Subject-Object Relative with Stylistic Inversion & 2.0 & 2.915 \\
\hline [23] Cleft-Object Causative ( Faire-par ) & 1.6 & 2.510 \\
\hline Mean $O M B+C O M B$ & 7.943 & \\
\hline Mean $\mathrm{OMB}+\mathrm{COMB}+\mathrm{POMB}$ & 7.557 & \\
\hline
\end{tabular}


Table A.A.2.3. Significantly Different Sentence Types-

Subset Aphasic Sample-OMBs

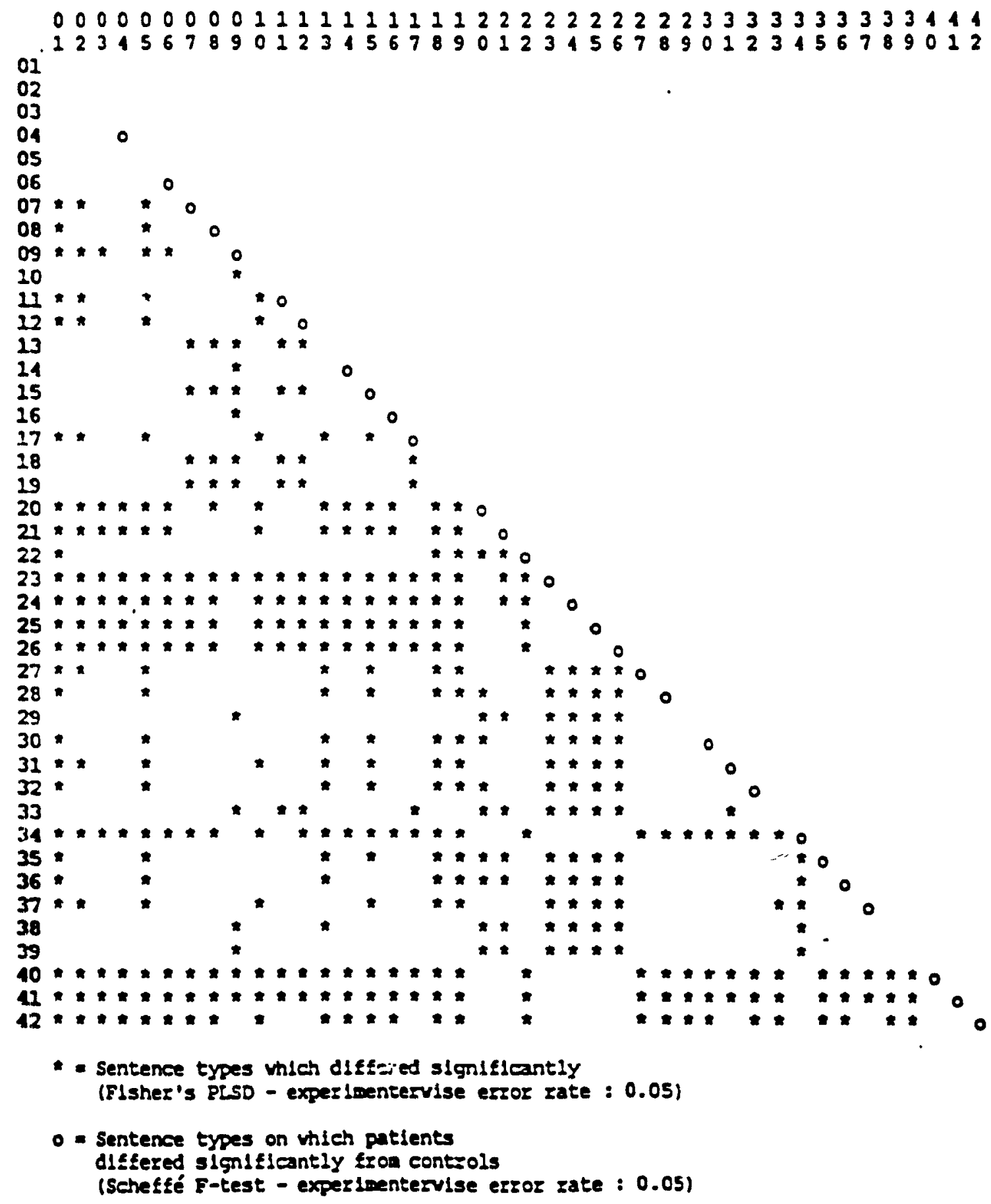


Table A.A.3.1. Raw Scores, Means, and Percent Correct-

Normal Controls-OMBs

\begin{tabular}{|c|c|c|c|c|c|c|c|c|c|c|c|c|c|}
\hline & Gilou nif & $\mathrm{n}$ & $m$ & $\boldsymbol{\sigma}$ & $\mathbf{W H}$ & $R$ & $M$ & in & $D$ & $n$ & $\alpha$ & $\operatorname{Mm}(100)$ & $80 \mathrm{mid}(\mathrm{q})$ \\
\hline 1 & ar & 12 & 12 & 12 & 12 & 12 & 12 & 12 & 12 & 12 & 12 & 1200 & 100000 \\
\hline 2 & are & 12 & 12 & 11 & 12 & iI & 12 & 12 & 12 & 12 & 12 & 1120 & 2030 \\
\hline 8 & $\operatorname{ars}$ & 12 & 12 & 12 & 12 & 12 & 12 & 12 & 12 & 12 & 12 & 12000 & 10000 \\
\hline 4 & ars & 12 & 12 & II & 12 & 12 & 12 & 12 & 12 & 12 & 12 & 11.50 & 9.10 \\
\hline 3 & ars & 12 & 12 & 12 & 12 & 12. & 12 & 12 & 12 & 12 & 12 & 12000 & 10000 \\
\hline 6 & ars & 12 & 11 & 10 & 12 & 10 & II & 9 & II & 12 & 12 & 1100 & 1607 \\
\hline 7 & ans & 12 & 12 & 8 & 12 & 8 & 12 & 11 & 12 & 12 & 8 & 10.700 & 0.167 \\
\hline g & 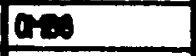 & 12 & 12 & 12 & 12 & III & 12 & 12 & 12 & 12 & 12 & 11.50 & 9.167 \\
\hline 2 & $\operatorname{ars}$ & 12 & 12 & 10 & III & 8 & 12 & 3 & 12 & 12 & 0 & 10200 & 8000 \\
\hline 10 & $\operatorname{arglo}$ & 12 & 12 & II & 12 & III & 12 & 3 & 12 & 10 & 12 & 11200 & 820 \\
\hline 11 & aril & 11 & II & 12 & 12 & 10 & 11 & II & 11 & 12 & 12 & 1130 & 8.10 \\
\hline 12 & arsi2 & 12 & 12 & 12 & 12 & 10 & 12 & 11 & 10) & 10 & 7 & 1020 & 5000 \\
\hline 11 & aris & 12 & 12 & 12 & 12 & 12 & 12 & 12 & $12]$ & 12 & 12 & 12000 & 10000 \\
\hline 14 & arsit & 12 & 12 & III & 12 & 12 & 12 & 12 & 12 & II & 12 & 11800 & 9030 \\
\hline $\mathbf{B}$ & arm & 12 & 12 & 12 & 12 & 12. & 12 & 12 & 12 & 12 & 12 & 12000 & 10000 \\
\hline 16 & one & 12 & 12 & 9 & 12 & 11 & 11 & 12 & 12 & 12 & 10 & 11300 & 4.167 \\
\hline 17 & ors & 10 & 12 & 12 & 12 & II & 12 & 10 & 12 & 10 & 12 & 11300 & 9.167 \\
\hline 10 & card & 12 & 12 & 12 & 12 & 12 & 12 & 12 & 12 & 12 & 12 & 12000 & 100000 \\
\hline B) & $100, s$ & 12 & 12 & 12. & 12 & 12. & 12 & II & 12] & 11 & 12 & 1120 & 2035 \\
\hline 2 & corses & 11 & 12 & 7 & 12 & 7 & 12 & 12 & 12 & 12 & 11 & $10 \mathrm{D00}$ & 50100 \\
\hline 21 & and & 11 & 12 & 7 & 11 & 8 & 12 & 3 & 12 & 12 & 8 & $9 \mathrm{sen}$ & 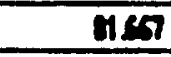 \\
\hline 2 & ars & 12 & 12 & II & 12 & 12 & 10 & 12 & 12 & 12 & 12 & 11.700 & $\pi 50$ \\
\hline ב & are & 12 & 12 & 2 & 12 & 3 & II & 8 & 12 & II & 1 & 9.100 & 7500 \\
\hline 21 & Coreso & 12 & 12 & 9 & 10 & 10 & 11 & 6 & 12 & II & 12 & 10500 & 0750 \\
\hline 2 & corst1 & 11 & 12 & 11 & 11 & 8 & 10 & 10 & 11 & 11 & II & $106 \mathrm{sm}$ & $m$ \\
\hline 8 & $\cos 12$ & II & 11 & 9 & 9 & 8 & 9 & 3 & 10 & 9 & 6 & 250 & 70268 \\
\hline 27 & arel3 & 12 & 12 & 10 & 11 & 12 & 12 & 12 & 12 & 11 & II & 1150 & $8 \sqrt{63}$ \\
\hline 2 & orolis & II & II & 11 & II & II & 11 & 12 & II & 12 & 11 & 11200 & 20353 \\
\hline 2 & prot & 12 & 12 & 12 & 12 & 12 & 12. & II & 12 & 12 & 12 & 1150 & 8.18 \\
\hline (2) & Pore & 11 & 12 & 12 & 12 & 12 & 12 & 12 & 12 & 12 & 12 & IIspo] & 9.107 \\
\hline 81 & pars & II & II & 12 & 12 & III & 12 & 12 & 12 & 12 & 12 & 11.70 & $n \leq 0$ \\
\hline 8 & rones & 12 & 12 & 12 & 12 & 12 & 12 & 10 & 12 & 12 & II & 11.70 & nIN \\
\hline 8 & hos & 12 & 12 & 12 & 12 & 11 & 11 & 12 & 12 & 12 & 12 & $11 \mathrm{~cm}$ & 920 \\
\hline $\boldsymbol{1}$ & has & 12 & 12 & 0 & II & III & 12 & 12 & 12 & II & II & 10,40 & 1657 \\
\hline 8 & hes & 12 & II & 12 & 12 & II) & 12 & 12 & 12 & II & II & $11 \mathrm{sm}$ & 567 \\
\hline 8 & rom & 12 & 12 & 12 & 11 & 12 & 12 & 12 & 12 & 12 & 11 & $11 \mathrm{sm}$ & 2133 \\
\hline 8 & fars & 12 & 12 & 12 & 12 & 10 & 12 & 9 & 11 & 12 & 12 & 11.100 & $3 \mathrm{mon}$ \\
\hline 2 & prosio & 12 & 12 & 12 & 12 & 12 & 12 & 12 & 12 & 12 & 12 & 1200 & 100000 \\
\hline$\theta$ & hasl & 12 & 12 & 12 & 12 & 12 & 12 & 12 & 12 & 12 & 12 & 1200 & 10080 \\
\hline$\infty$ & rasi2 & 12 & 12 & 0 & 11 & 10 & 12 & II & 12 & 12 & 5 & 9.70 & 0.63 \\
\hline 41 & rove & 11 & 11 & 1 & 11 & 6 & II & 1 & II & 12 & 5 & 200 & 6567 \\
\hline$Q$ & rasia & 12 & 9 & III & 10 & III & II & 4 & III & 9 & 1 & 890 & 74.10 \\
\hline
\end{tabular}


Table A.A.3.2. Group Results- 10 Controls (OMBs)

Sentence Type

[01] Active

[03] Truncated Passive

[05] Dative

[13] Active Conjoined Theme

[15] Direct Object Control, Intransitive Verb

[18] Causative + Intransitive Verb

[38] Causative-Reflexive Causer $=$ Theme, Truncated

[39] Causative-Theme=Causee cliticized, Intransitive Verb

[04] Cleft Object

[08] Conjoined

[29] Dative-Theme cliticized

[30] Dative-Goal cliticized

[02] Passive

[14] Passive Conjoned Agent

[19] Direct Object Control + Transitive Verb

[33] Causative-Reflexive Causer $=$ Theme

[36] Causative-Reflexiv's Causer=Goal, Truncated

[22] Causative (Fare-par)

[31] Causative-Therne cliticized

[32] Causative-Causee cliticized

[35] Causative-Reflexive Causer $=$ Goal

[27] SS Relative + Conjoined Theme

[37] Causative-Theme cliticized, Truncated

[11] Object-Object Relative

[16] Passivized Direct Object Control, Intransitive Verb

[17] Truncated Causative

[10] Object-Subject Relative

[28] Conjoned Clauses 4 NPs (No Deletion) (Baseline)

[06] Dative Passive

[12] Subject-Subject Relative

[20] Passivized Direct Object Control + Transitive Verb

[07] Cleft-Object Dative

[25] Causative + Dative

[24] Conjoned Causative

[34] Causative-Reflexive Causee

[09] Subject-Object Relative

[21] Causative ( Faire-à)

[40] Cleft-Object with Stylistic Inversion

[23] Cleft-Object Causative ( Farre-par)

[42] Object-Object Relative with Stylistic Inversion

[26] Causative + SS Relative

[41] Subject-Object Relative with Stylistic Inversion
Mean

SD

12.0

12.0

12.0

12.0

12.0

12.0

12.0

12.0

11.9

11.9

11.9

11.9

11.8

11.8

11.8

11.8

11.8

11.7

11.7

11.7

11.6

11.5

11.4

11.3

11.3

11.3

11.2

11.2

11.0

10.8

10.8

10.7

10.6

10.5

10.4

10.2

9.8

9.7

9.1

8.9

8.5

8.0
0

0

0

0

0

0

0

0

.316

.316

.316

.316

.422

.422

.422

.422

.422

.675

.483

.675

.516

.707

1.075

.675

1.059

.949

1.317

.422

1.054

1.619

2.044

1.889

1.075

1.900

3.688

2.440

2.573

4.029

3.814

3.573

2.415

4.372

Mean $\mathrm{OMB}+\mathrm{COMB}$
Mean $\mathrm{OMB}+\mathrm{COMB}+\mathrm{POMB}$

11.168

11.131 
220.

Table A.A.3.3. Significantly Different Sentence TypesNormal Controls-OMBs

000000000011111112111222222222222223333333333441 01 123456789012345678901234567890123456789012

02

03

04

05

67

08

$09 \ldots \ldots$

10

11

12

13

25

26

$=7$

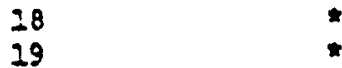

20
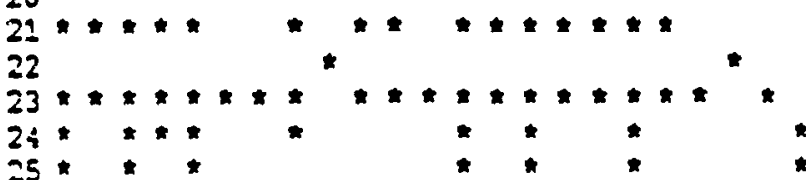

27

28

29

30

$\geq 2$

$\pm 3$

$34 * * *$

25

35

37

38

39

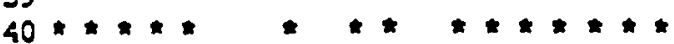

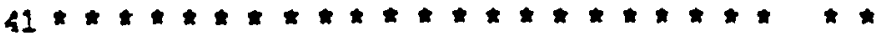

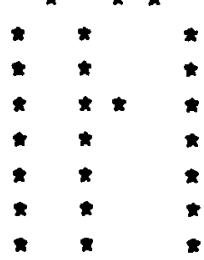

42

- = Sentence types whlch d!Efezed signlflcantly

(Flshez's PLSD - experimenterwise ezzor rate : 0.05 ) 
Fig. A.A.1. Effect of Number of NPs on Subjects' Accuracy Rates

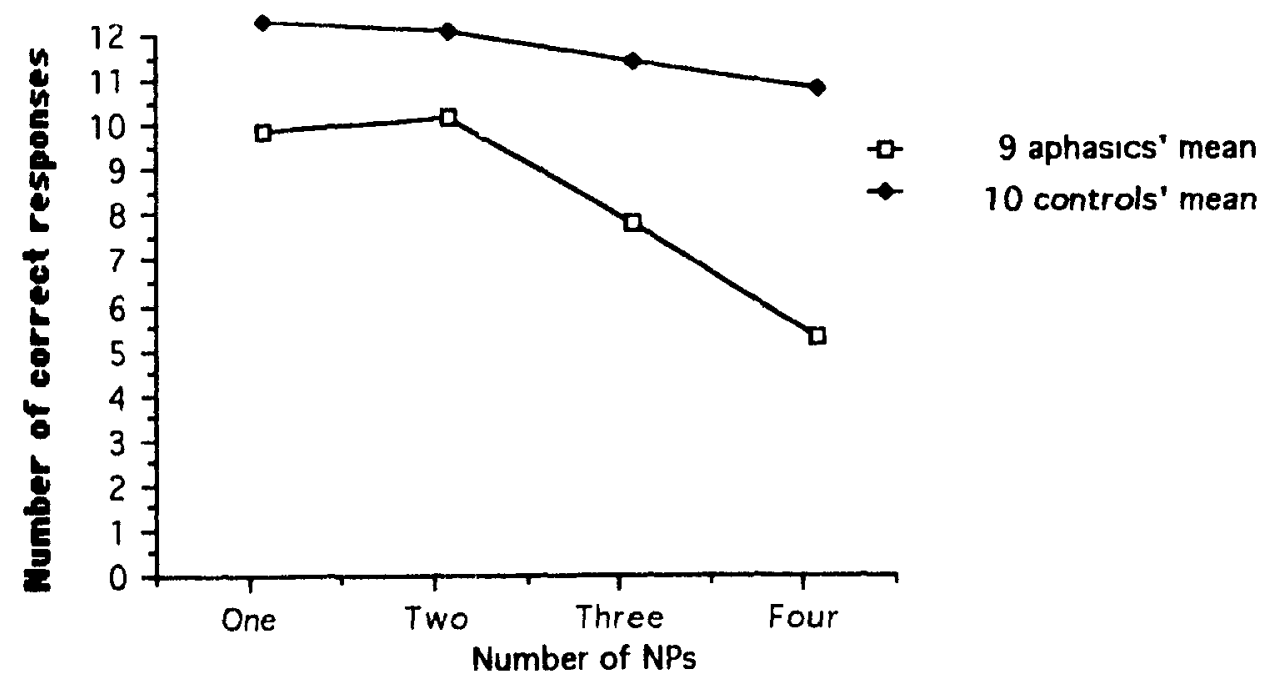

Fig. A.A.2. Effect of Number of Action Verbs on Subjects' Accuracy Rates

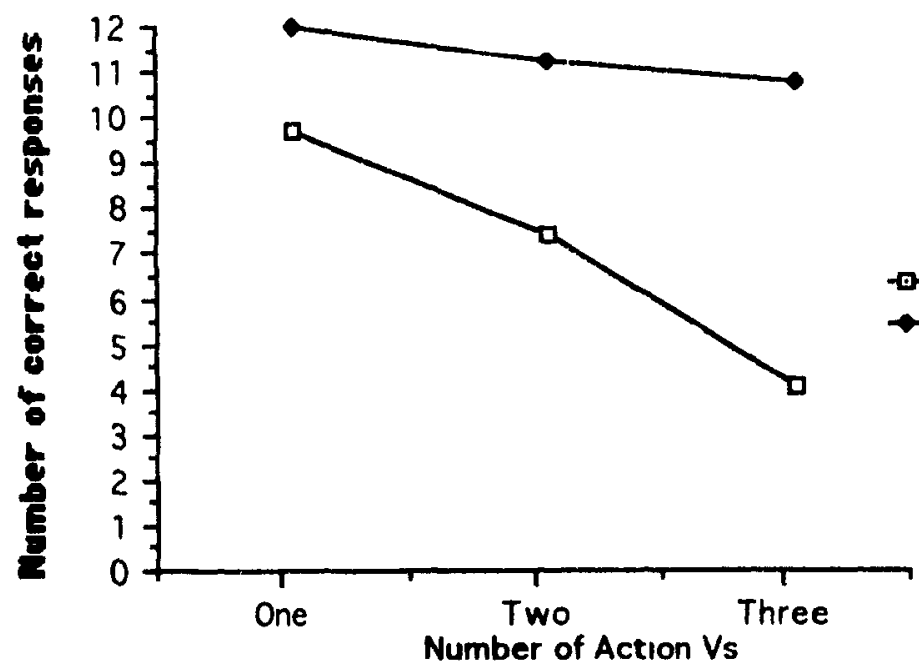

9 aphasics' mean 10 controls' mean 
222.

Fig. A.A.3. Effect of Number of Inflected Verbs on Subjects' Accuracy Rates

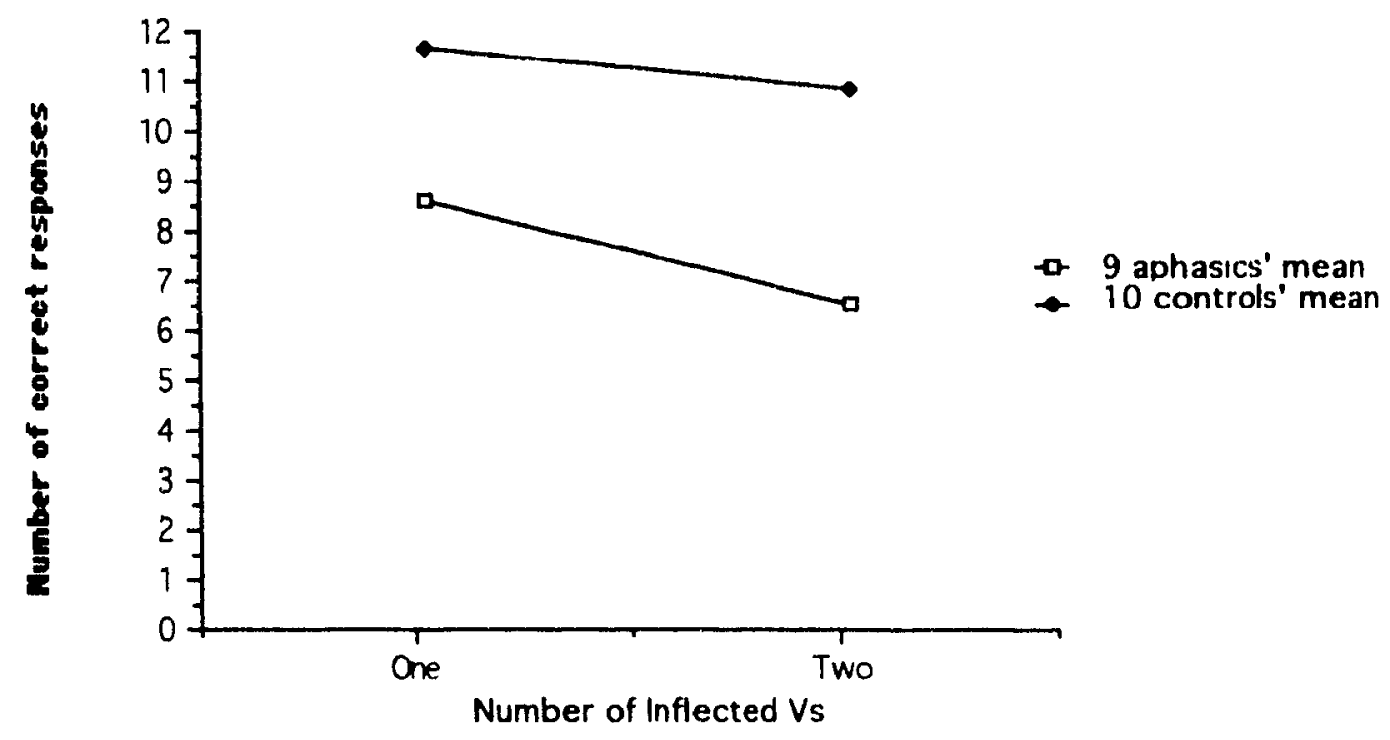

Fig. A.A.4. Effect of Maximum Number of Words on Subjects' Accuracy Rates

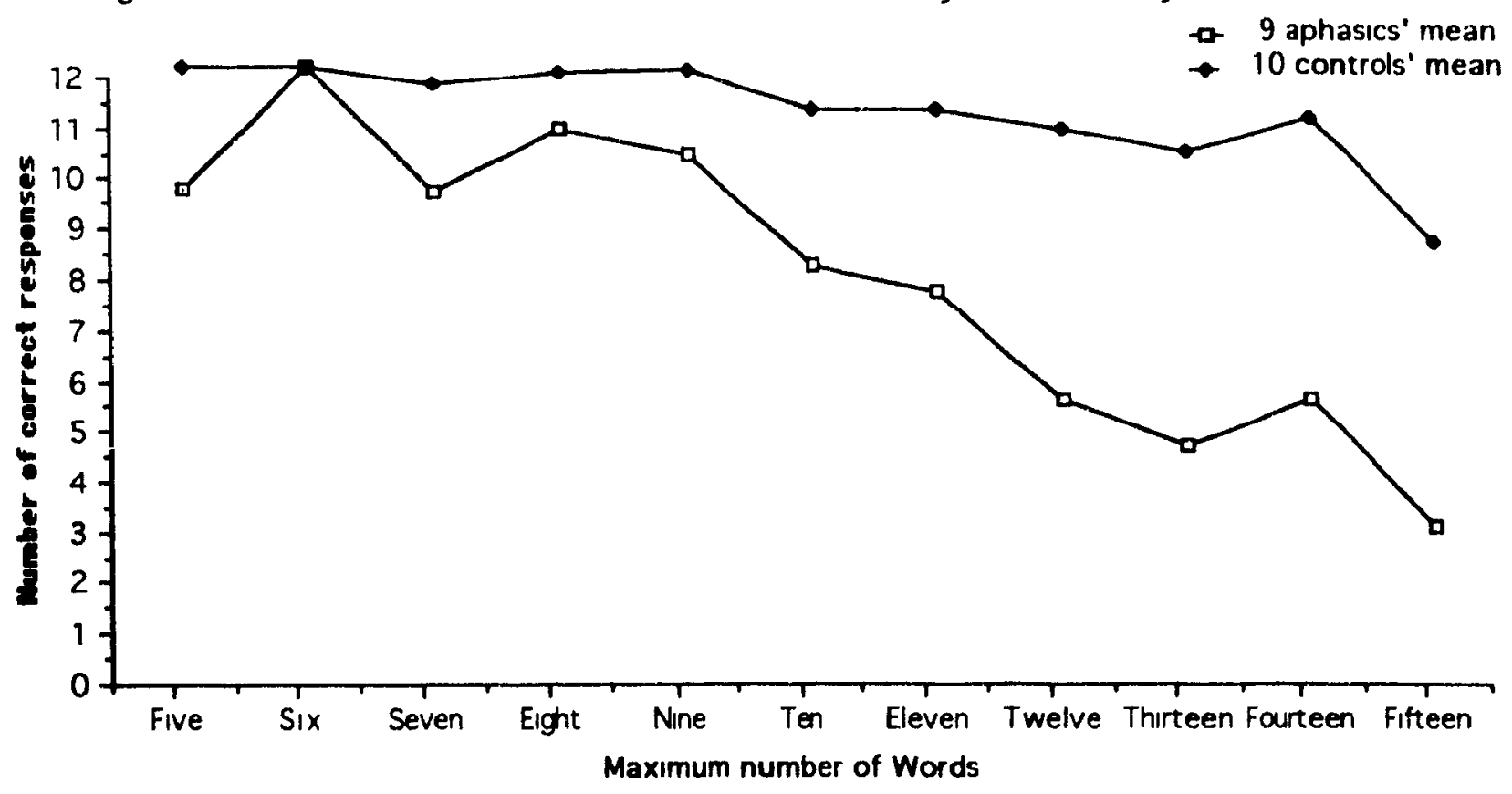




\section{Table A.A.4. Error Patterns for Object Manipulation Batteries}

\section{Aphasics/10 Aphasics/5 Controls}

[1] [OMB1] Active

$$
1.2
$$

[2] [OMB2] Passive

$2,1 \quad 1,2$

19

7

2

[3] [OMB3] Truncated Passive

$x, 1$

$1, x$

22

12

[4] [OMB4] Cleft Object

2,1

$$
1,2
$$

31
1

15

1

[5] [OMB5] Dative

$$
1,2,3
$$

$$
\begin{aligned}
& 2,1,3 \\
& 1,2 ; 2,3 \\
& 1,3 ; 3,2 \\
& 1,2 ; 1,3 \\
& 1,2+3
\end{aligned}
$$

[6] [OMB6] Dative Passive

$$
\begin{aligned}
& 3,1,2 \\
& 1,2,3 \\
& 3,2,1 \\
& 1,3,2 \\
& 2,1,3 \\
& 1,2+3 \\
& 2,3,1 \\
& 1,2: 2,3 \\
& 1,2 ; 1,3 \\
& 1,3 ; 3,2 \\
& 2,1 ; 3,1
\end{aligned}
$$

[7] [OMB7] Cleft-Object Dative

$$
\begin{array}{ll}
2,1,3 & 1,2,3 \\
& 1,3,2 \\
2,3,1 \\
1,2+3 \\
-, 1,3 \\
1,2 ; 2,3 \\
2,1 ; 3,1
\end{array}
$$

[8] [OMB8] Conjoned

$$
\begin{array}{ll}
1,2 ; 1,3 & 1,2 ; 2,3 \\
1,3 ; 3,2 \\
1,2 ; 3,1 \\
2,1 ; 2,3
\end{array}
$$

14
4
2
10
2
1
3
3
1
1

2

5

1

81

$\begin{array}{rr}39 & 22 \\ 3 & \\ 1 & 1 \\ 3 & \\ 1 & 1 \\ 3 & \\ 1 & \end{array}$

13

$\begin{array}{rr}34 & 21 \\ 1 & 1 \\ 1 & \end{array}$


[9] [OMB9] Subject-Object Relative

$$
\begin{aligned}
& 2,1 ; 1,3 \quad 1,2 ; 2,3 \\
& 1,2 ; 1,3 \\
& 2,1 ; 2,3 \\
& 2,3 ; 1,2 \\
& 1,3 ; 3,2 \\
& 1,2 ; 3,2 \\
& 3,1 ; 1,3 \\
& 2,1 ; 1+2,3
\end{aligned}
$$

$\begin{array}{rrr}43 & 25 & 4 \\ 12 & 3 & 2 \\ 2 & 1 & 10 \\ 1 & & 1 \\ & & 1 \\ 1 & & \\ 1 & & \\ 1 & 1 & \end{array}$

[10] [OMB10] Object-Subject Relative

$\begin{array}{ll}1.2 ; 2,3 & 1,2 ; 1,3 \\ & 1,2 ; 3,2 \\ 2,1 ; 1,3 \\ 1,3 ; 3,2 \\ 2,1 ; 2,3 \\ 1,2 ; 1+2,3\end{array}$

$\begin{array}{lll}8 & 5 & 6 \\ 1 & & 1 \\ 3 & 2 & 1 \\ 3 & & \\ 1 & & \\ 1 & 1 & \end{array}$

[11] [OMB11] Object-Object Relative

1,$2 ; 3,2 \quad 1,2 ; 2,3$
1,$2 ; 3,1$
1,$2 ; 1,3$
3,$1 ; 1,2$
3,$2 ; 2,1$
1,$3 ; 3,2$
2,$1 ; 1,3$
1,$3 ; 1,2$
1,$3 ;-\cdot-$
1,$2 ;-\cdot-$
1,$2 ; 3,-$
1,$2 ; 3,2 ; 3,1$

$\begin{array}{rrr}29 & 14 & 3 \\ 4 & 3 & 1 \\ 5 & 3 & 1 \\ & & 2\end{array}$

[12] [OMB12] Subject-Subject Relative

$$
\begin{array}{r}
1,2 ; 1,3 \quad 3,2 ; 2,3 \\
3,2 ; 3,1 \\
1,3 ; 2,3 \\
1,3 ; 2,1 \\
1,3 ; 3,2
\end{array}
$$

$$
\begin{aligned}
& 3 \\
& 2 \\
& 1 \\
& 1 \\
& 1 \\
& 1 \\
& 1 \\
& 1
\end{aligned}
$$

1

1

1

[13] [OMB13] Active Conjoned Theme

$$
\begin{array}{cl}
1,2+3 & 2,1+3 \\
& 3+2,1 \\
& 2,1,3 \\
& 1.2: 2.3 \\
1.2,3
\end{array}
$$

6
1

3
1
1
2

[14] [OMB 14] Passive Conjoined Agent

$$
2+3,1
$$

$1,2+3$

$2+1,3$

$1+2,3$

$2,1+3$

1,$2 ; 2,3$

1,$2 ; 1,3$

2,$1 ; 2,3$

3,$1 ; 1,2$

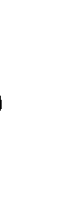


[15] [COMB1] Direct Object Control, Intransitive Verb

$$
1,2: 2 \mathrm{~V} \quad 2,1 ; 1 \mathrm{~V}
$$$$
1,2 ; i \mathrm{~V}
$$

[16] [COMB2] Passivized Direct Object Control, Intransitive Verb

$$
\begin{array}{rl}
2,1 ; 1 \mathrm{~V} & 1,2 ; 2 \mathrm{~V} \\
1,2 ; 1 \mathrm{~V} \\
2,1 ; 2 \mathrm{~V}
\end{array}
$$

[17] [COMB3] Truncated Causative

$$
\begin{array}{ll}
1,(\mathrm{X}) ; \mathrm{x}, 2 & 1,2- \\
& 1,2 \\
& 1,(2) ; 2,2 \\
& \mathrm{x},(1) ; 1,2 \\
& 1,2 ; 2, \mathrm{x} \\
& 1,(2) ; 2, \mathrm{x} \\
& 1 ; 1,2 \\
& 1,2 ; 2 \mathrm{~V} \\
& \mathrm{x}, 1-
\end{array}
$$

[18] [COMB4] Causative + Intransitive Verb 1,$2 ; 2 \mathrm{~V}$

[19] [COMB5] Direct Object Control + Transitive Verb

$$
\begin{array}{r}
1,2 ; 2,3 \quad 1,2 ; 3,2 \\
1,3 ; 3,2 \\
2,1 ; 1,3 \\
2,3 ; 3,1
\end{array}
$$

[20] [COMB6] Passivized Direct Object Control + Transitive Verb

$$
\begin{array}{rl}
2,1 ; 1,3 & 1,2 ; 2,3 \\
1,3 ; 3,2 \\
2,3 ; 1,2 \\
3,1 ; 1,2 \\
2,3 ; 2,1 \\
1,2 ; 1,3 \\
2,1 ; 2,3 \\
1 ;-
\end{array}
$$

[21] [COMB7] Causatıve (Faire-à )

$$
\begin{array}{ll}
1,(3) ; 3,2 & 1,(2) ; 2,3 \\
& 1,2 ; 2,3 \\
& 2,3 ; 1,(2) \\
& 1,2 ; 3,2 \\
& 1, x ; x, 2+3 \\
& 1,(x) ; x, 2,3
\end{array}
$$

[22] [COMB8] Causative ( Faire-par )

$$
\begin{array}{ll}
1,(3) ; 3,2 & 1,2 ; 2,3 \\
& 1,(2) ; 2,3 \\
1,2 ; 1,3 \\
1,2 ; 3,2 \\
1 ; 2,-; 3,- \\
1,2 ; 2,1 ; 2,3
\end{array}
$$


22E.

[23] [COMB9] Cleft-Object Causative ( Farre-par )

$\begin{array}{ll}2,(3) ; 3,1 & 1,2 ; 2,3 \\ 1,(2) ; 2,3 \\ 1,(3) ; 3,2 \\ 1,3 ; 3,2 \\ 1,(2) ; 3,2 \\ 1,2 ; 3,2 \\ 2,(1) ; 1,3 \\ 2,1 ; 1,3 \\ 2,1 ; 3,1 \\ 1,3 ; 2,(1) \\ 3,(2) ; 2,1 \\ 2,3 ; 3,2 \\ 1,2 ; 1,3 \\ 1,3- \\ 1,3 \\ 1 ; 3- \\ 1- \\ 1,2 ; 3- \\ 1,2 ; 2,3 ; 3,1 \\ 1,2 ; 2,-; 3,2\end{array}$

$\begin{array}{rrr}32 & 15 & 1 \\ 7 & 7 & 6 \\ 21 & 14 & 16 \\ 6 & 2 & \\ 5 & & \\ 1 & & 3 \\ 1 & 1 & 1 \\ 2 & 2 & 1 \\ 2 & & 1\end{array}$

[24] [COMB10] Conjoned Causative

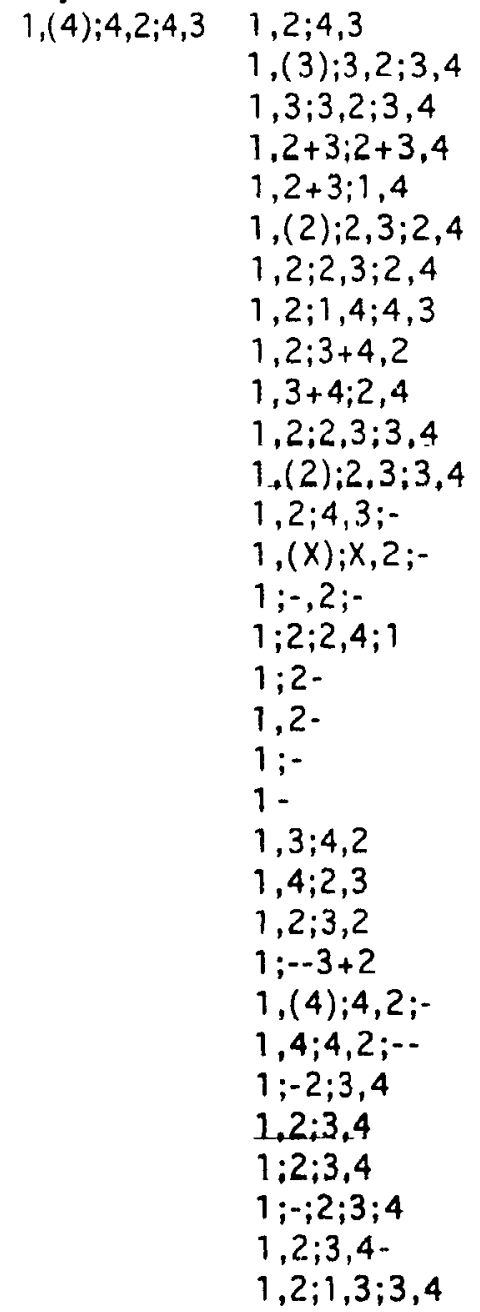

$\begin{array}{ll}3 & 6 \\ 3 & 3 \\ 3 & \\ & 1 \\ & 1 \\ & 1 \\ & 1\end{array}$


[24] ctd

$$
\begin{aligned}
& 1,2 ; 2,3 ; 4,3 \\
& 1,(2) ; 2,4 ; 4,3 \\
& 1,2 ; 2,4 ; 4,3 \\
& 1,3 ; 3,2 ; 2,4 \\
& 1,3 ; 1,2 ; 2,4 \\
& 1,3 ; 3,4 ; 4,2 \\
& 1,2 ; 4,3 ; 2,4 \\
& 1,3 ; 3,2 ;- \\
& 1,-; 2,4 ; 4,3 \\
& 1,2-4 \\
& 1 ; 2,3- \\
& 1 ;-2- \\
& 1 ;-, 2 ; 4,3 \\
& 1 ; 3,2 ; 4,- \\
& 1,2 ; 2,4- \\
& 2,3 ; 3,1 ; 1,4 \\
& 2,3 ; 1,4 \\
& 2,1+3 ; 1+3,4 \\
& 2,1 ; 3,4 \\
& 2,1 ; 1,3 ; 3,4 \\
& 4,3 ; 4,1 ; 2,(4) \\
& 4,3 ; 1,2 \\
& 4,1 ; 1,3 ; 3,2 \\
& N / R
\end{aligned}
$$

[25] [COMB1 1] Causative + Dative

$$
\begin{array}{ll}
1,(4) ; 4,2,3 & 1,2 ; 2,3 ; 3,4 \\
1,4 ; 4,3,2 & 1,(4) ; 4,3,2 \\
1,(3) ; 3,2,4 & 1,3 ; 3,2,4 \\
1,2 ; 2,3,4 \\
1,(2) ; 2,3,4 \\
1,(2) ; 2,4,3 \\
1,2 ; 2,3 ; 1,4 \\
1,3 ; 3,2 ; 2,4 \\
1,2 ; 2,3 ; 2,4 \\
1,2 ; 2,4 ; 2,3 \\
1,2 ; 2- \\
1 ; 2- \\
1,2- \\
1 ; 4,2,- \\
1,3 ; 3,4 ; 4,- \\
1,(2) ; 2,3,- \\
1,3 ; 3,2- \\
1 ; 3,2+4 \\
1,4 ; 4,1 ; 2,3 \\
1,(4) ; 4,2+3,- \\
1,(4) ; 4,2+3 \\
1,(4) ; 4,3+2 \\
1 ; 3- \\
1 ; 3,-2,-4 \\
1,2 ; 2,4 \\
1,3 ; 2,4 \\
1,2,3 ; 3,4
\end{array}
$$

$\begin{array}{lll}9 & 4 & \\ 5 & 1 & 1 \\ 3 & 3 & 6 \\ & & 1 \\ 2 & & 1 \\ 3 & 3 & 1\end{array}$


229.

[25] ctd

$$
\begin{aligned}
& 1,2 ; 2,3- \\
& 1,2 ; 3,4 \\
& 1,2 ; 2,4- \\
& 1,2 ; 4,3 \\
& 1 ; 2,-3,4 \\
& 1 ;-, 2+4,3 \\
& 1 ;- \\
& 1,- \\
& 1 ; 4,-, 3 \\
& 1 ; 3,-; 4- \\
& 1 ;-2,3 \\
& 1,4 ; 4,3 ; 3,2 \\
& 2- \\
& 2,1 ; 2,3 ; 2,4 \\
& 2,1 ; 1,3 ; 3,4 \\
& 2(4) ; 4,2+3 \\
& 4,3,2 ; 1,(4) \\
& 4,1 ; 1,2,3
\end{aligned}
$$

[26] [COMB12] Causative + SS Relative

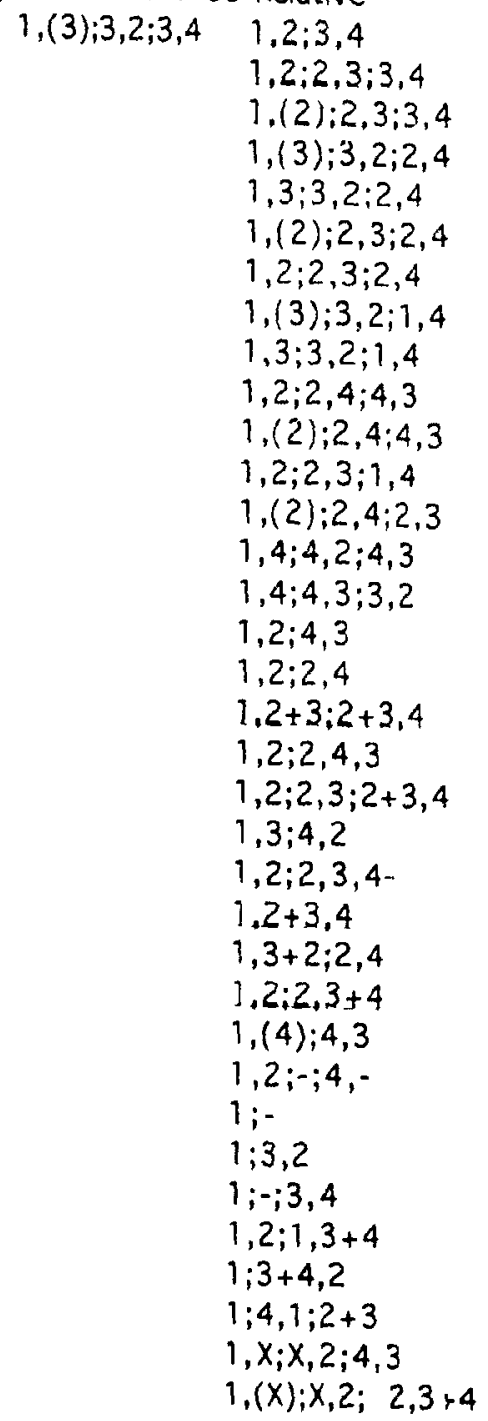

1,$2 ; 2,3 ; 1,4$

$1,(2) ; 2,4 ; 2,3$

1,$4 ; 4,3 ; 3,2$

1,$2 ; 4,3$

1,$2 ; 2,4$

$1,2+3 ; 2+3,4$

1,$2 ; 2,4,3$

, $2 ; 2,3 ; 2+3,4$

1,$3 ; 4,2$

$1,2+3.4$

$1,3+2 ; 2,4$

$1,2: 2,3+4$

$1,(4) ; 4,3$

1,$2 ;-; 4,-$

$1 ; 3,2$

$1 ;-; 3,4$

1,$2 ; 1,3+4$

$1 ; 3+4,2$

$1 ; 4,1 ; 2+3$

$1,(x) ; x, 2 ; 2,3+4$ 
229.

[26] ctd

$$
\begin{aligned}
& 2,1 ; 1,3 ; 3,4 \\
& 2,4 ; 4,1 ; 1,3 \\
& 3,-; 3,4 ; 2,1 \\
& 3,4 ; 1,2 ; 2,3 \\
& 3,2 ; 2,1 ; 1,4 \\
& 3,1 ; 2,4 \\
& 3,2 ; 3,4 \\
& -4- \\
& -; ; 3,4 ; 3,2 \\
& \text { N/R }
\end{aligned}
$$

[27] [COMB 13] SS Relative + Conjoned Theme

$\begin{array}{lllll}1,2+3 ; 1,4 & 12 & 5 & 1 \\ 1,2+3 ; 2+3,4 & 2 & 2 & \\ 1,2+3 ; 3+2,4 & 1 & 1 & \\ 1,2+3 ; 2+3 ; 1,4 & 1 & 1 & \\ 1,3+4 ; 3+4,2 & 1 & & \\ 1,4+3 ; 4+3,2 & 1 & & \\ 1,2+3 ; 2,4 & 2 & 2 & \\ 1,2+3 ; 3,4 & 1 & 1 & \\ 1,2+4 ; 1,3 & 3 & 1 & \\ 1,2+3 ; x, 2 & 1 & & \\ 1,2+3 ; 4,1 & 1 & 1 & \\ 1,4+3 ; 1,2 & & & \\ 1,2- & 1 & 1 & \\ 1 ;- & 1 & 1 & \\ 1,2+3 ;- & 2 & 2 & \\ 1,2,-; 4 & 1 & 1 & \\ 1,2 ; 1,2+3 & 1 & 1 & \\ 1,2+3 ;-- & 1 & & \\ 1,2 ; 3,4 & 1 & 1 \\ 1,3+2 ;-, 4 & 1 & 1 & \\ 1,2+3 ;-, 4 & 1 & 1 & \\ 1,2,3 ; 4,2+3 & 1 & & \\ 1,2+-; 4,3 & 1 & & \\ 1,2 ; 2,4 ; 4,3 & 2 & & \\ 1,4+2 ; 4+2,3 & 1 & & \\ 2,1+3 ; 2,4 & 1 & 1 & \\ 2,1 ; 3,4 ; 3 \vee & 1 & 1 & \\ 3,1 ; 1,2 ; 2,4 & 4,1 ; 3,2 & 1 & & \\ 4,2 ; 3 ; 1+2,4 & 1 & 1 & \end{array}$

[28] [COMB 14] Conjoned Clauses 4 NPs (No Deletion) (Baseline)

$$
\begin{array}{cl}
1,2 ; 3,4 & 1,2 ; 4,3 \\
1,2 ; 2,3 ; 3,4 \\
1,2+3 ; 2+3,4 \\
1,2+3 ; 1,1,4 \\
1,4 ; 4,3 ; 3,2 \\
1,3 ; 3,4 ; 4,2 \\
1,2 ; 2,4 ; 3 \vee \\
1,2 ;- \\
1,3 ; 2,4 \\
1,2 ; 3- \\
1,2,3,-
\end{array}
$$

1 
230.

[28] ctd

$$
\begin{aligned}
& 1,2 ; 2,4 \\
& 1,3 \\
& 1,2 ; 4,2 ; 2,3 \\
& 1,3 ; 1,2 ; 1,4 \\
& 1,4 ; 3,2 \\
& 2,1 ; 1,4 ; 4,3 \\
& 3,4 ; 2,1 \\
& 4,2 ; 3,1 \\
& N / R
\end{aligned}
$$

[29] [POMB 1] Dative-Theme cliticized

$$
\begin{array}{cl}
1,2,32=P & 1,3,2 \quad 2=P \\
2 \neq P & 3,2,12=P \\
& 2,3-2=P \\
& 1,3- \\
& 1,-, 3
\end{array}
$$

[30] [POMB2] Dative-Goal cliticized

$$
\begin{array}{ll}
1,3,2=P & \multicolumn{1}{c}{1,2,3 \quad 2=P} \\
2 \neq P & 2,3,1 \quad 2=P \\
& 1,3- \\
& 2,3,-2=P \\
& 1, X ;\{2 / 3\} \quad 2 \neq P \\
& -, 1,3
\end{array}
$$

1

[31] [POMB3] Causative-Theme clitıcized

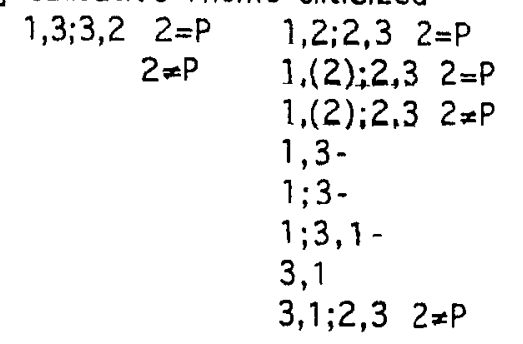


[34] ctd

$1,(3) ; 3 \mathrm{~V}$

1,3

3,1

$3,(1) ; 1,2=1$

1 .

[35] [POMB7] Causative-Reflexive Causer $=$ Goal

$\begin{array}{rlrl}(1,(4)) ; 4,3,2=1 & 1,(3) ; 3,4,2=1 & 3 & \\ & 3,4,2=1 & 1 & 2 \\ 1,3,4 & & 1 \\ 4,(1) ; 1,2,3 & & 1\end{array}$

$1,3: 3,4$

$1,(3): 3,4$

$1,3,4$

$1 ; 2=1,3,4$

$1 ; 3+4,-$

$1,-3+4,-$

$1 ;-, 3+2=1,4$

$4,2=1,3$

$1,3,-4$

$1 ;-3,4$

$1,(4) ; 4,3,-$

[36] [POMB8] Causative-Reflexive Causer $=$ Goal, Truncated $(1,(X)) ; X, 3,2=1 \quad 1,3-$

$$
\begin{array}{cc}
X=P & 1,(X) ; x, 2=1,3 \quad X \neq P \\
X \neq P & x, 2=1,3 \quad X=P \\
& 1,3, x \quad X \neq P \\
& 1 ; 2=1,3, X \quad X=P \\
& 1, X \quad X=P \\
& 3,1,2 \quad 2 \neq P \\
& 1 ; 2=1,3,- \\
& 1 ;-3,2=1 \\
1-
\end{array}
$$

2

1

2

3

1

1

1

1

10

1

1

1

1

1

1

1

[37] [POMB9] Causative-Theme cliticized, Truncated

$1, X ; X, 2$

$X=P \quad 2=P$

$X \approx P \quad 2 \approx P$

$X \approx P \quad Z=P$
$1,2: 2 \mathrm{~V} 2=\mathrm{P}$

$1,(2) ; 2,2 \quad 2=P$

$2, X ; X, 1 \quad X=P \quad 2=P$

$1,2 \quad 2=P$

$1,-$

$X-X=P$

$1 .(2) ; 2, X \quad X \neq P \quad 2=P$

1.(2) $; 2, X \quad X=P \quad 2 \approx P$

$2,1 \quad 2=P$

$1 ; 2,1 \quad 2=P$
1

4

1
[38] [POMB10] Causative-Reflexive Causer $=$ Theme, Truncated

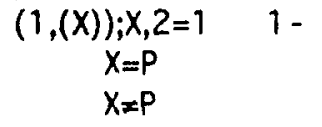

$$
2.1=2
$$$$
1,(X) ; X, 2 \quad X=P \quad 2=P
$$

8

1

1

1

3

1

11

1

[39] [POMB11] Causative-Theme=Causee cliticized, Intransitive Verb $1.2 ; 2 \vee 2=P$ $1,-$

2,$1 ; 1 \vee 2=P$ 
232.

[39] ctd

$2 \vee 2=P$

$1,(X) ; X, 2 \quad X=P \quad 2=P$

1

[40] \{POMB12] Cleft-Object with Stylistic Inversion

2,1

1,2

49

23

[41] [POMB13] Subject-Object Relative with Stylistic Inversion

2,$1 ; 1,3 \quad 1,2 ; 2,3$
1,$2 ; 1,3$
2,$1 ; 2,3$
1,$3 ; 1,2$
1,$3 ; 2,3$
2,$1 ; 3,1$
1,$2 ; 3,2$
1,$3 ; 3,2$
1,$2 ; 3,1$
2,$1 ;--$
1,$3 ;-$

32

19

1,$2 ; 1,3$

, $1 ; 2,3$

$3 ; 1,2$

, $3 ; 3,2$

2,$1 ;--$

1,3 ;-

$\begin{array}{lr}9 & 13 \\ & 5 \\ 1 & 1 \\ & 1 \\ 1 & 1 \\ 2 & \\ 2 & \\ 1 & \\ 1 & \\ 1 & \end{array}$

[42] [POME 14] Object-Object Relative with Stylistic Inversion

1,$2 ; 3,2$

1,$2 ; 2,3$

1,$2 ; 1,3$

3,$2 ; 2,1$

1,$2 ; 3,1$

3,$1 ; 1,2$

2,$3 ; 1,2$

2,$1 ; 3,1$

1,$3 ; 2,3$

$\begin{array}{rr}36 & 18 \\ 4 & 5 \\ 1 & 2 \\ & 3 \\ & 1 \\ & 1 \\ & 1\end{array}$


Table A.A.5. Generalizability of the Present Sample

Present Study

to a Larger Population

Sentence Types

[01] Aclive

[05] Dative

[10] Object-Subjecl Relatıve

102) Passive

104] Cleft Object

108) Conjoined

[06] Dative Passive

[09] Subject-Object Relatıve
Means/12 SD

11111

$10.111 \quad 1.537$

$9.899 \quad 2.759$

$8.444 \quad 2.963$

$8.000 \quad 3.742$

$7.444 \quad 4640$

$5.222 \quad 4.522$

$\begin{array}{llllllll}{[01]} & 105] & {[10]} & {[02]} & {[04]} & \text { [08] } & \text { 106] } & \text { [09] }\end{array}$

(Sentence types underlined by a common line do not differ on the Fisher PLSD set at a 95\% confidence level, sentences not underlined by a common line do differ significantiy.)

$\begin{array}{lllllllll}101] & {[05]} & {[10]} & {[02]} & {[04]} & {[08]} & {[06]} & {[09]}\end{array}$

(Sentence types underlined by a common line do not differ on Tukey's test set at an experimenterwise error rate of 005 , sentences not underlined by a common line do differ significantly)

Experiment 3 (Caplan and Hildebrandt, 1988)

Sentence Types

[01] Active

100] Cleft-Subject

[02] Passive

[05] Dative

[08] Conjoined

[04] Cleft Object

[10] Object-Subject Relative

[06] Dative Passive

[09] Subject-Object Relative

$\begin{array}{cc}\text { Means } 15 & \text { SO } \\ 4.1 & 1.5 \\ 4.0 & 1.6 \\ 3.2 & 1.8 \\ 2.9 & 2.0 \\ 2.8 & 2.0 \\ 2.7 & 1.8 \\ 2.1 & 1.9 \\ 1.9 & 2.1 \\ 1.4 & 1.6\end{array}$

$\begin{array}{llllllll}{[01]} & 102] & {[05]} & {[08]} & {[04]} & {[10]} & {[06]} & 109]\end{array}$

(Sentence types underlined by a common line do not differ on Tukey's test set at an experimenterwise error rate of 0.05 , sentences not underlined by a common line do differ significantly) 
234.

APPENDIX B

Summary Score Sheets for French Patients. and Subset of Controls For Each Battery 
PATIENT Ag

SUAKARY SCORE SHEET

(nO01-012) A2

Exaple: La grenouille a frappt le singe. CORRECT FORMS:

$$
1,2
$$

(Stage II: $E=6, \mathrm{df}=1$, $\chi^{2}=12.00, p=.0005 *$ )

(17013-024) P2

Exapple: Le singe a the frappt par la grenouille. CORRECT FORHS:

$$
2,1
$$

(Stage II: $E=6, d f=1$,

$\left.\chi^{2}=12.00, p=.0005 *\right)$

(H025-036) Truncated Passi ves

Exaple: le singe a ltt frappt. CORRECT FORHS:

$x, 1$

$12 / 12$

(Stage I: $E=6, \mathrm{df}=1$,

$\left.f^{2}=12.00, p=.0005 *\right)$

(H037-048) CO2

Exaple: C'est la vache que le lapin a eabrasste. CORRECT FORHS:

$$
2,1 \quad 11 / 12
$$

(Stage II: $E=6, \mathrm{df}=1$,

$\chi^{2}=8.333, p=.0039 *$ )

INCORRECT FORHS:

1,2

$1 / 12$

(n049-060) $\quad 13$

Exanple: Le lapin a confle la vache a la chevre. CORRECT FORHS:

$$
1,2,3
$$

$12 / 12$

(Stage II: $E=2, d f=5$, $\left.\chi^{2}=60.00, p=.0001 \%\right)$

(71061-072) P3

Exauple: L'tlephant a dte donnt au singe par la grenouille. CORRECT FORHS:

$$
3,1,2
$$

$12 / 12$

(Stage II: $E=2, \mathrm{df}=5$, $\left.\chi^{2}=60.00, p=0001 \%\right)$

(M073-084) $\mathrm{CO3}$

Example: C'est la chevre que le lapin a donnete la vache. CORRECT FORHS:

$$
2,1,3
$$

$12 / 12$

(Stage II: $E=2, d f=5$,

$\left.\chi^{2}=60.00, p=.0001 \%\right)$

\section{(11085-096) CON}

Exaple: le singe a gratte le lapin et a caresse l'bltphant. CORRECT FORAS:

$$
1,2 ; 1,3
$$

1,$3 ; 1,2$

$11 / 12$

(Stage II: $E=.33, \mathrm{df}=35$,

INCORRECT FORHS:

$$
1,2 ; 2,3 \quad 1 / 12
$$


PATIENT AG

i

SUMMARY SCORE SHEET

$(M 097-108) \quad S-0$

Exaple: Le singe que le lapin a salsi a bouscule la chevre. CORRECT FORMS:

$$
\begin{array}{lcl}
2,1 ; 1,3 & 12 / 12 & \left.X^{2}=424.244, p=.0001: *\right) \\
1,3 ; 2,1 & \ldots & X^{2}
\end{array}
$$

(Stage II: $E=.33, d E=35$,

(n109-120) 0-S

Exanple: La cherre a frapps le lapin qui a sarsi la vache. CORRECT FORHS:

1,$2 ; 2,3$

2,$3 ; 1,2$

$12 / 12$

(Stage II: $E=.33$. df $=35$, $\left.\chi^{2}=424.244, p=.0001 \therefore\right)$

(n121-132) $\quad 0.0$

Exaple: Le singe a chatouille la grenouslle que la chdvre a bousculte. CORRECT FORHS:

1,$2 ; 3,2$

3,$2 ; 1,2$

$11 / 12$

$1 / 12$

TOTAL CORRECT: $12 / 12$

(Stage II: $E=.33$, df $=35$, $\left.\gamma^{2}=357.77, p=.0001: 1\right)$

(n133-144) S-S

Exaple: La grenoullle qui a tenu la vache a attrape l'elephant.

CORREIT FORHS:

1,$2 ; 1,3$

1,$3 ; 1,2$

$10 / 12$

$1 / 12$

TOTAL CORRECT:

(Stage II: $E=.33, \mathrm{dE}=35$, $\chi^{2}=296.971, p=.0001 \%$ )

IMCORRECT FORHS:

1,$2 ; 2,3$

$1 / 12$

(H145-156) Active Conjoined These

Exanple: Le lapin a frappe la vache et la cheve. CORRECT FORMS:

$1,2+3$

$12 / 12$

(Stage II: $E=1, d f=11$, $1,3+2$ $-$

$\left.X_{C}=132.00, p=.0001:\right)$

(ni57-168) Passive Conjoined Agent

Exanple: La grenouslle a tte caresste par la chevre et la vache.

CORRECT FORHS:

$2+3,1$

11112

(Stage II: $E=1, d f=11$,

$3+2,1$

1/12 TOTAL CORRECT: $12 / 12$

$\left.\chi^{2}=110.00, p=.0001 *\right)$

-


patient ag

SUMYARY SCORE SHEET

(J001-012) Direct Object Control, Intransitive Verb

Exalple: La grenouslle a forcel le singe d bondsr. CORRECT FORMS:

1,$2 ; 2 \mathrm{~V} \quad 11 / 12$

$2 V ; 1,2$

$1 / 12$

YOTAL CORRECT:

(Stage II: $E=1.5, \mathrm{df}=7$,

$\left.\chi^{2}=69.333, p=.0001 \%\right)$

(J013-024) Passivized Direct ob ject Control, Intransitive Verb

Exasple: La vache a dts forcte par le lapin d danser.

CORRECT FORMS:

2,$1 ; 16$

IV; 2,1

$12 / 12$

(Stage II: $E=1.5, \mathrm{~d} f=7$,

$2=84.00, p=.0001 \%$

(J025-036) Truncated Causative

Exauple: Le lapin a fait frappep la vache.

CORRECT FORMS:

$\begin{array}{lc}1, x ; x, 2 & 9 / 12 \\ 1,(x) ; x, 2 & -- \\ x, 2 ; 1, x & 1 / 12 \\ x, 2 ; 1,(x) & --\end{array}$

(Stage I: $E=.33$, df $=35$,

$\chi^{2}=248.486, p=.0001 *$ )

$x, 2 ; 1, x \quad 1 / 12$

TOTAL CORRECT: $10 / 12$

JiCORBECT PORME:

$x, 1 ; 1,2 \quad 2 / 12$

(J037-049) Causabivetintransitive Verb

Exauple: La vache a fast dansar le lapin.

CORRECT FORMS:

1,$2 ; 2 \mathrm{~V}$

$2 V ; 1,2$

$12 / 12$

(Stage II: $E=1.5, \mathrm{df}=7$,

$\chi^{2}=84.00, p=.0001 \%$ )

(j04:-060) Direct Object Controltiransitive Verb

Exasple: Le lapin a forces la chevre a frapper la vache. COKRECT FORMS:

1,$2 ; 2,3 \quad 11112$

$2,3 i 1,2$

1/12 TOTAL CORRECT: $12 / 12$

(Stage II: $E=.33, \mathrm{df}=35$,

$\psi^{2}=357.577, p=.0001 \%$ )

(J061-072) Passivized Direct object Control+Transitive Vepb

Exanple: La grenouille a dte forcte par l'elephant d caresser le singe.

CORRECT FORHS:

2,$1 ; 1,3 \quad 9 / 12$

1,$3 ; 2,1 \quad 2 / 12$

TOTAL CORRECT: $11 / 12$

(S,tage II: $E=.33, \mathrm{df}=35$, $\left.\chi^{2}=248.486, p=.0001 *\right)$

INCORRECT FORHS:

2,$3 ; 2,1 \quad 1 / 12$ 
PATIENT AG

SUMHARY SCORE SHEET

(J073-08d) Causative (faire-j)

Example: La grenou.! le a last caressep le singe d l'slephant. CORRECT FORMS:

1,$3 ; 3,2$

$1,(3) ; 3,2$

$10 / 12$

3,$2 ; 1,3$

-.

3,$2 ; 1,(3)$

- TOTAL CORRECT: $11 / 12$

(Stage II: $E=.33, d f=35$, $\left.\chi^{2}=296.971, p=.0001 \%\right)$

\section{INCORRECT FORHS:}

$$
1,2 ; 3,2
$$

$1 / 12$

(J085-096) Causative (Faire-par)

Exaple: Le lapin a fast frapper la vache par la chevre.

CORRECT FORHS:

1,$3 ; 3,2$

$1,(3) ; 3,2$

$12 / 12$

3,$2 ; 1,3$

$+$

3,$2 ; 1,(3)$

$-$

$-\cdot$

(j097-108) Cleft ob ject-Causative (Fare-par)

Exaple: C'est l'elephant que le singe a falt sabsir par la grenoulle.

CORRECT FORMS:

2,$3 ; 3,1$

3,$1 ; 2,3$

$2,(3) ; 3,1$

3,$1 ; 2,(3)$

(Stage II: $E=.33, \mathrm{~d} t=3.5$,

(Stage II: $E=.33$, df $=35$,

$\left.\chi^{2}=424.244, p=.0001 \%\right)$

BRECT FORMS

2,$1 ; 3,1$

$2 / 12$

(J109-120) Conjoined Causative

Exanple: La grenouslie a fait frapper la vache et chatousller l'tlephant par le singe. CORRECT FORHS:

1,$4 ; 4,2 ; 4,3$

1,$4 ; 4,3 ; 4,2$

4,$2 ; 4,3 ; 1,4$

4,$3 ; 4,2 ; 1,4 \quad$..

$1,(4) ; 4,2 ; 4,3 \quad \cdots \quad$ TOTAL CORRECT: $8 / 12$

\section{IMCORRECT PORHS:}

1,$3 ; 3,2 ;--\quad 1 / 12$

1,$2 ; 2,3 ; 2,4 \quad 1 / 12$

1,$3 ; 3,2 ; 3,4 \quad 1 / 12$

1,$4 ; 4,2 ;-1-\quad 1 / 12$

(Stage II: $E=.0007, d f=1727$, $X_{2}^{2}=7702.382, p<.0001^{\circ}$ ) 
239.

PATIENT AG

SUMHARY SCORE SHEET

(J121-132) Causativetoative

Exanple: L'tlephant a fast apporter le singe a la grenouslle par la vache. CORRECT FORMS:

1,$4 ; 4,2,3 \quad 9 / 12$

$1,(4) ; 4,2,3 \quad \cdots$

$4,2,3 ; 1,4 \quad--$

$4,2,3 ; 1,(4)$

(Stage II: $E=.063, \mathrm{df}=191$,

$\left.\chi^{2}=1353.179, \mathrm{p}=.0001 *\right)$

INCORRECT FORMS:

1,$4 ; 4,3,2 \quad 2 / 12$

4,$1 ; 1,2,3 \quad 1 / 12$

(J133-144) CausativetS-S relative

Exalple: La grenouslle a fast chatouiller l'el epphant par le singe qui a frappe la vache. CORRECT FORMS:

$\begin{array}{lc}1,3 ; 3,2 ; 3,4 & 6 / 12 \\ 1,3 ; 3,4 ; 3,2 & -- \\ 3,2 ; 3,4 ; 1,3 & - \\ 3,4 ; 3,2 ; 1,3 & 1 / 12 \\ 3,4 ; 1,3 ; 3,2 & --\end{array}$

(Stage II: $E=.007, \mathrm{df}=1727$,

$6 / 12$

12

3,$4 ; 1,3 ; 3,2 \quad-. \quad$ TOTAL CORRECT: $7 / 12$

INCORRECT FORMS:

,$--; 3,4 ; 3, ?$

1,$3 ; 3,2 ; 2,4 \quad 4 / 12$

(J145-156) S-S relativetConjoined Theas

Exanple: L'dléphant qus a chatourlle la vache et le singe a frappt la grenouslle. CORRECI FORMS:

$\begin{array}{lc}1,2+3 ; 1,4 & 10 / 12 \\ 1,3+2 ; 1,4 & -- \\ 1,4 ; 1,2+3 & -- \\ 1,4 ; 1,3+2 & --\end{array}$

(Stage II: $E=.042, \mathrm{df}=287$, $\left.\chi^{2}=2416.667, \mathrm{p}=.0001 *\right)$

INCORRECT FORHS:

$1,2+3 ;--\quad 1 / 12$

1,$2 ; 3,4 \quad 1 / 12$

(J157-168) Conjoined clauses-4NPs(no deletion)(Baseline)

Exapple: La grenouille a frappt le singe et la vache a chatouillt l'slephant. CORRECT FORMS:

1,$2 ; 3,4$

$12 / 12$

(Stage II: $E=.083, \mathrm{df}=143$,

3,$4 ; 1,2$

$\left.\chi^{2}=1722.892, p=.0001 *\right)$ 
PATIENT CA

SUMMARY SCORE SHEET

(no01-012) 12

Exaple: La grenouslle a frappt le singe.

CORRECT FORHS: 1,2

$12 / 12$

(Stage II: $E=6, d f=1$,

$\chi^{2}=12.00, \mathrm{p}=.0005 \%$

(M013-024) P2

Exauple: Le singe a dte frappé par la grenourlle. CORRECT FORHS:

$$
2,1
$$

(Stage II: E 6, df $=1$, $x^{2}=12.00, p=.0005 \%$

(ro25-036) Truncat ed Passives

Exanple: Le singe a tte frapps. CORRECT FORMS:

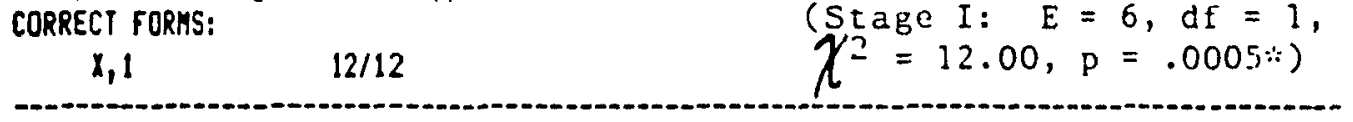

(M037-048) $\mathrm{CO2}$

Example: C'est la rache que le lapin a eabrassee. CORRECT FORMS:

$2,1 \quad 12 / 12$

$($ Sfage II: $E=6$, df $=1$
$\left.\chi^{2}=12.00, p=.0005 \%\right)$

(7049-060) A3

Exaple: Le lapin a confis la vache d la chevre. CORRECT FORHS:

$$
1,2,3
$$

$12 / 12$

(Stage II: $E=2, d E=5$, $\left.\chi^{2}=60.00, p=.0001 *\right)$

(M061-072) P3

Exanple: L'ellephant a tté donné au singe par la grenouille. CORRECT FORHS: $3,1,2$ $12 / 12$ (Stage II: $E=2, d \tilde{f}=5$, $\gamma^{2}=60.00, p=.0001: 1$

(n073-084) CO3

Exanple: c'est la chevre que le lapin a donnte d la vache. CORRECT FORHS:

$$
2,1,3 \quad 11 / 12
$$

(S,tage II: $E=2, d f=5$, $\left.\chi^{2}=49.00, p=.0001 \%\right)$

INCORRECT FORHS:

$1,2,3 \quad 1 / 12$

(n085-096) CON

Exapple: Le singe a gratt te le lapin et a caresst l'tlephant. CORRECT FORHS:

$\begin{array}{cc}1,2 ; 1,3 & 12 / 12 \\ 1,3 ; 1,2 & --\end{array}$

(Stage II: $E=.33, \mathrm{df}=35$, $\left.\gamma^{2}=424.244, p=.0001 \%\right)$ 
PATIENT CM

SUMAARY SCORE SHEET

(n097-108) S-0

Exapple: Le singe que le lapin a saist a bouscult la chevre. CORRECT FORMS:

$\begin{array}{rr}2,1 ; 1,3 & 11 / 12 \\ 1,3 ; 2,1 & 1 / 12\end{array}$ TOTAL CORRECT: $12 / 12$

(Stage II: $E=.33, \mathrm{df}=35$, $\left.\gamma_{2}=357.77, p=.0001 \%\right)$

(n109-120) $\quad 0-5$

Exapple: La chture a frappe le lapin qui a sassi la vache. CORRECT FORHS:

$$
\begin{array}{lcl}
\text { ECT PORMS: } & & (\text { Stage II: } E=.33, \text { df }=35, \\
1,2 ; 2,3 & 12112 & \left.\chi^{2}=424.244, p=.0001 \%\right) \\
2,3 ; 1,2 & -. &
\end{array}
$$

(ni21-132) 0-0

Exauple: Le singe a chatoullle la grenouille que la chtvre a bouscul te. CORRECT FORHS:

1,$2 ; 3,2$

3,$2 ; 1,2$

$10 / 12$

(Stage II: $E=.33$, df $=35$, $\chi_{2}^{2}=296.971, p=.0001 \%$ )

INCORRECT FORHS:
1,$2 ; 3,1$
$1 / 12$
3,$2 ; 2,1$
$1 / 12$

(HI33-144) S-S

Exaple: La grenouslle qui a tenu la vache a attrapt l'blephant.

CORRECT FORHS:

1,$2 ; 1,3$

1,$3 ; 1,2$

$12 / 12$

(Stage II: $E=.33$, df $=35$,

$\left.\chi^{2}=424.244, \dot{p}=.0001 \%\right)$

(n145-156) Active Conjoined There

Exauple: Le lapin a frappe la vache et la chevre. CORRECT FORHS:

$1,2+3$

$1,3+2$

$12 / 12$

(Stage II: $E=1$, df $=11$,

$\left.\chi^{2}=132.00, p=.0002 \%\right)$

(mis7-168) Passive Conjoined Agent

Exaple: La grenouille a tte caresste par la chevre et la vache.

CORRECT FURHS:

$2+3,1$

$3+2,1$

$12 / 12$

(Stage II: $E=1, \mathrm{df}=11$,

$\left.\chi^{2}=132.00, p=.0001 *\right)$

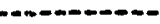


PATIENT CH

SUMMARY SCORE SHEET

(5001-012) Durect Ob ject Control, Intransitive Verb

Exanple: La grenouslle a force le singe d bondir. CORRECT FORMS:

$\begin{array}{ll}1,2 ; 2 V & 7 / 12 \\ 2 V ; 1,2 & 4 / 12\end{array}$

$4 / 12$

TOTAL CORRECT: $11 / 12$

(Stage II: $E=1.5, \mathrm{df}=7$,

$\left.\chi^{2}=32.00, p=.0001 \%\right)$

INCORRECT FORMS:

2,$1 ; 1 V \quad 1 / 12$

(J013-024) Passivized Direct objert Conbrol, intransitive Verb

Exanple: La vache a ets forcese par le lapin d danser. CORPECT FORHS:

2,$1 ; 1 \mathrm{~V}$

$6 / 12$

IV;2,1

$6 / 12$

TOTAL CORRECT: $12 / 12$

(Stage II: $E=1.5$, df $=7$, $\chi^{2}=36.00, p=.0001 \%$ )

(J025-036) Truncated Causative

Exaple: Le lapsn a fait frapper la vache. CORRECT FORMS:

$1, x ; x, 2$

$1,(x) ; x, 2$

$11 / 12$

$x, 2 ; 1, x$

$-$

$x, 2 ; 1,(x)$

$-$

$\cdots$

INCORRECT FORHS:

1,$2 ; 2, x \quad 1 / 12$

(J037-048) Causativetintransitive Vept

Exanple: La yache a fait danser le lapin. CORRECT GORMS:

1,$2 ; 2 \mathrm{~V}$

$6 / 12$

$2 \mathrm{~V} ; \mathrm{l}, 2$

$6 / 12$

TOTAL CORPECT: $12 / 12$

$($ Stage I: $E=.33, \mathrm{df}=35$,
$\left.\chi_{2}^{2}=357.577, \mathrm{p}=.0001 \%\right)$

(J049-060) Durect ob ject Controltiransituve Verb

Exanple: Le lapin a force la chdrre a frapper la vache. CORRECT FORMS:

1,$2 ; 2,3$

2,$3 ; 1,2$

$10 / 12$

$2 / 12$

TOTAL CORRECT: $12 / 12$

(Stage II: $E=1.5, \mathrm{df}=7$, $\chi^{2}=36.00, p=.0001 \%$ )

(J06!-072) Passivized Direct Object Control+Transative Verb

Exanple: La grenouslle a tte forcte par l'ellsphant a caresser le singe.

CORRECT FORHS:

2,$1 ; 1,3$

1,$3 ; 2,1$
$5 / 12$

$7 / 12$

TOTAL CORRECT: $12 / 12$

$($ Stage II: $E=.33, d f=35$,
$\left.\chi^{2}=212.122, p=.0001 \%\right)$ 
PATIENT CA

SUMMARY SCORE SHEET

(J073-084) Causative (Falre-d)

Exanple: La grenouille a fat caresser le singe d l'elephant.

CORRECT FORHS:

1,$3 ; 3,2$

$11 / 12$

(Stage II: $E=.33$, df $=35$,

$1,(3) ; 3,2$

$\chi^{2}=357.577, \mathrm{p}=.0001 \%$ )

3,$2 ; 1,3$

3,$2 ; 1,(3)$

$\cdots$

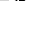

$-$

IMCORRECT FORHS:

$1,(2) ; 2,3$

$1 / 12$

(J085-096) Causative (Faste-par)

Exaple: Le lapin a latt frapper la vache par la chevre. CORRECT FORAS:

$\begin{array}{lc}1,3 ; 3,2 & 12 / 12 \\ 1,(3) ; 3,2 & -- \\ 3,2 ; 1,3 & -- \\ 3,2 ; 1,(3) & --\end{array}$

(Stage II: $E=.33, \mathrm{df}=35$,

$\left.\mathscr{\chi}^{2}=424.244, \dot{p}=.0001 \%\right)$

12

(J097-108) Cleft Object-Causative (Falre-par)

Exauple: C'est l'slephant que le singe a fast saisir par la grenoullle. CORRECT FORHS:

2,$3 ; 3,1$

$6 / 12$

(Stage II: $E=.33$, df $=35$,

3,$1 ; 2,3$

$\chi^{2}=175.759, p=.0001 \%$ )

$2,(3) ; 3,1$

3,$1 ; 2,(3)$

$-$

$-$

INCORRECT FORMS:

$\begin{array}{ll}1,(3) ; 3,2 & 5 / 12 \\ 2,3 ; 3,2 & 1 / 12\end{array}$

2,$3 ; 3,2$

$1 / 12$

(J10y-120) Conjoined Causative

Exanple: La grenouille a fat frapper la vache et chatouiller l'tltphant par le singe. CORRECT FORRS:

1,$4 ; 4,2 ; 4,3 \quad 9 / 12$

1,$4 ; 4,3 ; 4,2 \quad--$

4,$2 ; 4,3 ; 1,4 \quad--$

4,$3 ; 4,2 ; 1,4 \quad--$

$1,(4) ; 4,2 ; 4,3 \quad 1 / 12$ TOTAL CORRECT: $10 / 12$

IMCORRECT FORHS:

$1,(3) ; 3,2 ; 3,4 \quad 1 / 12$

1,$2 ; 4,3 ;-\quad 1 / 12$ 
PATIENT CH

SUMMARY SCORE SHEET

(J121-132) CausativetDative

Exanple: L'slephant a falt apporter le singe d la grenoullle par la vache. CORRECT FORMS:

$$
\begin{array}{lcl}
1,4 ; 4,2,3 & 9 / 12 \\
1,(4) ; 4,2,3 & 2 / 12 \\
4,2,3 ; 1,4 & -- & \\
4,2,3 ; 1,(4) & -- & \text { TOTAL CORRECT: } 11 / 12
\end{array}
$$

(Stage II: $E=.063, d f=191$, $\left.\chi^{2}=1924.607, p=.0001 \%\right)$

\section{INCORRECT FORMS:}

1,$4 ; 4,3,2$

$1 / 12$

(J133-144) Causativets-S ralative

Exanple: La grenoullle a fast chatousller l'elephant par le singe qui a frappt la vache. CORRECT FORHS:

$\begin{array}{lc}1,3 ; 3,2 ; 3,4 & 9 / 12 \\ 1,3 ; 3,4 ; 3,2 & -- \\ 3,2 ; 3,4 ; 1,3 & -- \\ 3,4 ; 3,2 ; 1,3 & -- \\ 3,4 ; 1,3 ; 3,2 & --\end{array}$

(Stage II: $E=.007$, df $=1727$, $\left.\chi^{2}=11988.096, \mathrm{p}<.0001 \%\right)$

IMIORRECT FORHS:

1,$2 ; 2,3 ; 3,4 \quad 1 / 12$

1,$4 ; 4,2 ; 4,3 \quad 1 / 12$

1,$3 ; 3,2 ; 2,4 \quad 1 / 12$

(J145-156) S-S relativetCon joined thene

Exauple: L'slephant qui a chatoulls la vache et le singe a frappes la grenourlle. CORRECT FORHS:

$\begin{array}{cc}1,2+3 ; 1,4 & 12 / 12 \\ 1,3+2 ; 1,4 & -- \\ 1,4 ; 1,2+3 & -- \\ 1,4 ; 1,3+2 & --\end{array}$

(Stage II: $E=.042$, df $=287$, $\left.\chi^{2}=3416.667, p=.0001 \%\right)$

(J157-168) Conjoined clauses-4MPs (no deletion)(Baseline)

Exaple: La grenouille a frappe le singe et la vache a chatouille l'blephont. CORRECT FORHS:

1,$2 ; 3,4$

$3,4 i 1,2$

$10 / 12$

$1 / 12$

TOTAL CORRECT: $11 / 12$

(Stage II: $E=.083, \mathrm{df}=143$,

$\gamma^{2}=1216.868, p=.0001 \%$

INCORRECT FORASS:

1,$2 ; 4,3 \quad 1 / 12$ 
245.

PATIENT CH

SUMMARY SCORE SHEET

(6001-012) Dative-These cliticized

Exaple: La chevre l'a offert d la vache. CORRECT FORMS:

$1,2,3 \quad 2=9 \quad 11 / 12$

$1,2,3219$

1/12 TOTAL CORRECT: $12 / 12$

(Stage I: $E=2$, df $=5$,

$\left.X^{2}=60.00, p=.0001 \%\right)$

(G013-024) Dative-foal claticized

Exanpla: La vache lus a rens la chevre. CORRECT FORHS:

$$
\begin{array}{lc}
1,3,2 & 2=p \\
1,3,2 \text { 2IP } & 10 / 12
\end{array}
$$

(Stage I: $E=2$, df $=5$,

$\left.\gamma^{2}=40.00, \mathrm{p}=.0001 \%\right)$

INCORRECT FORHS:

$$
1,2,32=9 \quad 2 / 12
$$

(6025-036) Causative-Thene cliticized

Exapple: Le lapin l'a last tensr par la chevre. CORRECT FOPMS:

$$
\begin{array}{lc}
1,3 ; 3,22=p & 11 / 12 \\
1,3 ; 3,2 \text { 21P } & -- \\
3,2 ; 1,32=p & -- \\
3,2 ; 1,321 p & --
\end{array}
$$

(Stage I: $E=.33, \mathrm{df}=35$, $\chi^{2}=357.577, \mathrm{p}=.0001 \%$ )

INCORRECT FORHS:

$1,(3) ; 3,2=3$

$1 / 12$

(6037-048) Causative-liausee eliticized

Exauple: L'tlephant lus a fat attraper la grenouslle. CORRECT FORHS:

$$
\begin{array}{lc}
1,2 ; 2,32=p & 12 / 12 \\
1,2 ; 2,321 P & -. \\
2,3 ; 1,22=p & -- \\
2,3 ; 1,221 \mathrm{P} & -.
\end{array}
$$

(Stage I: $E=.33, \mathrm{df}=35$, $\left.\chi^{2}=424.244, p=.0001 *\right)$

(6049-060) Causative-Reflexive "Causer" " "Theae" Exaple: la vache se fait sassir par le lapin. CORRECI FORHS:

$$
\begin{array}{lcl}
3,2=1 & -- & \\
1,(3) ; 3,2=1 & 12 / 12 & \\
3,2=1 ; 1,(3) & -- & \\
1,3 ; 3,2=1 & -- & \\
3,2,2=1 ; 1,3 & -- & \text { TOTAL CORRECT: } 12 / 12
\end{array}
$$

(Stage II: $E=3, \mathrm{df}=3$, $\left.X^{2}=36.00, p=.0001 \%\right)$ 
PATIENT CH

SUMHARY SCORE SHEET

(6061-072) Causative-Rellexive Causet

Exaple: La chevre fast se serrer la vache. CORRECT FORHS:

1,$3 ; 3,2=3$

$3,2=3 ; 1,3$

$1,(3) ; 3,2=3$

-

-- TOTAL CORRECT: $10 / 12$

(Stage II: $E=3, d f=3$, $q^{2}=22.667, p=.0001 \div$ )

INCORFECT FORMS:

$1,(3) ; 3 \mathrm{~V}$ $2 / 12$

(6073-084) Causahive-Reflexive Causer $=60 a$ !

Exalple: La vache se falt resettre la chevre par le lapin. CORRECT FORMS:

$4,3,2=1$

$-$

1,$4 ; 4,3,2=1 \quad$..

(Stage II: $E=.67, \mathrm{df}=17$,

$4,3,2=1 ; 1,4 \quad-$

$1,(4) ; 4,3,2=1 \quad 12 / 12$

$4,3,2=1 ; 1,(4) \quad--\quad$ TOTAL CORRECT: $12 / 12$

(6085-096) Causative-Reflexive Causer=60al, Truncated

Exaple: La chevre se fat offrir le lapin.

CURRECT FORHS:

$x, 3,2=1 \quad x=p \quad 1 / 12$

(Stage I: $E=.67, \mathrm{dF}=17$,

$x, 3,2=1$ XIP $\quad--$

$1, x ; x, 3,2=1 \quad x=p \quad 11 / 12$

$1, x ; x, 3,2=1$ XIP

TOTAL COKRECT: $12 / 12$

(6097-108) Causative-These clisticized, Truncated

Exanple: la chevre le fat serrer.

CORRECT FORMS:

$1, x_{i} x, 2 \quad x=p \quad 2=p \quad 11 / 12$

(Stage I: $E=.33, \mathrm{df}=35$,

$1, x_{i} x, 2$ XIP $2 \mathbb{2} \quad-$

$X, 2 ; 1, x \quad X=P \quad z=P \quad-$

$X, 2 ; 1, x \quad X \in P$ 2IP $\quad--$

$1, x ; x, 2$ XIP $2=p \quad-$

INCORRECT FORHS:

1,$2 ; 2, x$ XIP $2=p \quad 1 / 12$

(6109-120) Causative-Reflexive "Causer" =' Thene', Truncated

Exanple: La chevre se fait bousculer. CORRECT FORHS:

$x, 2=1 \quad x=p$

$x, 2=1 x \in P$

$\chi^{2}=357.577, \mathrm{p}=.0001 \%$ )

$X^{2}=202.985, p=.000(\therefore)$

$\left.X^{2}=202.985, \mathrm{p}=.0001 .4\right)$

$1,(x) ; x, 2=1 \quad x=p \quad 3 / 12$

$1,(x) ; x, 2=1$ IIP $\quad-$.

$1, x_{i} x, 2=1 \quad x=p \quad 8 / 12 \quad$ TOTAL CORRECT: $11 / 12$

INCORRECT FORMS:

$1, x ; x, 2 \quad x=p \quad 2=p \quad 1 / 12$

(Stage I: $E=3$, df $=3$, $\left.\chi^{2}=28.667, \mathrm{p}=.0001 \%\right)$ 
PATIENT CH

SUAMARY SCORE SHEET

(6121-132) Causative-Theae=Causee claticized, Intransitave Verb

Exaople: L'elephant le lalt treabler.

CORRECT FORHS:

1,$2 ; 2 \vee 2=p \quad 12 / 12$

1,$2 ; 2 V 21 \mathrm{P} \quad--$

$2 V_{i} 1,2 \quad 2=p \quad--$

$2 V_{i} 1,2$ 2IP

(G133-144) Cleft ob ject(CO2) with Stylistic Inversion

Exanple: C'est le lapan qu'a flatts l'el ephant.

CORRECT FORHS:

$2,1 \quad 6 / 12$

(Stage I: $E=1.5, d f=7$, $\chi^{2}=84.00, p=.0001 \%$ )

INCORRECT FORMS:

$1,2 \quad 6 / 12$

(6145-156) Subject-object relative vith Stylistic Inversion

Exapple: Le lapin qu'a gratte l'elephant a frappt le singe. CORRECT FORMS:

2,$1 ; 1,3$

1,$3 ; 2,1$

$6 / 12$

1/12 TOTAL CORRECT: $7 / 12$

(Stage II: $E=6, \mathrm{df}=1$, $\chi^{2}=0, p=1$

IMCORRECT FORMS:

$\begin{array}{ll}2,1 ; \cdots & 1 / 12 \\ 1,3 ; 1,2 & 1 / 12 \\ 1,2 ; 1,3 & 2112 \\ 1,2 ; 3,1 & 1 / 12\end{array}$

(6157-168) Object-0bject relative vith Stylistic Inversion

Exapple: Le lapan a gratte la chtvre qu'a eabrassete le singe. CORRECT FORHS:

1,$2 ; 3,2$

3,$2 ; 1,2$

$10 / 12$

$1 / 12$

TOTAL CORRECT: $11 / 12$

(Stage II: $E=.33, \mathrm{df}=35$, $\left.\chi^{2}=121.213, \mathrm{p}=.0001 \%\right)$

IMCORRECT FORHS:

1,$2 ; 2,3$

$1 / 12$

(Stage II: $E=.33$, df $=35$, $\chi^{2}=296.971, p=.0001 \%$ )

$1 / 12$


PATIENT JT

SUMWARY SCORE SHEET

(MOOI-012) A2 $\begin{array}{ll}\text { Exauple: La grenouslle a frappe le singe. } & (\text { St age I I : } E=6, \mathrm{df}=1 \text {, } \\ \text { CORRECT FORHS: } & \left.\gamma^{2}=12.00, p=.0005^{\circ}\right)\end{array}$

$$
1,2 \quad 12 / 12
$$

(no13-024) P2

Exarple: Le singe a the frappt par la grenouille. CORRECT FORMS:

2,1

$12 / 12$

(Stage II: $E=6$, df $=1$, $2=12.00, p=.000 \%$ )

(M025-036) Truncated Passives

Exaple: Le singe a ette frappé. CORRECT FORHS:

$$
x, 1 \quad 11112
$$

Stage I: $E=6, d f=1$,

$\left.\chi^{\prime}=8.333, p=.0039 .^{\circ}\right)$

\begin{tabular}{|c|c|c|}
\hline $1, x$ & $1 / 12$ & \\
\hline $\begin{array}{l}(\text { MO3T-048) CO? } \\
\text { Example: C'est } \\
\text { CORRECT FORMS: } \\
2,1\end{array}$ & $\begin{array}{l}\text { lache que le lapin a eobrassée. } \\
10 / 12\end{array}$ & $\begin{array}{l}(\text { Stage II: } E=6, d r=1, \\
\left.P^{\prime}=5.333, \quad p=.0209^{\prime}\right)\end{array}$ \\
\hline $\begin{array}{c}\text { INCORRECT FORHS } \\
1,2\end{array}$ & $2 / 12$ & \\
\hline $\begin{array}{l}\text { (M049-060) A3 } \\
\text { Exanple: Le la } \\
\text { CORRECT FORHS: } \\
\qquad 1,2,3\end{array}$ & $\begin{array}{l}\text { confile la vache d la cherre. } \\
12 / 12\end{array}$ & $\begin{array}{l}\text { (Stage II: } E=2, \text { df }=5, \\
\left.X^{2}=60.00, p=.0001^{\circ}\right)\end{array}$ \\
\hline
\end{tabular}

INCORRECT FORHS:

(M061-072) P3

Exauple: L'elephant a ette donnt au singe par la grenouslle.

CORRECT FORAS:

$3,1,2 \quad 10 / 12 \quad X=39.00, p=.0001 *)$

IHCORRECT FORMS:

$\begin{array}{ll}3,2,1 & 1 / 12 \\ 1,3,2 & 1 / 12\end{array}$

(n073-084) CO3

Exaeple: C'est la chevre que le lapin a donnte d la vache.

CORRECT FORHS:

$2,1,3 \quad 6 / 12$

(Stage II: $E=2, d f=5$,

$\gamma^{2}=24.00, p=.0002 \%$ )

INCORRECT FORHS:

$$
1,2,3 \quad 6 / 12
$$


PATIENT JT

SUMHARY SCORE SHEET

(7085-096) CON

Exaple: Le singe a gratte le lapin et a caresse l'tl ephant. CORRECT FORHS:

1,$2 ; 1,3$

$12 / 12$

Stage II: $E=0.33, d f=35$,

1,$3 ; 1,2$

(M097-108) 5-0

Example: Le singe que le lapin a salsi a bouscule la chivre. CORRECT FORHS:

2,$1 ; 1,3$

$6 / 12$

(Stage II: $E=0.33, \mathrm{df}=35$,

1,$3 ; 2,1$

$t^{2}=424.24, p=.0001 \%$ )

INCORRECT FORAS:

$\begin{array}{ll}1,2 ; 1,3 & 1 / 12 \\ 1,2 ; 2,3 & 1 / 12 \\ 3,1 ; 1,3 & 1 / 12\end{array}$

(n109-120) 0-5

Exanple: La cherre a trappe le lapin qui a sassi la vache. CORRECT FORHS:

$\begin{array}{ll}1,2 ; 2,3 & 9 / 12 \\ 2,3 ; 1,2 & \cdots\end{array}$

Stage II: $E=0.33$, df $=35$,

2,$3 ; 1,2$

$\chi^{2}=248.486, p=.0001 \%$

IMCORRECT FORHS:

1,$3 ; 3,2$

1,$2 ; 3,2$

$2 / 12$

$1 / 12$

(*121-132) $0-0$

Exaple: Le singe a chatouille la grenoulle que la chevre a bousculete. CORRECT FORAS:

$$
\begin{array}{lcl} 
& & \text { Stage II: } E=0.33, \mathrm{fJ}=35, \\
1,2 ; 3,2 & 12 / 12 & \{2=424.24, \mathrm{P}=.0001:)
\end{array}
$$

(n133-144) S-S

Exanple: La grenouille qui a tenu la vache a attrupt l'elephant. CORRECT FORHS:

$$
1,2 ; 1,3
$$

$12 / 12$

(Stage II: $E=0.33$, df $=35$, 1,$3 ; 1,2$

$\left.\chi^{2}=424.24, p=.0001 *\right)$

(n145-156) Active Conjoined these

Exaople: Le lapin a frappe la vache et la chevre. CORRECT FORHS:

$\begin{array}{cc}1,2+3 & 12 / 12 \\ 1,3+2 & \cdots\end{array}$

S Stage II: $E=1, \mathrm{df}=11$,

$\{2=132.00, p=.0001 \%$ 
250.

$\therefore$ is

PATIENT JI

SUMHARY SCORE SHEET

(M157-168) Passive Conjolned Agent

Exapple: La grenouille a ete caresste par la cherre et la vache. CORRECT FORMS:

$2+3,1$

$3+2,1$

$16 / 12$

$1 / 12$

TOTAL CORRECT: $11 / 12$

(Stage II: $E=1$, df $=11$,

$\chi^{*}=90.00, p=.0001^{\circ}$ )

INCORRECT FORHS:

$2,1+3$ $1 / 12$ 
PATIENT JT

SUMMAEY SCORE SHEET

(Jo01-012) Direct Object Control, Intransitive Vers

Exapple: La grencualle a forces le singe a bondar. CORGECT FORMS:

$$
\begin{array}{lcc}
1,2 ; 2 V & 12112 & \left.\chi^{2}=84.00, p=.0001 *\right) \\
2 V ; l, 2 & -- &
\end{array}
$$

(j013-024) Passivized Direct Object Control, Intransitive Verb

Exanple: La vache a sts forcse par le lapin a danser. CORRECT FORMS:

2,$1 ; 14$

IV; 2,1

$11 / 12$

(Stage II: $E=1.5$, df $=7$,

$\left.\chi_{2}^{2}=69.333, p=.0001 \div\right)$

$-$

INCORRECT FORHS:

$$
1,2 ; 2 \mathrm{~V} \quad 1 / 12
$$

(J025-036) Truncated lausative

Exanple: Le lapsn a fast frapper la vache. CORRECT TORMS:

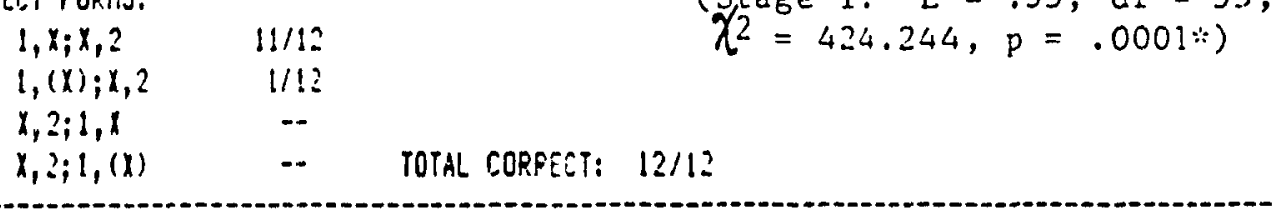

(j037-048) Causativetintransitive Verb

Exalaple: La vache a last danser la lapin. CORRECT FORHS:

$$
\begin{array}{lcl}
\text { ROCT FORMS: } & \text { (Stage II: } E=1.5, \text { df }=7, \\
1,2 ; 2 V & 13112 & \left.\chi^{2}=84.00, p=.0001:\right) \\
2 V ; l, 2 & -. &
\end{array}
$$

(j049-060) Oirect object Controltiransitive Vept

Exaple: Le lapin a forces la ehsure a frapper la vache. CORRECT FORHS:

$$
\begin{array}{lcl}
1,2 ; 2,3 & 12,12 & \left.\chi^{2}=424.244, p=.0001 \%\right) \\
2,3 ; 1,2 & \cdots &
\end{array}
$$

(Stage II: $E=.33$, df $=35$,

(J061-072) Passivized Direct Object Controltiransitive Verb

Exaple: La grenouslle a tete forcte par l'elesphant d caresser le singe.

CORRECT FORHS:

2,$1 ; 1,3$

1,$3 ; 2,1$

$7 / 12$

Stage II: $E=.33$, df $=35$, $\left.\chi^{2}=212.122, p=.0001 *\right)$

INCORRECT FORHS:

1,$2 ; 2,3 \quad 5 / 12$


PATIENT JT

SUMIARY SCORE SHEET

(j073-084) Causative (farre-d)

Exapple: La grenoullle a fatt caresser le singe d l'tlephant. CORRECT FORHS:

1,$3 ; 2,2$

$1,(3) ; 3,2$

$9 / 12$

(Stage II: $E=.33, \mathrm{df}=35$,

3,$2 ; 1,3$

$\left.\chi^{2}=260.607, p=.0001:\right)$

3,$2 ; 1,(3)$

$-$

$-$

$--$

INCORRECT FORHS:

1,$2 ; 2,3 \quad 3 / 12$

(J085-096) Causative (Fatre-par)

Exaple: Le lapin a last frapper la vache par la chevre. CORRELT FORMS:

1,$3 ; 3,2$

$1,(3) ; 3,2$

$10 / 12$

(Stage II: $E=.33, d f=35$,

3,$2 ; 1,3$

3,$2 ; 1,(3)$

$-\cdot$

$-\cdot$

$--$

IMCORRECT FORHS:
1,$2 ; 2,3$
$2 / 12$

(j097-108) Cleft Object-Causative (Faire-par)

Exaople: C'est l'sliphant que le singe a fait saisir par la grenouslle. CORPECT FORMS:

2,$3 ; 3,1$

3,$1 ; 2,3$

$3 / 12$

Stage II: $E=.33$, df $=35$,

$2,(3) ; 3,1$

3,$1 ; \hat{2},(3)$

$-$

$-$

$\cdots$

IMCORRECT FORMS:

$1,(3) ; 3,2 \quad 7 / 12$

$1,(2) ; 2,3 \quad 1 / 12$

1,$3 ; 3,2 \quad 1 / 12$

(J10'3-120) Conjoined Causative

Exapple: La grenouslle a fast frapper la vache et chatoulller l'sllephant par le singe. CORRECT FORHS:

1,$4 ; 4,2 ; 4,3 \quad 3 / 12$

1,$4 ; 4,3 ; 4,2 \quad 4 / 12$

4,$2 ; 4,3 ; 1,4 \quad--$

4,$3 ; 4,2 ; 1,4 \quad-\cdot$

$1,(4) ; 4,2 ; 4,3$ 4/12 TOTAL CORRECT: $11 / 12$

INCORRECT FORHS:

$1,-; 2,4 ; 4,3 \quad 1 / 12$

(Stage II: $E=.007$, df $=1727$,

$\chi^{2}=9416.667, p<.0001:$ ) 
PATIENT JT

SUMAARY SCORE SHEET

(J121-132) CausativetDative

Exaple: L'slepphant a fast apporter le sange a la grenoullle par la vache. CORRECT FORMS:

$$
\begin{aligned}
& 1,4 ; 4,2,3 \quad 3 / 12 \\
& 1,(4) ; 4,2,3 \quad 3 / 12 \\
& 4,2,3 ; 1,4 \\
& 4,2,3 ; 1,(4) \quad 1 / 12 \text { TOTAL CORRECT: } 7 / 12
\end{aligned}
$$

(Stage II: $E=.063$, df $=191$, $\left.\gamma^{2}=654.766, p=.0001^{\circ}\right)$

$\begin{array}{ll}\text { INCOREECT FORMS: } & \\ 1,2 ; 2- & 1 / 12 \\ 1,4 ; 4,1 ; 2,3 & 1 / 12 \\ 1,2 ; 2,4 ; 2,3 & 1112 \\ 1,4 ; 4,3,2 & 1 / 12 \\ 1,2 ; 2,3,4 & 1 / 12\end{array}$

(J133-144) CaugativetS-S relative

Exanple: La grenouslle a fat chatounller l'slephant par le singe qui a frapps la vache. CORRECT FORHS:

$\begin{array}{ll}1,3 ; 3,2 ; 3,4 & 4 / 12 \\ 1,3 ; 3,4 ; 3,2 & -- \\ 3,2 ; 3,4 ; 1,3 & -- \\ 3,4 ; 3,2 ; 1,3 & -- \\ 3,4 ; 1,3 ; 3,2 & --\end{array}$

(Stage II: $E=.007$, df $=1727$, $\left.y^{2}=6559.525, p<.0001 \%\right)$

INCORRECT FORHS:

$\begin{array}{ll}1,3 ; 3,2 ; 1,4 & 2 / 12 \\ 1,3 ; 3,2 ; 2,4 & 5 / 12 \\ 1,2 ; 2,3 ; 2,4 & 1 / 12\end{array}$

(J145-156) S-S ielativetConjoined thene

Erasple: L'ellephant qui a chatouslle la vache et le singe a frappe la grenouslle. CORRECT FORMS:

$\begin{array}{lcc}1,2+3 ; 1,4 & 11 / 12 & \left.\chi^{2}=2892.858, p=.0001 \%\right) \\ 1,3+2 ; 1,4 & 1 / 12 & \\ 1,4 ; 1,2+3 & -- & \text { TOTAL CORRECT: } 12 / 12 \\ 1,4 ; 1,3+2 & -- & \end{array}$

(J157-168) Conjoined clauses-4NPs (no deletion)(Baseline)

Exanple: La grenouslle a frappe le singe et la vache a chatouille d'elephant. CORRECT FORMS:

1,$2 ; 3,4$

$9 / 12$

(Stage II: $E=.083, \mathrm{df}=143$,

3,$1 ; 1,2$

--

$\left.X^{2}=1072.289, \mathrm{p}=.0001 \%\right)$

INCORRECT FORMS:

1,$2 ; 4,3 \quad 3 / 12$


PAIIEKT OC

SUMMARY SCORE SHEET

(17001-012) 12

Fxaple: La grenouslle a frappe le singe. CORRECT FORHS:

$$
1,2
$$

$12 / 12$

(Stage II: $E=6$, df $=1$,

$\left.\chi^{2}=12.00, p=.0005: 1\right)$

(M013-024) P2

Exaple: Le singe a dte frappt par la grenouille. CORRECT FORHS:

$$
2,1
$$

$12 / 12$

(Stage II: $E=6, d f=1$, $\left.X^{2}=12.00, p=.0005:\right)$

(M025-036) Iruncated Passives

Exanple: Le singe a tte frappt.

CORRECT CORMS:

$$
\begin{array}{lll}
x, 1 & 12 / 12 & \mathcal{V}=12.00, p=.0005 \div)
\end{array}
$$

Stage I: $E=6, d E=1$,

(n037-048) CO2

Exanple: C'est la vache que le lapin a eabrasste. CORRECT FORHS:

$$
2,1 \quad 9 / 12
$$

(Stage II: $E=6, d f=1$, $\chi^{2}=3.00, p=.0833$ )

IMCORRECT FORHS:
1,2
$3 / 12$

(7049-060) A3

Exanple: Le lapin a confit la rache d la chevre. CORRECT FORMS:

$$
1,2,3
$$

$12 / 12$

(S,tage II: $E=2$, df $=5$, $\left.\chi^{2}=60.00, p=.0001 \div\right)$

(n061-072) P3

Example: L'elephant atte donne au singe par la grenouslle. CORRECT FORHS:

$$
3,1,2
$$

$11 / 12$

(Stage II: $E=2, d f=5$,

IMCORRECT FORNS:

$3,2,1 \quad 1 / 12$

(no73-084) CO3

Exauple: C'est la chevre que le lapin a donnete d la vache. CORRECT FORMS:

$$
2,1,3
$$

$8 / 12$

(Stage II: $E=2, d f=5$,

$\left.\chi^{2}=28.00, p=.0001 \%\right)$

\section{IMCORRECT FORHS:}

$\begin{array}{ll}1,2,3 & 3 / 12 \\ -, 1,3 & 1 / 12\end{array}$


PATIENT DC

SUMHARY SCORE SHEET

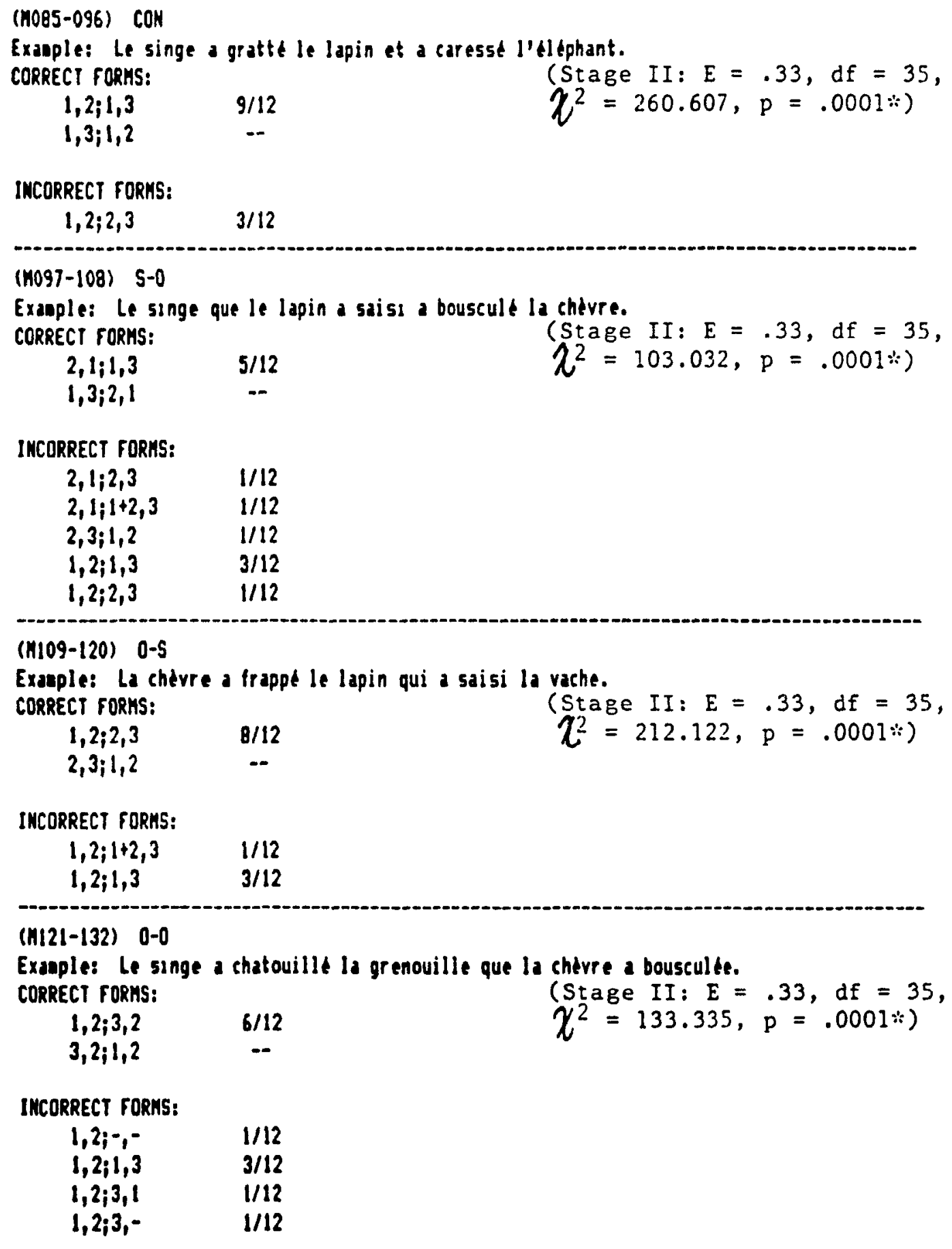

INCORRECT FORHS:

1,$2 ; 1+2,3 \quad 1 / 12$

1,$2 ; 1,3 \quad 3 / 12$

(n121-132) $0-0$

Example: Le singe a chatouille la grenouille que la chivre a bousculte. CORRECT FORHS:

$$
\begin{array}{lc}
1,2 ; 3,2 & 6 / 12 \\
3,2 ; 1,2 & --
\end{array}
$$

(Stage II: $E=.33, \mathrm{df}=35$, $\left.\chi^{2}=133.335, \mathrm{p}=.0001 *\right)$

INCORRECT FORNS:

$\begin{array}{ll}1,2 ;-1- & 1 / 12 \\ 1,2 ; 1,3 & 3 / 12 \\ 1,2 ; 3,1 & 1 / 12 \\ 1,2 ; 3,- & 1 / 12\end{array}$


PATIENT DC

SUMHARY SCORE SHEET

(nis3-144) s-s

Example: La grenouslle qua a tenu la vache a attrapt l'elephant. CORRECT FORMS:

$$
1,2 ; 1,3
$$

1,$3 ; 1,2$

$9 / 12$

(Sfage II: $E=.33$, df $=35$, $\left.\chi^{2}=248.486, p=.0001 \div\right)$

INCORRECT FORHS:
1,$2 ; 2,3$
$2 / 12$
1,$3 ; 2,1$
$1 / 12$

(ni45-156) Active Conjoined these

Exanple: Le lapan a frappe la vache et la chevre. CORRECT FORHS:

$$
\begin{array}{ccc}
1,2+3 & 12 / 12 & \left.\chi^{2}=132.00, p=.00011^{\circ}\right) \\
1,3+2 & \cdots &
\end{array}
$$

(Stage II: $E=1, \mathrm{df}=11$,

(n157-168) Passive Conjoined Agent

Exaple: La grenouille a the caresse par la chevre et la vache. CORRECT FORMS:

$2+3,1$

$3+2,1$

$9 / 12$

$2 / 12$

TOTAL CORRECT: $11 / 12$

(Stage II: $E=1$, dI $=11$, $\left.\gamma^{2}=74.00, p=.0001^{\circ}\right)$

INCORRECT FORAS:
$1,2+3$
$1 / 12$ 
PATIENT OC

SUMMARY SCORE SHEET

(J001-012) Direct Object Control, Intransitave Verb

Exaople: La grenouslle a force le singe a bondir. CORRECI FORHS:

$$
\begin{array}{lcl} 
& \text { (Stage II: } E=1.5, \text { df }=7, \\
1,2 ; 2 V & 12112 & \left.X^{2}=84.00, P=.0001 \%\right) \\
2 V ; 1,2 & -- &
\end{array}
$$

(J013-024) Passivized Direct Object Control, Intransitive Verb

Exaople: La vache a etse forcese par le lapin a danser. CORPECT FORMS:
2,$1 ; 1 V$
$8 / 12$
$\left.X^{2}=41.333, \mathrm{p}=.0001 \%\right)$

(Stage II: $\mathrm{E}=1.5$, df $=7$,

$1 V_{i} 2,1$

INCORRECT FORHS:

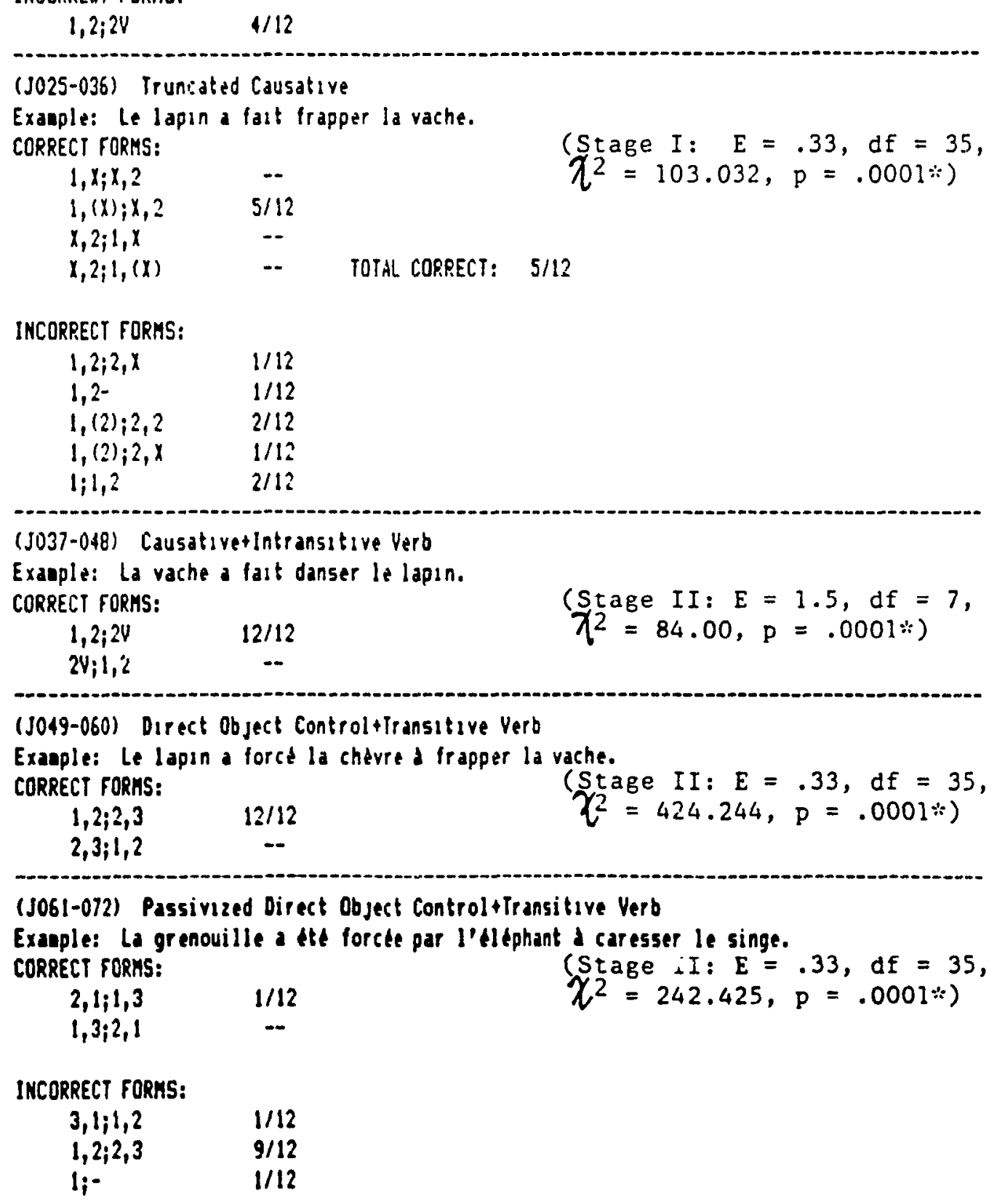


PATIENT DC

SUMHARY SCORE SHEET

(J073-084) Causative (Faure-d)

Exaple: La grenouille a fast caresser le singe d l'sl sphant. CORRECT FORHS:

1,$3 ; 3,2$

$1,(3) ; 3,2$

3,$2 ; 1,3$

$6 / 12$

3,$2 ; 1,(3)$

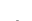

(Stage II: $E=.33, d f=35$, $W=206.062, \mathrm{p}=.0001 \therefore$ )

INCORRECT FORMS:

$\begin{array}{ll}1,2 ; 2,3 & 1 / 12 \\ 1,(2) ; 2,3 & 5 / 12\end{array}$

(J085-096) Causative (Fatre-par)

Exauple: Le lapin a fait frapper la vache par la chérre. CORRECT FORMS:

1,$3 ; 3,2$

$1,(3) ; 3,2$

$--$

3,$2 ; 1,3$

$9 / 12$

3,$2 ; 1,(3)$

$-$

-- TOTAL CORRECT: $9 / 12$

INCORRECT FORMS:

$$
1,(2) ; 2,3 \quad 3 / 12
$$

(J097-108) Cleft Object-Causative (Fatre-pap)

Example: C'est l'elephant que le singe a falt salsir par la grenounlle. CORRECT FORMS:

$\begin{array}{lc}2,3 ; 3,1 & 1 / 12 \\ 3,1 ; 2,3 & -- \\ 2,(3) ; 3,1 & -- \\ 3,1 ; 2,13) & --\end{array}$

(Stage II: $E=.33$, df $=35$, $\left.\chi^{2}=260.607, p=.0001 \%\right)$

INCORRECT FORMS:

$\begin{array}{ll}1,(3) ; 3,2 & 5 / 12 \\ 1 ; 3- & 1 / 12 \\ 1,(2) ; 2,3 & 5 / 12\end{array}$




\section{PATIENT DC \\ SUMMARY SCORE SHEET}

(J109-120) Conjoined Cassative

Exapple: La grenoulle a fast frapper la vache et chatouiller l'sliphant par le singe. CORRECT FORMS:

1,$4 ; 4,2 ; 4,3 \quad \cdots$

(Stage II: $E=.007$, df $=1727$,

1,$4 ; 4,3 ; 4,2$

4,$2 ; 4,3 ; 1,4 \quad--$

4,$3 ; 4,2 ; 1,4 \quad \cdots$

$1,(4) ; 4,2 ; 4,3$ 1/12 TOTAL CORRECT: $1 / 12$

INCORGECT FORMS:

$1,(x) ; x_{1} 2_{i-} \quad 1 / 12$

$1 ;-, 2 ;-\quad 1 / 12$

$1 ; 2 ; 2,4 ; 1 \quad 1 / 12$

$1 ; 2-\quad 1 / 12$

$1 ;-\quad 1 / 12$

$1 ;--3+\hat{2} \quad 1 / 12$

$1,(4) ; 4,2 ;-\quad 1 / 12$

$1 ;-2 ; 2,4 \quad 1 / 12$

$1 ; 2 ; 2,4 \quad 1 / 12$

$1 ;-2 ; 3 ; 4 \quad 1 / 1 ?$

0,$0 ; 0,0 ; 0,0 \quad 1 / 12$

(J121-132) CausativetDative

Exauple: L'dlsphant a last apporter le singe d la grenoullle par la vache. CORRECT FORMS:

1,$4 ; 4,2,3 \quad \cdots$

$1,(4 ;: 4,2,3 \quad$-.

$4,2,2 ; 1,4 \quad \cdots$

$4,2,5 i l,(4) \quad \ldots$

INCORRECT FORMS:

$1 i^{-} \quad 5 / 12$

$1 ; 2-\quad 1 / 12$

$1 ; 4,-, 3 \quad 1 / 12$

2- $\quad 1 / 12$

$1 ; 4,2,-\quad 1 / 12$

$1 ; 3,-; 4-\quad 1 / 12$

$1 ; 4,2-\quad 1 / 12$

$1 ;-2,3 \quad 1 / 12$ 
260.

PATIENT DC

SUKHARY SCORE SHEEY

(J133-144) CausativetS-S relative

Exaple: La grenouille a fait chatoulller l'slephant par le singe qua a frapps la vache. CORRECT FORMS:

$\begin{array}{lc}1,3 ; 3,2 ; 3,4 & 1 / 12 \\ 1,3 ; 3,4 ; 3,2 & -- \\ 3,2 ; 3,4 ; 1,3 & -- \\ 3,4 ; 3,2 ; 1,3 & -- \\ 3,4 ; 1,3 ; 3,2 & --\end{array}$

(Stage II: $E=.007, \mathrm{df}=1727$,

IHCOPREST FORMS:

$\begin{array}{ll}1,4 ; 4,3 & 1 / 12 \\ 1,2 ; 4,3 & 1 / 12 \\ 1,2,-; 4,- & 1 / 12 \\ 1 ;- & 1 / 12 \\ 1 ; 3,2- & 1 / 12 \\ 3,2 ; 3,4 & 1 / 12 \\ 1,2 ; 2,4 & 1 / 12 \\ 1 ;-; 3,4 & 1 / 12 \\ 1,2 ; 3,4 & 1112 \\ 1,2 ; 1,3+4 & 1 / 12 \\ -4- & 1 / 12\end{array}$

(J145-156) S-S relailvetion joined theee

Exaaple: L'elléphant qui a chatouslle la vache et le singe a frappe la grenouille. CORRECT FORMS:

$1, \hat{2}+3 ; 1,4$

$1,3+\hat{i} ; 1,4$

$1,4 i+2+3$

$1,+i, 3+2$

$5 / 12$

$1 / 12$

$\left.\chi^{2}=1702.382, p<.0(0) 1\right)$

$1 / 12$

112

$1 / 12$

$1 / 12$

1112

$1 ! 12$

$11 ?$

$1 / 12$

INCORRECT FORMS:

$\begin{array}{ll}1,2+4 ; 1,3 & 1 / 12 \\ 1,2- & 1 / 12 \\ 1 ;- & 1 / 12 \\ 1,2+3 ;- & 2 / 12 \\ 1,2,-; 4 & 1 / 12\end{array}$

(J157-168) Conjoined clauses-4NP5 (no del etion) (Baseline)

Exanple: La grenouille a frapos le singe et la vache a chatoullle l'slephant. CORRECT FORMS:

1,$2 ; 3,4$

$8 / 12$

(Stage II: $E=.083, \mathrm{dE}=143$,

3,$4 ; 1,2$

-- TDIAL CQREET: EII2

(Siage II: $E=.042$, CE $=287$, $\chi 2=797.62, p=.0001 \%$ $\chi^{2}=831.325, p=.0001 \%$

INCORRECT FORMS:

$\begin{array}{ll}1,2 ;- & 2 / 12 \\ 0,0 ; 0,0 & 1 / 12 \\ 1,2 ; 4,3 & 1 / 12\end{array}$


PATIENT OC

SUMWARY SCORE SHEET

(6001-0!2) Dative-Thene cliticized

Exanple: La chevre l'a offert d la vache. CORRECT FORHS:

$1,2,3 \quad 2=p$

$1,2,3219$

$12 / 12$

(Stage I: $E=2, d f=5$,

$x^{2}=60.00, p=.0001 \div 3$

(G013-024) Dative-60al cliticized

Exacple: La vache lus a reess la chévre.

CORRECT FORMS:

$1,3,2 \quad 2=p$

$1,3,2$ 2IP

$8 / 12$

TOTAL CORRECT:

(Stage I: $E=2$, df $=5$,

$\left.\chi^{2}=23.00, p=.0003:\right)$

INCORRECT FORMS:

$1, x ; 2,3 \quad 219$

$-, 1,3$

$1 / 12$

$1,2,3 \quad 21 \mathrm{P}$

$1 / 12$

$2 / 12$

(6025-026) Causalive-Thene cliticized

Exapple: Le lapin l'a fait tenir par la chevre. CORRECT FORMS:

1,$3 ; 3,2 \quad 2=$

1,$3 ; 3,2$ 2IP

$-\cdot$

3,$2 ; 1,3 \quad 2=P$

$3 / 12$

3,$2 ; 1,3$ 2If

-- TOTAL COFRECT: $3 / 12$

(Stage I: $E=.33, \mathrm{df}=35$, $\chi^{2}=133.335, p=.0001 \%$ )

INCORRECT FORMS:

1,$2 ; 2,3219 \quad 6 / 12$

$1 ; 3-\quad 1 / 12$

$3,1 \quad 1 / 12$

3,$1 ; 2,3219 \quad 1 / 12$

(6037-048) Causative-Causee cliticized

Exanple: L'blephant lus a falt attraper la grenouslle. CORRECT FORHS:

1,$2 ; 2,3 \quad 2=p$

1,$2 ; 2,32$ IIP

2,$3 ; 1,2 \quad 2=p$

2,$3 ; 1,2$ 2IP

$-$

$7 / 12$

$-$

-- TOTAL CORRECT: $7 / 12$

IMCORRECT FORHS:

$1,(3) ; 3,3$

$2 / 12$

$1 ; 2=1,3$

$2 / 12$

1,3

$1 / 12$

(Stage I: $E=.33$, df $=35$,

$\left.\chi^{2}=163.638, \mathrm{p}=.0001 *\right)$ 
PATIENT OC

SUMMARY SCORE SHEET

(6049-060) Causative-Reflexive 'Causer" ="Thene"

Exasple: La vache se fait saisir par le lapin. CORRECT FORMS:

$$
\begin{array}{lll}
3,2=1 & 7 / 12 \\
1,(3) ; 3,2=1 & 1 / 12 \\
3,2=1 ; 1,(3) & -- & \\
1,3 ; 3,2=1 & -- & \\
3,2,2=1 ; 1,3 & -- & \text { TOTAL CORRECT: } 11 / 12
\end{array}
$$

\begin{tabular}{|c|c|c|c|}
\hline 1,3 & $1 / 12$ & & \\
\hline (6061-072) Causats & $-R \in l l e$ & Causet & \\
\hline Exaeple: La chevre & ait se & irer la vache. & \\
\hline CORRECT FORMS: & & & (Stage I: $E=.15 \mathrm{df}=80$ \\
\hline 1,$3 ; 3,2=3$ & -- & & $\left.\chi^{2}=308.15, p=.0001 \cdots\right)$ \\
\hline $3,2=3 ; 1,3$ & -- & & \\
\hline $1,(3) ; 3,2=3$ & $6 / 12$ & & \\
\hline $3,2=3 ; 1,(3)$ & -- & TOTAL CORRECT: & $6 / 12$ \\
\hline \multicolumn{4}{|l|}{ INCORRECT FORHS: } \\
\hline $1,(2) ; 2,321 p$ & $3 / 12$ & & \\
\hline $1,(3) ; 3,221 P$ & $1 / 12$ & & \\
\hline 1,3 & $1 / 12$ & & \\
\hline $3,(1) ; 1,2=1$ & $1 / 12$ & & \\
\hline
\end{tabular}

(Stage II: $E=3, d E=3$, $\chi^{2}=28.667, p=.0001 \therefore$ )

INCORRECT FORHS:

(6073-084) Causative-Reflexive Causer =6oal

Exaaple: La vache se fart revettre la chevre par le Iapin. CORRECT FORMS:

$4,3,2=1$ $3 / 12$

(Stage II: $E=.67$, UE $=17$, 1,$4 ; 4,3,2=1$

$4,3,2=1 ; 1,4 \quad=$

$1,(4) ; 4,3,2=1 \quad 4 / 12$

$4,3,2=1 ; 1,(4) \quad \cdots \quad$ TOTAL CORRECT: $7 / 12$

INCORRECT FORHS:

$\begin{array}{ll}1 ; 2=1,3,4 & 3 / 12 \\ 1,-3+4,- & 1 / 12 \\ 1 ;-, 3+2=1,4 & 1 / 12\end{array}$

(6085-096) Causative-Reflexive Causer=6oal, Truncated

Exanple: La cherre se fast offerp le lapin. CORRECT FORHS:

$x, 3,2=1 \quad x=p$

$x, 3,2=1 X P P$

$1, x ; x, 3,2=1 \quad x=p \quad=-$

$1, x ; x, 3,2=1$ IIP $8 / 12$ TOTAL CORRECT: $8 / 12$

$i$

INCORRECT FORHS:

$1,-3,2=1 \quad 1 / 12$

$1 ; 2=1,3,-\quad 1 / 12$

$1, x ; x, 2=1,3$ IIP $\quad 1 / 12$

$3,1,2$ 2IP $\quad 1 / 12$ 
PATIENT DC

SUMHARY SCORE SHEET

(6097-108) Causative-Theae cliticized, Truncated

Exaple: La chevre le falt serrer. CORRECT FORMS:

$1, x ; x, 2 \quad x=P \quad 2=P \quad--$

(Stage I: $E=.33$, df $=35$,

$1, x ; 1,2 \quad x \in P \quad 2 \| P \quad 11 / 12$

$\chi^{2}=424.244, \mathrm{p}=.0001 \%$ )

$X, 2 ; 1, x \quad x=P \quad 2=P \quad-$

$x, 2 ; 1, x \quad x \in P 21 P \quad--$

$1, x_{i} x, 2$ XIP $2=P \quad 1 / 12$ TOTAL CORPECT: $12 / 12$

(6109-120) Causative-Reflexive "Causer" $=$ "Thene', Truncated

Exanple: La cherre se last bousculer. CORRECT FORHS:

$x, 2=1 \quad x=p$

$--$

$x, 2=1 X O P \quad 9 / 12$

$1,(x) ; x, 2=1 \quad x=p \quad--$

$1,(x) ; x, 2=1$ xep $3 / 12$

$1, x ; x, 2=1 \quad x=P \quad--\quad$ TOTAL CORRECT: $12 / 12$

(G121-132) Causative-Thene=Causee cliticized, Intransitive Verb

Exanple: L'slesphant le fait treabler. CORRECT CORHS:

1,$2 ; 24,2=p$

$-\infty$

(Stage I: $E=1.5, \mathrm{df}=7$,

1,$2 ; 2 V 2$ IP

$12 / 12$

$2 V ; 1,2 \quad 2=P$

$--$

$2 V ; 1,221 \mathrm{P}$

-. TOtal CORRECT: $12 / 12$

(Stage I: $\quad E=6, \mathrm{df}=1$,

$\left.\chi^{2}=12.00, \mathrm{p}=.0005 *\right)$

(Gi33-144) Cleft Ob ject (CO2) with Stylistic Inversion

Exanple: C'est le lapin qu'a llatte l'el sphant. CORRECT FORMS:

$$
2,1 \quad 1 / 12
$$

(Stage II: $E=6, \mathrm{df}=1$, $\left.\chi^{2}=8.333, p=.0039 \%\right)$

INCORRECT FORMS:

1,2

$11 / 12$

(6145-156) Subject-object relative vith Stylistic Inversion

Exaple: Le lapin qu'a gratte l'tlephant a frappe le sunge. CORRECT FORHS:

2,$1 ; 1,3$

1,$3 ; 2,1$

$-$

(Stage II: $E=.33, \mathrm{df}=35$,

$\left.\chi^{2}=200.001, \mathrm{p}=.0001 \%\right)$

IMCORRECT FORKS:

$\begin{array}{ll}1,2 ; 2,3 & 8 / 12 \\ 1,2 ; 1,3 & 2 / 12 \\ 1,3 ;- & 1 / 12 \\ 1,3 ; 3,2 & 1 / 12\end{array}$




\section{4.}

PATIENT DC

SUMHARY SCORE SHEET

(6157-168) Object-object relative vith Stylistic Inversion Exanple: Le lapin a gratte la chevre qu'd enorasste le singe. CORRECT FORHS:

1,$2 ; 3,2$

3,$2 ; 1,2$

$3 / 12$

(Stage II: $E=.33$, df $=35$,

$\chi^{2}=151.516, p=.0001 \cdots$ )

INCORRECT FORHS:

1,$2 ; 2,3 \quad 6 / 12$

1,$2 ; 1,3 \quad 3 / 12$ 
PATIENT TP

SUMMARY SCORE SHEET

(14001-012) $\quad 12$

Exasple: La grenoullle a frappl le singe. CORRECT FORHS:

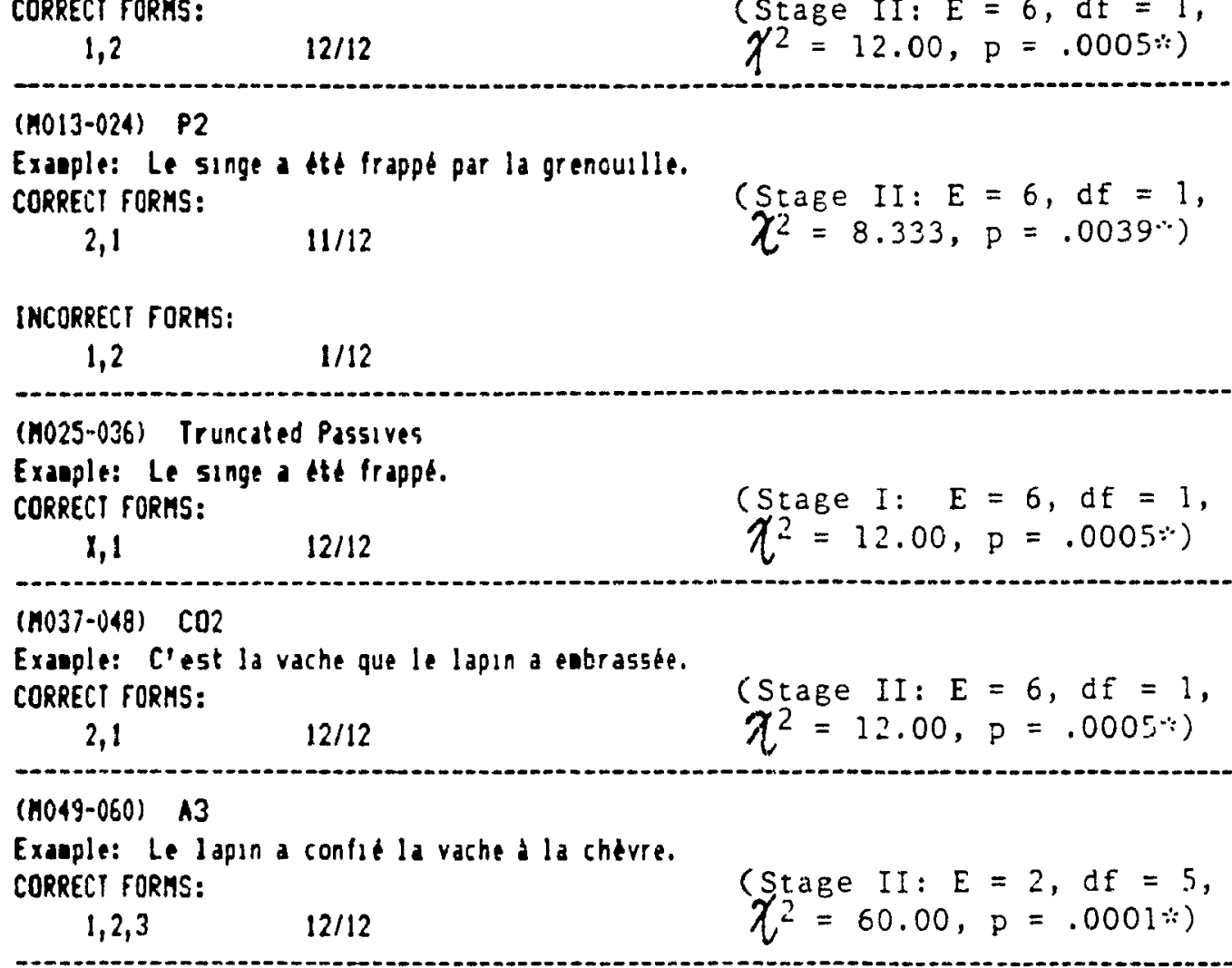

(n06/-072) P3

Exaople: L'elephant a dfé donnes au singe par la grenouslle. CORRECT FORMS: $3,1,2 \quad 7 / 12$ (Stage II: $E=2, d f=5$, $\left.\eta^{2}=19.00, p=.0019 \div\right)$

INCORRECT FORMS:

$\begin{array}{ll}3,2,1 & 2 / 12 \\ 2,1,3 & 3 / 12\end{array}$

(n073-084) CO3

Example: C'est la chidure que le lapin a donnée d la vache. CORRECT FORMS:

$$
2,1,3
$$

$9 / 12$

(Stage II: $E=2$, $d f=5$, $\left.\chi^{2}=31.00, p=.0001 *\right)$

\section{IMCORRECT FORHS:}

$\begin{array}{ll}1,2,3 & 2 / 12 \\ 2,3,1 & 1 / 12\end{array}$


PATIENT FP

SUMMARY SCORE SHEET

(M085-096) CON

Exanple: Le singe a gratte le lapan et a caressé l'slephant. CORRECT FORAS:

$$
\begin{array}{lcc} 
& (\text { Stage II }: E=.33, \mathrm{df}=35, \\
1,2 ; 1,3 & 10 / 12 & \chi^{2}=303.032, \mathrm{p}=.0001 \%
\end{array}
$$

INCORRECT FORHS:

1,$2 ; 2,3 \quad 2 / 12$

(nog7-108) S-0

Exaeple: Le singe que le lapin a saist a bouscule la chavre. CORRECT FORHS:

$\begin{array}{ll}2,1 ; 1,3 & 7 / 12 \\ 1,3 ; 2,1 & --\end{array}$

(Stage II: $E=.33, \mathrm{df}=35$, 1,$3 ; 2,1$ $--$

$\chi_{2}^{2}=212.122, p=.0001 \%$ )

IMCORRECT FORMS:

1,$2 ; 2,3 \quad 5 / 12$

$(m 109-120) \quad 0-5$

Exanple: La cherre a frappe le lapin qui a salsi la vache. CORRECT FORMS:

$$
\begin{array}{cc}
1,2 ; 2,3 & 10 / 12 \\
2,3 ; 1,2 & --
\end{array}
$$

(Stage II: $E=.33, \mathrm{df}=35$, $\chi^{2}=303.032, p=.0001 \cdot$ )

INCORRECT FORMS:

1,$2 ; 1,3 \quad 2 / 12$

(M121-132) 0-0

E.aaple: Le singe $i$ chatourlle la grenouille que la cherre a bousculde. CORRECT GORMS:

1,$2 ; 3,2$

3,$2 ; 1,2$

$9 / 12$

$1 / 12$

TOTAL CORRECT: $10 / 12$

(Stage II: $E=.33, \mathrm{df}=35$, $\left.\chi^{2}=242.425, p=.0001 \therefore\right)$

INCORRECT FORAS:
3,$2 ; 2,1$
$1 / 12$
1,$2 ; 2,3$
$1 / 12$

(n133-144) S-5

Exaple: La grenoullle qus a tenu la vache a attrapt l'elephant. CORRECT FORKS:

$\begin{array}{lc}1,2 ; 1,3 & 10 / 12 \\ 1,3 ; 1,2 & -- \\ & \\ & \\ 1,2 ; 2,3 & 1 / 12 \\ 1,3 ; 3,2 & 1 / 12\end{array}$

(Stage II: $E=.33$, df $=35$, $\chi^{2}=296.971, p=.0001 \%$ )

\section{IMCORRECT FORHS:}


PATIENT FP

SUMMARY SCORE SHEET

(m145-156) Active Conjoined these

Exapple: Le lapin a frappet la vache et la chevre. CORRECT FORMS:

$$
1,2+3
$$

$1,3+2$

$12 / 12$

(Stage II: $E=1, d f=11$, $\left.\chi^{2}=132.00, p=.0001 \%\right)$

(hi57-168) Passive Conjoined Agent

Exaple: La grenouille a tte caresste pap la chevre et la vache. CORRECT FORMS:

$2+3,1$

$11 / 12$

(Stage II: $E=1$, df $=11$,

$3+2,1$

$\left.\chi^{2}=110.00, p=.0001 \%\right)$

IMCORRECT FORMS:

$2,1+3$

$1 / 12$ 
PATIENT $P P$

SUKMARY SCORE SHEET

(J001-012) Direct object Control, Intransitive Verb Exanple: La grenoullle a lorce le singe a bondir. CORRECT FORMS:

1,$2 ; 2 \mathrm{~V}$

$12 / 12$

(Stage II: $E=1.5, p=7$,

$2 V_{i} l, 2$

$\chi^{2}=84.00, p=.0001 \%$ )

$-$

(J013-024) Passivized Oirect Object Control, Intransitive Verb

Exanole: La vache a efté forcée par le lapin a danser. CORRECT FORMS:

$\begin{array}{ll}2,1 ; 14 & 9 / 12 \\ 111 ; 2,1 & --\end{array}$

(Stage II: $E=1.5$, df $=7$,

$17 ; 2,1$

$\chi^{2}=48.00, p=.0001 \therefore$ )

INCORRECT FORMS:

1,$2 ; 2 \mathrm{~V} \quad 3 / 12$

(J025-036) Truncated Causative

Exauple: Le lapin a fast Irapper la vache. CORRECT FORHS:

$1, x_{i} x_{1} 2$

$1,(x) ; x, 2$

$9 / 12$

$2 / 12$

$x, 2 ; 1, x$

$x, 2 ; 1,(x)$

-- TOTAL CORRECT: $11 / 12$

(Stage I: $E=.33$, df $=35$, $\left.\chi^{2}=357.577, p=.0001^{\circ}\right)$

INCORRECT FORHS:

1,2

$1 / 12$

(J037-048) Causativetintransative Verb

Exaaple: La vache a fait danser le lapin. CORRECT FORMS:

$$
1,2 ; 2 V
$$

12112

Stage II: $E=1.5, \mathrm{df}=7$,

$2 V_{i} 1,2$

$-\cdot$

$\left.\chi^{2}=84.00, r=.0001:\right)$

(j049-060) Durect object Controltiransitive Verb

Example: Le lapin a forct la chevre a frapper la vache.

CORRECT FORHS:

1,$2 ; 2,3$

$12 / 12$

(Stage II: $E=.33, \mathrm{df}=35$,

2,$3 ; 1,2$

$--$

$\left.\chi^{2}=424.244, p=.0001 \div\right)$

(J061-072) Passivized Darect Object Control transitive Verb

Exanple: La grenouslle a the forcte par l'ellephant a caresser le singe.

CORRECT FORHS:

2,$1 ; 1,3$

1,$3 ; 2,1$

$-$

(Stage II: $E=.33$, df $=35$,

$\left.\chi^{2}=424.244, p=.0001 \%\right)$

INCORRECT FORHS:

1,$2 ; 2,3 \quad 12 / 12$


269.

PATIENT FP

SUMAARY SCORE SHEET

(5073-084) Causative (fasre-d)

Exauple: La grenouille a fait caressef le singe a l'tlephant.

CORRECT FORHS:

1,$3 ; 3,2 \quad 1 / 12$

$1,(3) ; 3,2 \quad$-.

3,$2 ; 1,3 \quad$-.

3,$2 ; 1,(3) \quad$-.

INCORRECT FORMS:

$1,(2) ; 2,3 \quad 7 / 12$

1,$2 ; 2,3 \quad 4 / 12$

(J085-096) Causative (Faure-par)

Exaple: Le lapina lait frapper la vache par la chevre. CORRETT RORMS:

1,$3 ; 3,2 \quad 8 / 12$

$1,(3) ; 3, ? \quad 1 / 12$

3,$2 ; 1,3 \quad \cdots$

3,$2 ; 1,(3) \quad$-- TOTAL CORKECT: $9 / 12$

INCORRECT FORMS:

$1,(2) ; 2,3 \quad 2 / 12$

1,$2 ; 2,3 \quad 1 / 12$

(J097-108) Cleft Object-Causative (Faire-par)

Exanple: C'est l'ellphant que le singe a falt saisir par la grenouslle. CORRETT FORMS:

2,$2 ; 3,1$

$1 / 12$

(Stage II: $E=.33$, df $=35$,

3,$1 ; 2,3$

$\left.\chi^{2}=121.213, p=.0001 \%\right)$

$2,(3) ; 3,1$

3,$1 ; 2,(3)$

$-$

$--$

$--$

IMCORRECT FORMS:

$1,(2) ; 2,3 \quad 3 / 12$

$1,(3) ; 3,2 \quad 3 / 12$

$2,(1) ; 1,3 \quad 1 / 12$

1,$2 ; 2,3 \quad 2 / 12$

1,$2 ; 2,3 ; 3,1 \quad 1 / 12$

1,$3 ; 3,2 \quad 1 / 12$


PATIENT FP

SUMMARY SCORE SHEET

(J10!-120) Conjolned Causative

Exaaple: La grenoulle a lalt frapper la vache et chatouller l'elephant par le singe. COREECT FORMS:
1,$4 ; 4,2 ; 4,3$
1,$4 ; 4,3 ; 4,2$
$-\cdot$
$2 / 1 ?$
4,$2 ; 4,3 ; 1,4$
4,$3 ; 4,2 ; 1,4$
$1,(4) ; 4,2 ; 4,2 \quad 2 / 12$
TOTAL CORRECT: $\quad 4 / 12$

Stage II: $E=.007$, dE $=1727$,

$X^{2}=3988.096, \mathrm{p}<.00101$ )

INEORREIT PORMS:

$\begin{array}{ll}1,2 ; 4,3 & 2 / 12 \\ 1,(2) ; 3,2 ; 3,4 & 2 / 12 \\ 1- & 1 / 12 \\ 1,3 ; 4,2 & 1 / 12 \\ 1 ;-, 2 ; 4,3 & 1 / 12 \\ 1 ; 3,2 ; 4,- & 1 / 12\end{array}$

(J12!-132) Cuusativetoative

Example: L'tltphant a fast apporter le singe a la gienouslle par la vache. CORREET FORKS:

1,$4 ; 4,2,3$

$1 / 12$

(Stage II: $E=.063, \mathrm{df}=191$,

$1,(4) ; 4,2,3 \quad-$

$\chi^{2}=210.322, p=.1609$ )

$4,2,3 ; 1,4$

--

$4,2,3 ; 1,(4)$

$--$

INCORRECT FORMS:

$\begin{array}{ll}1 ; 3- & 1 / 12 \\ 1,(4) ; 4,3+2 & 1 / 12 \\ 1,(4) ; 4,2+3 & 2112 \\ 1 ; 3,244 & 1 / 12 \\ 1,(4) ; 4,2+3,- & 1 / 12 \\ 1 ;-, 2+4,3 & 1 / 12 \\ 1 ; 4,2+3,- & 1 / 12 \\ 1,(3) ; 3,2,4 & 1 / 12 \\ 1,(2) ; 2,3,4 & 1 / 12 \\ 2,(4) ; 4,2+3 & 1 / 12\end{array}$

(J133-144) Causativets-s relative

Exaple: La grenouille 1 fat shatouiller l'el ephant par le singe qua a frappe la vache. CORREET FORHS:

$\begin{array}{cc}1,3 ; 3,2 ; 3,4 & 3 / 12 \\ 1,3 ; 3,4 ; 3,2 & 1 / 12 \\ 3,2 ; 3,4 ; 1,3 & -- \\ 3,4 ; 3,2 ; 1,3 & -- \\ 3,4 ; 1,3 ; 3,2 & --\end{array}$

(Stage II: $E=.007, \mathrm{df}=1727$,

$3 / 12$

$\left.\chi^{2}=4273.81, p<.0001 \%\right)$

1,$3 ; 3,4 ; 3,2 \quad 1 / 12$

3,$4 ; 3,2 ; 1,3$

3,$4 ; 1,3 ; 3,2 \quad \cdots \quad$ TOTAL CORRECT: $\$ / 12$

IMCORRECT PORKS:

$\begin{array}{ll}1,2 ; 2,3 ; 3,4 & 4 / 12 \\ 1 ; 4,1 ; 2+3 & 1 / 12 \\ 1,2 ; 4,3 & 1 / 12 \\ 1,2 ; 3,4 & 1 / 12 \\ 1 ; 3+4,2 & 1 / 12\end{array}$


PATIENT SP

SUMMARY SCORE SHEET

(J145-156) S-S relativetConjoined thene

Exaple: L'elsphant qui a chatounlls la vache et le singe a frappe la grenoulle. CORRECT FORMS:

$\begin{array}{lc}1,2+3 ; 1,4 & 10112 \\ 1,3+2 ; 1,4 & -- \\ 1,4 ; 1,2+3 & -- \\ 1,4 ; 1,3+2 & --\end{array}$

(Stage II: $E=.042$, df $=287$,

$\chi^{2}=2416.667, \mathrm{p}=.0021 \%$

INCORRECT FORMS:

$1,2+3 ; 4,1 \quad 1 / 12$

1,$2 ; 1,2+3 \quad 1 / 12$

(J157-168) Conjoined clauses-4NPs (no deletion) (Baseline)

Exaple: La grenouslle a frappet le singe et la vache a chatouille l'elephant. CORRECT FORHS:

$\begin{array}{lc}1,2 ; 3,4 & 11 / 12 \\ 3,4 ; 1,2 & --\end{array}$

(Stage II: $E=.083, \mathrm{df}=143$,

3,$4 ; 1,2$

$-$

$\left.\chi^{2}=1457.832, p=.0001 \%\right)$

INCORRECT FORMS:

1,$2 ; 4,3 \quad 1 / 12$


PAIIENT FP

SUMMARY SCORE SHEET

(G001-012) Dative-Thene cliticized

Exaple: La chérre l'a offert a la vache.

CORRECT FORMS:

$1,2,32=p$

$1,2,32$ IF

$11 / 12$

(Stage I: $E=2, \mathrm{~d} f=5$,

$\chi=49.00, \mathrm{p}=.0001:$ )

IMCORRECT FORMS:

$1,3,2 \quad 2=p$

$1 / 12$

(G013-024) Dative-6oal cliticized

Exasple: La vache lur a renis la chevre.

CORRECT FORHS:

$1,3,2 \quad 2=8 \quad 10 / 12$

$1,3,2219$

(Stace I: $E=2, \mathrm{df}=5$,

$\chi^{2}=40.00, p=.0001:$ )

IHCORRECT FORMS:

$1,2,32=p \quad 2 / 12$

(60.5-036) Causative-These cliticraed

Exauple: Le lapan l'a falt tenar par la chèvre. CORRECT FORHS:

1,$3 ; 3,2 \quad 2=\mathrm{P}$

$9 / 12$

(Stage I: $E=.33, \mathrm{df}=35$,

1,$3 ; 3,2$ 2 19

$\left.\chi^{2}=260.607, \mathrm{p}=0001 \%\right)$

3,$2 ; 1,32=p$

$-$

3,$2 ; 1,32 \geq P$

$--$

$--$

IMCORRECT FORMS:

1,$2 ; 2,32=p$

$3 / 12$

(6037-048) Causative-Causee cliticized

Exaple: L'el taphant lus a fast attraper la grenouslle. CORRECT FORMS:

1,$2 ; 2,32=$

$12 / 12$

(Stage I: $E=.33, d E=35$,

1,$2 ; 2,32$ IIP

$\chi^{2}=4.24 .244, \mathrm{p}=.0001 \therefore$ )

2,$3 ; 1,2 \quad 2=p$

$-$

2,$3 ; 1,2218$

$--$

(6049-060) Causative-Refiexive 'Causer "= 'Theae"

Exaaple: La vache se fait salsir par le lapin. CORRECT FORMS:

$\begin{array}{lc}3,2=1 & 12 / 12 \\ 1,(3) ; 3,2=1 & -- \\ 3,2=1 ; 1,(3) & -- \\ 1,3 ; 3,2=1 & -- \\ 3,2,2=1 ; 1,3 & --\end{array}$

(Stage I: $E=6, \mathrm{df}=1$, $\chi^{2}=12.00, \mathrm{p}=.0005 \%$ )

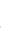


PATIENT FP

SUMKARY SCORE SHEET

(6061-072) Causative-Reflexive Causee

Exanple: La chevre fait se serrer la vache. CORRECT FORMS:

$$
\begin{array}{ll}
1,3 ; 3,2=3 & -\cdot \\
3,2=3 ; 1,3 & - \\
1,(3) ; 3,2=3 & -- \\
3,2=3 ; 1,(3) & --
\end{array}
$$

(Stage I: $E=.15, \mathrm{df}=80$,

INCORRECT FORMS:

$$
\begin{array}{ll}
1,(2) ; 2,3 \text { 2tP } & 9 / 12 \\
3,2=1 & 3 / 12
\end{array}
$$

(G073-084) Causative-Reflexive Causer $=60 a$ al

Exanple: La vache se fait resettre la thevre par le lapin. CORRECT FORMS:

$4,3,2=1 \quad 7 / 12$

1,$4 ; 4,3,2=1 \quad-\cdot$

$4,3,2=1 ; 1,4 \quad \cdots$

$1,(4), 4,3,2=1 \quad 4 / 1 ?$

$4,3,2=1 ; 1,(4) \quad \cdots \quad$ TOTAL CORRECT: $11 / 12$

(Stage II: $E=.67, \mathrm{df}=17$, $X^{2}=170.15, p=.0001 \%$ )

INCORRECT FORHS:

$1,(3) ; 3,4,2=1 \quad 1 / 12$

(6085-096) Causative-Reflexive Causer =lioal, Truncated Exanple: La chevre se falt offrar le lapin. CORRECT FORMS:

$x, 3,2=1 \quad x=$

$10 / 12$

Stage I: $E=.67, d f=17$,

$x, 3,2=1 \quad x \in P$

$--$

$1, x_{;} x, 3,2=1 \quad x=p \quad 2 / 12$

$1, x ; x, 3,2=1$ XIP $\quad-$

TOTAL CORRECT: $12 / 12$

(6097-108) Causative-Theae cliticized, Truncated

Exanple: La chevre le fait serrer.

\section{CORRECT FORMS:}

$1, x_{i} x_{1}, \quad x=P \quad 2=P \quad 6 / 12$

$1, x ; x, 2$ XIP 2 IIP $\quad-$

$x, 2 ; 1, x \quad x=p \quad 2=p \quad--$

$X, 2 ; 1, x$ XiP $21 P \quad-$

$1, x_{i} x, 2$ XIP $2=p \quad$-.

IMCORRECT FORMS:

$2,12=P$

$1,22=$

$3 / 12$

1,$2 ; 2, X \quad X=P$ 2

$1 ; 2,1 \quad 2=P$
(Stage I: $E=.33, \mathrm{df}=35$, $\chi^{2}=133.335, \mathrm{p}=.0001 \%$ ) 
PAT IENT FP

SUMHARY SCORE SHEET

(6109-120) Causative-Reflexive "Causer"='Thene', Truncated

Exaoplei La chevre se faik bousculer.

CORRECT FORMS:

\begin{tabular}{|c|c|}
\hline$x, 2=1 \quad x=p$ & $12 / 12$ \\
\hline$x, 2=1 \quad x \in P$ & -- \\
\hline $1,(x) ; x, 2=1 \quad x=f$ & $\cdots$ \\
\hline $1,(x) ; x, 2=1 \quad x \in$ & - \\
\hline $1, x ; x, 2=1 \quad x=f$ & \\
\hline
\end{tabular}

(Stage I: $E=6, \mathrm{df}=1$,

$\left.t^{2}=12.00, \mathrm{p}=.0005 *\right)$

(G121-132) Causative-Thene=Causee clibicized, Intransitive Verb

Exanple: L'slephant le lait trenblar. CORRECI FORHS:

1,$2 ; 2 V \quad 2=p$

1,$2 ; 2 V 2 I P$

$2 V_{i} l, 2 \quad 2=p$

$2 V_{i} l, 2$ 2IP
$9 / 12$

$1 / 12$

$-$

-- TOTAL CORRECT: $10 / 12$
(Stage I: $E=.67, \mathrm{~d} f=17$, $\mathcal{L}^{2}=140.299, \mathrm{p}=.0001 \%$ )

\section{INCORRECT FORMS: \\ 2,$1 ; 1 V \quad 2=p \quad 1 / 12$ \\ $1, x_{i} x, 2 \quad x=p \quad 2=p \quad 1 / 12$}

(G133-144) Cleft ob ject(CO2) vith Stylistic inversion

Exanple: C'est le lapin qu'a flatte l'sléphant. CORRECT FORHS:

$$
2,1 \quad 3 / 12
$$

(Stage II: $E=6, \mathrm{~d} E=1$, $\hat{W}=3, \mathrm{p}=.0833$ )

IHCORRELT FORMS:

$1,2 \quad 9 / 12$

(6145-156) Subject-0bject relative vith Stylistic Inversion

Exaaple: Le lapin qu'a gratte l'elephant a trapps le singe. CORRECT FORMS:

2,$1 ; 1,3$

$--$

Stage II: $E=.33$, df $=35$ 1,$3 ; 2,1$

$--$

INCORRECT FORHS:

1,$2 ; 3,2 \quad 2 / 12$

1,$2 ; 2,3 \quad 8 / 12$

2,$1 ; 3,1 \quad 1 / 12$

1,$2 ; 1,3 \quad 1 / 12$

(6157-168) object-0b ject relative vith Stylistic Inversion

Exanple: Le lapin a gratte la chture qu'a eabrasste le singe.

CORRECT FORHS:

1,$2 ; 3,2$

$3 / 12$

(Stage II: $E=.33$, df $=35$,

3,$2 ; 1,2$

$-$

INCORRECT FORMS:

1,$2 ; 2, ? \quad 8 / 12$

1,$2 ; 1,3 \quad 1 / 12$ 
(nOOL-012) $\quad 12$

Exanple: La grenouille a frappe le singe. CORRECT FORMS:

(no13-024) P2

Exaaple: Le singe a dté frappe par la grenoulle. CORRECT FORMS:

$2,1 \quad 7 / 12$

(Stage II: $E=6, \mathrm{df}=1$,

$\chi^{2}=.333, \mathrm{p}=.5637$ )

INCORRECT FORMS:

1,2

$5 / 12$

(n025-036) Iruncated Passives

Exanple: Le singe att frappt.

CORRECT FORMS:

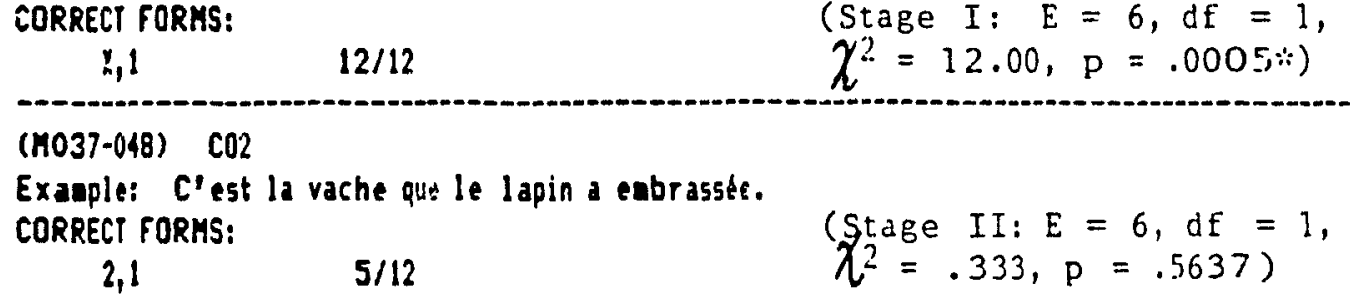

INCORRECT FORHS:

$1,2 \quad 7 / 12$

(n049-060) A3

Example: Le lapin a confié la vache d la chevre. CORRECT FORMS:

$$
1,2,3
$$

$12 / 12$

(Stage II: $E=2$, df $=5$, $\left.\mathcal{X}^{2}=60.00, \mathrm{p}=.0001 \%\right)$

(Y061-072) P3

Exanple: L'elephant a tet donne au singe par la grenouille.

CORRECT FORMS:

$3,1,2$

$7 / 12$

(Stage II: $E=2, d f=5$,

$\left.\chi^{2}=21.00, p=.0008 \%\right)$

INCORRECT FORHS:

$\begin{array}{ll}2,1,3 & 4 / 12 \\ 1,2,3 & 1 / 12\end{array}$

$1,2,3$

$1 / 12$

(no\%3-084) CO3

Exauple: C'est la chevre que le lapin a donnte d la vache. CORRECT FORHS:

$$
2,1,3 \quad 5 i 12
$$

(Stage II: $E=2, \mathrm{df}=5$,

$\left.\chi^{2}=25.00, p=.0001 *\right)$

\section{INCORRECT FORHS:}

$$
1,2,3 \quad 7 / 12
$$


PATIENT JR

SWhHARY SCORE SHEET

(M085-096) CON

Exapple: Le singe a gratte le lapin et a caresst l'tlephant. CORRECT FORAS:

$$
1,2 ; 1,3 \quad 6 / 12
$$

(Sfage II: $E=.33$, df $=35$,

1,$3 ; 1,2$

$\left.\chi^{2}=175.759, p=.0001 *\right)$

INCORRECT FORMS:

$\begin{array}{ll}1,2 ; 2,3 & 5 / 12 \\ 1,3 ; 3,2 & 1 / 12\end{array}$

(17097-109) 5-0

Exauple: Le singe que le lapin a saisi a bouscult la chtrre. CORRECT FORAS:

$\begin{array}{ll}2,1 ; 1,3 & 1 / 12 \\ 1,3 ; 2,1 & --\end{array}$

(Stage II: $E=.33$, df $=35$, 1,$3 ; 2,1$ $\left.\lambda^{2}=296.971, p=.0001 *\right)$

INCORRECT FORMS:

$\begin{array}{lr}1,2 ; 2,3 & 10 / 12 \\ 1,2 ; 1,3 & 1 / 12\end{array}$

(n109-120) O-S

Exaople: La chture a frappl le lapin qui a saisi la vache. CORRECT PORHS:
1,$2 ; 2,3$
$12 / 12$ 2,$3 ; 1,2$
$--$

(Stage II: $E=.33$, df $=35$,

(h121-132) $\quad 0-0$

Exanple: Le singe a chatoulllt la grenouille que la chevre a bousculte. CORRECT FORAS:

1,$2 ; 3,2$

$4 / 12$

(Stage II: $E=.33$, df $=35$, 3,$2 ; 1,2$

$-$ $\chi^{2}=187.88, p=.0001 \%$ )

INCORRECT FORMS:

1,$2 ; 2,3$

1,$3 ; 3,2$

$7 / 12$

$1 / 12$

(nt33-144) S-S

Exasple: La grenoville qui a tenu la vache a attrapt l'tltphant. CORRECT FORHS:

$\begin{array}{ll}1,2 i 1,3 & 2 / 12 \\ 1,3 ; 1,2 & \ldots\end{array}$

Stage II: $E=.33$, df $=35$,

1,$3 ; 1,2$

$\left.\gamma_{2}=303.032, \mathrm{p}=.0001 \%\right)$

INCORRECT FORHS:

1,$2 ; 2,3 \quad 10 / 12$ 
PATIENT JR

SUMHARY SCORE SHEET

(M145-156) Active Conjoined thene

Exaaple: Le lapin a frappt la vache et la chève. CORRECT FORHS:

$1,2+3$

$12 / 12$

(Stage II: $E=1, \mathrm{df}=11$,

$1,3+2$ $--$

$\chi^{2}=132.00, p=.0001 *$ )

(m157-168) Passive Conjoined Agent

Exanple: La grenouille a tte caresset par la cherre et la vache.

CORRECT FORMS:

$2+3,1$

$8 / 12$

(Stage II: $E=1, \mathrm{df}=11$,

$3+2,1$

--

$\left.\chi^{2}=68.00, p=.0001 \div\right)$

INCORRECT FORHS:

$1,2+3 \quad 1 / 12$


PATIENT JR

SUMMARY SCORE SHEET

:J001-012) Direct Object Control, Intransative Vero

Exaaple: La grenouslle a force le singe d bordar. CORRECT FORMS:

$\begin{array}{lcc}1,2 ; 2 V & 12 / 12 & \left.\chi^{2}=84.00, p=.0001 \%\right) \\ 2 V ; 1,2 & -- & \end{array}$

(J013-024) Passivized Direct Object Control, Intransitive Verb

Exaople: La vache a the forcke pap le lapin d danser. CORRELT FORMS:

$$
\begin{array}{lcl} 
& \text { (Stage II: } E=1.5, \mathrm{df}=7, \\
2, l ; 1 \mathrm{~V} & 9 / 12 & \left.\chi^{2}=48.00, \mathrm{p}=.0001 *\right) \\
1 V ; 2,1 & -- &
\end{array}
$$

INCORRECT FORHS:

$$
1,2 ; 20 \quad 3 / 12
$$

\section{(J025-036) Truncated Causative}

Exauple: Le lapin a fast frapper la vache. CORRECT FORHS:

$$
\begin{array}{lcl}
1, x_{i} x, 2 & 1 / 12 & \\
1,(x) ; x_{1} 2 & 5 / 12 & \\
x, 2 ; 1,1 & -. & \\
x, 2 ; 1,(x) & -- & \text { TOTAL CORRECT: } 6 / 12
\end{array}
$$

(Stage I: $E=.33$, df $=35$, $\left.\chi^{2}=175.759, \mathrm{p}=.0001 \%\right)$

IMCORRECT FORAS:

$\begin{array}{ll}1,2- & 5 / 12 \\ 1 ; 1,2 & 1 / 12\end{array}$

(J037-048) Causativetintransitive Verb

Exanple: La vache a lait danser le lapin. CORPECT FORMS:

$$
1,2 ; 2 \mathrm{~V}
$$

$2 V ; 1,2$

$12 / 12$

(Stage II: $E=1.5, \mathrm{df}=7$, $X^{2}=84.00, p=.0001 *$ )

(j049-060) Direct Object Controltiransitive Verb

Exaple: Le lapan a lorce la chèred frapper la vache. CORRECT FORHS:

1,$2 ; 2,3$

$12 / 12$

(Stage II: $E=.33, \mathrm{df}=35$, 2,$3 ; 1,2$

(J061-072) Passivized Direct Object Controltiransitive Verb

Exaple: La grenouslle a dté forcle par l'elephant a caresser le singe. CORRECT FORHS:

2,$1 ; 1,3$

1,$3 ; 2,1$

$3 / 12$

(Stage II: $E=.33, \mathrm{df}=35$, $\chi^{2}=260.607, p=.0001 *$ )

IMCORRECT FORHS:

1,$2 ; 2,3$ $9 / 12$ 
(5073-084) Causalive (ralre-d)

Exaple: La grenouille a falt caressar le singe a l'tlephant. CORRECT FORHS:

1,$3 ; 3,2$

$1 / 12$

(Stage II: $E=.33$, dE $=35$,

$1,(3) ; 3,2$

$3 / 12$

3,$2 ; 1,3$

3,$2 ; 1,(3)$

$-$

-- TOTAL CCRRE:T: $\quad 4 / 12$

IMCORRELT FORMS:

1,$2 ; 2,3 \quad 2 / 12$

$1,(2) ; 2,3 \quad 6 / 12$

(J085-0,96) Causative (Faire-par)

Exanple: Le lapin a falt frapper la vache par la chavre. CORRECT FORHS:

1,$3 ; 3,2$

$1,(3) ; 3,2$

3,$2 ; 1,3$

$3,2 i l,(3)$

$3 / 12$

(Stage II: $E=.33$, dE $=35$, $\left.\chi^{2}=303.032, \mathrm{p}=.0001 \%\right)$

1112

-. TOTAL cORgEt: $10 / 12$

INCORRELT FORYS:

1,$2 ; 2,3 \quad 1 / 12$

$1,(2) ; 2,3 \quad 1 / 12$

(5037-108) Cleft ob ject-Causative (Faire-par)

Exaple: C'est l'dlephant que le singe a fait salsir par la grenouille. COPRECT PORMS:

2,$3 ; 3,1$

3,$1 ; 2,3$

$-$

(Stage II: $E=.33, d f=35$,

$2,(3) ; 3,1$

$\left.\chi^{2}=248.486, p=.0001: 1\right)$

$3, ! ; 2,(3)$

-.

$-$

-.

INCORRECT FOR HS:

$\begin{array}{ll}1,2 ; 2,3 & 6 / 12 \\ 1,(2) ; 2,3 & 3 / 12 \\ 1,3 ; 3,2 & 1 / 12 \\ 1- & 1 / 12 \\ 1,(3) ; 3,2 & 1 / 12\end{array}$


PATIENT JR

SUMMARY SCORE SHEET

(J109-120) Conjoined Causative

Eáaple: La grenouille a last frappep la vache et chatoulllep l'slsphant par le singe. CORRECT FORMS:

1,$4 ; 4,2 ; 4,3 \quad \cdots$

(Stage II: $E=.007, \mathrm{dt}=1727$,

$1,4,4,3 ; 4,2 \quad$-.

$\left.\mathcal{X}^{2}=2845.239, \mathrm{P}<.0001^{\circ}\right)$

4,$2 ; 4,3 ; 1,4 \quad \cdots$

4,$3 ; 4,2 ; 1,4 \quad \cdots$

$1,(4) ; 4,2 ; 4,3 \quad \cdots$

INIORRELT FORUS:

$\begin{array}{ll}1,2- & 2 / 12 \\ 1,2-4 & 1 / 12 \\ 1,2 ; 2,3 ; 3,4 & 3 / 12 \\ 1 ; 2,3- & 1 / 12 \\ 1,2 ; 2,4 & 1 / 12 \\ 1 ;- & 1 / 12 \\ 1,2 ; 4,3 & 1 / 12 \\ 1 ;-2- & 1 / 12 \\ 1,2 ; 3,2 & 1 / 12\end{array}$

(S12!-132; Causative+Dative

Exaple: L'elephant a fast apporter le singe d la grenouslle par la vache. CORRECT FORMS:

1,$4 ; 4,2,3 \quad-$.

$1,(4) ; 4,2,3 \quad 1 / 12$

$4,2,3 ; 1,4 \quad--$

$4,2,3 ; 1,(4) \quad--$ TOTAL CORREIT: $1 / 12$

INCORRECT FURMS:

$1,2-\quad \quad 1 / 12$

$1 ; 4,2-\quad 1 / 12$

$1,(2) ; 2,3,4 \quad 1 / 12$

$1,(3) ; 3,2,4 \quad 2 / 12$

1,$2 ; 2,3 ; 3,4 \quad 1 / 12$

1,$3 ; 3,4 ; 1-\quad 1 / 12$

$1,(2) ; 2,3,-\quad 1 / 12$

$1 ; 2-\quad 1 / 12$

1,$2 ; 3,4 \quad 1 / 12$

$1,-\quad 1 / 12$

(Stage II: $E=.063$, df $=191$, $\chi^{2}=210.322, p=.1609$ ) 
PATIENT JR

SUMMARY SCORE SHEET

(S133-14t) Causativets-S relative

Exaaple: La grenouslle a last chatousller l'tlephant par le singe qui a frappé la vache. CORRECT FORMS:

$\begin{array}{ll}1,3 ; 3,2 ; 3,4 & 1 / 12 \\ 1,3 ; 3,4 ; 3,2 & -- \\ 3,2 ; 3,4 ; 1,3 & -- \\ 3,4 ; 3,2 ; 1,3 & -- \\ 3,4 ; 1,3 ; 3,2 & --\end{array}$

(Stage II: $E=.007, d f=1727$, $\left.X_{j}=5988.096, p<.0001\right)$

$\cdots$

IIIOORRELT FORHS:

$\begin{array}{ll}0,0 ; 0,0 ; 0,0 & 1 / 12 \\ 1,2 ; 3,4 & 6112 \\ 1,3 ; 3,2 ; 2,4 & 1 / 12 \\ 1,2 ; 2,4 ; 4,3 & 1 / 12 \\ 1,2 ; 2,2 ; 2,4 & 1 / 12 \\ 1,2 ; 2,4,3 & 1 / 12\end{array}$

(J145-156) S-5 relativetConjoined These

Exaple: L'ellephant qui a chatouslle la vache et le singe a frappes la grenouslle. CORRECT FORTS:

$1,2+3 ; 1,4$

$3 / 12$

$1,3+2 ; 1,4$

$--$

1,$4 ; 1,2+3$

1,$4 ; 1,3+2$

$-$

$-$

INCORRECT FORMS:

$\begin{array}{ll}1,3+2 ;--4 & 1 / 12 \\ 4,2 ; 3 ; 1+2,4 & 1 / 12 \\ 1,2+3 ; 2,4 & 1 / 12 \\ 1,2+3 ; 3+2,4 & 1 / 12 \\ 1,2+3 ; 2+3,4 & 3 / 12 \\ 1,2+3 ;-14 & 1 / 12 \\ 1,2,3 ; 4,2+3 & 1 / 12\end{array}$

(J157-168) Conjoined clauses-4HPs (no deletion)(Baseline)

Exaple: La grensullle a frappl le singe et la vache a chatouilld l'slephant, CORRECT FORMS:

$\begin{array}{ll}1,2 ; 3,4 & 4 / 12 \\ 3,4 ; 1,2 & --\end{array}$

(Strage II: $E=.083$, df $=143$, 3,$4 ; 1,2$

INCORRECT FORHS:

$\begin{array}{ll}1,2 ; 3,- & 1 / 12 \\ 1,2,3- & 1 / 12 \\ 1,2 ; 2,4 & 1 / 12 \\ 1,2 ; 2,3 ; 3,4 & 3 / 12 \\ 1,2 ; 4,3 & 2 / 12\end{array}$


PATIENT JR

SUMHARY SCORE SHEET

(b001-012) Oative-These cliticized

Exanple: La chevra l'a offert a la vache. CORRECT FORMS:

$1,2,32=p$

$11 / 12$

(Stage I: $E=2$, df $=5$,

$1,2,3 \geq \mathrm{IP}$

$-$

$\left.\eta=49.00, p=.0001^{\circ}\right)$

INCORRECT FORHS:

$1,3,2 \quad 2=p$

$1 / 12$

(b013-024) Oative-6oal cliticized

Exasple: La vache lui a reais la cherre. CORRECT FORAS:

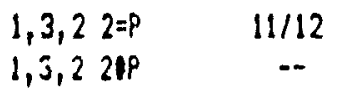

(Stage I: $E=2$,

$\left.\chi^{2}=49.00, p=.0001 \%\right)$

INCORRECT FORHS:

$2,3,12=p$

$1 / 12$

(15025-036) Causative-These chiticlaed

Exanple: Le lapin l'a fast tenar par la chevre. CORRECT FORMS:

$\begin{array}{lc}1,3 ; 3,22=p & 11 / 12 \\ 1,3 ; 3,221 P & -- \\ 3,2 ; 1,32=p & -- \\ 3,2 ; 1,321 P & --\end{array}$

(Stage I: $E=.33$, df $=35$, $\left.\mathcal{X}^{2}=357.577, \dot{p}=.0001 \%\right)$

1,$3 ; 3,221 p$

$-$

3,$2 ; 1,321 P$

IMCORRECT FORMS:

$1, \hat{2} ; 2,3 \quad 2=9$

$1 / 12$

(6ica7-048) Causative-Causee chiticized

Exauple: L'slephant lus a falt attraper la grenoullle. CORRECT FORHS:

$$
\begin{array}{ll}
1,2 ; 2,32=p & 9 / 12 \\
1,2 ; 2,321 \mathrm{IP} & - \\
2,3 ; 1,2 \text { 2=P } & -- \\
2,3 ; 1,2 \text { 21P } & -.
\end{array}
$$

(Stage I: $E=.33, \mathrm{df}=35$, $\left.\chi^{2}=260.607, p=.0001 \%\right)$

INCORRECT FORMS:

1,$3 ; 3,2 \quad 2=p$

$3 / 12$
(6043-060) Causative-Reflexive 'Causer" ="Theac"

Exapple: la vache se fait saisir par le lapin. CORRECT FORHS:

$$
\begin{aligned}
& 3,2=1 \quad 10 / 12 \\
& 1,(3) ; 3,2=1 \quad 1 / 12 \\
& 3,2=1 ; 1,(3) \quad- \\
& 1,3 ; 3,2=1 \quad \cdots \\
& 3,2,2=1 ; 1,3 \quad \cdots \quad \text { TOTAL CORRECT: } 11 / 12
\end{aligned}
$$

(Stage I: $E=.33, d f=35$, $\left.\chi^{2}=357.577, \mathrm{p}=.0002 \%\right)$

\section{INCORRECT FORHS:}

$x, 2=1 \quad x=P \quad 1 / 12$ 
(G061-072) Causative-Reflerive Causee

Exaple: La chevre fart se serrer la vache. CORRECT FORMS:

1,$3 ; 3,2=3$

$3,2=3 ; 1,3$

$1,(3) ; 3,2=3$

$3,2=3 ; 1,(3)$

(Stage II: $E=3, d f=3$,

$\left.\chi^{2}=36.00, p=.0001 \%\right)$

IMCORRECT FORHS:

$1,3 \quad 12 / 12$

(6073-084) Causative-Reflecive Causer Gioal

Exaaple: La vache se falt reuettre la chevre par le lapin. CORRECT FGRHS:

$4,3,2=1$

$4 / 12$

1,$4 ; 4,3,2=1 \quad$-.

$4,3,2=1 ; 1,4 \quad--$

$1,(4) ; 4,3,2=1 \quad 5 / 12$

$4,3,2=1,1,(4) \quad$ - $\quad$ TOTAL CORPECT: $9 / 12$

(Stage II: $E=.67, \mathrm{df}=17$, $\chi^{2}=122.388, p=.0001 \%$ )

NCORRELT FORAS:

$1,(3) ; 3,4.2=1 \quad 2 / 12$

$3,4,2=1$

$1 / 12$

(6085-096) Causative-Reflexive Causer=boal, Truncated

Exaple: La chevre se last offrip le lapin. CORPECT GOPMS:

$x, 3,2=1 \quad x=p \quad 4 / 12$

$x, 3,2=1 X \notin P \quad--$

$1, x ; x, 3,2=1 \quad x=p \quad 6 / 12$

$1, x_{i} x, 3,2=1$ XIP -- TOTAL CORRECT: $10 / 12$

INCDRRECT FORMS:

$1 ; 2=1,3, x \quad X=P \quad 1 / 12$

$1 ; 3, x, 2=1 \quad x=P \quad 1 / 12$

(6097-108) Causative-These claticized, Truneated

Exanple: La chevre le fait serrer. CORRECT FORHS:

$1, x ; x, 2 \quad x=P \quad 2=p \quad 5 / 12$

(Sytage I: $E=.33, \mathrm{df}=35$,

$1, x ; x, 2$ XIP $210 \quad-$

(Stage I: $E=.67, \mathrm{df}=17$,

$x, 2 ; 1, x \quad x=P \quad 2=P \quad-$

$X, 2 ; 1,1$ XIP 2 IIP $\quad-$

1,$1 ; x, 2$ I:P $2=p \quad-$

INCORRECT FORHS:

$1,22=p \quad 7 / 12$ 
PATIENT JR

SUMHARY SCORE SHEET

(6109-120) Causative-Refleyve "Causer'="Thene', Truncated

Exanple: La chievre se falt bousculer.

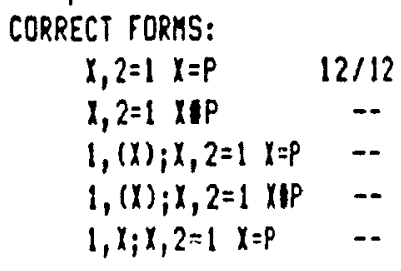

(Stage I: $E=6, d f=1$,

$\left.\gamma^{2}=12.00, p=.0005 \%\right)$

$1,2=1$ XIP $\quad-\cdot$

$1,(x) ; x, 2=1$ XIP $\quad-$

(6121-132) Causative-Thene:Causee cliticized, Intransitive Verb

Exanple: L'tlephant le fait treabler.

CORRECT FORHS:

1,$2 ; 2 \vee 2=p$

$12 / 12$

(Stage I: $E=1.5, \mathrm{df}=7$,

1,$2 ; 2 V 2 \mathbb{P P} \quad--$

$2 V_{i} l, 2 \quad 2=P \quad-$

$2 V_{i} 1,221 P \quad--$

(5!33-144) Cleft Object(CO2) with Stylistic Inversion

Exaple: C'est le lapin qu'a flatte l'sléphant. CORRECT FORMS:
2,1
$1 / 12$

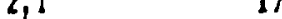
$\lambda^{2}=8.333, \mathrm{p}=.0039 *$ )

(Stage II: $E=6, \mathrm{df}=1$,

INCORRECT FORHS:

$1,2 \quad 11 / 12$

(6145-156) Subject-0bjert relative vith Stylistic Inversion

Exaaple: Le lapin qu'a gratte l'elephant a frappe le singe. CORRECT FORMS:

$\begin{array}{ll}2,1 ; 1,3 & 1 / 12 \\ 1,3 ; 2,1 & --\end{array}$

(Stage II: $E=.33, \mathrm{df}=35$,

$\chi^{2}=296.971, p=.0001 \%$

INCORRECT PORHS:

1,$3 ; 3,2 \quad 1 / 12$

1,$2 ; 2,3 \quad 10 / 12$

(6157-168) Object-0h ject relative vith Stylistic Inversion

Exanple: Le lapin aratte la chevre qu'a eabpasste le singe.

CORRECT FORMS:

1,$2 ; 3,2 \quad 2 / 12$

(Stage II: $E=.33, \mathrm{df}=35$,

3,$2 ; 1,2$

$\left.\chi^{2}=248.486, \mathrm{p}=.0001 \%\right)$

INCORRECT FORHS:

3,$2 ; 2,1 \quad 1 / 12$

1,$2 ; 2,3 \quad 9 / 12$ 
$(1001-012) \quad 12$

Exarple. La grenoulle a frappe le singe. CORRECT FORMS: 1,2 $12 / 12$

(Stage II: $E=6, \mathrm{df}=1$, $\left.\chi^{2}=12.00, p=.0005\right)$

(H013-024) P2

Exanple: Le singe a té frappé par la grenouslle. CORRECT FORMS:

$2,1 \quad 7 / 12$

(Stage II: $E=6, \mathrm{df}=1$, $\chi^{2}=.333, \mathrm{p}=.5637$ )

INCORRECT FORMS:

1,2 $5 / 12$

(H025-036) Truncated Passives

Exanple: Le singe a été frappé. CORRECT FORHS:

$$
x, 1
$$

$12 / 12$

(Stage I: $E=6, \mathrm{df}=1$,

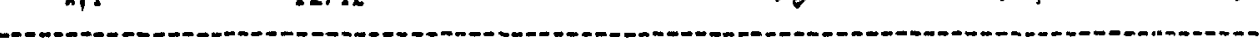

(H037-048) CO2

Exanple: C:est la vache que le lapin a eubrassée. CORRECT FORAS:

$$
2,1 \quad 6 / 12
$$

(Stage II: $E=6, d f=1$,

INCORRECT FORMS:

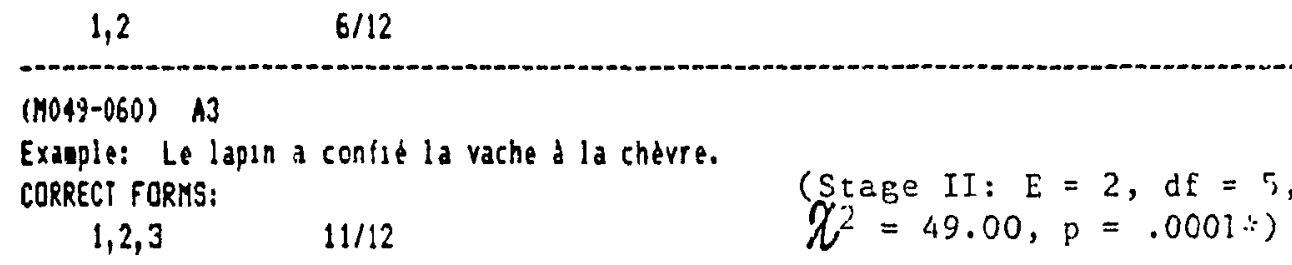

IMCORRECT FORHS:

$2,1,3 \quad 1 / 12$

(M061-072) P3

Exanple: L'elephant a tte donnt au singe par la grenouille. CORRECT FORMS:

$$
3,1,2
$$$$
-
$$

(Stage II: $E=2, d f=5$, $\left.Z^{2}=22.00, p=.0005 \%\right)$

\section{INCORRECT FORHS:}

$\begin{array}{ll}1,2,3 & 8 / 12 \\ 1,2 ; 1,3 & 1 / 12 \\ 2,1,3 & 1 / 12 \\ 2,3,1 & 1 / 12 \\ 2,1 ; 3,1 & 1 / 12\end{array}$


PATIENT CD

SUMMARY SCORE SHEET

(n073-084) $\quad$ CO3

Exanple: C'est la chtrre que le lapin a donnese d la vache. CORRECT FORMS:

$2,1,3$

$2 / 12$

(Stage II: $E=2, d f=5$,

$\left.\chi^{2}=23.00, \mathrm{p}=.0003 *\right)$

INCORRECT FORHS:

$\begin{array}{ll}1,3,2 & 1 / 12 \\ 1,2,3 & 8 / 12 \\ 2,1 ; 3,1 & 1 / 12\end{array}$

(H085-096) CON

Exaaple: Le singe a gratte de lapin et a caresst l'elephant.

CORRECT FORHS:

1,$2 ; 1,3$

1,$3 ; 1,2$

$6 / 12$

Stage II: $E=.33$, df $=35$,

$\chi^{2}=175.759 \mathrm{p}=.0001 \%$

INCORRECT SORMS:

1,$2 ; 2,3 \quad 5 / 12$

1,$2 ; 3,1 \quad 1 / 12$

(M097-108) S-0

Example: Le singe que le lapan a saiss a bouscule da chevre.

CORRECT FORMS:

2,$1 ; 1,3$

1,$3 ; 2,1$

$--$

(Stage II: $E=.33$, df $=35$,

$\left.\chi^{2}=151.516, \mathrm{p}=.0001 \%\right)$

IMCORRECT FORHS:

$\begin{array}{ll}1,2 ; 1,3 & 4 / 12 \\ 1,2 ; 3,2 & 1 / 12 \\ 1,2 ; 2,3 & 6 / 12 \\ 2,1 ; 2,3 & 1 / 12\end{array}$

(n109.120) 0-5

Exaple: La chevre a frappt le lapin qui a saisi la vache.

CORRECT FORUS:

1,$2 ; 2,3$

2,$3 ; 1,2$

$9 / 12$

(Stage IJ: $E=.33, \mathrm{df}=35$,

$-$

INCORRECT FORMS:

1,$2 ; 1,3 \quad 3 / 12$

(n121-132) $0-0$

Exanple! Le singe a chatouille la grenouille que la chevre a bouscule. CURRECT FORAS:

1,$2 ; 3,2$

3,$2 ; 1,2$

$2 / 12$

(Stage II: $E=.33$, df $=35$,

IMCORRECT FORHS:

$\begin{array}{ll}1,2 ; 2,3 & 5 / 12 \\ 1,2 ; 1,3 & 2 / 12 \\ 1,3 ; 3,2 & 1 / 12 \\ 1,2 ; 3,1 & 1 / 12 \\ 1,2 ; 3,2 ; 31 & 1 / 12\end{array}$


PATIENT CD

SUMMARY SCORE SHEET

(nis3-144) S-5

Exanple: La grenouille qui a tenu la vache a attrapt l'elephant. CORRECT FORMS:

$\begin{array}{ll}1,2 ; 1,3 & 3 / 12 \\ 1,3 ; 1,2 & --\end{array}$

(Stage II: $E=.33, \mathrm{df}=35$,

1,$3 ; 1,2$

$\chi^{2}=212.122, \mathrm{p}=.0001 \%$ )

INCORRECT TORKS:

1,$2 ; 2,3 \quad 8 / 12$

1,$3 ; 2,3 \quad 1 / 12$

(m145-156) Active Conjoined These

Exaaple: Le lapin a frappe la vache et la chevre. CORRECT FORMS:

$\begin{array}{cc}1,2+3 & 11 / 12 \\ 1,3+2 & --\end{array}$

(Stage II: $E=1, \mathrm{df}=11$,

$\left.\chi^{2}=110.00, \mathrm{p}=.0001 \%\right)$

$1,3+2$

$-$

IMCORRECT FORHS:

$3+2,1$

$1 / 12$

(ni57-168) Passive Conjoined Agent

Exaple: La grenouille a tte caressete par la chevre et la vache. CORRECT FORHS:

$2+3,1 \quad 5 / 12$

(Stage II: $E=1$, df $=11$,

$3+2,1$

$5 / 12$

$\chi^{2}=50.00, \mathrm{p}=.0001 \%$ )

INCORRECT FORHS:

$1,2+3 \quad 6 / 12$

$1+2,3 \quad 1 / 12$ 
PATIENT CO

SUMMARY SCORE SHEET

(Jo01-012) Direct object Control, Intransitive Verb

Exaople: La grenouille a forct le singe d bondsr. CORRECT FORHS:

1,$2 ; 2 v$

$12 / 12$

(Stage II: $E=1.5, \mathrm{df}=7$, $2 V_{i} 1,2$

$\chi^{2}=84.00, p=.0001 \%$ )

(J013-024) Passivized Direct Object Control, Intransitive Verb

Exanple: La vache a tete forcte par le lapin a danser. CORRECT FORHS:

2,$1 ; 10 \quad 1 / 12$

IVi 2,1

$-$

(Stage II: $E=1.5$, df $=7$, $x^{2}=32.00, p=.0001 *$ )

INCORRECT FORAS:

$\begin{array}{ll}1,2 ; 2 V & 7 / 12 \\ 1,2 ; 14 & 4 / 12\end{array}$

(J025-036) Truncated Causative

Example: le lapin a fast trapper la vache. CORRECT PORHS:

$1, x_{;} x_{1} ?$

$1,(x) ; x, 2$

$6 / 12$

$x, 2 ; 1, x$

$x, 2 ; 1,(x)$

$--$

$-$

$-$

INCORRECT FORNS:

$\begin{array}{ll}1,2 & 3 / 12 \\ 1,2- & 3 / 12\end{array}$

(J037-048) Causativet Intransilive Varb

Exanple: La vache a fait danser le lapin. CORRECT RORHS:

$\begin{array}{lcc}1,2 ; 2 V & 12 / 12 & \left.\chi^{2}=84.00, p=.0001 \%\right) \\ 2 V_{i} l, 2 & -. & \end{array}$

(J049-060) Direct Object Controltiransitive Verb

Exanplei Le lapin a forct la chevre a frapper la vache.

CORRECT FORHS:

1,$2 ; 2,3$

$11 / 12$

(Stage I: $E=.33, d f=35$,

$2,3 i 1,2$

$--$

(Stage II: $E=.33$, df $=35$,

$\left.\chi^{2}=357.577, \dot{p}=.0001 \%\right)$

IMCORRECT FORHS:

1,$2 ; 3,2$

$1 / 12$ 
PATIENT CD

SUMMARY SCORE SHEET

(J061-072) Passivized Direct Object ControltTransative Verb

Exaple: la grenouille a the forcese par l'elephant d caresser le singe.

CORRECT FORHS:

2,$1 ; 1,3$

1,$3 ; 2,1$

(Stage II: $E=.33, \mathrm{df}=35$,

$1 / 12$

$\left.\chi^{2}=296.971, p=.0001 \%\right)$

INCORRECT FORMS:

1,$2 ; 2,3 \quad 10 / 12$

1,$2 ; 1,3 \quad 1 / 12$

(J073-084) Causative (Farre-d)

Exaple: La grenourlle a fait caresser le singe 1 l'sltphant.

CORRECT FORMS:

1,$3 ; 3,2 \quad 1 / 12$

$1,(3) ; 3,2 \quad \cdots$

3,$2 ; 1,3 \quad \cdots$

3,$2 ; 1,(3)$

(Stage II: $E=.33, \mathrm{df}=35$,

$\left.\chi^{2}=357.577, \mathrm{p}=.0001 \%\right)$

IMCORRECT FORHS:

1,$2 ; 2,3 \quad 11 / 12$

(J085-096) Causative (Fatre-par)

Exanple: Le lapin a fast frapper la vache par la chèvre. CORRECT FORHS:

1,$3 ; 3,2$

$-$

(Stage II: $E=.33, \mathrm{~d} f=35$,

$1,(3) ; 3,2$

$\left.\chi^{2}=248.486, p=.0001 \%\right)$

3,$2 ; 1,3$

3,$2 ; 1,(3)$

$-$

$-$

$-$

IMCORRECT FORMS:

$\begin{array}{ll}1,2 ; 1,3 & 2 / 12 \\ 1,2 ; 2,3 & 9 / 12 \\ 1,2 ; 2,1 ; 2,3 & 1 / 12\end{array}$

(J097-108) Cleft Object-Causative (Faire-par)

Exanple: C'est l'dlephant que le singe a fat salsir par la grenoullle.

CORRECT FORMS:

2,$3 ; 3,1$

(Stage II: $\Sigma=.33$, df $=35$,

3,$1 ; 2,3$

$\left.\chi^{2}=193.941, \mathrm{p}=.0001 \%\right)$

$2,(3) ; 3,1$

3,$1 ; 2,(3)$

INCORRECT FORUS:

1,$2 ; 2,3$

1,$2 ; 1,3$

--

$-$

1,$3 ; 3,2$

1,3-

--

$-$

1,$2 ; 3,2$

$1 / 12$

$1 / 12$

$1 / 12$ 
PATIENT CO

SUMHARY SCORE SHEET

(J109-120) Conjoined Causative

Exasple: La grenourlle a fait frapper la vache et chatoulller l'slephant par le singe. CORRECT FORHS:

$\begin{array}{ll}1,4 ; 4,2 ; 4,3 & -- \\ 1,4 ; 4,3 ; 4,2 & -. \\ 4,2 ; 4,3 ; 1,4 & -- \\ 4,3 ; 4,2 ; 1,4 & -. \\ 1,(4) ; 4,2 ; 4,3 & --\end{array}$

(Stage II: $E=.007, \mathrm{df}=1727$, $\left.\gamma_{2}^{2}=5988.096, p<.0001 \%\right)$

INCORRECT FORHS:

1,$2 ; 2,3 ; 3,4 \quad 6 / 12$

1,$2 ; 1,3 ; 3,4 \quad 1 / 12$

$1,2-\quad 1 / 12$

1,$2 ; 2,3 ; 4,3 \quad 1 / 12$

1,$2 ; 2,4 ; 4,3 \quad 1 / 12$

1,$3 ; 3,2 ; 2,4 \quad 1 / 12$

1,$3 ; 1,2 ; 2,4 \quad 1 / 12$

(J121-132) Causative+Dative

Exaaple: L'dlephant a fat apporter le singe d la grenouille par la vache. CORRECT FORHS:

$\begin{array}{ll}1,4 ; 4,2,3 & 2 / 12 \\ 1,(4) ; 4,2,3 & -- \\ 4,2,3 ; 1,4 & -- \\ 4,2,3 ; 1,(4) & -.\end{array}$

(Stage II: $E=.063$, df $=191$,

$1,(4) ; 4,2,3 \quad--$

$4,2,3 ; 1,4$

INCORRECT FORMS:

1,$3 ; 2,4 \quad 1 / 12$

$1,2,3 ; 3,4 \quad 1 / 12$

1,$2 ; 2,3 ; 3,4 \quad 2 / 12$

1,$2 ; 2,3-\quad 1 / 12$

1,$2 ; 3,4 \quad 1 / 12$

1,$3 ; 3,2 ; 2,4 \quad 1 / 12$

1,$2 ; 2,3 ; 1,4 \quad 1 / 12$

1,$2 ; 2,4-\quad 1 / 12$

2,$1 ; 2,3 ; 2,4 \quad 1 / 12$ 
PATIENT CD

SUMKARY SCORE SHEET

(J133-144) Causativets-S relative

Exaaple: La grenouslle a lat chatouiller l'slephant par le singe qus a frappes la vache. CORRECT FORMS:

$\begin{array}{ll}1,3 ; 2,2 ; 3,4 & -- \\ 1,3 ; 3,4 ; 3,2 & -- \\ 3,2 ; 3,4 ; 1,3 & -- \\ 3,4 ; 3,2 ; 1,3 & -- \\ 3,4 ; 1,3 ; 3,2 & --\end{array}$

(Staie II: $E=.007, \mathrm{~d} f=1727$,

INCORRECT FORHS:

$\begin{array}{ll}1,2 ; 2,3 ; 2+3,4 & 1 / 12 \\ 1,2 ; 2,3 ; 1,4 & 1 / 12 \\ 1,3+2 ; 2,4 & 1 / 12 \\ 1,2 ; 2,4 ; 4,3 & 1 / 12 \\ 1,2 ; 2,3+4 & 1 / 12 \\ 2,4 ; 4,1 ; 1,3 & 1 / 12 \\ 1,2 ; 2,3 ; 3,4 & 6 / 12\end{array}$

(J145-15E) S-S relative+ionjoined These

Exapla: L'el sphant qua a chatourlle la vache et le singe a frapps la grenouille. CORRECT FORMS:

$\begin{array}{cc}1,2+3 ; 1,4 & 3 / 12 \\ 1,3+2 ; 1,4 & 1 / 12 \\ 1,4 ; 1,2+3 & -- \\ 1,4 ; 1,3+2 & -- \\ & \\ \text { INCORRECT FORMS: } & \\ 1,3+4 ; 3+4,2 & 1 / 12 \\ 1,2+4 ; 1,3 & 2 / 12 \\ 1,2+3 ; 2+3,4 & 3 / 12 \\ 1,2+3 ; 2,4 & 1 / 12 \\ 1,2+3 ; x, 2 & 1 / 12\end{array}$

(J157-168) Conjoined clauses-4NPs(no deletion)(Baseline)

Exauple: La grenouille a frappet le singe et la vache a chatouillt l'elephant. CORRECT FORMS:

$\begin{array}{ll}1,2 ; 3,4 & 5 / 12 \\ 3,4 i 1,2 & --\end{array}$

(Stage II: $E=.042, \mathrm{~d} f=287$, $\left.\partial_{i}^{2}=607.344, p=.0001 \%\right)$

12

TOTAL CORRECT: $4 / 12$

INCORRECT FORMS:

1,$2 ; 2,3 ; 3,4 \quad 3 / 12$

$1,3 \quad 1 / 12$

1,$2 ; 4,3 \quad 1 / 12$

1,$2 ; 4,2 ; 2,3 \quad: 1 / 12$

1,$3 ; 1,2 ; 1,4 \quad 1 / 12$

(Stage II: $E=.083$, df $=143$, $\left.\chi^{2}=445.783, p=.0001 \%\right)$ 
PATIENT JO

SUMAARY SCORE SHEET

(h001-012) 12

Exanple: La grenoullie a frappt le singe.

CORRECT FORHS:

1,2

$12 / 12$

(Stage II: $E=6, \mathrm{df}=1$,

(no13-024) P2
Exanple: Le singe a dte trappt par la grenouslle.

CORRECT FORMS:

$$
2,1 \quad 5 / 12
$$

(Stage II: $E=6, \mathrm{df}=1$,

$2=.333, p=.5637$ )

IHCORRECT FORHS:

$1,2 \quad 7 / 12$

(M025-036) Truncated Passives

Exanple: Le singe a tete trappt.

CORRECT FORMS:
$x, 1$
$3 / 12$
$x^{2}=3.00, p=.0833$ )

(Stage I: $E=6$, df $=1$,

INCORRECT FORHS:

$1, x \quad 9 / 12$
$\begin{aligned} & \text { (MO37-048) CO2 } \\ & \text { Exanple: C'est la vache que le lapin a eabrasste. } \\ & \text { CORRECT fORnS: } \\ & 2,1\end{aligned} \quad 5 / 12$
$($ Stage II: $E=6$, df $=1$,
$2=.333, P=.5637)$

INCORRECT FORHS:

\begin{tabular}{|c|c|c|}
\hline 1,2 & $7 / 12$ & \\
\hline $\begin{array}{l}\text { (MO49-060) A3 } \\
\text { Exanple: Le } 1 \\
\text { CORRECT FORHS: } \\
\qquad 1,2,3\end{array}$ & $\begin{array}{l}\text { confie la vache d la chevre. } \\
6 / 12\end{array}$ & $\begin{array}{l}(\text { Stage II: } E=2, \mathrm{df}=5, \\
\left.\chi^{2}=12, p=.0348 \%\right)\end{array}$ \\
\hline $\begin{array}{c}\text { IMCORRECT FORI } \\
1,3 ; 3,2 \\
1,2+3 \\
1,2 ; 2,3 \\
1,2 ; 1,3\end{array}$ & $\begin{array}{l}1 / 12 \\
1 / 12 \\
3 / 12 \\
1 / 12\end{array}$ & \\
\hline
\end{tabular}

(n061-072) P3

Exanple: L'elephant a tte donne au singe par la grenouille. CORRECT FORHS:

$3,1,2$

(Stage II: $E=2, d f=5$, $x^{2}=11, p=.0514$ )

INCORRECT FORMS:

$\begin{array}{ll}1,2,3 & 2 / 12 \\ 1,2 ; 2,3 & 3 / 12 \\ 2,1,3 & 1 / 12 \\ 1,3,2 & 1 / 12 \\ 1,2 ; 1,3 & 2 / 12 \\ 1,2+3 & 2 / 12 \\ 1,3 ; 3,2 & 1 / 12\end{array}$


PATIENT JD

SUMHAQY SCORE SHEET

(H073-084) $\mathrm{CO3}$

Exanple: C'est la chevre que le lapin a donnee d la vache.

CORRECT FORKS:

$$
2,1,3 \quad 1 / 12
$$

(Stage II: $E=2$, df $=5$,

INCORRECT FORHS:

$\begin{array}{ll}1,2,3 & 3 / 12 \\ 1,3,2 & 2 / 12 \\ 1,2 ; 2,3 & 3 / 12 \\ 1,2+3 & 3 / 12\end{array}$

(M085-096) CON

Exanple: Le singe a gratte le lapin et a caresst l'elephant.

CORRECT FORMS:

1,$2 ; 1,3$

1,$3 ; 1,2$

$5 / 12$

(Stage II: $E=.33, \mathrm{df}=35$,

$\chi^{2}=4, \mathrm{p}=.5494$

IMCORRECT PORMS:

1,$2 ; 2,3 \quad \pi / 12$

(M097-108) S-0

Exanple: Le singz que le lapin a saisi a bouscule la cherre.

CORRECT FORHS:

2,$1 ; 1,3$

1,$3 ; 2,1$

$1 / 12$

(Stage II: $E=.33, \mathrm{df}=35$,

$\left.\chi^{2}=357.577, \mathrm{p}=.0001 \%\right)$

INCORRECT FORMS:
1,$2 ; 2,3$
$11 / 12$

$(m 109-120) \quad 0-5$

Exanple: La chevre a frappe le lapin qui a saisa la vache. CORRECT FORMS:

1,$2 ; 2,3$

2,$3 ; 1,2$

$9 / 12$

(Stage II: $E=.33$, df $=35$, $\left.\chi^{2}=242.425, p=.0001 \%\right)$

INCORRECT FORHS:

$\begin{array}{ll}1,3 ; 3,2 & 1 / 12 \\ 2,1 ; 1,3 & 1 / 12 \\ 2,1 ; 2,3 & 1 / 12\end{array}$

(n121-132) $0-0$

Exanple: Le singe a chatouillt la grenouille que la chevre a bousculte. CORRECT FORHS:

1,$2 ; 3, \hat{2}$

$1 / 12$

(Stage II: $E=.33$, df $=35$,

3,$2 ; 1,2$

$\left.\chi^{2}=296.971, \mathrm{p}=.0001 *\right)$

INCORRECT FORHS:

1,$2 ; 2,3 \quad 10 / 12$

1,$3 ; 1,2 \quad 1 / 12$ 
PATIENT JD

SUMHARY SCORE SHEET

(n133-144) S-S

Exaple: La grenouille qui a tenu la vache a attrapt l'elephant. CORRECT FORHS:

1,$2 ; 1,3$

1,$3 ; 1,2$

$2 / 12$

(Stage II: $E=.33$, df $=35$,

$\chi^{2}=303.032, \mathrm{p}=.0001 \%$ )

IMCORRECT FORHS:

1,$2 ; 2,3 \quad 10 / 12$

(mi45-156) Active Conjoined these

Exauple: Le lapin a frappl la vache et la chevre. CORRECT FORHS:

$\begin{array}{lc}1,2+3 & 7 / 12 \\ 1,3+2 & -- \\ & \\ 2,1,3 & 1 / 12 \\ 1,2,3 & 1 / 12 \\ 1,2 ; 2,3 & 2 / 12 \\ 2,1+3 & 1 / 12\end{array}$

(mis7-168) Passive Conjoined Agent

Exaple: La grenouille a ett caresste par la chevre et la vache.

CORRECT FORHS:

$2+3,1$

$3+2,1$

$2 / 12$

$-$

IMCORRECT FORHS:

1,$2 ; 2,3$

2,$1 ; 2,3$

$1,2+3$

1,$2 ; 1,3$

3,$1 ; 1,2$
(Stage II: $E=1$, df $=11$, $\left.\chi^{2}=44.00, p=.0001 \%\right)$

(Stage II: $E=1, d f=11$, $\chi^{2}=24.00, \mathrm{p}=.0127 \%$ ) 
(5001-012) Direct Object Control, Intransitive Vepb

Exauple: La grenouslle a forcet le singe d bondir.

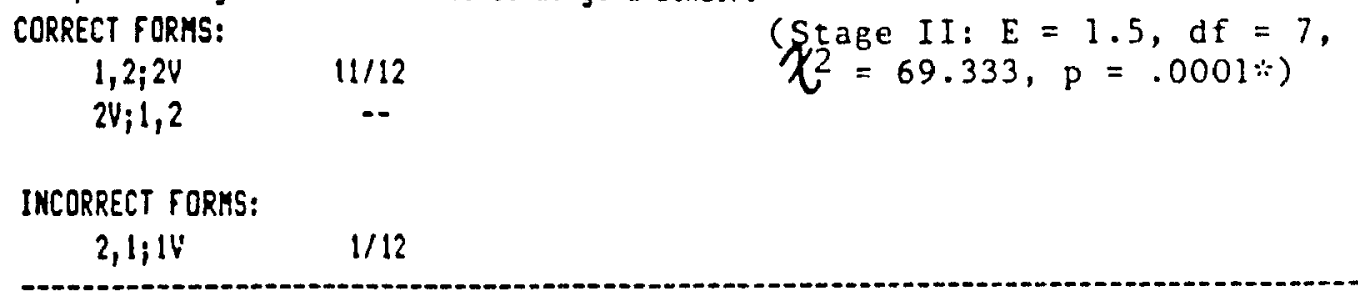

(jo13-024) Passivized Diract object Control, intransitive Verb

Example: La vache a dte forcte par le lapin d danser. CORRECT FORAS:

2,$1 ; 10 \quad 2 / 12$

(Stage II: $E=1.5, \mathrm{df}=7$,

$1 V_{i} 2,1$

$\left.x^{2}=25.333, p=.0007 *\right)$

IMCORRECT FORMS:

$$
\begin{array}{ll}
1,2 ; 2 \mathrm{~V} & 6 / 12 \\
1,2 ; 1 \mathrm{~V} & 4 / 12
\end{array}
$$

(J025-03E) Truncated Causative

Exanple: Le lapin a fast trapper la vache. CORRECT FORHS:

$\begin{array}{lc}1, x ; x, 2 & 2 / 12 \\ 1,(x) ; x, 2 & -- \\ x, 2 ; 1, x & -- \\ x, 2 ; 1,(x) & --\end{array}$

Stage I: $E=.33, \mathrm{df}=35$,

$\chi^{2}=303.032, \mathrm{p}=.0001 \%$

$x, 2 ; 1, x$

$-$

$-$

IMCORRECT FORMS:
$1,2-$
$10 / 12$

(J037-048) Causativetintransitive Verb

Exaple: La vache a fait danser le lapin. CORRECT FORMS:

$$
\begin{aligned}
& 1,2 ; 2 V \\
& 2 V ; 1,2
\end{aligned}
$$

$12 / 12$

(Stage II: $E=1.5, \mathrm{dE}=7$,

(5049-060) Durect Object Controlsiransitive Verb Exanple: Le lapin a force la chevre a frapper la vache. CORRECT FORMS:

$$
1,2 ; 2,3
$$

$10 / 12$

(Stage II: $E=.33, \mathrm{df}=35$, 2,$3 ; 1,2$ $\chi^{2}=296.971, \mathrm{p}=.0001 \%$ )

\section{IMCORRECT FORHS:}

1,$3 ; 3,2 \quad 1 / 12$

2,$1 ; 1,3 \quad 1 / 12$


PATIENT JD

SUMMARY SCORE SHEET

(J061-072) Passivized Darect Object Controltiransitive Verb

Example: La grenoulle a tle lorcte par l'sliphant a caresset le singe. CORRECT FORMS:

2,$1 ; 1,3$

1,$3 ; 2,1$

(Stage II: $E=.33$, df $=35$,

$\left.\chi^{2}=357.577, p=.0001 \%\right)$

INCORRECT FORHS:

1,$2 ; 2,3 \quad 11 / 12$

1,$3 ; 3,2 \quad 1 / 12$

(3073-084) Causative (Fare-d)

Exanple: La grenoullle a fait caresser le singe d l'elephant.

CORRECT FORMS:

1,$3 ; 3,2$

$1,(3) ; 3,2$

$1 / 12$

3,$2 ; 1,3$

$--$

3,$2 ; 1,(3)$

$-$

$-$

INCORRECT FORMS:

1,$2 ; 2,3 \quad 11 / 12$

(J085-096) Causative (Faire-par)

Exanple: Le lapin a last trapper la vache par la chevre.

CORRECT FORHS:

1,$3 ; 3,2 \quad 2 i 12$

$1,(3) ; 3,2 \quad--$

3,$2 ; 1,3 \quad-\cdot$

3,$2 ; 1,(3) \quad-\cdots$

(Stage II: $E=.33$, df $=35$, $\left.\chi^{2}=357.577, \mathrm{p}=.0001 \%\right)$

TRPECT FORMS:

1,$2 ; 2,3 \quad 10 / 12$

(j097-108) Cleft Object-Causative (Faire-par)

Exaple: C'est l'dlephant que le singe a fat saisir par la grenouille. CORRECT FORHS:

2,$3 ; 3,1$

3,$1 ; 2,3$

$-$

$2,(3) ; 3,1$

3,$1 ; 2,(3)$

$-$

(Stage II: $E=.33$, df $=35$, $\left.\chi^{2}=303.032, p=.0001 \%\right)$

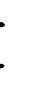

INCORRECT FORMS:

1,$2 ; 2,3 \quad 9 / 12$

$1,3 \quad 1 / 12$

1,$3 ; 3,2 \quad 2 / 12$ 
PATIENT JD

SUMMARY SCORE SHEET

(J109-120) Conjoined Causative

Exaple: La grenouslle a fast frapper la vache et chatousllet l'alsphant par le singe. CORRECT FORMS:

1,$4 ; 4,2 ; 4,3 \quad$-.

1,$4 ; 4,3 ; 4,2 \quad--$

4,$2 ; 4,3 ; 1,4 \quad--$

4,$3 ; 4,2 ; 1,4 \quad \cdots$

$1,(4) ; 4,2 ; 4,3 \quad--$

INCORRELT FORKS:

1,$2 ; 2,4 ; 4,3 \quad 1 / 12$

1,$2 ; 3,4-\quad 1 / 12$

4,$1 ; 1,3 ; 3,2 \quad 1 / 12$

1,$2 ; 2,4-\quad 1 / 12$

1,$2 ; 4,3 ; 2,4 \quad 1 / 12$

1,$2 ; 2,3 ; 3,4 \quad 2 / 12$

1,$3 ; 3,4 ; 4,2 \quad 1 / 12$

2,$3 ; 3,1 ; 1,4 \quad 1 / 12$

2,$3 ; 1,4 \quad 1 / 12$

2,$1 ; 3,4 \quad 1 / 12$

2,$1 ; 1,3 ; 3,4 \quad 1 / 12$

(J121-132) CausativetDative

Exaple: L'eltephant a fat apporter le singe d la grenouille pat la vache. CORRECT FORMS:

$\begin{array}{ll}1,4 ; 4,2,3 & 1 / 12 \\ 1,(4) ; 4,2,3 & -- \\ 4,2,3 ; 1,4 & -- \\ 4,2,3 ; 1,(4) & --\end{array}$

(Stage II: $E=.063$, df $=191$, $\left.\chi^{2}=337.306, \mathrm{p}=.0001 \therefore\right)$

IMCORRECT FORHS:

1,$2 ; 2,3,4 \quad 1 / 12$

1,$3 ; 3,2 ; 2,4 \quad 2 / 12$

1,$2 ; 2,3 ; 3,4 \quad 3 / 12$

1,$4 ; 4,3 ; 3,2 \quad 2 / 12$

1,$2 ; 2,4 \quad 1 / 12$

2,$1 ; 1,3 ; 3,4 \quad 1 / 12$

1,$2 ; 2,3 ; 2,4 \quad 1 / 12$ 
PATIENT JD

SUMAARY SCORE SHEET

(J!33-144) Causativets-s relative

Exasple: La grenoulle a fait chatounller l'ellephant par le singe qus a frappe la rache. CORRECT FCRMS:

1,$3 ; 3,2 ; 3,4$

1,$3 ; 3,4 ; 3,2$

$-$

(Stage II: $E=.007, \mathrm{df}=1727$,

3,$2 ; 3,4 ; 1,3$

3,$4 ; 3,2 ; 1,3$

3,$4 ; 1,3 ; 3,2$

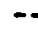

$\left.\chi^{2}=5130.953, \mathrm{p}<.0001 *\right)$

INCORRECT FORHS:

1,$2 ; 2,3 ; 3,4$

3,$2 ; 2,1 ; 1,4 \quad 1 / 12$

1,$2 ; 2,4 ; 4,3 \quad 2 / 12$

2,$1 ; 1,3 ; 3,4 \quad 1 / 12$

(J145-156) S-5 relativetconjoined these

Exapole: L'dléphant qui a chatousllt la vache et le singe a frappes la grenouille. CORPEIT FORMS:

$\begin{array}{lc}1,2+3 ; 1,4 & 1 / 12 \\ 1,3+2 ; 1,4 & -- \\ 1,4 i 1,2+3 & -- \\ 1,4 ; 1,3+2 & --\end{array}$

(Stage II: $E=.042$, df $=287$, $1,3+2 ; 1,4$ $\left.\chi^{2}=607.144, p=.0001 *\right)$

1,$4 ; 1,3+2$

IMCORRECT FORAS:
2,$1 ; 3,4 ; 34$
$1 / 12$
$1,2+-; 4,3$
$1 / 12$
3,$1 ; 1,2 ; 2,4 \quad 1 / 12$
$1,2+3 ; 2+3,4 \quad 4 / 12$
1,$2 ; 2,4 ; 4,3 \quad 1 / 12$
$1,4+3 ; 4+3,2 \quad 1 / 12$
$1,4+2 ; 4+2,3 \quad 2 / 12$

(J157-168) Conjoined clauses-4NPs (no deletion) (Baseline)

Exapple: La grenoullle a frappe le singe st la vache a chatouillt l' ll tehant. CORRECT FORMS:

1,$2 ; 3,4$

3,$4 ; 1,2$

IMCORRECT FORHS:

$\begin{array}{ll}1,2 ; 2,4 ; 3 V & 1 / 12 \\ 1,4 ; 4,3 ; 3,2 & 1 / 12 \\ 1,2 ; 4,3 & 1 / 12 \\ 1,4 ; 3,2 & 2 / 12 \\ 1,2+3 ; 2+3,4 & 1 / 12 \\ 1,2 ; 2,3 ; 3,4 & 4 / 12 \\ 2,1 ; 1,4 ; 4,3 & 1 / 12 \\ 1,3 ; 3,4 ; 4,2 & 1 / 12\end{array}$

(Stage II: $E=.083$, df $=143$, $\left.\chi^{2}=301.205, p=.0001 *\right)$ 
PATIENT PR

SUMGAARY SCORE SHEET

(MOO1-012) A2

Exanple: La grenouille a frappe le singe. CORRECT FORHS:

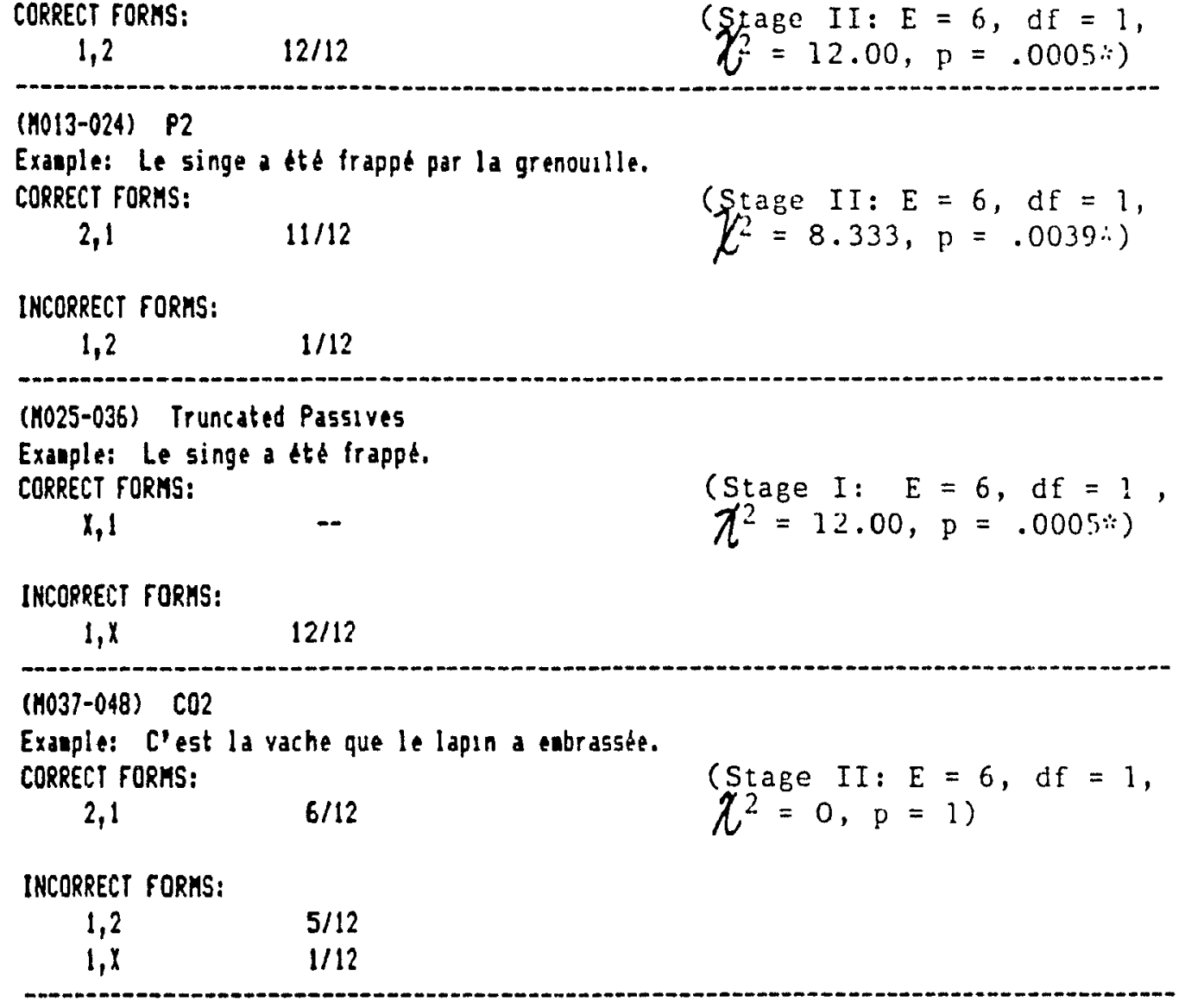

$(1049-060) \quad A 3$

Exanple: Le lapin a confile la vache a la chevre. CORRECT FORMS:

$1,2,3 \quad 11 / 12$

(Stage II: $E=2, \mathrm{df}=5$, $\left.\gamma^{2}=49.00, p=.0001 \%\right)$

INCARRECT FORHS:

$2,1,3 \quad 1 / 12$

(n06:-072) P3

Exaaple: L'elephant a tte donnt au singe par la grenouille. CORRECT FORMS:

$$
3,1,2
$$

$8 / 12$

(Stage II: $E=2$, df $=5$, $\psi^{2}=25.00, p=.0001 *$ )

\section{INCORRECT FORHS:}

$\begin{array}{ll}1,2,3 & 3 / 12 \\ 2,1,3 & 1 / 12\end{array}$


PATIENT PR

SUMMARY SCORE SHEET

(no73-084) CO3

Exanple: C'est la cherre que le lapan a donné d la vache. CORRECT FORKS:

$2,1,3 \quad 3 / 12$

$2,1,3 \quad 3 / 12$

(Stage II: $E=2$, df $=5$,

$\chi^{2}=33.00, \mathrm{p}=.0001 \%$ )

INCORRECT FORMS:

$1,2,3$

$9 / 12$

(nO85-096) CON

Exasple: Le singe a gratte le lapin et a caressé l'ellophant. CORRECT FORHS:

1,$2 ; 1,3 \quad 1 / 12$

(Stage II: $E=.33, \mathrm{df}=35$,

1,$3 ; 1,2$

$\left.\chi^{2}=357.577, p=.0001 *\right)$

IMCORRECT FORMS:

1,$2 ; 2,3 \quad 11 / 12$

(H097-108) S-0

Exauple: Le singe que le lapin a sassi a bouscule la cheure. CORRECT FORMS:

$\begin{array}{ll}2,1 ; 1,3 & 3 / 12 \\ 1,3 ; 2,1 & -.\end{array}$

(Stage II: $E=.33$, df $=35$, 1,$3 ; 2,1$

$\chi^{2}=260.607, p=.0001 \%$

INCORRECT FORKS:

1,$2 ; 2,3 \quad 9 / 12$

(n109-120) 0-5

Exauple: La cherre a frappe le lapin qui a salsi la vache.

CORRECT FORMS:

1,$2 ; 2,3$

2,$3 ; 1,2$

$10 / 12$

(Stage II: $E=.33$, df $=35$,

$\chi^{2}=303.032, p=.0001 \%$ )

IMCORRECT FORHS:

2,$1 ; 1,3 \quad 2 / 12$

(n121-132) $\quad 0.0$

Exanple: Le singe a chatouslle la grenouille que la chevre a bousculfe. CORRECT FORHS:

1,$2 ; 3,2$

3,$2 ; 1,2$

$2 / 12$

(Stage II: $E=.33$, df $=35$, $\left.\chi^{2}=121.213, p=.0001 *\right)$

\section{IMCORRECT FORAS:}

$\begin{array}{ll}1,2 ; 2,3 & 6 / 12 \\ 2,1 ; 1,3 & 1 / 12 \\ 3,2 ; 2,1 & 1 / 12 \\ 1,2 ; 3,1 & 1 / 12 \\ 1,3 ;-1- & 1 / 12\end{array}$


PATIENT PR

SUMHARY SCORE SHEET

(n133-144) S-S

Exaople: La grenouille qui a tenu la vache a attrape l'elephant.

CORRECT FORMS:

1,$2 ; 1,3$

1,$3 ; 1,2$

$2 / 12$

(Stage II: $E=.33$, df $=35$,

$\left.\chi^{2}=303.032, \dot{p}=.0001 *\right)$

INCORRECT FORMS:

1,$2 ; 2,3$

$10 / 12$

(Mi45-156) Active Conjouned these

Exanple: Le lapin a frappe la vache et la chevre. CORRECT FORHS:

$\begin{array}{lc}1,2+3 & 11 / 12 \\ 1,3+2 & --\end{array}$

(Stage II: $\mathrm{E}=1$, df $=11$, $1,3+2$

11112

$\left.\chi^{2}=110.00, \mathrm{p} .0001 *\right)$

IMCORRECT FORHS:

$2,1+3$

$1 / 12$

(M157-168) Passive Conjoined Agent

Exaaple: La grenounlle a thé caresste par la chevre et la vache.

CORRECT FORMS:

$\begin{array}{lc}2+3,1 & 5 / 12 \\ 3+2,1 & --\end{array}$

(Stage II: $E=1, d E=11$, $2+3,1$
$3+2,1$

$5 / 12$

$\left.\not{\chi}^{2}=62.00, \mathrm{p}=.0001 *\right)$

INCORRECT PORHS:

$1,2+3 \quad 7 / 12$ 
PATIENT PR

SUMYARY SCORE SHEET

(J001-012) Direct object Control, Intransitive Verb

Exaople: La grenoulle a force le sange a bondar. CORRECT FORHS:

$$
1,2 ; 2 \mathrm{~V}
$$

$11 / 12$

(Stage II: $E=1.5, \mathrm{df}=7$,

$2 V_{i} i, 2$

$-$

$x^{2}=69.333, p=.0001 \%$ )

INCORRECT FORAS:

$$
1,2 ; 1 V
$$

$1 / 12$

(J013-024) Passivized Direct object Control, Intransitive Verb

Exapple: La vache a dts forcte par le lapan a danser. CORRECT FORMS:

2,$1 ; 1 V$

$8 / 12$

(Stage II: $E=1.5$, df $=7$,

$\mid V_{i}, 2,1$

$\chi^{2}=34.667, p=.0001 *$ )

INCORRECT FORHS:

$\begin{array}{ll}1,2 ; 1 V & 2 / 12 \\ 1,2 ; 2 V & 1 / 12 \\ 2,1 ; 2 V & 1 / 12\end{array}$

(J025-036) Truncated Causative

Exapple: Le lapina fat frapper la vache. CORRECT FORHS:

$1, x_{i} x_{2} 2$

$1,(x) ; x_{1} 2$

$-$

$-$

$x, 2 ; 1, x$

$-$

$x, 2 ; !,(x)$

$--$

INCOFRECT FORHS:

$$
1,2-\quad 11 / 12
$$

$1,1-\quad 1 / 12$

(J037-048) Causativetintransitive Verb

Exanple: La vache a hat danser le lapin. CORRECT FORMS:

$$
1,2 ; 2 \mathrm{~V}
$$

$12 / 12$

(Stage I: $E=.33, \mathrm{df}=35$,

$2 \mathrm{~V} ; \mathrm{I}, 2$

$$
\begin{aligned}
& \text { (Stage II: E: } 1.5, \mathrm{df}=7, \\
& \left.\chi^{2}=84.00, \mathrm{p}=.0001 \%\right)
\end{aligned}
$$

(J049-060) Direct object Control transitive Verb

Exasple: Le lapin a force la chevre a frapper la vache. CORRECT FORHS:

$\begin{array}{cc}1,2 ; 2,3 & 12 / 12 \\ 2,3 ; 1,2 & \cdots\end{array}$

(Stage 11: $E=.33, \mathrm{df}=35$, $\left.\chi^{2}=424.244, p=.0001 *\right)$

2,$3 ; 1,2$ 
PATIENT $P R$

SUMRARY SCORE SHEET

(J061-072) Passivized Direct Object ControltTransitive Verb

Exanple: La grenouille a dle forcte par l'elephant d caresser le singe. CORRECT FORHS:
2,$1 ; 1,3$
1,$3 ; 2,1$
$5 / 12$
$\left.\chi^{2}=175.759, \dot{p}=.0001 \%\right)$

(S.tage II: $E=.33, \mathrm{df}=35$,

INCORSELT FORMS:
1,$2 ; 2,3$
1,$3 ; 3,2$
$6 / 12$
$1 / 12$
(J073-084) Causative (Fatre-d)
Exanple: La grenouslle a last carasser le singe d l'slisphant. CORRECT FORMS:

$\begin{array}{ccc}1,3 ; 3,2 & 3 / 12 & \left.\chi^{2}=260.607, p=.0001 *\right) \\ 1,(3) ; 3,2 & -- & \\ 3,2 ; 1,3 & -- & \\ 3,2 ; 1,(3) & -- & \\ \text { INCORGECT FORMS: } & \\ 1,2 ; 2,3 & 3 / 12 \\ 1,(2) ; 2,3 & 6 / 12 & \end{array}$
(Stage II: $E=.33, \mathrm{df}=35$,

(j085-096) Causative (faire-pap)

Exaple: Le lapin a fatt frapper la vache par la chivre.

CORRECT FORMS:

1,$3 ; 3,2$

$3 / 12$

(Stage II: $E=.33, \mathrm{df}=35$,

$1,(3) ; 3,2$

$\chi^{2}=139.395, \mathrm{p}=.0001 \%$ )

3,$2 ; 1,3$

3,$2 ; 1,(3)$

$--$

$\cdot$

$\cdots$

INCORRECT FORMS:

$\begin{array}{ll}1,(2) ; 2,3 & 1 / 12 \\ 1,2 ; 3,2 & 2 / 12 \\ 1,2 ; 2,3 & 5 / 12 \\ 1 ; 2,-; 3,- & 1 / 12\end{array}$

(J097-108) Cleft Object-Causative (faire-par)

Exanple: C'est l'slephant que le singe a fait saisir par la grenouille. CORRECT FORMS:

$\begin{array}{ll}2,3 ; 3,1 & -- \\ 3,1 ; 2,3 & -- \\ 2,(3) ; 3,1 & -- \\ 3,1 ; 2,(3) & --\end{array}$

(Stage II: $E=.33, \mathrm{df}-35$,

INCORRECT FORHS:

$\begin{array}{ll}1,2 ; 2,3 & 1 / 12 \\ 1,2 ; 2,-; 3,2 & 1 / 12 \\ 2,1 ; 1,3 & 2 / 12 \\ 1,3- & 1 / 12 \\ 1,2 ; 3- & 1 / 12\end{array}$


304.

PATIENT PR

SUHAARY SCORE SHEET

(J109-120) Conjoined Causaive

Exasple: La grenoulle a lait frapper la vache et chatousller l'slephant par le singe. CORRECT FORMS:

1,$4 ; 4,2 ; 4,3 \quad \cdots$

Stage II: $E=.007$, dE $=1727$,

1,$4 ; 4,3 ; 4,2 \quad--$

4,$2 ; 4,3 ; 1,4 \quad--$

4,$3 ; 4,2 ; 1,4 \quad \cdots$

$1,(4) ; 4,2 ; 4,3 \quad--$

INCORRELT FORMS:

$1,(2) ; 2,3 ; 3,4 \quad 1 / 12$

$1,2+3 ; 2+3,4 \quad 3 / 12$

$1,3+4 ; 2,4 \quad 1 / 12$

$1,(2) ; 2,4 ; 4,3 \quad 1 / 12$

1,$4 ; 2,3 \quad 1 / 12$

1,$2 ; 3,4 \quad 2 / 12$

1,$2 ; 3+4,2 \quad 1 / 12$

$2,1+3 ; 1+3,4 \quad 1 / 12$

2,$3 ; 1,4 \quad 1 / 12$

(J121-132) CausativetOa!ive

Example: L'elephant a fait apporter le sange d la grenouille par la vache. CORRECT FORMS:

1,$4 ; 4,2,3 \quad 1 / 12$

(Stage II: $E=.063, d f=287$,

$1,(4) ; 4,2,3 \quad 1 / 12$

$4,2,3 ; 1,4 \quad-\cdots$

$4,2,3 ; 1,(4) \quad$-- TOTAL CORRECT: $2 / 12$

INCORRECT FORMS:

1,$2 ; 3,4 \quad 1 / 1,1$

$1 ; 2,-2,-4 \quad 1 / 12$

1,$3 ; 3,2 ; 2,4 \quad 1 / 12$

1,$3 ; 3,2-\quad 1 / 12$

1,$2 ; 2,3 ; 3,4 \quad 3 / 12$

$1,(2) ; 2,3,4 \quad 1 / 12$

$1 ; 2,-3,4 \quad 1 / 12$

1,$2 ; 4,3 \quad 1 / 12$ 
(J133-144) Causativets-S relative Exaaple: La grenoullle a fait chatoulller l'slephant par le singe qui a frappes la vache. CORRECT FORMS:

$\begin{array}{ll}1,3 ; 3,2 ; 3,4 & - \\ 1,3 ; 3,4 ; 3,2 & - \\ 3,2 ; 3,4 ; 1,3 & - \\ 3,4 ; 3,2 ; 1,3 & - \\ 3,4 ; 1,3 ; 3,2 & -\end{array}$

(Stage II: $E=.007$, df $=1727$, $\left.\chi^{2}=4559.525, \mathrm{p}<.0001 \div\right)$

INCORRELT FORMS:

$\begin{array}{ll}1,2 ; 3,4 & 5 ; 12 \\ 1,3 ; 2,3 ; 3,4 & 1 / 12 \\ 1,3 ; 4,2 & 1 / 12 \\ 3,1 ; 2,4 & 1 / 12 \\ 1,2 ; 4,3 & 1 / 12 \\ 1,2 ; 2,3,4- & 1 / 12 \\ 1,3 ; 3,2 ; 2,4 & 1 / 12 \\ 1,2+3,4 & 1 / 12\end{array}$

(J!+5-15i) $\$-s$ relativetionjoned thene

Exasple: L'sléphant qua a chatouille la vache te le singe a frappé la grenouille. CORGECT FORMS:
$1,2+3 ; 1,4$
$4 i 12$
$1,3+2 ; 1,4$
$1 / 13$
$1,4 i 1,2+3$
$1,4,1,3+2$

$\begin{array}{ll}1,2+3 ; 3+3 ; 1,4 & 1112 \\ 4,1 ; 3,2 & 1 / 12 \\ 1,2+3 ; 2+3,4 & 2 ! 12 \\ 1,3+2 ; 3+2,4 & 2 / 12 \\ 1,2+3 ; 2,4 & 1 / 12\end{array}$

-- TOTAL CORREIT: $5 / 12$

(Siage II: $E=.042, \mathrm{~d}^{5} 288$, $\left.x^{2}=654.763, \dot{p}=.004.\right)$

INCJPSECT FORYE:

(J157-168) Conjoined clausts-4hPs (no deletion)(Baseline)

Exappla: La grenouille a frappe le singe et la vache a chatoualls l'slephart. CORRECT FORMS:

$$
\begin{array}{ll}
1,2 ; 2,4 & 71 ! 2 \\
3,4 ; 1,2 & --
\end{array}
$$

(Sfage II: $E=.083, \mathrm{dE}=143$, $\left.\chi^{2}=662.651, p=.0001 \%\right)$

INCORPECT FORMS:

$\begin{array}{ll}1,2+3 ; 2+3,4 & 1 / 12 \\ 4,2 ; 3,1 & 1 / 12 \\ 1,2 ; 4,3 & 2 / 12 \\ 1,3 ; 2,4 & 1 / 12\end{array}$


PATIENT PR

SUMHARY SCORE SHEET

(6001-012) Dative-Thene clibicized

Exauple: La chévre l'a offert d la vache. CORSECT FORMS:

$1,2,3 \quad 2=p$

$1,2,3219$

$-$

$1,2,3219$

(Stage I: $E=2, \mathrm{df}=5$,

INCOREECT FORMS:

$\begin{array}{ll}2,3-2=8 & 1 / 12 \\ 1,-33 & 5 / 12 \\ 1,3- & 6 / 12\end{array}$

(6013-024) Dative-fual cliticized

Exasple: La vache lua a reas la chévre.

CORRECT FORHS:

$1,3,2 \quad 2=\mathrm{P}$

$1 / 12$

$5 / 12$

$1,3,2$ 2IP

(Stage I: $E=2, d f=5$,

$\chi_{2}=49.00, p=.0001 * 1$

INCORRECT FORMS:

$1,3-\quad \quad 11112$

$2,3,-2=p \quad 1 / 12$

(6025-036) Causative-Thene cliticized

Exauple: Le lapin l'a fast tenar par la chevre. CORRELI FORMS:

1,$3 ; 3,2 \quad 2=$

1,$3 ; 3,2$ IIP

3,$2 ; 1,32=p$

3,$2 ; 1,3$ 2IP

$\left.\chi^{2}=19.00, p=.0019: *\right)$

INCORRECT FORMS:

$\begin{array}{ll}1,3- & 8 / 12 \\ 1 ; 3- & 3 / 12 \\ 1 ; 3,1- & 1 / 12\end{array}$

(6037-048) Causative-Causee sliticized

Exanple: L'elephant lus a fast attraper la grenouille. CORRECT FORAS:

1,$2 ; 2,32=p$

1,$2 ; 2,321 P$

2,$3 ; 1,2 \quad 2=p$

2,$3 ; 1,2$ 2IP

(Stage I: $E=.33$, df $=35$,

$x 2=212.122, p=.0001 \%$ )

$-$

$-$

-.

CRPECT FORMS:

1,3-

$12 / 12$

(Stage I: $E=.33, d f=35$, $\chi^{2}=42.244, p=.0001 *$ ) 
(604'-060) Causative-Reflexive "Causer'= 'Thene"

Exaple: La vache se fast saisir par le lapin. CORRECT PORMS:

$$
\begin{array}{lll}
3,2=1 & 211 ? & \\
1,(3) ; 3,2=1 & 41 ! 2 & \\
3,2=1 ; 1,(3) & -- & \\
1,3 ; 3,2=1 & -- & \\
3,2,2=1 ; 1,3 & -- & \text { TOTALL CORRECT: } 6 / 12
\end{array}
$$

(Stage I: $E=.33$, df $=35$, $\left.x^{2}=151.516, \dot{p}=.0001 \div\right)$

INDEREET PORMS:
1,3
$3 / 12$
$x, 3 x=p$
$3 i ! 2$

(6061-072) Causative-Reflexite Cususes

Exanple: La chivre fait se extper la vache. CORRE:T FOPMS:

$\begin{array}{lc}1,3 ; 3,2=3 & -- \\ 3,2=3 ; 1,3 & -- \\ 1,(3) ; 3,2=3 & 1 / 12 \\ 3,2=3 ; 1,(3) & --\end{array}$

(Stage I: $E=.15$, df $=80$,

$X^{2}=241.483, p=.0001 \%$ )

$3, \hat{2}=3 ; i,(3) \quad \cdots \quad$ TOTAL CORRECT: $1 / 12$

INCORREET FORMS;

$\begin{array}{ll}i,(2) ; 2,321 p & 1 / 12 \\ 3,1 & 3 / 12 \\ 1,3 & 5 / 12 \\ 1,(3), 3,2=1 & 1 / 12 \\ 1- & 1 / 12\end{array}$

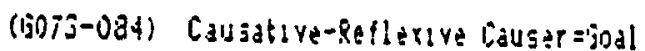

Example: La vache se lait reastate la churre par le lapin. CORRECT FORAS:
$4,3,2=1$
1,$4 ; 4,3,2=1 \quad$-.
$4,3,2=! ; 1,4 \quad--$
$1,(4) ; 4,3,2=1 \quad$-.
$4,3,2=1 ; 1,(4) \quad \cdots$

Stage I: $E=.67$, df $=17$,

INLORRELT FORHS:

$\begin{array}{ll}4,2=1,3 & 1 / 12 \\ 1 ;-, 3,4 & 1 / 12 \\ 1,3,4 & 2 / 12 \\ 1 ; 3+4,- & 1 / 12 \\ 1,3,-44 & 1 / 12 \\ 1,3 ; 3,4 & 4 / 12 \\ 1,(3) ; 3,4 & 1 / 12 \\ 1,(4) ; 4,3,- & 1 / 12\end{array}$


PATIENT PR

SUMMARY SCORE SHEET

(6ij85-036) Causative-Reflexive Causer $=60 a l$, Truncated

Exasple: La chture se faut offrar le lapan. CORPECT FORMS:

$$
\begin{aligned}
& x, 3,2=1 \quad x=p \quad- \\
& x, 3,2=1 \text { XIP } \quad-- \\
& 1, X ; X, 3,2=1 \quad X=P \quad-- \\
& 1, x ; x, 3,2=1 \text { XIP } \quad--
\end{aligned}
$$

IMCORRECT FORMS:

$\begin{array}{lr}1- & 1 / 12 \\ 1, X X=P & 1 / 12 \\ 1,3- & 10 / 12\end{array}$

(6097-108) Causative-Thene cliticized, Pruncated

Exanple: La chevre le falt seprer. CORRECT FORMS:

$$
\begin{aligned}
& 1, x ; x, 2 \quad x=P \quad 2=p \quad \ldots \\
& \text { - } 1, x ; x, 2 \text { XIP } 2 \mathbb{P} \quad- \\
& X, 2 ; 1, x \quad X=P \quad 2=P \quad-- \\
& x, 2 ; 1, x \text { Xip } 2 I P \quad- \\
& 1, x ; x, 2 \text { XIP } 2=P \quad-
\end{aligned}
$$

(Stage I: $E=.67, \mathrm{df}=17$, $\left.\chi^{2}=140.299, \mathrm{p}=.0001 \%\right)$

INCORRECT FORMS:

$$
\begin{array}{lr}
1,- & 11 / 12 \\
x-X=p & 1 / 12
\end{array}
$$

(6109-120) Causative-Reflexive "Causer"="Thene", Truncated

Exanple: La chevre se fast bousiuler.

CORRECT FORMS:

$x, \hat{z}=1 \quad x=$

$x, 2=1 \quad x \in P$

(Stage I: $E=.33, \mathrm{df}=35$,

$1,(x) ; x, 2=1 \quad x=p \quad \cdots$

$1,(x) ; x, 2=1$ IIP $\quad-$

$1, x ; x, 2=1 \quad x=p \quad--$

$\left.\chi^{2}=357.577, p=.0001 \%\right)$

INCORRECT FORHS:

$\begin{array}{lr}1- & 11 / 12 \\ 2,1=2 & 1 / 12\end{array}$

(6121-132) Causative-Thene=Causee clitucized, Irtransitive Verb

Exauple: L'slephant le fait trenbler.

CORRECT FORMS:

1,$2 ; 2 V 2=\mathrm{P}$

1,$2 ; 24214$

$2 V_{i} 1,2 \quad 2=p$

$2 V ; 1,221 P$

IMCORRECT FORMS:

I,-

$202=p$
(Stage I: $E=6, d f=1$, $\left.\chi^{2}=8.333, p=.0039\right)$ 
PATIENT PR

SUMMARY SCORE SHEET

(6133-144) Cleft ob ject(CO2) vith Stylistic Inversion

Exaople: C'est le lapin qu'a flatte l'el ephant. CORRECT FORHS:

2,1

$-\cdot$

(Stage II: $E=6, d f=1$,

$\gamma^{2}=12.00, p=.0005:$ )

INCORRECT FORMS:

$1,2 \quad 12 / 12$

(9145-156) Subject-0bject relative vith Stylistic Inversion

Exaple: Le lapin qu'a gratte l'tlephant a frappet le singe.

CORRECT FORMS:

2,$1 ; 1,3$

$2 / 12$

(Stage II: $E=.33, d f=35$,

1,$3 ; 2,1$

$\chi^{2}=157.577, p=.0001 \%$ )

INCORRECT FORHS:

$1, \hat{\therefore} ; 2,3$

$6 / 12$

1,$2 ; 1,3$

$4 / 12$

(B157-168) Objecb-Object relative vith Stylistic Inversion

Exaaple: Le lapin a gratté la chivre qu'a eabrassése le singz. CORRECT FORMS:

$\begin{array}{ll}1,2 ; 3,2 & - \\ 3,2 ; 1,2 & -\end{array}$

(Stage II: $E=.33$, df $=35$,

3,$2 ; 1,2$

$-$

$\left.\chi^{2}=424.244, p=.0001 \div\right)$

INCQRRECT FORMS:

1,$2 ; 2,3 \quad 12 / 13$ 
Table A.B.1. Summary Results of Control of

\% Correct

Active

100

Truncated Passive

Dative

Conjoined

Object-Object Relative

Subject-Subject Relative

Active Conjoined Theme

Direct Object Control, Intransitive Verb

Truncated Causative

Causative + Intransitive Verb

Direct Object Control + Transitive Verb

Dative-Theme cliticized

Dative-Goal cliticized

Causative-Theme cliticized

Causative-Causee cliticized

Causative-Reflexive Causer $=$ Theme

Causative-Reflexive Causer $=\mathrm{Goal}$

Causative-Reflexive Causer $=$ Goal, Truncated

Causative-Theme cliticized, Truncated

Causative-Reflexive Causer $=$ Theme, Truncated

Causative-Theme=Causee cliticized, Intransitive Verb

Passive

Cleft Object

Object-Subject Relative

Passive Conjoined Agent

Causative ( Falre-par)

Causative + Dative

Conjoined Clauses 4 NPs (No Deletion) (Baseline)

Object-Object Relative with Stylistic Inversion

Dative Passive

Subject-Object Relative

SS Relative + Conjoined Theme

Passivized Direct Object Control, Intransitive Verb

Conjoined Causative

Causative + SS Relative

Cleft-Object Dative

Passivized Direct Object Control + Transitive Verb

Causative (Faire-à )

Cleft-Object Causative ( Faire-par )

Subject-Object Relative with Stylistic Inversion 
Figure A.B.1. Accuracy Rate of Control OF - 'Sentence Contrasts 1'

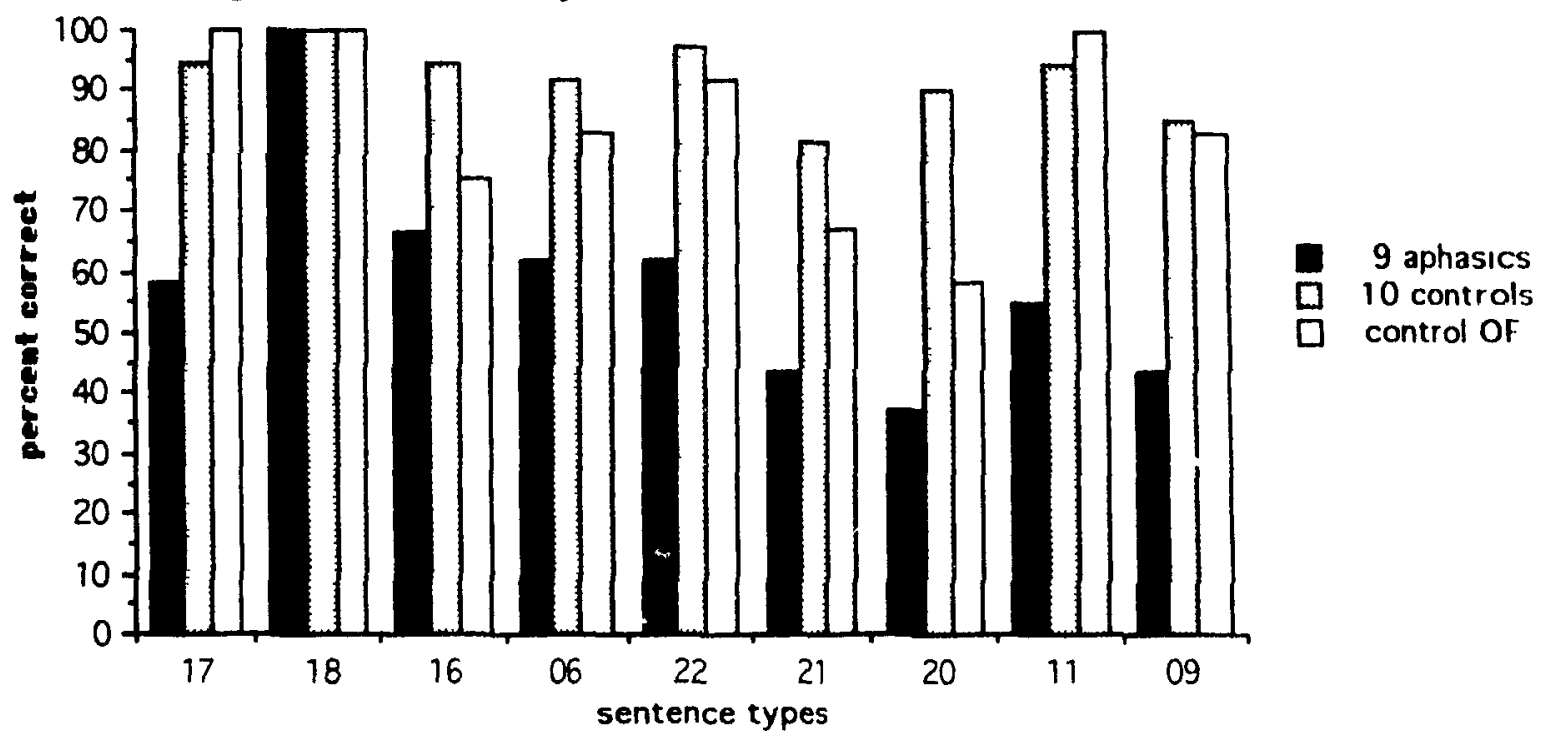

[17] Truncated Causative

[18] Causative + Intransitive Verb

[16] Passivized Direct Object Control, Intransitive Verb

[06] Dative Passive

[22] Causative ( Faire-par)

[21] Causative ( Faire-à )

[20] Passivized Direct Object Control + Transitive Verb

[11] Object-Object Relative

[09] Subject-Object Relative 
CONTROL OF

SUMMARY SCORE SHEET

(n001-012) A2

Exanple: La grenouslle a frappe le sunge. CORRECT FORHS: 1,2 $\$ 2 / 12$

(Stage II: $E=6, d f=1$, $\left.\chi^{2}=12.00, p=.0005 *\right)$

(nO13-024) P2

Exanple: Le singe a tte frappt par la grenoullle. CORRECT FORMS:

2,1

$11 / 12$

(Stage II: $E=6, d f=1$, $\left.y^{2}=8.333, p=.0039 \%\right)$

INCORRECT FORMS:

1,2

$1 / 12$

(M025-036) Truncated Passives

Exanple: Le sange a tét frappes. CORRECT FORHS:
$x, 1$
$12 / 12$
$\left.x^{2}=12.00, \quad \mathrm{p}=.0005 \%\right)$

(Stage I: $E=6$, df $=1$,

(n037-048) CO2

Exanple: C'est la vache que le lapin a eabrassee. CORRECT FORMS:
2,1
$11 / 12$

(Stage II: $E=6, d f=1$,

$\left.\chi^{2}=8.333, p=.0039 \%\right)$

INCORRECT FORHS:

1,2

$1 / 12$

(H049-060) A3

Example: Le lapin a confie la vache a la chèrre. CORRECT FORHS:

$$
1,2,3
$$

$12 / 12$

(Stage II: $E=2, d f=5$, $\chi^{2}=60.00, \mathrm{p}=.0001 \%$ )

(m061-072) P3

Exanple: L'el sphant CORRECT FORHS:

$3,1,2$

$10 / 12$

(Stage II: $E=2$, df $=5$,

$\not f=39.00, p=.0001 \%)$

INCORRECT FORHS:

$1,2,3 \quad 1 / 12$

$3,2,1 \quad 1 / 12$

(n073-084) CO3

Exauple: C'est la chevre que le lapin a donnte l la vache.

CORRECT FORHS:

$2,1,3$

$8 / 12$

(Stage II: $E=2, \mathrm{df}=5$,

$\left.\gamma^{2}=28.00, p=.0001 \%\right)$

INCORRECT FORHS:

$1,2,3 \quad 4 / 12$


CONTROL OF

SUMMARY SCORE SHEET

(n085-095) CON

Exauple: Le singe a gratte le lapin et a caresse l'tlephant.

CORRECT FORKS:

1,$2 ; 1,3$

1,$3 ; 1,2$

$12 / 12$

(Stage II: $E=.33, \mathrm{df}=35$,

$\left.X^{2}=424.244, p=.0001 \%\right)$

(H097-108) S-0

Exaple: Le singe que le lapin a saist a bouscule la chevre.

CORRECI FORMS:

2,$1 ; 1,3$

$10 / 12$

(Stage II: $E=.33$, df $=35$,

1,$3 ; 2,1$

$-\cdot$

$\left.\chi^{2}=296.971, p=.0001 \div\right)$

INCORRECT FORHS:

1,$2 ; 2,3 \quad 1 / 12$

2,$1 ; 2,3 \quad 1 / 12$

(n109-120) 0-5

Exauple: La cherre a trappe le lapin qui a saisi la vache.

CORRECT FORMS:

1,$2 ; 2,3$

2,$3 ; 1,2$

$11 / 12$

(Stage II: $E=.33, \mathrm{df}=35$,

$\chi^{2}=357.77, \mathrm{p}=.0001 *$ )

INCORRECT FORMS:

1,$2 ; 1,3 \quad 1 / 12$

(n121-132) $0-0$

Exanple: Le singe a chatousllé la grenourlle que la chevre a bouscul se. CORRECT FORMS:

$$
1,2 ; 3,2
$$

3,$2 ; 1,2$

$12 / 12$

(Stage II: $E=.33, \mathrm{df}=35$,

$\left.\eta^{2}=424.244, p=.0001 \%\right)$

(n133-144) S-S

Exauple: La grenouslle qus a tenu la vache a attrape l'tlephant. CORRECT FORMS:

1,$2 ; 1,3$

$12 / 12$

(Stage II: $E=.33, d f=35$,

1,$3 ; 1,2$

$\left.\chi^{2}=424.244, p=.0001 \%\right)$

(n145-156) Active Conjoined these

Exanple: Le lapin a frappe la vache ot la chevre. CORRECT FORHS:

$1,2+3$

$12 / 12$

(Stage II: $E=1$, df $=11$,

$1,3+2$ 
CONTROL OF

SUMHARY SCORE SHEET

(m157-168) Passive Conjoined Agent

Exauple: La grenouille a the caresste par la chevre et la vache.

CORRECT FORHS:

$2+3,1$

$3+2,1$

11112

(Stage II: $E=1, d f=11$,

$\left.\chi^{2}=110.00, \mathrm{p}=.0001 *\right)$

INCORRECT FORHS:

$1+2,3$

$1 / 12$ 
CONTROL OF

SUMMARY SCORE SHEET

(Jo01-012) Direct Object Control, Intransative Verb

Exapple: La grenourlle a force le singe d bondzr. CORRECT FORMS:

$$
\begin{array}{lcc}
1,2 ; 2 V & 12 / 12 & \left.X^{2}=84.00, P .0001 *\right) \\
2 V ; 1,2 & -- &
\end{array}
$$

(Stage II: $E=1.5, \mathrm{df}=7$,

(jo13-024) Passivized Durect object Control, Intransituve Verb

Exauple: La vache a sté forcese par le lapin à danser. CGRPECT FORMS:

2,$1 ; 16 \quad 9 / 12$

(Stage II: $E=1.5, d r=7$, $1 V_{i} 2,1$

$\left.\lambda^{2}=48.00, p=.0001 \%\right)$

INCORRECT FORMS:

1,$2 ; 2 v$ $3 / 12$

(j025-036) Truncated Causative

Exaaple: Le lapsn a fait frapper la vache. CORPEDT FORYMS:

$1, x ; x, 2$

$1,(x) ; x, 2$

$x, 2 ; 1, x$

$x, 2 ; 1,(x)$

$12 / 12$

Stage I: $E=.33$, df $=3.5$ $X^{2}=424.244, p=.0001 \%$ )

$--$

-- TOTAL CORGETT: $12 / 12$

(J037-048) Causativetintransitive Verb

Exanpla: La vache a falt dansep le lapan. CORRECT FORMS:

$$
1,2 ; 2 V
$$

$12 / 12$

$2 V ; 1,2$

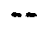

(Stage II: $E=1.5, \mathrm{df}=7$, $\mathcal{X}^{2}=84.00, p=.0001 \%$

(j04?-JEO) Darect Object Controltiransitive Vepb

Exanple: Le lapin a forces la chesure a frapper la vache. CORRECT FORMS:

$$
\begin{array}{cc}
1,2 ; 2,3 & 12 / 12 \\
2,3 ; 1,2 & -.
\end{array}
$$

(Stage II: $E=.33, \mathrm{df}=35$,

(J061-072) Passavized Darect object Controltiransitive Verb

Exaaple: La grenoulle a tts forcée par l'slisphant a caresser le singe.

CORRECT FORMS:

2,$1 ; 1,3$

$7 / 12$

1,$3 ; 2,1$

INCORRECT FORHS:

1,$2 ; 2,3$
$--$

$5 / 12$
(Stage II: $E=.33, d f=35$,

$\chi^{2}=212.122, p=.0001 \%$ 
316.

CONTROL DF

SUMAARY SSORE SHEET

(J073-084) Causative (Faire-d)

Exauple: La grenouslle a last caresser le singe d l'al ephant. CORRECT FORHS:

$$
\begin{array}{lcc}
1,3 ; 3,2 & -- & \\
1,(3) ; 3,2 & 7112 & \\
3,2 ; 1,3 & -- & \\
3,2 ; 1,(3) & -- & \text { TOTAL CORRECT: } 7 / 12
\end{array}
$$

(Stage II: $E=.33$, cit $=35$, $\chi^{2}=187.88, \mathrm{p}=.0001 \%$ )

$\begin{array}{ll}\text { INCORRECT FORMS: } & \\ 1,(2) ; 2,3 & 1 / 12 \\ 1,(x) ; x, 2,3 & 1 / 12\end{array}$

(J085-096) Causative (Faire-par)

Exauple: Le lapin a fast frapper la vache par la chevre. CORRECT FORHS:

$$
\begin{array}{lcl}
1,3 ; 3,2 & 3 / 12 & \\
1,(3) ; 3,2 & 8 / 12 & \\
3,2 ; 1,3 & -- & \\
3,2 ; 1,(3) & -- & \text { TOTAL CORRECT: } 11 / 12
\end{array}
$$

(Stage II: $E=.33$, df $=35$,

INCORRECT FORMS:

$$
1,2 ; 2,3 \quad 1 / 12
$$

(J097-108) Cleft Ob ject-Causative (Falre-par)

Exanple: C'est l'slephant que le singe a fast saisir par la grenouille. CORRECT FORHS:

$\begin{array}{lc}2,3 ; 3,1 & -- \\ 3,1 ; 2,3 & -- \\ 2,(3) ; 3,1 & 2 / 12 \\ 3,1 ; 2,(3) & -- \\ & \\ \text { ORRECT FORMS: } & \\ 1,(3) ; 3,2 & 8112 \\ 1,(2) ; 2,3 & 2 / 12\end{array}$

(J10y-120) Conjusned Causative

Exaaple: La grenouille a fast frapper la vache et chatouiller l'blephant par le singe. CORRECT FORMS:

1,$4 ; 4,2 ; 4,3$

1,$4 ; 4,3 ; 4,2$

4,$2 ; 4,3 ; 1,4 \quad \cdots$

4,$3 ; 4,2 ; 1,4 \quad--$

$1,(4) ; 4,2 ; 4,3 \quad 9 / 12 \quad$ TOTAL CORRECT: $9 / 12$

INCORRECT FORHS:

$1,(3) ; 3,2 ; 3,4 \quad 1 / 12$

$1,2+3 ; 1,4 \quad 1 / 12$

$1,(2) ; 2,3 ; 2,4 \quad 1 / 12$ 
(J121-132) Causativetoative

Exaple: L'elephant a fast apporter le singe d la grenouslle par la vacha. CORRECT FORHS:

$$
\begin{aligned}
& 1,4 ; 4,2,3 \quad-\quad \text { (Stage II: } E=.063 \text {, df }=191 \text {, } \\
& \left.1,(4), 4,2,3 \quad 11 / 12 \quad X^{2}=1924.607, \mathrm{p}=.0001 \%\right) \\
& 4,2,3 ; 1,4 \quad-- \\
& 4,2,3 ; 1,(4) \quad-- \text { TOTAL CORRECT: } 11 / 12
\end{aligned}
$$

INCORRECT FORMS:

$$
1,(1) ; 4,3,2 \quad 1 / 12
$$

(J133-144) Causative+S-s relative

Exanple: La grenoulle a fast thatouiller l'elephant par le singe qui a frappes la vache. CORRECT FORHS:

$\begin{array}{lc}1,3 ; 3,2 ; 3,4 & 9 / 12 \\ 1,3 ; 3,4 ; 3,2 & -- \\ 3,2 ; 3,4 ; 1,3 & -- \\ 3,4 ; 3,2 ; 1,3 & -- \\ 3,4 ; 1,3 ; 3,2 & --\end{array}$

INCORRE:T FORMS:

$\begin{array}{ll}1,2 ; 2,3 ; 2,4 & 1 / 12 \\ 1,2 ; 2,3 ; 3,4 & 1 / 12 \\ 1,3 ; 3,2 ; 2,4 & 1 / 1 ?\end{array}$

(J145-15E) S.S relativetConjoined thene

Exaple: b'al tephant qui a chatouills la vache et le singe a frappé la grenouslle. CORRELT FORMS:

$1,2+3 ; 1,4$

$1,3+2 ; 1,4$

1,$4 ; 1,2+3$

1,$4 ; 1,3+2$

$9 / 12$

$1 / 12$

(Stage II: $E=.042, \mathrm{df}=287$, $\left.\chi^{2}=1988.096, p=.0001: 1\right)$

$\cdots$

-. TOTAL CORRECT: $10 / 12$

INCORRECT FORHS:

$$
\begin{array}{ll}
1,2+4 ; 1,3 & 1 / 12 \\
1,4+3 ; 1,2 & 1 / 12
\end{array}
$$

(J157-168) Conjoined clauses-4NPs (no deletion) (Baseline)

Exanple: La grenouslle a frappé le singe et la vache a chatouille l'elephant. CORRETT FORHS:

$$
\begin{array}{cc}
1,2 ; 3,4 & 11 / 12 \\
3,4 ; 1,2 & -.
\end{array}
$$$$
\text { (Stage II: } E=.083, \mathrm{df}=143 \text {, }
$$$$
\left.\mathcal{X}^{2}=1457.832, p=.0001 \%\right)
$$

INCORRECT FORHS:

$$
1,2+3 ; 1,4 \quad 1 / 12
$$


CONTROL OF

SUMMARY SCORE SHEET

(BDO1-012) Oative-Thent cliticized

Exaple: La cherre l'a offert a la vache. CORRECT FORMS:

$1,2,3 \quad 2=\mathrm{P}$

$1,2,32 \mathrm{tP}$

12/12 TOTAL CORRECT: $12 / 12$

(Stage I: $E=2, d f=5$,

$\left.\chi^{2}=60.00, p=.0001 *\right)$

(6013-024) Dative-6oal claticized

Eraaple: La vache lui a renis la chère.

CORKECT FORMS:

$1,3,2 \quad 2=p$

$1,3,221 \mathrm{P}$

$12 / 12$

TOTAL CORFETT: 12/12

(Stage I: $E=2, \mathrm{df}=5$,

$\chi 2=60.00, p=.0001 \%)$

(G025-036) Causative-Thene clitisized

Exaaple: Le lapin l'a fast tenir par la chevre. CORRECT FORHS:

1,$3 ; 3,2 \quad 2=$

1,$3 ; 3, ?$ 2IP

$12 / 12$

3,$2 ; 1,32=p$

3,$2 ; 1,321 \mathrm{P}$

$--$

-- TOTAL CORPECT: $12 / 12$

(5037-048) Causative-Causea clitacized

Example: L'slsphant lul a falt attraper la grenouille. CORRECT FORMS:

1,$2 ; 2,32=p$

1,$2 ; 2,32 \mathbb{I P}$

$--$

2,$3 ; 1,2,2=9$

$131 ! 3$

2,$3 ; 1,221 \mathrm{P}$

$-$

-. TOTAL CORRECT: $12 / 12$

(Stage I: $E=.33, \mathrm{df}=35$, $\left.\gamma^{2}=424.244, p=.0001 \%\right)$

(bit:?-0EO) Causative-Reflexive "Causer" ="Theae"

Example: La vache 5e falt $5 a j 5 l$ par le lapin. CORRECT FORMS:

$\begin{array}{lc}3,2=1 & 12 / 12 \\ 1,(3) ; 3,2=1 & -- \\ 3,2=1 ; 1,(3) & -- \\ 1,3 ; 3,2=1 & -- \\ 3,2,2=1 ; 1,3 & --\end{array}$

(Stage I: $E=.33$, df $=35$, $\left.\gamma^{2}=424.244, p=.0001 *\right)$

(G001-072) Causative-Reflexive Cause:

Example: La chevre falt se serrer la vache. CORRECT FORHS:

1,$3 ; 3,2=3$

$3,2=3 ; 1,3$

$1,(3) ; 3,2=3$

$3,2=3 ; 1,(3)$

$-$

$\cdots$

(Stage II: $E=6$, df $=1$,

$\left.\chi^{2}=12.00, p=.0005 *\right)$

INCORRECT FORHS:

1,$2 ; 2,3219 \quad 1 / 12$

1,$3 ; 3,2211 \quad 1 / 12$

$1,2 \quad 3 / 12$

$1 ; 1,2 \quad 1 / 12$

$3,2=1 \quad 6 / 12$

Stage I: $E=.15, d f=80$, $\left.\chi^{2}=308.15, p=.0001 \%\right)$ 
CONTROL OF

SUANARY SCORE SHEET

(6073-084) Causative-Reflexive Causer $=60 \mathrm{~d}$

Exanple: La vache se last reaettre la chevre par le lapin. CORRECT FORMS:

$4,3,2=1$

$12 / 12$

(Stage II: $E=2, d f=5$,

1,$4 ; 4,3,2=1$

$--$

$\left.\chi^{2}=60.00, p=.0001:\right)$

$4,3,2=1 ; 1,4 \quad \cdots$

$1,(4) ; 4,3,2=1 \quad--$

$4,3,2=1 ; 1,(4) \quad \cdots$

(G085-036) Causative-Reflexive Causer=ioal, Truniated

Exaple: La chevre se fast offerr le lapin.

CORRECT FORHS:

$x, 3,2=1 \quad x=p \quad \quad=-$

(Stage I: $E=2, d f=5$,

$x, 3,2=1 \quad x \in P \quad 12 / 12$

$1, x ; x, 3,2=1 \quad x=p \quad--$

$1, x ; x, 3,2=1$ XIP $\quad--\quad$ TOTAL CORREST: $12 / 12$

(6097-108) Causative-Thene cliticized, Iruncated

Example: La chévre le fat serper.

COPRECT FORMS:

$1, x_{i}, x_{1}, 2 \quad x=P 2=P \quad--$

$1, x_{i} x_{1} 2$ XIP alp $12 / 12$

$x, 2 ; 1, x \quad x=P \quad 2=P \quad-$

$x, 2 ; 1, x$ xif $2 \mathbb{P} \quad--$

$1, x ; x_{1} 2 x \in P 2=P \quad--\quad$ TOTAL CORRECT: $12 / 12$

(6i09-120) Causative-Ratlex:ve 'Causer'=" Theae", Truncated

Exasple: La cheyre se falt bousruler.

CQRRECT ORMS:

$x, 2=1 \quad x=p$

$x, 2=1 \quad x+P$

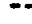

$\chi^{2}=60.00, p=.0001 \%$ )

(Stage I: $E=.33, \mathrm{df}=35$, $\left.X^{2}=424.244, \mathrm{p}=.0001 \%\right)$

$1,(x) ; x, 2=1 \quad x=p \quad \cdots$

$1,(x) ; x, 2=1$ xip $\quad-$.

$1, x ; x, 2=1 \quad x=p \quad--\quad$ TOTAL CORRECT: $12 / 12$

(G121-132) Causative-Thene=Causee cliticazed, Intransitive Verb

Exanple: L'blephant le fait trenbler. CORRECT FORMS:

$1, \hat{2} ; 2 V \quad 2=p$

1,$2 ; 2 V 21 P$

$2 V ; 1,2 \quad 2=P$

$2 V ; 1,221 P \quad--\quad$ TOTAL CORRECT: $12 / 12$

12112

(Stage I: $E=6$, df $=1$,

$\left.\chi^{2}=12.00, p=.0005 \%\right)$

(Stage I: $E=1.5, d I=7$, $\left.\chi^{2}=84.00, \mathrm{p}=.0001 \%\right)$ 
CONTROL OF

SUMHARY SCORE SHEET

(6133-144) Cleft Object(CG2) with Stylistic Inversion

Exauple: C'est le lapin qu'a flatte l'slephant.

CORRECT FORHS:

2,1

(Stage II: $E=6, \mathrm{df}=1$,

$\left.\chi^{2}=12.00, \mathrm{p}=.0005 \%\right)$

INCORRECT FORHS:

$1,2 \quad 12 / 12$

(15145-156) Subject-Object relative vith Stylistic Inversion

Exauple: Le lapin qu'a gratte l'slephant a frapps le singe.

CORRECT FORMS:

2,$1 ; 1,3$

1,$3 ; 2,1$

$1 / 12$

(Stage II: $E=.33$, df $=35$,

$\left.\chi^{2}=175.759, \mathrm{p}=.0001 \%\right)$

INCORRECT FORMS:

1,$2 ; 2,3$

1,$2 ; 1,3$

$5 / 12$

$6 / 12$

(6157-168) Object-obje:t relative vith Stylistic Inversion

Example: Le lapin a gratts la charre qu'a eabrasste le singe. CORGEGT FORMS:

$$
1,2 ; 3,2
$$

3,$2 ; 1,2$

$11 / 12$

(Stage II: $E=.33$, df $=35$,

$\left.\chi^{2}=357.577, \mathrm{p}=.0001 *\right)$

INCORRECT FORMS:

1,$2 ; 2,3$

$1 / 12$ 
Table A.B.2. Summary Results of Control RL

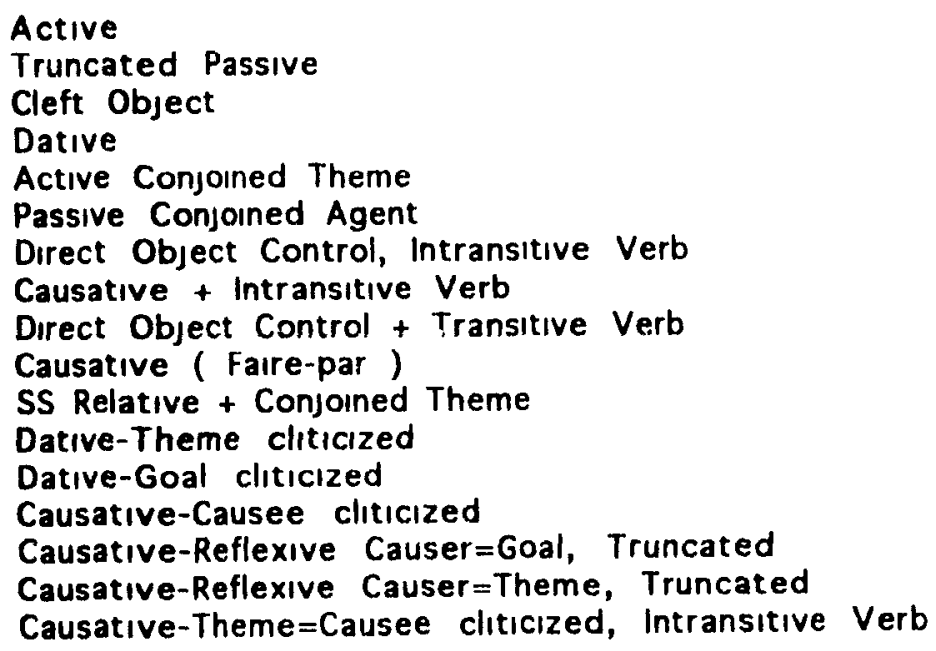

Dative Passive

Object-Object Relative

Subject-Subject Relative

Conjoined Causative

Causative-Theme clitıcized, Truncated

Cleft-Object with Stylistic Inversion

Cleft-Object Dative

Subject-Object Relative

Causative (Faire-à )

Causative + Dative

Causative + SS Relative

Passivized Direct Object Control + Transitive Verb

Subject-Object Relative with Stylistic Inversion 
Figure A.B.2. Accuracy Rate of Control RL - 'Sentence Contrasts 1'

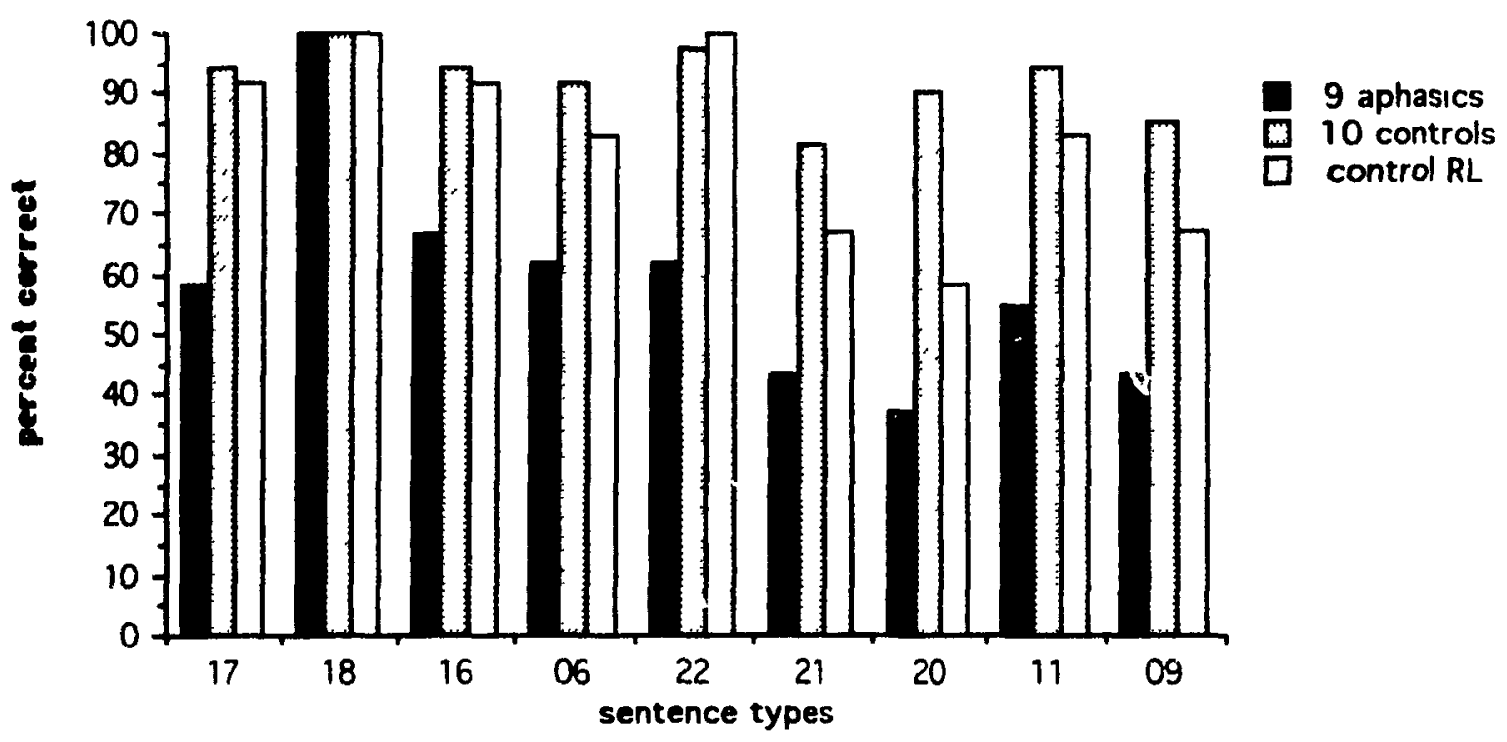

[17] Truncated Causative

[18] Causative + Intransitive Verb

[16] Passivized Direct Object Control, Intransitive Verb

[06] Dative Passive

[22] Causative ( Faire-par)

[21] Causative (Faire-à )

[20] Passivized Direct Object Control + Transitive Verb

[11] Object-Object Relative

[09] Subject-Object Relative 
CONTROL RL

SUMHARY SCORE SHEET

(nO01-012) A2

Exanple: La grenouslle a frappe le singe. CORRECT FORHS:

1,2

$12 / 12$

(Stage II: $E=6, d f=1$,

$\chi^{2}=12.00, \mathrm{p}=.0005 \%$ )

(Ho13-024) P2

Exauple: Le singe a dte frappt pat la grenouslse. CORRECT FORMS:

2,1

$11 / 12$

(Stage II: $E=6, d f=1$, $\left.X^{2}=8.333, p=.0039 \%\right)$

INCORRECT FORHS:

1,2
$\begin{aligned} & \text { Exanple: Le singe d tte frapps. } \\ & \text { CORRECT FORHS: } \\ & x, 1\end{aligned} \quad \begin{aligned} & \text { Stage I: } E=6, \text { df }=1, \\ & \left.\chi^{2}=12.00, P=.0005 \%\right)\end{aligned}$

(M037-048) CO2

Exaaple: C'est la vache que le lapin a eabrassée. CORRECT FORAS: 2,1 $12 / 12$

(Stage II: $E=6, \mathrm{~d} f=1$, $X^{2}=12.00, p=.0005 \%$

(n049-060) A3

Example: Le lapin a confit la vache a la chevre. CORRECT FORMS:
$1,2,3$
$12 / 12$
(Stage II: $E=2, d f=5$,
$\chi^{2}=60.00, \mathrm{p}=.0001 *$ )

(H061-072) P3

Exauple: L'elephant a ette donnt au singe par la grenouslle. CORRECT FORAS:

$3,1,2 \quad 10 / 12$

(Stage II: $E=2$, df $=5$,

$\left.\mathcal{X}^{2}=39.00, p=.0001 \%\right)$

INCORRECT FORMS:

$\begin{array}{ll}1,3,2 & 1 / 12 \\ 1,2,3 & 1 / 12\end{array}$

(n073-084) CO3

Exaple: C'est la shevre que le lapin a donnee d la vache.

CORRECT FORHS:

$2,1,3$

$8 / 12$

(Stage II: $E=2, d f=5$,

$\left.\chi^{2}=28.00, p=.0001:\right)$

INCORRECT FORMS:

$1,2,3 \quad \quad 4 / 12$


CONTROL RL

SUMHARY SCORE SHEET

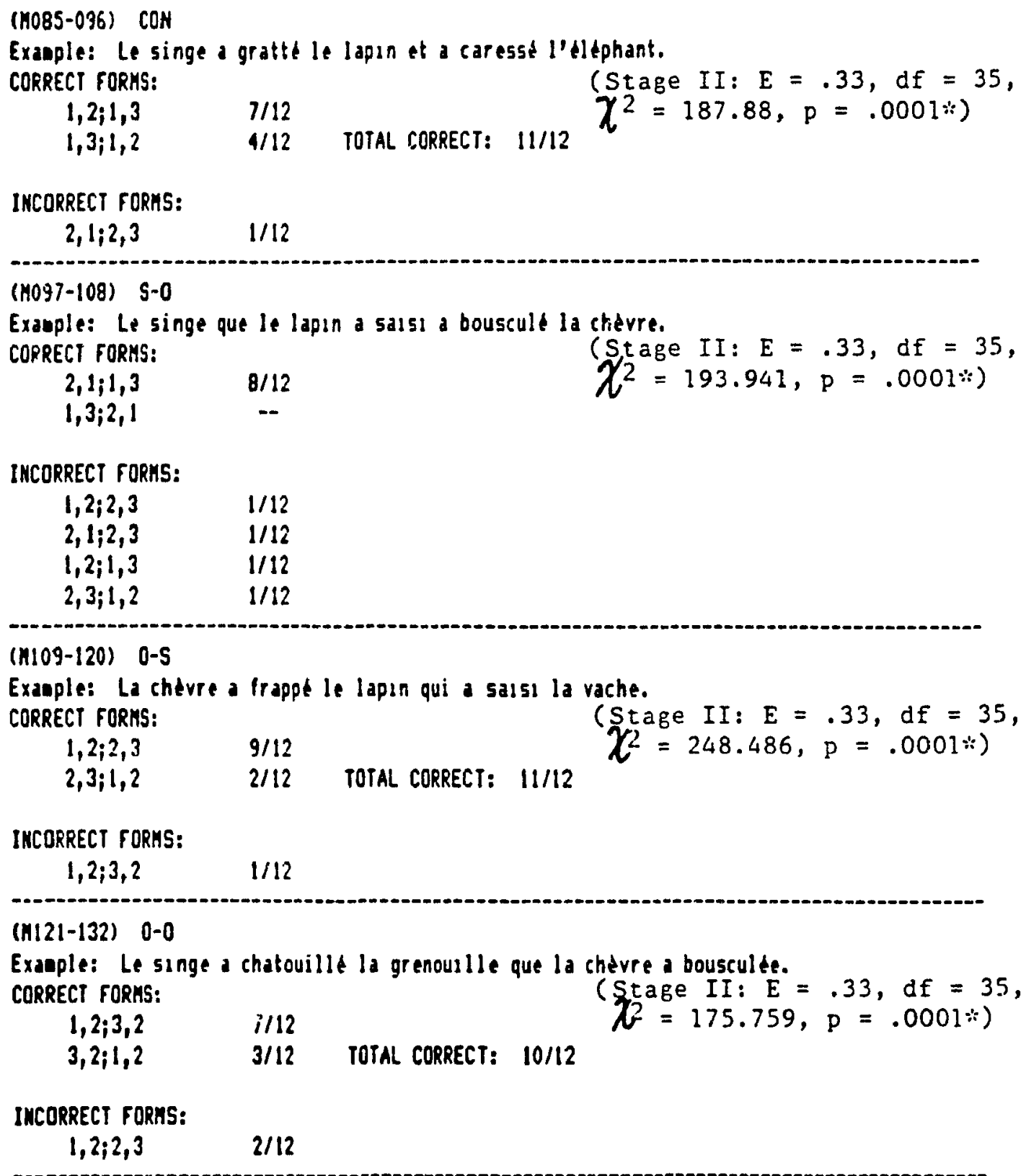

(ni33-144) S-5

Exaple: La grenouille qui a tenu la vache a attrapt l'ellephant. CORRECT FORHS:

1,$2 ; 1,3 \quad 6 / 12$

1,$3 ; 1,2 \quad 4 / 12$ TOTAL CORRECT: $10 / 12$

(Sfage II: $E=.33$, df $=35$, $\left.\chi^{2}=157.577, p=.0001 \%\right)$

IMCORRECT FORIS:

1,$2 ; 2,3 \quad 2 / 12$


COHTROL RL

SUMHARY SCORE SHEET

(nl45-156) Active Conjoined These

Exaaple: Le lapin a frappt la vache et la chevre. CORRECT FORMS:

$1,2+3 \quad 11 / 12$

$1,3+2 \quad 1 / 12$ TOTAL CORRECT: $12 / 12$

(Stage II: $E=1$, df $=11$,

$\left.\chi^{2}=110.00, p=.0001 *\right)$

(M157-168) Passive Conjoined Agent

Exauple: La grenouille a dte caresste par la cherre et la vache.

CORRECT FORHS:

$2+3,1$

$8 / 12$

$3+2,1$

$4 / 12$

TOTAL CORRECT: $12 / 12$

(Sfage II: $E=1, \mathrm{df}=11$,

$\left.V^{2}=68.00, \mathrm{p}=.0001 \%\right)$ 
CONTROL RL.

SUAMARY SCORE SHEET

(JCO1-012) Direct Object Control, Intransitive Verb

Exasple: La grenouslle a forces le singe d bondir. CORRECT FORKS:

$$
\begin{array}{lcl}
1,2 ; 2 V & 12 / 12 & \left.\chi^{2}=84.00, \mathrm{p}=.0001 \%\right) \\
2 V_{i} !, 2 & -- &
\end{array}
$$

(Stage II: $E=1.5, \mathrm{df}=7$,

(J013-024) Passivized Direst object Control, Intransitive Verb

Exaaple: La vache a ete forcte par le lapin d danser. CORRELT FORHS:

$\begin{array}{lc}2,1 ; 1 V & 11 / 12 \\ 1 V ; 2,1 & \cdots\end{array}$

(Stage II: $E=1.5, \mathrm{df}=7$, $1 V_{i} 2,1$

$\left.\chi^{2}=69.333, \mathrm{p}=.0001 \%\right)$

IHCORRECT FORMS:

1,$2 ; 2 \mathrm{~V} \quad 1 / 12$

(J025-036) Truncated Causative

Exaple: Le lapin a falt frapper la vache. COPSECT FORMS:

$$
\begin{array}{lcl}
1, x ; x, 2 & -- & \\
1,(x) ; x, 2 & 11 / 12 \\
x, 2 ; 1, x & -- & \\
x, 2 ; 1,(x) & -- & \text { TOTAL CORRECi: } 11 / 12
\end{array}
$$

(Stage I: $E=.33, \mathrm{df}=35$, Stage I: $E=.33$, df $=35$
$\left.\chi^{2}=357.577, p=.0001 *\right)$

INCORRECT FORHS:

$$
x,(1) ; 1,2
$$

$1 / 12$

(J03i-048) CausativetIntransitive Verb

Example: La vache a lait danser le lapin. COSBELTT FORMS:

$$
1,2 ; 2 \mathrm{~V}
$$

$24 ; 1,2$

$12 / 12$

(Stage II: $E=1.5, \mathrm{df}=7$,

$$
\left.\chi^{2}=84.00, \mathrm{p}=.0001 *\right)
$$

(5019-060) Durect Ob ject Controltiransitive Verb

Exaaple: Le lapin a forcs la chevre d frapper la vache. CORRECT FORHS:

1,$2 ; 2,3$

2,$3 ; 1,2$

$12 / 12$

(Stage II: $E=.33, \mathrm{df}=35$, $\left.\chi^{2}=424.244, \mathrm{p}=.0001 \%\right)$

(J061-072) Passavized Direct Object Controltiransitive Verb

Exauple: La grenouille a tte forcé par l'ellephant d caresser le singe. CORRECT FORHS:

2,$1 ; 1,3$

1,$3 ; 2,1$

$5 / 12$

$2 / 12$

TOTAL CORRECT: $7 / 12$

(Stage II: $E=.33, \mathrm{df}=35$,

IMCORRECT FORHS:

$\begin{array}{ll}1,2 ; 2,3 & 3 / 12 \\ 2,3 ; 1,2 & 2 / 12\end{array}$


CONTROL RL

SUMMARY SCORE SHEEI

(J073-084) Causative (Fatra-d)

Exaple: La grenoullle a falt caresser le singe d l'ellephant.

CORRECT FORMS:

1,$3 ; 3,2$

$1,(3) ; 3,2$

$8 / 12$

3,$2 ; 1,3$

3,$2 ; 1,(3)$

$--$

-. total correct: $8 / 12$

(Stage II: $E=.33$, $\mathrm{df}=35$,

$\left.\chi^{2}=212.122, \dot{p}=.0001 \%\right)$

INCORRECT FORMS:

$1,(2) ; 2,3$

$3 / 12$

2,$3 ; 1,(2)$

$1 / 12$

(J085-09E) Causative (Fatre-par)

Exaaple: Le lapin a fast frapper la vache par la chevre. CORRECT FORMS:

1,$3 ; 3,2$

$1,(3) ; 3,2$

3,$2 ; 1 ; 3$

3,$2 ; !,(3)$

$--$

$7 / 12$

$--$

S/12 TDTAL CORRECT: $12 / 12$

(Stage II: $E=.33, \mathrm{df}=35$,

$x^{2}=212.22, \mathrm{p}=.0001 \div$ )

Jogi-108) Cleft object-Causative (Faure-par)

Example: C'est l'sléphant que le singe a fait saisir par la grenoullle. CORRECT FORMS:

2,$3 ; 3,1$

3,$1 ; 2,3$

$-$

(Stage II: $E=.33$, df $=35$,

$2,(3) ; 3,1$

$--$

$\left.\chi^{2}=84.85, \mathrm{p}=.0001 \%\right)$

3,$1 ; 2,(3)$

$3 / 12$

-- total coprett: 3/1?

INCORRECT FORMS:

$\begin{array}{ll}1,(2) ; 2,3 & 3 / 12 \\ 2,(1) ; 1,3 & 2 / 12 \\ 1,(3) ; 3,2 & 3 / 12 \\ 1,3 ; 2,(1) & 1 / 12\end{array}$

(J109-120) Conjoined Causative

Exanple: La grenouille a fast frapper la vache et chatousller l'tlephant par le singe. CORRECT FORHS:

1,$4 ; 4,2 ; 4,3$

1,$4 ; 4,3 ; 4,2 \quad 1 / 12$

(Stage II: $E=.007, \mathrm{df}=1727$,

4,$2 ; 4,3 ; 1,4 \quad 5 / 12$

4,$3 ; 4,2 ; 1,4 \quad 2 / 12$

$1,(4) ; 4,2 ; 4,3$ 2/12 TOTAL CORRECT: $10 / 12$

INCORRECT FORMS:

$1,(2) ; 2,3 ; 2,4 \quad 1 / 12$

4,$3 ; 4,1 ; 2,4 \quad 1 / 12$ 
CONTROL RL

SUMHARY SCORE SHEET

(J121-132) Causabive+Dative

Exaple: L'elephant a last apporter le singe d la grenoull le par la vache. CORRECT FORMS:

$$
\begin{array}{lcll}
1,4 ; 4,2,3 & -- & & \\
1,(4) ; 4,2,3 & 3 / 12 & \\
4,2,3 ; 1,4 & -- & \\
4,2,3 ; 1,(4) & 5 / 12 & \text { TOTAL CORRECT: } 8 / 12
\end{array}
$$

$$
\begin{aligned}
& \text { (Stage II: } E=.063, \text { df }=191, \\
& \left.\chi^{2}=623.02, \mathrm{p}=.0001 *\right)
\end{aligned}
$$

INCDRRECT FORMS:

$1,(2) ; 3,2,4 \quad 2 / 12$

$1,(2), 2,3,4 \quad 1 / 12$

$4,3,2 ; 1,(4) \quad 1 / 1 !$

(J133-144) Causativets-S relative

Exanple: La grenoulle a fast chatoulller l'el ephant par le singe qui a frappe la vache. CORRECT FORMS:

1,$3 ; 3,2 ; 3,4 \quad 3 / 12$

(Stage II: $E=.007, d f=1727$,

1,$3 ; 3,4 ; 3,2 \quad 1 / 12$

$3, \hat{2} ; 3,4 i 1,3 \quad--$

3,$4 ; 3,2 ; 1,3 \quad 3 / 12$

2,$4 ; 1,3 ; 2,2$ 1/12 TOTAL CORRECT: $8 / 12$

INCORRECT FORMS:

1,$3 ; 3,2 ; 2,4 \quad 1 / 12$

$1,(2) ; 2,4 ; 2,3 \quad 1 / 12$

$1,(2) ; 2,3 ; 3,4 \quad 1 / 12$

$3,-; 3,4 ; 2,1 \quad 1 / 12$

(J145-156) S-S relativetionjarned thene

Exanple: L'slephant qus a chatouslles la vache et le singe a frappé la grenouslle. CORRECT FORHS:

$1,2+3 ; 1,4 \quad 6 / 12$

$1,3+2 ; 1,4 \quad 2 / 12$

1,$4 ; 1,2+3 \quad 3 / 12$

1,$4 ; 1,3+2 \quad 1 / 12$ TOTAL CORRECT: $12 / 12$

(J157-168) Conjoined clauses-4MPs (no deletion)(Baseline)

Exapple: La grenouille a frappe le singe et la vache a chatoullle l'eltphant. CORRECT FOEMS:

1,$2 ; 3,4$

3,$4 ; 1,2$

$4 / 12$

$7 / 12$

TOTAL CORRECT: $11 / 12$

(Stage II: $E=.042$, df $=287$, $\left.\chi^{2}=1178.572, \quad p=.0001 *\right)$

(Stage II: $E=.083$, df $=143$, $\left.\chi^{2}=783.133, p=.0001 \%\right)$

INCORRECT FORHS:

3,$4 ; 2,1 \quad 1 / 12$ 
CONTROL RL

SUMMARY SCORE SHEET

(6001-012) Dative-These cliticlied

Exanple: La chevre l'a offert d la vache. CORRECT FORMS:

$1,2,3 \quad 2=P$

$1,2,3249$

$12 / 12$

(Stage I: $E=2, d f=5$,

$\left.d^{2}=60.00, p=.0001 \div\right)$

(6013-024) Dative-6ual cliticized

Eranple: La vache lua a renis la chèvre.

CORRECT FORHS:

$1,3,22=P$

$1,3,221 \mathrm{P}$

$12 / 12$

(Stage I: $E=2, \mathrm{df}=5$,

$\chi^{2}=60.00, p=.0001 \%$ )

(6025-036) Causative-These cliticized

Exanple: Le lapin l'a falt tenar par la chevre. CORRECT FORMS:

$\begin{array}{cc}1,3 ; 3,22=p & 11112 \\ 1,3 ; 3,221 \mathrm{i} & -- \\ 3,2 ; 1,32=\mathrm{F} & -- \\ 3,2 ; 1,32 i p & --\end{array}$

(Stage I: E.33, df $=35$,

1,$3 ; 3,22=p$

$1 / 12$

$\left.\chi^{2}=357.577, p=.0001 *\right)$

3,$2 ; 1,32=1$

$-$

$-$

INCOPRECT FORMS:

1,$2 ; \hat{\imath}, 3 \quad 2=p \quad 1 / 12$

(1037-048) Causative-Causee cliticized

Exanple: L'tlephant luz a fait attraper la grenouslle. CORRELT FORMS:

$12 / 12$

Stage I: $E=.33, \mathrm{df}=35$

1,$2 ; 2,32=$

$--$

2,$3 ; 1,2$ 2=P

2,$3 ; 1,221 p \quad$-.

(6049-060) Causative Reflexive "Causer"= 'Thene"

Exaaple: La vache se falt salsir par le lapin. CORRECT FORMS:

$\begin{array}{lc}3,2=1 & 11112 \\ 1,(3) ; 3,2=1 & \ldots \\ 3,2=1 ; 1,(3) & -. \\ 1,3 ; 3,2=1 & .- \\ 3,2,2=1 ; 1,3 & -.\end{array}$

(Stage II: $E=6, \mathrm{df}=1$,

INCORRECT GORHS:

1,3 
CONTROL RL

SUMFARY SCORE SHEET

(6061-072) Causative-Reflexive Causes

Exaople: La chevre fat se serrer la vache. CORRECT FORHS:

$$
\begin{array}{lcl}
1,3 ; 3,2=3 & -. & \\
3,2=3 ; 1,3 & -- & \\
1,(3) ; 3,2=3 & 11 / 12 \\
3,2=3 ; 1,(3) & -. & \text { TOTAL CORRECT: } 11 / 12
\end{array}
$$

(Stage II: $E=3, d f=3$, $\left.X^{2}=28.667, p=.0001 *\right)$

INCORPECT FORMS:

$$
1,(3) ; 3 \mathrm{~V} \quad 1 / 12
$$

(6073-084) Causative-Rellexive Causer = Goal

Exanple: La vache se last reaettre la chevre par le lapan. CORPECT FORAS:

$\begin{array}{lc}4,3,2=1 & 10112 \\ 1,4 ; 4,3,2=1 & -- \\ 4,3,2=1 ; 1,4 & -- \\ 1,(4) ; 4,3,2=1 & 1 / 12 \\ 4,3,2=1 ; 1,(4) & --\end{array}$

(Stage II: $E=.67, \mathrm{df}=17$,

1,$4 ; 4,3,2=$

112

$$
\left.\chi^{2}=170.15, p=.0001 \%\right)
$$

$1,(4) ; 4,3,2=1$
$4,3,2=1 ; 1,(4)$

-. TOTAL CORRECT: $11 / 12$

INCORRECT FORMS:

$$
3,4,2=1
$$

$1 / 12$

(6085-096) Causative-Rellexive Causer= Goal, Truncated

Exaple: La cherre se fat offrip le lapin. CORRECT FORHS:

$x, 3.2=1 x=p \quad 12 / 12$

$x, 3,2=1$ XIP

$-\cdot$

$1, x_{i} x, 3,2=1 \quad x=p \quad \cdots$

$1, x ; x, 3,2=1 \quad x \in P \quad--$

(i097-108) Cousative-Theoe cliticized, Truncated

Example: La chture le last serrer. CORRECT FORHS:

$1, x ; x, 2 x=p \quad 2=p \quad 10 / 12$

$1, x ; x, 2$ XIP $2 I P \quad$-.

$X, 2: 1, x \quad X=P \quad 2=P \quad-$

$X, 2 ; 1, x$ XIP $2 I P \quad$-.

$1, x ; x, 2$ XIP $2=P \quad-$

INCORRECT PORMS:

1,$2 ; 2 V 2=p \quad 1 / 12$

$2, x ; x, 1 \quad x=p \quad 2=p \quad 1 / 12$

$($ Stage I: $E=.33, \mathrm{df}=35$,
$\left.V^{2}=424.244, p=.0001 \%\right)$

(Stage I: $E=2$, df $=5$,

$\left.\chi^{2}=60.00, p=.0001 *\right)$ 
CONTROL RL

SUWMARY SLORE SHEET

(6109-120) Causatuve-Reflexive 'Causer" $="$ Thene', Truncated

Exapple: La chlyre se falt bousculer. CORRECT FORMS:

$x, 2=1 \quad x=p \quad 12 / 12$
$x, 2=1 \quad x \in p \quad \cdots$
$1,(x) ; x, 2=1 \quad x=p$
$1,(x) ; x, 2=1 x \in P$
$1, x ; x, 2=1 x=p$

(Stage I: $E=6, \mathrm{df}=1$, $\left.\chi^{2}=12.00, p=.0005 \div\right)$

(G121-132) Causative-Theas=Causee cliticazed, Intransilive Verb

Exaaple: L'slephint le fast tresbler. CORRELT FORMS:

1,$2 ; 2 \vee 2=p \quad 12 / 1$ 1,$2 ; 2 \vee 21 P \quad$..

$2 V_{i} 1,2 \quad 2=P \quad--$

$2 V ; 1,2$ 2lP $\quad$-.

(E:33-144) Clelt ob je:t:(CO2) with Stylista: Inversion

Example: C'est le lapin qu'a flatt! l'sl ephant.

CORRECT FOFAS:

$2,1 \quad 10 / 1 ?$

(Stage I: $E=1.5, d f=7$, $\chi^{2}=84.00, \mathrm{p}=.0001^{\cdot}$ )

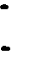

$$
\left.\chi^{2}=84.00, \mathrm{p}=.0001^{\prime}\right)
$$

INCORGECT FORHE:

INCORRECT FORHE:
1,2
-

(G145-156) Subject-0bjeit relative vith Stylistic Inversion

Exapple: Le lapin qu'a grattes l'elephant a frappes le singe.

CORRECT FORMS:

2,$1 ; 1,3$

1,$3 ; 2,1$

5112

(Stage II: $E=.33, d f=35$,

$\chi^{2}=90.91, p=.0001 \therefore$

(Stage II: $E=6, \mathrm{df}=1$,

$\chi^{2}=5.333, \mathrm{p}=.0209:$ )

INCORRECT FORMS:

$\begin{array}{ll}1,3 ; 1,2 & 1 / 12 \\ 1,2 ; 2,3 & 2 / 12 \\ 1,3 ; 2,3 & 1 / 12 \\ 1,2 ; 1,3 & 1 / 12 \\ 2,1 ; 2,3 & 1 / 12\end{array}$

(6157-168) Object-0b ject relative vith Stylistic Inversion

Exauple: Le lapin a gratte la chevre qu' a enbrasste le singe. CORRECT FORHS:

1,$2 ; 3,2$

3,$2 ; 1,2$

$2 / 12$

$9 / 12$

TOTAL CORRECT:

(Stage II: $E=.33, \mathrm{df}=35$,

$\left.\chi^{2}=248.486, p=.0001 \%\right)$

INCORRECT FORHS:

2,$3 ; 1,2 \quad 1 / 12$ 
Table A.B.3. Summary Results of Control LN

Active

\% Correct

Passive

100

Truncated Passive

Cleft Object

Dative

Conjoined

Active Conjoined Theme

Passive Conjoined Agent

Direct Object Control, Intransitive Verb

Passivized Direct Object Control, Intransitive Verb

Causative + Intransitive Verb

Passivized Direct Object Control + Transitive Verb

Causative (Faire-par )

SS Relative + Conjoined Theme

Conjoined Clauses 4 NPs (No Deletion) (Baselıne)

Dative-Goal cliticized

Causative-Therie cliticized

Causative-Reflexive Causer=Theme

Causative-Reflexive Causee

Causative-Reflexive Causer=Goal

Causative-Reflexive Causer $=$ Goal, Truncated

Causative-Reflexive Causer $=$ Theme, Truncated

Causative-Theme=Causee cliticized, Intransitive Verb

Cleft-Object Dative

Object-Object Relative

Subject-Subject Relative

Direct Object Control + Transitive Verb

Dative-Theme cliticized

Cleft-Object with Stylistic Inversion

Truncated Causative

Causative + Dative

Causative-Causee clitıcızed

Dative Passive

Causative-Theme cliticized, Truncated

Cleft-Object Causative ( Fare-par)

Subject-Object Relative

Causative (Faire-à )

Object-Object Relative with Stylistic Inversion

Causative + SS Relative 
Figure A.B.3. Accuracy Rate of Control LN - 'Sentence Contrasts 1 '

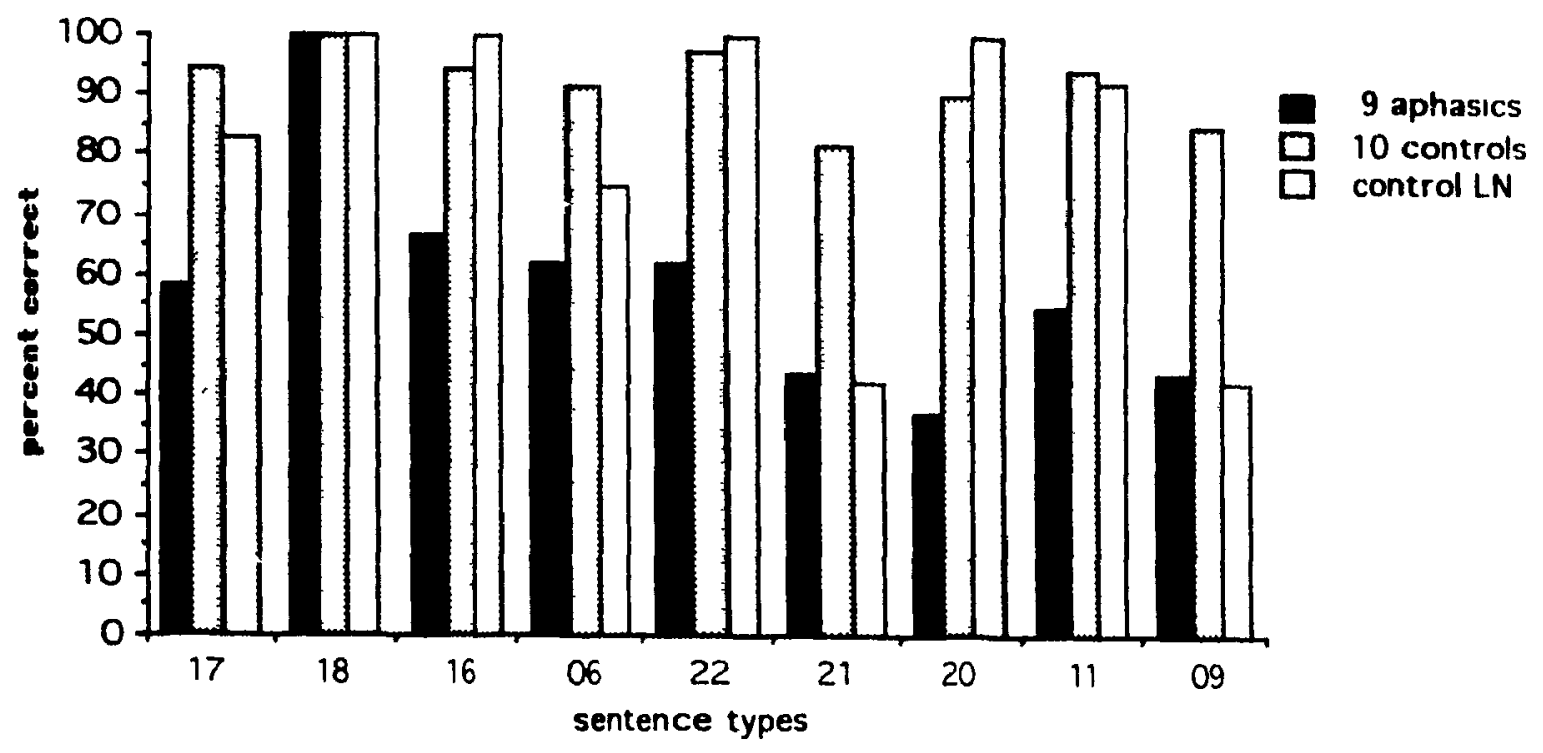

[17] Truncated Causative

[18] Causative + Intransitive Verb

[16] Passivized Direct Object Control, Intransitive Verb

[06] Dative Passive

[22] Causative (Falre-par)

[21] Causatıve (Farre-à )

[20] Passivized Direct Object Control + Transitive Verb

[11] Object-Object Relative

[09] Subject-Object Relative 
CONTROL LN

SUAKARY SCORE SHEET

(nO01-012) A2

Exaple: La grenouille a frappe le singe. CORRECT FORHS:

1,2

(no13-024) P2

Exauple: Le singe a tte trappe par la grenouille. CORRECT FORHS:

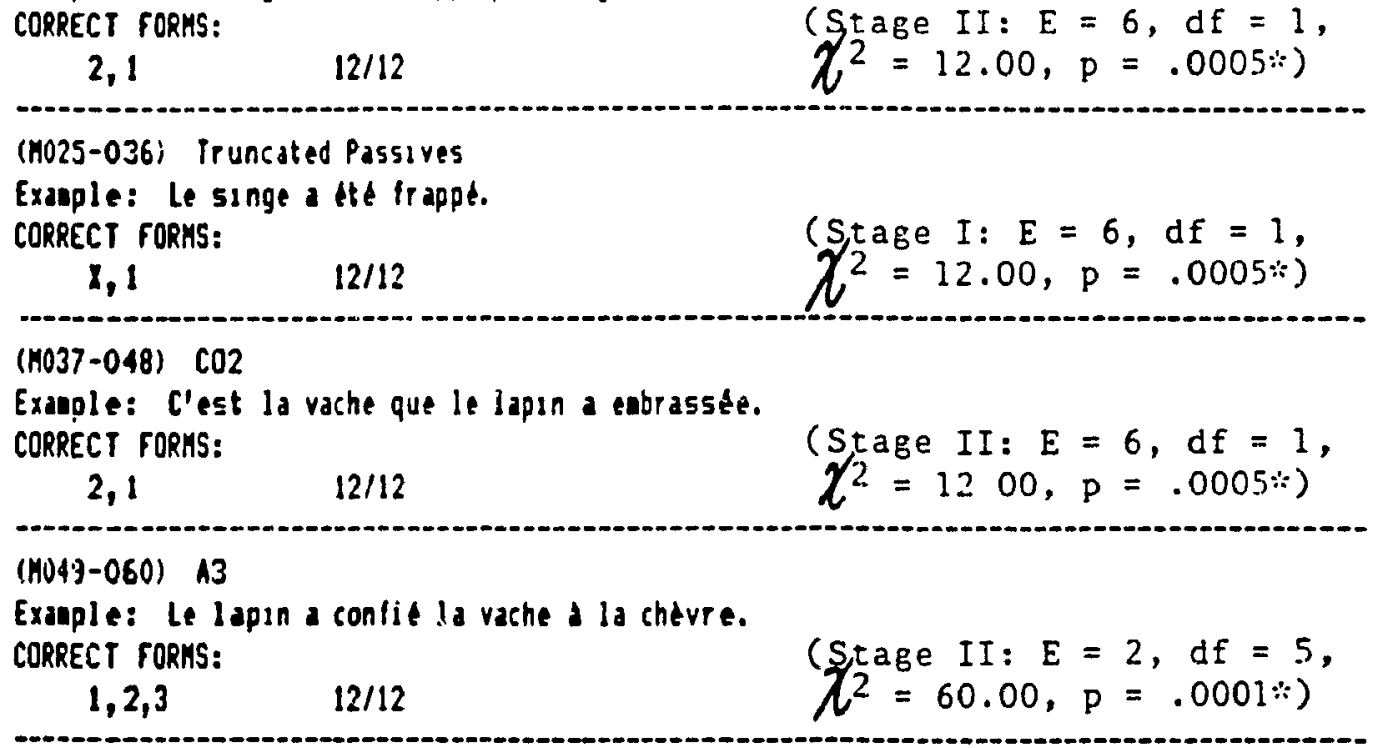

(n061-072) P3

Exauple: L'elephant a ett donne au singe par la grenoulle. CORRECT FORHS:

$3,1,2 \quad 9 / 12$

(Stage II: $E=6, d f=1$, $\chi=12.00, p=.0005 \%)$

$-$


CONTROL LN

SUMMARY SCORE SHEET

(n097-108) S-0

Exaaple: Le singe que le lapin a saisi a bouscule la chevre. CORRECT FORMS:

$$
\begin{array}{lc}
2,1 ; 1,3 & 5 / 12 \\
1,3 ; 2,1 & \cdots
\end{array}
$$

(Stage II: $E=.33, \mathrm{df}=35$,

IMCORRECT FORHS:

$\begin{array}{ll}2,1 ; 2,3 & 5 / 12 \\ 1,2 ; 1,3 & 1 / 12 \\ 1,2 ; 2,3 & 1 / 12\end{array}$

(miog-120) 0-5

Exauple: La chevre a frappt le lapin qui a sassi la vache. CORRECT FORHS:

1,$2 ; 2,3$

2,$3 ; 1,2$

$8 / 12$

(Stage II: $E=.33, \mathrm{df}=35$,

$\left.\chi^{2}=.230 .304, \mathrm{p}=.0001 \%\right)$

IMCORRECT FORHS:

1,$2 ; 1,3$

$4 / 12$

$($ (n121-132) $\quad 0-0$

Exanple: Le singe a chatouslle la grenouille que la chavre a bousculte.

CORRECT GORHS:

1,$2 ; 3,2$

3,$2 ; 1,2$

$10 / 12$

$1 / 12$

TOTAL CORRECT: $11 / 12$

(Stage II: E.33, df $=35$,

$\left.\chi^{2}=296.971, \mathrm{p}=.0001 *\right)$

IHCORRECT FORMS:

1,$2 ; 2,3$

$1 / 12$

(ni33-144) S-S

Exasple: La grenouslle qui a tenu la vache a attrapt l'elephant. CORRECT FORHS:

$$
\begin{array}{lc}
1,2 ; 1,3 & 11 / 12 \\
1,3 ; 1,2 & -.
\end{array}
$$

(Stage II: $E=.33$, df $=35$,

$\left.\chi^{2}=357.577, \mathrm{p}=.0001 *\right)$

INCORRECT FORAS:

1,$2 ; 2,3 \quad 1 / 12$

(M145-156) Active Conjorned these

Exanple: Le lapin a frappe la vache et la chevre. CORRECT FORHS:

$1,2+3$

$1,3+2$

$111 / 12$

$1 / 12$

TOTAL CORRECT: $12 / 12$

(Stage II: $E=1, \mathrm{df}=11$,

$\left.\pi^{2}=110.00, p=.0001 \%\right)$ 
CONTROL LN

SUHARY SCORE SHEET

(hi57-168) Passive Con joined Agent

Exaple: La grenoulle a lle caresste par la chevre et la vache. CORRECT FORIS:

$2+3,1$

$3+2,1$

$9 / 12$

$3 / 12$

(Stage II: $E=1, \mathrm{df}=11$,

TOTAL CORRECT: $12 / 12$

$\left.\chi^{2}=78.00, p=.0001 \%\right)$ 
CONTROL LN

SUMMARY SCORE SHEET

(so01-012) Direct Object Control, Intransative Verb

Exanple: La getnouille a force le singe a bondir. CORRECI FORMS:

1,$2 ; 2 V$

$12 / 12$

(Stage II: $E=1.5, \mathrm{df}=7$,

$2 V_{i} l, 2$

$-$

$\chi^{2}=84.00, \mathrm{p}=.0001 \div$ )

(j013-024) Passivized Direct object Control, intransitive Verb

Exanple: l.a vache a sta forcese par le iapin danser.

CORRECT FORMS:

2,$1 ; 10$

$1 V_{i}, 2,1$

$12 / 12$

(Stage II: $E=1.5, p=7$,

$\left.\chi^{2}=84.00, p=.0001 \%\right)$

(J025-036) Truncated Causative

Exanple: Le lapin a fait frapper la vache. CORRECT FORMS:

$$
\begin{aligned}
& 1, x ; x, 2 \\
& 1,(x) ; x_{1}, 2 \\
& 10 / 12 \\
& x, 2 ; 1, x \\
& x, 2 ; 1,(x) \\
& -\cdot \\
& \text {-- TOTAL CORGECT: (1)/12 }
\end{aligned}
$$

(Stage I: $E=.33$, df $=35$, $\chi^{2}=296.971, p=.0001 \%$ )

INCORRECT FORMS:
1,2
$1 / 12$
1,$2 ; 2 \mathrm{~V}$
$1 / 12$

(S037-048) Causativetintransitive Verb

Exauple: La vache a fait danser le lapin. CORRECT FORMS:

$$
\begin{aligned}
& 1,2 ; 2 V \\
& 2 V ; 1,2
\end{aligned}
$$

$12 / 12$

Stage II: $E=1.5, \mathrm{df}=7$,

$\left.\chi^{2}=84.00, p=.0001: 1\right)$

(5049-06D) Ourect object Controlt Transitive Verb

Exauple: Le lapin a forces la chture d frapper la vache. CORRECT FORMS:

$$
\begin{array}{cc}
1,2 ; 2,3 & 11112 \\
2,3 ; 1,2 & --
\end{array}
$$

(Stage 11: $E=.33, \mathrm{df}=35$, $\left.X^{2}=424.244, \dot{p}=.0001 *\right)$

INCORRECT FORMS:

$$
2,3 ; 3,1 \quad 1 / 12
$$

(J061-072) Passivized Diecet Objest Controltiransitive Verb

Exauple: La grenouslle a tte forcéte par l'elephant d caresser le singe. CORRECT FORHS:

$$
2,1 ; 1,3
$$

1,$3 ; 2,1$

$12 / 12$

(Stage II: $E=.33, \mathrm{df}=35$, $\left.\chi^{2}=424.244, p=.0001 \%\right)$ 
CONTROL LN

SUMAARY SCORE SHEET

(J073-084) Causative (Fare-d)

Exanple: La grenouille a last caresser le singe d l'bl éphant. CORRECT FORHS:

1,$3 ; 3,2$

$1,(3) ; 3,2$

$--$

3,$2 ; 1,3$

$5 / 12$

3,$2 ; 1,(3)$

-- TOTAL CORRECT: $5 / 12$

Stage II: $E=.33, \mathrm{df}=35$, $\chi^{2}=212.122, p=.0001 \%$ )

INCORPECT FORMS:

$1,(2) ; 2,3$

$7 / 12$

(J085-096) Causative (Fatre-par)

Exauple: Le lapin a fast frapper la vache par la chevre. CORREIT FORHS:

1,$3 ; 3,2$

$1,(3) ; 3,2$

$12 / 12$

(Stage II: $E=.33$, df $=35$, 3,$2 ; 1,3$

3,$2 ; 1,(3)$

$--$

-- TOTAL CORRECT: $12 / 12$

(J097-108) Cleft object-Causative (Faire-par)

Exanple: C'est l'eléphant que le singe a lait sassir par la grenoulle. CORRECT FORHS:
2,$3 ; 3,1$
$--$
3,$1 ; 2,3$
$-$
$2,(3) ; 3,1$
$8 / 12$
3,$1 ; 2,(3)$
-- TOTAL CORRECT: 8/12

(Stage II: $E=.33$, df $=35$,

IMCORRECT FORNS:
$1,(3) ; 3,2$
$3 / 12$
$2,(1) ; 1,3$
$1 / 12$

(J109-120) Con joined Causative

Exaaple: La grenoulle a fait frapper la vache et chatousllep l'ellephant gar le singe. CORRECT FORHS:
1,$4 ; 4,2 ; 4,3$
$1 / 12$
1,$4 ; 4,3 ; 4,2 \quad 1 / 12$
4,$2 ; 4,3 ; 1,4 \quad--$
4,$3 ; 4,2 ; 1,4 \quad--$

$\begin{array}{ll}1,(3) ; 3,2 ; 3,4 & 1 / 12 \\ 1,2 ; 4,3 & 4 / 12 \\ 1,3 ; 1,2 & 1 / 12\end{array}$

$1,(4) ; 4,2 ; 4,3 \quad 4 / 12$ TOTAL CORRECT: 6/12

(Stage II: $E=.007, \mathrm{df}=1727$,

INCORRECT FORHS: 
CONTROL LN

SUMMARY SCORE SHEET

(J121-132) Causativet Dative

Exaplei L'tlephant a fast apporter le singe a la grenouille par la vache. CORRECT FORHS:

1,$4 ; 4,2,3$

$1,(4) ; 4,2,3$

$4,2,3 ; 1,4$

$4,2,3 ; 1,(4)$

(Stage II: $E=.063, \mathrm{df}=191$,

$\chi^{2}=1638.893, p=.0001 \%$ )

$10 / 12$

-- TOTAL CORPECT: $\quad$ 10/12

INCORRECT FORHS:

$1,(3) ; 3,2,4$

$2 / 12$

(J133-144) CausativetS-S relative

Example: La grenouslle a fast chatousller l'el tphant par le singe qui a frappe la vache. CORRECT FORHS:

1,$3 ; 3,2 ; 3,4$

$3 / 12$

1,$3 ; 3,4 ; 3,2$

3,$2 ; 3,4 ; 1,3$

3,$4 ; 3,2 ; 1,3$

3,$4 ; 1,3 ; 3,2$

(Stage II: $E=.007, \mathrm{df}=1727$, $X^{2}=5702.382, \mathrm{p}<.0001^{\prime}$ )

INCORRECT FORMS:

1,$2 ; 3,4$

$2 / 12$

1,$3 ; 3,2 ; 2,4$

$1 / 12$

1,$3 ; 3,2 ; 1,4$

$5 / 12$

$1,(x) ; x, 2 ; 3,4$

$1 / 12$

(J145-156) S-S relativetionjoined These

Exaple: L'sl tophant qui a chatouslle la vache et le singe a frappt la grenouslle. CORRECT FORMS:

$1,2+3 ; 1,4$

$12 / 12$

(Stage II: $E=.042, \mathrm{df}=287$ $1,3+2 ; 1,4$ $\left.\chi^{2}=3416.667, p=.0001:\right)$

1,$4 ; 1,2+3$

1,$4 ; 1,3+2$

$-$

$-$

$-\infty$

(J157-168) Conjoined clauses-4NPs (no deletion)(Baseline)

Exanple: La grenouslle a frappt le singe et la vache a chatouills l'eltphant.

CORRECT FORHS:

$$
1,2 ; 3,4
$$

$12 / 12$

(stage II: $E=.083, \mathrm{df}=143$,

3,$4 ; 1,2$

$\left.\chi^{2}=1722,892, p=.0001 \%\right)$ 
CONTROL LN

SUMMARY SCORE SHEET

(6001-012) Dative-These cliticized

Exaple: La chevre l'a offert a la vache. CORRECT FORHS:

$\begin{array}{lc}1,2,32=p & 11 / 12 \\ 1,2,321 P & --\end{array}$

(Stage I: $E=2$, df $=5$,

$1,2,3219 \quad \cdots$

$\chi^{2}=49.00, \mathrm{p}=.0001 \%$ )

INCORRECT FORHS:

$3,2,1 \quad 2=p$

$1 / 12$

(io)13-0â4) Oative-foal cliticized

Exauple: La vache lus a reass la chivre. CORRECT FORMS:

$1,3,2$ 2=p

$1,3,2219$

$12 / 12$

(Stage I: $E=2, d f=5$,

$\left.\chi^{2}=60.00, p=.0001 *\right)$

(6025-036) Causative-Thene cliticized

Exapple: Le lapii l'a fast tenir par la chevre. CORRECT EORMS:

1,$3 ; 3,2 \quad 2=p$

1,$3 ; 3,2$ 2IP

$12 / 12$

(Stage I: $E=.33, d f=35$,

3,$2 ; 1,32=P$

$-$

3,$2 ; 1,3219$

$-$

$-$

(6037-048) Causative-Causee cliticized

Exaple: L'tlephant lua a fat attraper la grenouslle. CORRECT FORMS:

1,$2 ; 2,32=P \quad 10 / 12$

(Stage I: $E=.33, \mathrm{df}=35$,

1,$2 ; 2,321 P$

-.

2,$3 ; 1,22=P \quad \cdots$

2,$3 ; 1,2$ 2IP

$\chi^{2}=424.244, p=.0001 \%$ )

IMCORAECT FORHS:

1,$3 ; 3,2$ 2=P $\quad 2 / 12$

(6049-060) Causative-Reflexive "Causer" ="Theae"

Exapple: La vache se falt salsir par le lapin. CORRECT FORMS:

$3,2=1$

$12 / 12$

$\left.X^{2}=303.032, p=.0001 *\right)$

$1,(3) ; 3,2=1$

$--$

$3,2=1 ; 1,(3) \quad--$

1,$3 ; 3,2=1 \quad-$

$3,2,2=1 ; 1,3 \quad \cdots$

(Stage II: $E=6, \mathrm{df}=1$,

$X^{2}=12.00, p=.0005 \%$ ) 
CONTROL LN

SUMMARY SCORE SHEET

(6061-072) Causabive-Reflexive Causee

Exanple: La chivre fart se serper la vache. CORRECT FORMS:

$\begin{array}{lcc}1,3 ; 3,2=3 & -- & \text { (Stage II: } E=3, d f=3, \\ 3,2=3 ; 1,3 & -\ldots & \\ 1,(3) ; 3,2=3 & 12 / 12 & \end{array}$

(G073-084) Causative-Reflerive Causer =lios]

Exaaple: La vache se falt renettre la chavre par le lapin. CORRECT FORMS:

$\begin{array}{lc}4,3,2=1 & 11 / 12 \\ 1,4 ; 4,3,2=1 & -- \\ 4,3,2=1 ; 1,4 & -- \\ 1,(4) ; 4,3,2=1 & 1 / 12 \\ 4,3,2=1 ; 1,(4) & --\end{array}$
(Stage II: $E=.67$, df $=17$,
$\left.X^{2}=202.985, p=.0001 *\right)$

TOTAL CORRECT: $12 / 12$

(G085-096) Causative-Peflexive Causer $=60 a 1$, Truncated

Exauple: La chevpe se fast offrir le lapin.

CORRECT FOPMS:

$x, 3,2=1 \quad x=P$

$x, 3,2=1$ XIP

$11 / 12$

$1, x ; x, 3,2=1 \quad x=8 \quad 1 / 12$

$1, x ; x, 3,2=1 \quad x \neq P \quad-$
(Stage I: $E=.67, \mathrm{df}=17$, $\left.\chi^{2}=202.985, \mathrm{p}=.0001 \therefore\right)$

TOTAL CORRECT: $12 / 12$

(G097-108) Causative-Theae Claticized, Truncated

Exaple: La chevre le fast serrer. CORRECT FORMS:

$1, x ; x, 2 \quad x=p \quad 2=p \quad q / 12$

(Stage I: $E=.33$, df $=35$,

$1, x ; x, 2$ XIP $2 \& P \quad-$

$x, 2 ; 1, x \quad x=p \quad 2=p \quad--$

$x, 2 ; 1, x$ XIP $2 \mathbb{A P} \quad-$

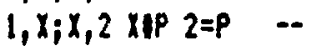

INCORRECT FORMS:

$1,(2) ; 2,22=p \quad 3 / 12$

(6109-120) Causative-Reflexive "Causer " $=$ 'Thene", Truncated

Exaple: La chère se fait bousculer.

CORRECT FORHS:

$x, 2=1 \quad x=p \quad 12 / 12$
$x, 2=1 \quad x i p \quad--$
$1,(x) ; x, 2=1 \quad x=p \quad--$
$1,(x) ; x, 2=1 \quad x \in p \quad--$
$1, x ; x, 2=1 \quad x=p \quad-$

(Stage I: $E=6, \mathrm{df}=1$,

$\left.\chi^{2}=12.00, p=.0005 \%\right)$ 
CONTROL LN

SUMAARY SCORE SHEET

(6121-132) Causative-Thene=Causee cliticazed, Intransa tive Vepb

Exanple: L'bl sphant le fat trenbler. CORRECT FORMS:

\begin{tabular}{|c|c|}
\hline 1,$2 ; 2 \cup 2=P$ & $12 / 12$ \\
\hline 1,$2 ; 2 \cup 2 \mathbb{P}$ & -- \\
\hline $2 v_{i} l, 2 \quad 2=p$ & \\
\hline $2 V_{i} l, 2 \quad 2 \leqslant P$ & -- \\
\hline
\end{tabular}

$$
\begin{aligned}
& \text { (Stage I: } E=1.5, \mathrm{df}=7, \\
& \left.\chi^{2}=84.00, p=.0001 *\right)
\end{aligned}
$$

$2 V_{i} l, 2 \quad 2=p$

$-$

$-$

(6133-144) Cleft ob ject(CO2) vith Stylistic Inversion

Exapple: c'est le lapin qu'a flatte l'blephant.

CORRECT FORMS:

$$
\left.2,1 \quad 11 / 12 \quad \chi^{2}=8.333, p=.0039 *^{\circ}\right)
$$

INCORRECT FORAS:

$1,2 \quad 1 / 12$

(ij145-156) Subject-Object relative vith Stylistic Inversion

Exanple: Le lapin qu'd gratté l'tlephant a frappe le singe. CORRECT FORMS:

$\begin{array}{ll}2,1 ; 1,3 & 1 / 12 \\ 1,3 ; 2,1 & --\end{array}$

(Stage II: $E=.33$, df $=35$,

1,$3 ; 2,1$

$\left.\chi^{2}=133.335, \mathrm{p}=.0001 *\right)$

IHCORRECT FORHS:

$\begin{array}{ll}1,2 ; 1,3 & 3 / 12 \\ 1,2 ; 2,3 & 6 / 12 \\ 2,1 ; 3,1 & 1 / 12 \\ 2,1 ; 2,3 & 1 / 12\end{array}$

(6157-168) Object-0bject relative vith Stylistic inversion

Exanple: Le lapin a gratte la chevre qu'a eabrasste le singe. CORRECT FORAS:

1,$2 ; 3,2$

$3 / 12$

(Stage II: $E=.33$, df $=35$,

$3, ; i l, 2$

I/12 TOTAL CORRECT: $\quad 1 / 12$

$x^{2}=121.213, p=.0001 \%$

IMCORRECT FORHS:

1,$2 ; 2,3 \quad 3 / 12$

1,$2 ; 1,3 \quad 5 / 12$ 